\title{
Perinatal modulators of respiratory outcome after preterm birth
}

Citation for published version (APA):

Been, J. V. (2010). Perinatal modulators of respiratory outcome after preterm birth. [Doctoral Thesis, Maastricht University]. Maastricht University. https://doi.org/10.26481/dis.20100924jb

Document status and date:

Published: 01/01/2010

DOI:

10.26481/dis.20100924jb

Document Version:

Publisher's PDF, also known as Version of record

\section{Please check the document version of this publication:}

- A submitted manuscript is the version of the article upon submission and before peer-review. There can be important differences between the submitted version and the official published version of record.

People interested in the research are advised to contact the author for the final version of the publication, or visit the DOI to the publisher's website.

- The final author version and the galley proof are versions of the publication after peer review.

- The final published version features the final layout of the paper including the volume, issue and page numbers.

Link to publication

\footnotetext{
General rights rights.

- You may freely distribute the URL identifying the publication in the public portal. please follow below link for the End User Agreement:

www.umlib.nl/taverne-license

Take down policy

If you believe that this document breaches copyright please contact us at:

repository@maastrichtuniversity.nl

providing details and we will investigate your claim.
}

Copyright and moral rights for the publications made accessible in the public portal are retained by the authors and/or other copyright owners and it is a condition of accessing publications that users recognise and abide by the legal requirements associated with these

- Users may download and print one copy of any publication from the public portal for the purpose of private study or research.

- You may not further distribute the material or use it for any profit-making activity or commercial gain

If the publication is distributed under the terms of Article $25 \mathrm{fa}$ of the Dutch Copyright Act, indicated by the "Taverne" license above, 


\title{
Perinatal modulators of respiratory outcome after preterm birth
}

\author{
Jasper V. Been
}


Cover design

Maaike van der Beek-Been (H2O ontwerpstudio)

Cover photography

Dorcas Been-de Koning

ISBN 978-90-9025546-0 


\title{
Perinatal modulators of respiratory outcome after preterm birth
}

\author{
DISSERTATION \\ to obtain the degree of Doctor at \\ the Maastricht University, \\ on the authority of the Rector Magnificus, \\ Prof. dr. G.P.M.F. Mols \\ in accordance with the decision of the Board of Deans, \\ to be defended in public \\ on Friday the $24^{\text {th }}$ of September 2010, at 14.00 hours \\ by \\ Jasper V. Been
}




\section{Supervisor}

Prof. dr. L.J.I. Zimmermann

\section{Co-supervisor}

Dr. J.F. van Iwaarden

\section{Assessment Committee}

Prof. dr. J.G. Nijhuis (voorzitter)

Prof. dr. S. Bambang Oetomo (Eindhoven University of Technology, Netherlands)

Prof. dr. W.A. Buurman

Prof. dr. C.P. van Schayck

Prof. dr. F.J. Walther (Leiden University Medical Centre, Netherlands)

\section{Publication of this thesis was financially supported by}

Abbott

Astra Zeneca

Chiesi Pharmaceuticals

Greiner Bio-One

Fisher \& Paykel Healthcare SAS

Hans Been Architecten BNA

Nutricia Nederland BV

Stichting Bevordering Kindergeneeskunde

Teva Pharma Nederland BV 



\section{Contents}

Part 1

Chapter 1

Chapter 2

Chapter 3

Part 2

Chapter 4

Chapter 5

Chapter 6

Chapter 7

Chapter 8
Introduction

General introduction : preterm birth and the lung

What's new in surfactant? A clinical view on recent developments in neonatology and paediatrics

Eur J Pediatr 2007; 166: 889-99

Histological chorioamnionitis and respiratory outcome

51 in preterm infants

Arch Dis Child Fetal Neonatal Ed 2009; 94: F218-25

Aims of the thesis

71

Laboratory and translational observations

Bronchoalveolar lavage fluid cytokine and chemokine

73

profiles in ventilated preterm infants

Submitted

Bronchoalveolar lavage fluid from preterm infants with chorioamnionitis inhibits alveolar epithelial repair Respir Res 2009; 10: 116

Early alterations in growth factor patterns in bronchoalveolar lavage fluid from preterm infants developing bronchopulmonary dysplasia

Pediatr Res 2010; 67: 83-9

Pulmonary vascular endothelial growth factor expression and disaturated phospholipid content in a chicken model of hypoxia-induced fetal growth restriction Neonatology 2010; 97: 183-9

Mitochondrial DNA damage analysis in broncho- 
Part 3

Chapter 9 Histologic chorioamnionitis, fetal involvement, and antenatal steroids: effects on neonatal outcome in preterm infants

Am J Obstet Gynecol 2009; 201: 587.e1-8

Appendix I Antenatal corticosteroids to prevent preterm birth Lancet 2009; 373: 894

Chapter 10 Antenatal steroids in chorioamnionitis: evidence and practice

BJOG; provisionally accepted

Chapter 11 Chorioamnionitis, 'secondary hits', and bronchopulmonary dysplasia

Submitted

Chapter 12 Chorioamnionitis alters the response to surfactant in preterm infants

J Pediatr 2010; 156: 10-5

Part 4

Appendix II
General discussion 201

In utero and early-life conditions and adult health and disease N Engl J Med 2008; 359: 1523-4

Summary

Nederlandse samenvatting

Curriculum vitae

List of publications

Dankwoord 


\section{Part 1}

Introduction 


\section{Chapter 1}

General introduction:

preterm birth and the lung 


\section{Preterm birth}

\section{Epidemiology}

Preterm birth is a major health issue across the globe. In the Western world preterm birth accounts for $5-13 \%$ of all live births, with important regional differences ${ }^{1,2}$. The current rate of preterm live birth in the Netherlands is $7.4 \%, 1 \%$ being born before the $32^{\text {nd }}$ week of gestation ${ }^{3,4}$. The incidence of preterm birth continues to rise steadily, posing society to increasing medical and social expenses ${ }^{1,2}$.

Independent general risk factors for preterm delivery include previous preterm delivery, multiple gestation, short interval between pregnancies, black race, low socioeconomic status, low and high maternal ages, and low pre-pregnancy body mass index (BMI) ${ }^{1,2}$. Conversely, East Asian and Hispanic ethnicity and high BMI are relatively protective ${ }^{1}$. Specific risk factors are highly associated with different causes of preterm birth, including intrauterine infection / inflammation (IUI), premature preterm rupture of membranes (PPROM), and maternal preeclampsia / HELLP syndrome (haemolysis, elevated liver enzymes, low platelets). Finally, genetic factors play an important role in susceptibility for preterm delivery ${ }^{1,2}$.

\section{Consequences}

Worldwide, preterm birth accounts for more than $25 \%$ of neonatal mortality ${ }^{5}$. In the Netherlands $21 \%$ of deaths during the first year of life was attributable to preterm birth in $2005{ }^{6}$. Of infants delivered between 22 and 32 weeks of gestation, a quarter die during pregnancy, $13 \%$ during delivery or in the delivery room, and $8 \%$ in the neonatal intensive care unit (NICU) ${ }^{7}$. Obviously, the incidences of both perinatal mortality and short-term and long-term morbidity are inversely correlated with gestational age at birth ${ }^{8}$. Moreover, a low gestational age-dependent birth weight percentile increases the risk of adverse outcome. The relatively high rate of perinatal mortality after preterm birth in the Netherlands is partly explained by a reluctance towards active management of extremely preterm infants born before 25 weeks of gestation ${ }^{7}$.

Over the last decades, important advances have been made in the treatment of preterm newborns. These include the introduction of antenatal steroid administration and exogenous surfactant treatment, both of which have greatly improved outcome after preterm birth ${ }^{9,10}$. However, due to the consequent increased survival of more extremely preterm infants, the overall mortality and morbidity associated with preterm birth are improving only gradually ${ }^{11}$.

The major factor limiting viability in extremely preterm infants, is development of the lung and associated maturation of its surfactant system ${ }^{12}$. Because of these being underdeveloped, treatment of acute respiratory problems by mechanical ventilation is often unavoidable, although acute lung injury and adverse lung development are recognised and feared consequences ${ }^{13}$. These in turn may lead to chronic lung disease of prematurity (bronchopulmonary dysplasia; BPD) in an important subset of preterm infants, with im- 
portant long-term consequences ${ }^{14}$. A more detailed description of the epidemiology, aetiology, and underlying mechanisms for adverse lung development is given in the section 'Preterm birth and the lung'.

Besides having effects on the lung, preterm birth is associated with increased risk for serious infections, circulatory disturbances (hypotension, patent ductus arteriosus), necrotising enterocolitis (NEC), retinopathy and adverse neurologic outcome, including intraventricular haemorrhage (IVH), periventricular leucomalacia (PVL), and white matter damage (WMD). It is mainly these neurologic disturbances that affect long-term prognosis as they may lead to hearing loss, visual impairment, developmental delay, psychological and behavioural problems, and cerebral palsy ${ }^{8,11}$.

\section{Aetiology}

Roughly, causes of preterm birth can be divided into two groups: indicated preterm birth, and preterm birth preceded by spontaneous preterm labour or PPROM ${ }^{1,2,15}$. The former group consists mostly of infants delivered by caesarean section for fetal or maternal indications. These include severe intrauterine growth retardation (IUGR), and maternal preeclampsia and HELLP syndrome ${ }^{16}$. Preterm deliveries in the larger group of spontaneous preterm labour and PPROM on the other hand are often associated with IUI ${ }^{17}$. IUI is clearly associated with preterm birth, and its relative contribution to all preterm births increases with decreasing gestational age ${ }^{17-20}$.

In addition, multiple gestation is also associated with increased incidences of both spontaneous and indicated preterm delivery ${ }^{2}$. Less frequent causes of preterm delivery include placental abruption and cervical insufficiency ${ }^{15,21}$. Although multiple causal factors may be involved, an identifiable cause is absent only in a small minority of cases. Distinction between various causes of preterm birth is imperative not only from an aetiological perspective, but also because important associations have been demonstrated between the cause of preterm birth and neonatal outcome ${ }^{22-24}$.

\section{Underlying mechanisms}

The mechanisms underlying preterm birth differ for the diverse causes of preterm birth. Obviously, in indicated preterm delivery the direct cause is iatrogenic. A decision for indicated preterm delivery is made upon fetal and/or maternal indications. Common fetal indications include IUGR, chronic fetal compromise or acute fetal distress. These conditions often result from placental insufficiency and are associated with fetal hypoxia and malnutrition and with adverse metabolic consequences in later life ${ }^{25}$.

Maternal indications for preterm delivery are often associated with preeclampsia or HELLP syndrome. Features of preeclampsia include hypertension, proteinuria and multisystem abnormalities in the mother, while the fetus may suffer from IUGR, reduced amniotic fluid and intrauterine hypoxia ${ }^{26}$. Preeclampsia is a heterogeneous clinical entity, the pathogenesis of which is unknown ${ }^{26}$. Both vascular mechanisms and the immune system seem to play important roles ${ }^{26,27}$. A key concept in preeclampsia is maternal-fetal immune 
maladaptation, mediated by the presence of paternal antigens ${ }^{26}$. A feared complication of preeclampsia is the HELLP syndrome, occurring in about $15-20 \%$ of cases of severe preeclampsia ${ }^{23}$. Microangiopathy, haemolytic anaemia, liver injury, and intravascular platelet activation and consumption are key characteristics of HELLP ${ }^{23}$. The syndrome is often progressive in nature and may lead to serious complications in both mother and fetus. Therefore, delivery is frequently indicated irrespective of gestational progression ${ }^{23}$.

The subgroup of preterm births preceded by spontaneous preterm labour and PPROM most often are associated with IUI ${ }^{28}$. Ascending bacterial invasion of the uterine cavity is thought to be the most common route of infection ${ }^{28}$. Organisms most frequently associated with chorioamnionitis are bacteria of mainly low virulence, including Ureaplasma spp. and Mycoplasma spp. ${ }^{28,29}$. Both the maternal and fetal immune system play an important role in chorioamnionitis, given the demonstrated associations between polymorphisms in immunoregulatory genes and risk of chorioamnionitis and preterm labour ${ }^{30,31}$. The majority of cases of IUI remain clinically silent. These may be diagnosed by culture or proteomic profiling of the amniotic fluid ${ }^{32,33}$, by microbial culture or footprinting ${ }^{34,35}$, or by histological examination of the placenta after birth ${ }^{29,36}$. More serious cases of IUI may become clinically apparent and cause both general (fever, leukocytosis, raised C-reactive protein (CRP)) and local symptoms (uterine tenderness, vaginal discharge) ${ }^{37}$. Although a combination of these symptoms is often given the syndromic description 'clinical chorioamnionitis', overlap with the histological diagnosis of chorioamnionitis has been shown to be only modest ${ }^{17}$. The presence of fetal signs of inflammation, such as funisitis or elevated cord blood interleukin-6 (IL-6), in chorioamnionitis are though to reflect the more serious side of the continuum of IUI ${ }^{17,29,36,38}$.

Less frequent underlying mechanisms of spontaneous preterm labour and PPROM include uterine overdistention (due to multiple pregnancy, excessive fetal growth or polyhydramnios), placental haemorrhage, and psychological stress. These may cause stimulation of the fetal and maternal hypothalamic pituitary axis, increased production of uterotonins (most importantly prostaglandins), myometrial activation and uterine extracellular matrix degradation, which in turn may lead to premature uterine contractions, cervical changes and PPROM ${ }^{2}$. Additional mechanisms involved in preterm birth include hormonal influences ${ }^{39,40}$ and immune modulation at the fetal-maternal interface ${ }^{41}$.

\section{Lung development}

\section{Development and structure}

Underdevelopment of the lung is the major factor limiting viability in extremely preterm infants. Below the threshold of viability as determined by gestational age, the preterm lung cannot facilitate proper gas exchange necessary for survival in the extrauterine environment. Before birth gas exchange is regulated by the placenta, from where oxygen is transported to the fetus through the umbilical cord. Although fetal breathing movements 
are present from the second trimester onwards, their function is to stimulate lung development and they do not affect or regulate gas exchange ${ }^{42}$.

Normal human embryonic and fetal lung development can be divided into various stages, primarily based on histological appearance. These are: embryonic stage, pseudoglandular stage, canalicular stage, saccular stage, and alveolar stage. A graphic representation of these overlapping stages of lung development during gestation is shown in figure 1.

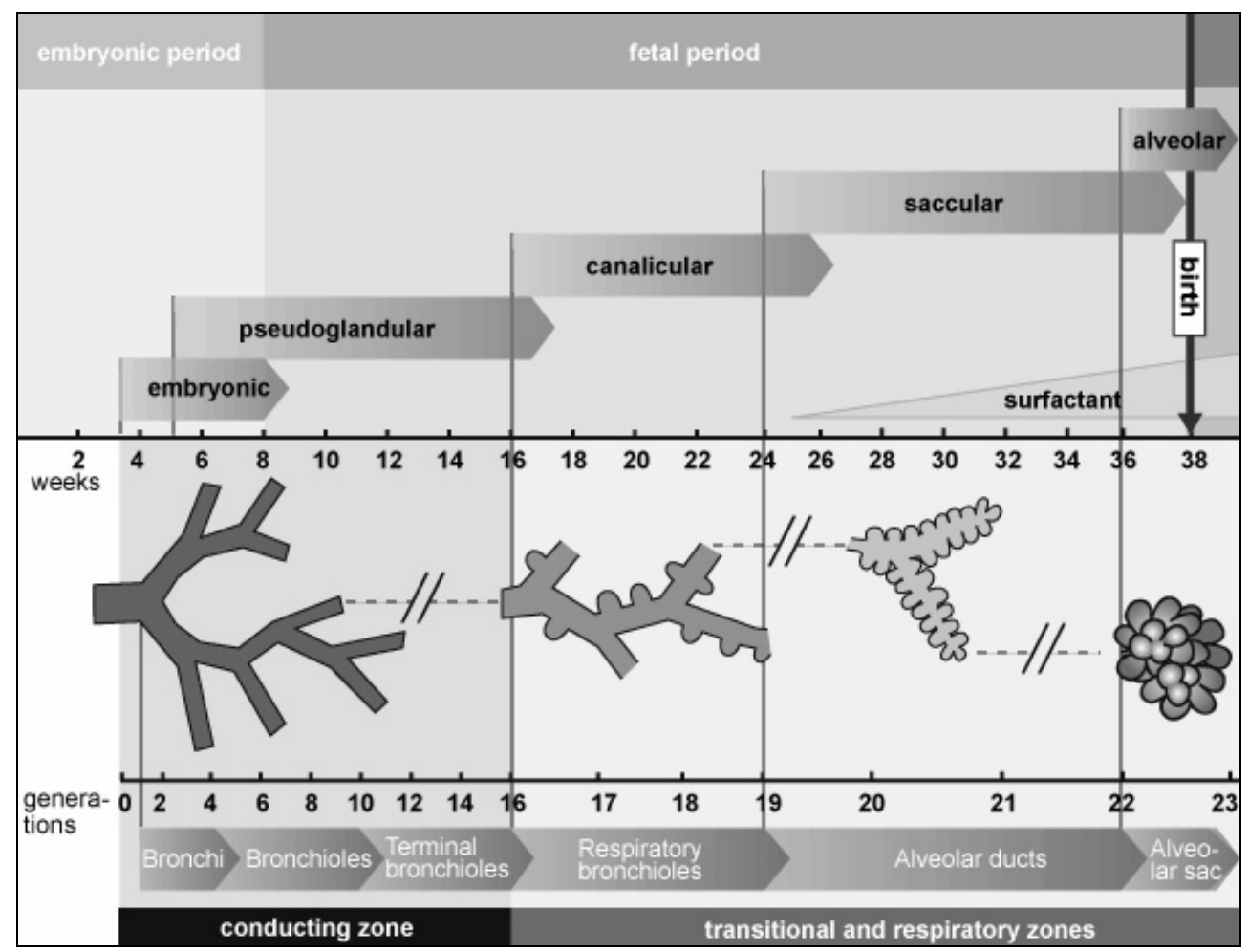

Figure 1. Prenatal lung development. (source: http://www.embryology.ch/anglais/rrespiratory/phasen07.html)

By embryonic day 26 the lung bud develops from the foregut, which will eventually develop into the esophagus. The lung bud branches into five saccules, representing the foundations of the five lung lobes: two on the left and three on the right ${ }^{43}$. Through successive stages of branching, 20 generations of airways are formed during the pseudoglandular phase, the name of which is derived from the glandular appearance of the airways at this time ${ }^{43}$. Simultaneously, the pulmonary vasculature is formed through progressive branching from the pulmonary artery ${ }^{44}$. Mesenchyme separates the airways from the vasculature and orchestrates proper lung development through close communication with these tissues ${ }^{44}$. 
During the canalicular phase, the pulmonary acinus develops, capillaries are formed and airway epithelial cells start to differentiate ${ }^{43,44}$. Epithelium and interstitial thinning gradually increase proximity of the airways to the capillaries, allowing for marginal gas exchange capacity at some point between 22 and 26 weeks of gestation ${ }^{43}$. At this stage, peripheral airways begin to form saccules, marking the saccular stage of lung development. These saccules are the primary gas-exchange areas, which subsequently develop into alveoli through a process of secondary septation ${ }^{43,44}$. Alveolarisation commences around the $36^{\text {th }}$ week of gestation, just before the normal time of birth, and continues into childhood ${ }^{43,44}$. Mature alveoli are characterised by a dense structural organisation and an extremely thin blood-air barrier, facilitating highly efficient gas-exchange ${ }^{44}$.

A key point during lung development is the initiation of surfactant synthesis and secretion by alveolar type II (ATII) cells. Surfactant is a mixture of $90 \%$ lipids and $10 \%$ proteins, which is highly effective in reducing alveolar surface tension. Low surface tension is essential to prevent alveolar collapse during expiration and facilitate gas exchange throughout the respiratory cycle. Along with the primitive lung architecture, surfactant deficiency is a key limiting factor for survival after preterm birth.

Other cell types besides ATII cells that exhibit critical roles in the newborn lung include alveolar type I (ATI) cells, fibroblasts, endothelial cells and alveolar macrophages (AMs). ATI cells line the majority of the alveolar surface and facilitate gas exchange through their extremely flat ultrastructure. Fibroblasts regulate pulmonary cellular and extracellular matrix (ECM) homeostasis by producing growth factors and immunomodulators. Endothelial cells reside in close proximity to ATI cells and regulate gas exchange and chemotaxis of immune cells. The alveolar space is further inhabited by AMs, with key roles in host defence and surfactant catabolism.

\section{Molecular regulators of lung development}

Key molecular regulators of the early stages of lung development include members of the fibroblast growth factor (FGF) family, the transforming growth factor- $\beta$ (TGF $\beta$ ) superfamily, and Sonic hedgehog (Shh) ${ }^{44}$. A well-known clinical result of dysregulation during this early phase of lung development is congenital diaphragmatic hernia (CDH), which is associated with pulmonary hypoplasia. From the developmental perspective of BPD, the later process of alveolarisation is critical. While the regulators of the earlier stages of lung development are also important during this phase, additional molecules come into play. These include transcription factors, growth factors, and ECM proteins ${ }^{44}$.

A wide range of transcription factors have been implicated in both normal and abnormal lung development. Transcription factors control the expression of effector molecules through modulation of DNA transcription. GATA- 6 regulates alveolar cell differentiation and proliferation from the surrounding mesenchyme and is an upstream regulator of several other transcription factors ${ }^{43,44}$. Branching of the lung is under close control by thyroid transcription factor-1 (TTF1) ${ }^{43,44}$. TTF1 also regulates alveolarisation at a later 
stage, along with Forkhead box (Fox) and other transcription factors such as hypoxiainducible factor (HIF) and the vitamin A metabolite retinoic acid ${ }^{43-45}$.

Increasing evidence supports the critical role of growth factors during lung development. The importance of TGF $\beta 1$, an ubiquitous regulator of embryonic development, in early lung development was mentioned earlier. Along with TGF $\beta 1$, other growth factors come into play during branching morphogenesis, including platelet-derived growth factors (PDGFs), epidermal growth factors (EGFs; including TGF $\alpha$ ), Wnt growth factors and vascular endothelial growth factor (VEGF) ${ }^{43,44}$. The latter has been shown to be a key regulator of both vascularisation and alveolarisation within the lung ${ }^{46}$.

ECM constituents involved in regulation of alveolarisation include collagens, fibronectin, elastin and matrix metalloproteinases (MMPs) ${ }^{44}$. Elastin is expressed throughout the connective tissue in the lung and proper localisation of elastin deposition is essential for the process of secondary septation ${ }^{47}$. MMPs, formerly known as collagenases, regulate connective tissue remodelling necessary for development of the highly efficient lung architectural structure ${ }^{44}$.

Lastly, both glucocorticoid and thyroid hormones have an impact on the later stages of lung development ${ }^{44}$. Thyroid hormones stimulate secondary septation, while glucocorticoids accelerate lung maturation through thinning of the alveolar wall and increased surfactant synthesis and secretion ${ }^{44,48}$. The fact that the regulatory molecules discussed comprise only a fraction of the modulators involved in lung development, underlines the complexity of this process and the multitude of pathways susceptible for dysregulation.

\section{Preterm birth and the lung}

\section{Respiratory distress syndrome}

In uncomplicated pregnancies, the uterus provides the optimal environment for normal lung development. When the fetus is delivered preterm, this uterine environment is no longer available, challenging the adaptive ability of the developing lung. The immature stage the lung is in after preterm delivery predisposes the preterm newborn to both acute respiratory distress and long-term adverse effects on lung development.

Structural lung immaturity and pulmonary surfactant deficiency are the main causes for acute respiratory distress after preterm birth, referred to as (infant) respiratory distress syndrome (RDS) ${ }^{12}$. The tight functional relationship with lung immaturity is illustrated by the close inverse correlation between RDS incidence and gestational age at birth. Infants with RDS may present with tachypoea, expiratory grunting, chest wall retractions, cyanosis and a typical 'ground glass' appearance on chest radiography ${ }^{49}$. The introduction of antenatal steroid administration and exogenous surfactant suppletion has significantly contributed to the prevention and treatment of RDS over the last decades and this has allowed more immature and preterm infants to survive ${ }^{10}$. As a result, RDS has 
become a disease of more immature infants, while its overall incidence has not changed much.

Besides prevention by antenatal steroids and early treatment by postnatal surfactant administration, treatment of RDS is mainly supportive ${ }^{12}$. Supplemental oxygen administration is often necessary to prevent hypoxaemia. Ventilation may be supported by noninvasive methods such as continuous positive airway pressure (CPAP), nasal intermittent mandatory ventilation or air flow administered by nasal cannula. More seriously affected infants will have to be intubated and mechanically ventilated for a period of time. The use of one or more of these treatments often is unavoidable to prevent morbidity and mortality after preterm birth. On the other hand it is primarily the application of these treatments during a critical phase of lung development that predisposes preterm infants to the development of BPD ${ }^{50-52}$.

\section{Bronchopulmonary dysplasia - Background and definition}

Chronic lung disease of prematurity (bronchopulmonary dysplasia; BPD) is a common and serious complication of preterm birth. It was initially described by Northway et al. in a small group of ventilated moderately preterm infants with relatively high birth weights around 2400 grams ${ }^{53}$. With increased use of antenatal steroids, surfactant, and noninvasive modes of ventilation, allowing for increased survival of moderately preterm infants, BPD has become a disease seen primarily in extremely preterm infants. As a consequence, BPD now affects preterm lungs at an earlier stage of lung development, resulting in a different pathological picture. Whereas in the initial reports of BPD the lungs of affected infants displayed widespread fibrosis and emphysaema, the current picture of BPD is primarily characterised by an arrest in lung development, resulting in alveolar simplification. The two phenotypes have often been referred to as 'old BPD' and 'new BPD', respectively. The main characteristics of both entities are summarised in table 1.

Table 1. Characteristics of 'old' and 'new' BPD. (adapted from Kramer BW, Lievense S, Been JV, Zimmermann LJ; Ned Tijdschr Geneeskd 2010)).

\begin{tabular}{lll}
\hline & $\begin{array}{l}\text { Old BPD } \\
\text { (Northway et al., 1967) }\end{array}$ & $\begin{array}{l}\text { New BPD } \\
\text { (Jobe and Bancalari, 2001) }\end{array}$ \\
\hline Gestational age & 32 weeks & $24-26$ weeks \\
Birth weight & $2000-3000 \mathrm{~g}$ & $500-1000 \mathrm{~g}$ \\
Lung maturity & (nearly) mature lungs & (extremely) immature lungs \\
Aiways & highly affected & minimally affected \\
Fibrosis & severe & minimal \\
Alveoli & emphysaema / fibrosis & simplification \\
Primary aetiology & secondary injury & developmental arrest \\
\hline
\end{tabular}


A key clinical feature of BPD is prolonged dependency on respiratory support, including supplemental oxygen and ventilatory support, either non-invasive or invasive. Whereas BPD was initially defined as oxygen requirement at 28 days postnatally, additional definitions emerged over time. In a consensus meeting of the National Institutes of Health of the United States in 2000 the current definition was adopted (Table 2) ${ }^{54}$. This definition allows for subclassification into 'mild', 'moderate' and 'severe' BPD, depending on the intensity of respiratory support. Comparison of outcome data in a large cohort of preterm infants subsequently showed significant correlations between BPD severity and both pulmonary and neurological outcomes at follow-up, confirming the usefulness and predictive value of the new definition ${ }^{55}$.

Table 2. Current diagnostic criteria for bronchopulmonary dysplasia (BPD). (adapted from Jobe AH and Bancalari E, Am J Respir Crit Care Med 2001). PMA = postmenstrual age, PPV = positive pressure ventilation, $C P A P=$ continuous positive airway pressure.

\begin{tabular}{lll}
\hline & $<32$ weeks gestation & $\geq 32$ weeks gestation \\
\hline Time point of assessment & $\begin{array}{l}36 \text { weeks PMA } \\
\text { or at discharge }\end{array}$ & $\begin{array}{l}28 \text { to } 56 \text { days postnatal age } \\
\text { or at discharge }\end{array}$ \\
Diagnosis & Treatment with $>21 \% \mathrm{O}_{2}$ for $\geq 28$ days, plus: \\
Mild BPD & Breathing room air at & Breathing room air at \\
& 36 weeks PMA or discharge & 56 days postnatal age or discharge \\
Moderate BPD & Need for $<30 \% \mathrm{O}_{2}$ at & Need for $<30 \% \mathrm{O}_{2}$ at \\
Severe BPD & 36 weeks PMA or discharge & 56 days postnatal age or discharge \\
& Need for $\geq 30 \% \mathrm{O}_{2}$ & Need for $\geq 30 \% \mathrm{O}_{2}$ \\
& and/or PPV or CPAP at & and/or PPV or $\mathrm{CPAP}$ at \\
& 36 weeks PMA or discharge & 56 days postnatal age or discharge \\
\hline
\end{tabular}

\section{Bronchopulmonary dysplasia-Epidemiology}

BPD is the most common cause of chronic lung disease in infants ${ }^{56}$. A wide range of incidence data for BPD have been reported, mainly depending on the BPD definition used and characteristics of the population from which data were derived. Moreover, important differences in BPD incidence have been shown to be present between different NICUs ${ }^{57,58}$. In a large multicentre cohort the incidence ranged from about 7\% in infants with birth weights between 1250 and 1500 grams to more than $50 \%$ in those between 500 and 750 grams $^{55}$.

Clinical risk factors for BPD development have been extensively studied and are widely accepted. They include prematurity, low birth weight, white race, male sex, RDS, oxygen supplementation, mechanical ventilation and infection ${ }^{50,59}$. Obviously, the contribution of lung immaturity is reflected in the associations between BPD and prematurity, low birth weight, and RDS. How white race and male sex contribute to BPD development 
is less clear, although male sex is recognised as a general risk factor for adverse outcome after preterm birth. Oxygen supplementation, mechanical ventilation and infection all exert their effects through causing direct injury to the immature lung and affecting lung development. In the absence of effective measures to prevent preterm birth, these represent the majority of potentially preventable contributors to BPD development. Associations of BPD with other clinical parameters, such as patency of the ductus arteriosus and chorioamnionitis have been reported less consistently ${ }^{57,59,60}$.

\section{Bronchopulmonary dysplasia-Consequences}

BPD is a disease with several long-term consequences. Severely affected infants may require oxygen supplementation for up to several months to years, adversely affecting quality of life within families ${ }^{61-63}$. Many experience respiratory symptoms in childhood such as recurrent cough and wheezing, associated with increased use of bronchodilators and steroids ${ }^{64}$. Rehospitalisation is frequent in infants with BPD and is most often associated with respiratory disorders ${ }^{65,66}$. In line with these observations, lung function parameters are often abnormal in children with BPD ${ }^{14,56}$. Findings in adolescents and young adults are similar although these should be interpreted with care since these patients represent former infants with 'old BPD', a part of the spectrum distinct from that currently observed in preterm infants ${ }^{14,67}$. Apart from its pulmonary consequences, BPD is associated with long term feeding difficulties, growth retardation, osteopenia, nephrocalcinosis, and adverse neurological outcome ${ }^{68,69}$.

\section{Bronchopulmonary dysplasia-Underlying mechanisms}

BPD is a complex and multifactorial disease. A wide range of contributing factors and potential underlying mechanisms have been identified. Although many have contributed to our current understanding of abnormal lung development and modulation of lung injury and repair, a comprehensive picture of pathways leading to the disease is currently lacking. Several underlying mechanisms will be discussed below, with a focus on human studies.

\section{Oxygen toxicity}

One of the first recognised risk factors for BPD was exposure to high levels of oxygen ${ }^{53}$. Oxygen exposure leads to generation of reactive oxygen species (ROS). Recruited inflammatory cells in the lung and increased endogenous levels of free iron may be additional sources of ROS ${ }^{51,70-72}$. In the lung, ROS lead to cell death, surfactant inactivation, induction of pro-inflammatory processes, and increased MMP activity which may lead to ECM degradation ${ }^{51,73,74}$. Preterm infants are particularly sensitive to oxygen toxicity due to reduced intracellular anti-oxidant capacity ${ }^{51}$. A link between oxygen toxicity and BPD is further supported by increased levels of carbonyl and peroxidation products in bronchoalveolar lavage fluid (BALF) and urine from infants developing BPD. In animals prolonged exposure to high levels of oxygen results in pulmonary growth arrest, emhysaema, fibrosis and in- 
flammation, similar to the pathologic picture of BPD seen in human infants ${ }^{75,76}$. Despite the evidence supporting a role of oxidant stress in BPD, trials evaluating the efficacy of anti-oxidants to reduce BPD have rendered disappointing results ${ }^{51,77}$.

\section{Ventilator associated lung injury, inflammation and infection}

Mechanical ventilation in preterm infants is a well known and characterised risk factor for BPD. Initiation of mechanical ventilation readily induces cytokine and chemokine expression in the preterm lung, soon followed by influx and activation of neutrophils from the circulation, which further aggravates the inflammatory cascade ${ }^{78,79}$. Lung overdistention, repetitive alveolar collapse and regional atelectasis have been shown to enhance this response ${ }^{80-82}$. In addition, primary lung injury may elicit a systemic inflammatory response ${ }^{83}$. Conversely, systemic infections which occur frequently in preterm infants, may enhance the local inflammatory response in the lung.

Increased numbers of neutrophils in tracheal aspirates from preterm infants are associated with BPD development ${ }^{79,84-87}$. Correspondingly, the expression of several molecular mediators of leukocyte adhesion that regulate this influx is elevated in BPD infants ${ }^{84,87-90}$. Attracted leucocytes elicit an inflammatory response within the lung and produce toxic ROS and proteases capable of degrading the pulmonary ECM ${ }^{50}$. Additional injury to the lung may disrupt the epithelial-endothelial barrier and lead to leakage of fluid and serum proteins into the alveolar space, further contributing to local inflammation and surfactant inhibition ${ }^{50,91}$.

Numerous reports have shown associations between increased cytokines and chemokine concentrations in both blood and lung-derived fluid and development of BPD. These include cytokines such as tumour necrosis factor- $\alpha$ (TNF $\alpha)^{92}$, interleukin-1 $\beta$ (IL1 $\beta$ ) 90,92,93 , IL-6 ${ }^{79,92,94-96}$, IL-10 ${ }^{97-99}$, and chemokines including monocyte chemoattractant proteins (MCPs) ${ }^{78}$, macrophage inflammatory proteins (MIPs) ${ }^{78}$, and CXCL8 (IL-8) $79,94,95,97,98,100$. The latter additionally recruit macrophages into the alveolar space which contribute to the inflammatory state. Enhanced expression of many of these mediators has also been reported after chorioamnionitis, providing some support for a link between intrauterine inflammation and BPD ${ }^{78,94,97,101-106}$. Many of these effects are probably mediated by nuclear factor kappa-B (NFKB), an ubiquitous regulator of inflammation. Indeed, increased expression of NFKB has been associated with chorioamnionitis ${ }^{105}$, prolonged mechanical ventilation ${ }^{105,107}$, and development of BPD ${ }^{107}$.

Although most of the evidence discussed is derived from human studies, a large body of evidence from neonatal animal studies confirms the association between induced lung injury, inflammation and subsequent adverse lung development ${ }^{50}$. Moreover, animal studies have greatly increased our understanding on how antenatal inflammation adversely affects the development of several fetal organs, including the lung ${ }^{108,109}$ (figure 2). However, results from human studies have not been consistent regarding the association between chorioamnionitis and development of BPD, as discussed later ${ }^{60}$. 


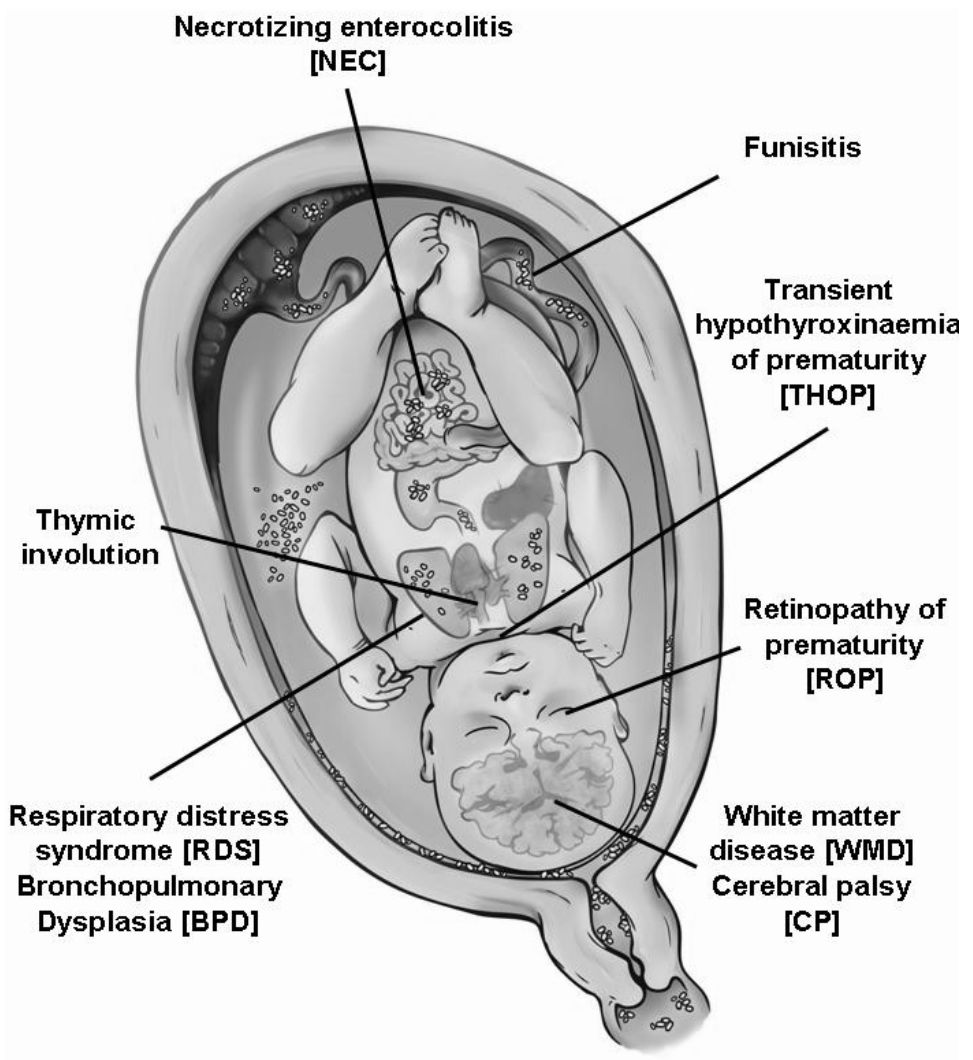

Figure 2. Graphic representation of organs known to be affected by prenatal exposure to inflammation. (source: Gantert M, Been JV, et al. J Perinatol (in press)).

\section{Transcription factors}

The transcription factor most extensively studied with regard to BPD is probably vitamin A. Through binding of its active metabolite retinoic acid to several nuclear receptors, it regulates the transcription of a wide range of proteins involved in lung development. Infants developing BPD have been shown to be vitamin A deficient ${ }^{110-112}$, and vitamin A supplementation is one of very few measures that has proven to effectively reduce the incidence of BPD ${ }^{113}$.

Other transcription factors implicated in the pathophysiology of BPD include peroxisome proliferator-activated receptor- $\gamma$ (PPAR $\gamma$ ) and HIFs. PPAR $\gamma$ is a key determinant of the lipofibroblast phenotype within the lung. Stimulation of PPAR $\gamma$ prevents transdifferentiation into myofibroblasts, which partly determines the fibrotic picture seen in BPD ${ }^{114}$. HIFs are widely expressed in the lungs during fetal life, and upregulation of HIF activity in animal models improves lung development after injury, corresponding to their function as upstream regulators of key modulators of lung development ${ }^{45,115-117}$. 


\section{Growth factors}

Growth factors play a critical role in normal lung development, as discussed previously. Several studies have addressed a potential role of individual growth factors in BPD development. Low VEGF expression has quite consistently been shown to be associated with BPD development ${ }^{118-120}$. Alterations in pulmonary concentrations of several other growth factors have been described. These include hepatocyte growth factor (HGF; a regulator of normal alveolarisation), keratinocyte growth factor (KGF / FGF7; a promotor of epithelial repair), TGF $\beta 1$ (a regulator of lung development with pro-fibrotic properties), PDGFs (profibrotic factors also implicated in lung growth), and regulators of angiogenesis such as endostatin and angiopoetin-1 ${ }^{121-126}$.

Many associations between alterations in growth factor expression in the lung are supported by mechanistic evidence from animal studies. Possibly the best example is VEGF. VEGF expression is reduced in various animal models of BPD and experimental inhibition of VEGF disrupts both alveolar and pulmonary vascular development ${ }^{115,127-130}$. Conversely, upregulation of VEGF reduces respiratory distress and mortality both in preterm animals and animals exposed to hyperoxia $45,129,131,132$. Similar close correlations between human findings and animal studies are present for many other growth factors.

\section{Extracellular matrix constituents and degradants}

During normal lung development, close balancing of pulmonary expression of proteinases and their inhibitors is critical. Lungs from children who develop BPD contain increased levels of collagen fibres ${ }^{133-135}$. Moreover, several reports have shown alterations in expression patterns of MMPs and tissue inhibitors of MMPs (TIMPs) to be associated with $B P D$, providing a pathophysiological basis for this dysregulation of collagen deposition ${ }^{136-}$ ${ }^{140}$. Prenatal modulation of these mechanisms has been suggested by reports of an association between alterations in pulmonary MMP expression and prior exposure to chorioamnionitis ${ }^{141,142}$. Other modulators of ECM integrity such as elastase and trypsin-2 have also been implicated in the pathophysiology of BPD ${ }^{86,143}$. Besides controlling ECM production and degradation, proteinases may aggravate the inflammatory response through stimulation of proteinase-activated receptor-2 $\left(\mathrm{PAR}_{2}\right)$, the expression of which is increased in infants developing BPD ${ }^{50,144}$.

\section{Genetic contributions}

With the recent expansion of research on the genetic basis of disease, evidence supporting a genetic component determining BPD susceptibility is emerging. A recent twin study even suggests that genetic factors may explain a large majority of the observed variance in BPD incidence among preterm infants ${ }^{145}$. Polymorphisms in genes encoding for surfactant protein-B ${ }^{146}$, angiotensin-converting enzyme ${ }^{147}$, gluthathione-S-transferase-P1 ${ }^{148}$, MMP$16^{139}$ and the inflammatory mediator TNF- $\alpha{ }^{149}$ have all been linked to BPD susceptibility and may thus explain part of this variation. Additional research using newer techniques such as genome-wide association studies carry the potential to reveal novel genetic asso- 
ciations underlying BPD susceptibility. These in turn may lead to increased understanding of molecular mechanisms associated with development of the disease ${ }^{150}$.

\section{Changing picture of $B P D$}

The wide range of mechanisms implicated in the pathophysiology of BPD underlines the complexity of this disease process. Adding to this complexity is the apparent change over time in both the pathological picture of BPD and the population at risk. Increased use of antenatal steroids and postnatal surfactant, less invasive ventilatory strategies and restrictive use of supplemental oxygen are among the practice changes that have greatly contributed to this transformation. Without a doubt, pathophysiological mechanisms will have changed along both in nature and in magnitude of contribution to the development of chronic lung injury. Given the practice changes mentioned and the altered pathological picture observed, the relative importance of inflammation, ventilator-induced lung injury and oxygen toxicity may well have decreased. On the other hand, the current concept of BPD representing a developmental arrest of the lung may well implicate increasing contributions of ECM proteins, alterations in growth factor expression and cellular mechanisms in its pathophysiology.

\section{Conclusion}

Despite the complexity of the aetiology and pathogenesis of BPD, increased knowledge about the mechanisms that currently contribute to the disease is highly relevant, given the extent of the problem and the paucity of measures available for prevention and treatment of the disease ${ }^{77,151}$. Thus, ongoing research is vital to increase our understanding and to be able to optimise treatment and improve future prospects of preterm infants.

\section{References}

1. Goldenberg RL, Culhane JF, lams JD, Romero R. Epidemiology and causes of preterm birth. Lancet 2008;371:75-84

2. Menon R. Spontaneous preterm birth, a clinical dilemma: etiologic, pathophysiologic and genetic heterogeneities and racial disparity. Acta Obstet Gynecol Scand 2008;87:590-600

3. Mohangoo AD, Buitendijk SE, Hukkelhoven CW, Ravelli AC, Rijninks-van Driel GC, Tamminga P, Nijhuis JG. [Higher perinatal mortality in The Netherlands than in other European countries: the Peristat-II study]. Ned Tijdschr Geneeskd 2008;152:2718-27

4. Tamminga P, Rijninks-van Driel GC, Mohangoo AD, Hukkelhoven CW, Nijhuis JG, Buitendijk SE, Ravelli AC. Neonatale uitkomsten. NTOG 2009;122:83-7

5. Lawn JE, Rudan I, Rubens C. Four million newborn deaths: is the global research agenda evidence-based? Early Hum Dev 2008;84:809-14

6. www.statline.cbs.nl 
7. Draper ES, Zeitlin J, Fenton AC, Weber T, Gerrits J, Martens G, Misselwitz B, Breart G. Investigating the variations in survival rates for very preterm infants in 10 European regions: the MOSAIC birth cohort. Arch Dis Child Fetal Neonatal Ed 2009;94:F158-63

8. Moster D, Lie RT, Markestad T. Long-term medical and social consequences of preterm birth. N Engl J Med 2008;359:262-73

9. Bonanno C, Wapner RJ. Antenatal corticosteroid treatment: what's happened since Drs Liggins and Howie? Am J Obstet Gynecol 2009;200:448-57

10. Been JV, Zimmermann L. What's new in surfactant? A clinical view on recent developments in neonatology and paediatrics. Eur J Pediatr 2007;166:889-99

11. Robertson CM, Watt MJ, Dinu IA. Outcomes for the extremely premature infant: what is new? And where are we going? Pediatr Neurol 2009;40:189-96

12. Rodriguez RJ. Management of respiratory distress syndrome: an update. Respir Care 2003;48:279-86; discussion 86-7

13. Ramanathan R. Optimal ventilatory strategies and surfactant to protect the preterm lungs. Neonatology 2008;93:302-8

14. Greenough A. Long-term pulmonary outcome in the preterm infant. Neonatology 2008;93:324-7

15. McElrath TF, Hecht JL, Dammann O, Boggess K, Onderdonk A, Markenson G, Harper M, Delpapa E, Allred EN, Leviton A. Pregnancy disorders that lead to delivery before the 28th week of gestation: an epidemiologic approach to classification. Am J Epidemiol 2008;168:980-9

16. Irminger-Finger I, Jastrow N, Irion O. Preeclampsia: a danger growing in disguise. Int J Biochem Cell Biol 2008;40:1979-83

17. Dammann O, Allred EN, Leviton A, Shen-Schwarz S, Heller D, Genest DR, Collins MH. Fetal vasculitis in preterm newborns: interrelationships, modifiers, and antecedents. Placenta 2004;25:788-96

18. Lahra MM, Beeby PJ, Jeffery HE. Maternal versus fetal inflammation and respiratory distress syndrome: a 10-year hospital cohort study. Arch Dis Child Fetal Neonatal Ed 2009;94:F13-6

19. Lahra MM, Beeby PJ, Jeffery HE. Intrauterine inflammation, neonatal sepsis, and chronic lung disease: a 13-year hospital cohort study. Pediatrics 2009;123:1314-19

20. Lahra MM, Jeffery HE. A fetal response to chorioamnionitis is associated with early survival after preterm birth. Am J Obstet Gynecol 2004;190:147-51

21. Hecht JL, Allred EN, Kliman HJ, Zambrano E, Doss BJ, Husain A, Pflueger SM, Chang CH, Livasy CA, Roberts D, Bhan I, Ross DW, Senagore PK, Leviton A. Histological characteristics of singleton placentas delivered before the 28th week of gestation. Pathology 2008;40:372-6

22. Johanzon M, Odesjo H, Jacobsson B, Sandberg K, Wennerholm UB. Extreme preterm birth: onset of delivery and its effect on infant survival and morbidity. Obstet Gynecol 2008;111:42-50

23. Haram K, Svendsen E, Abildgaard U. The HELLP syndrome: clinical issues and management. A Review. BMC Pregnancy Childbirth 2009;9:8

24. Dammann O, Kuban KC, Leviton A. Perinatal infection, fetal inflammatory response, white matter damage, and cognitive limitations in children born preterm. Ment Retard Dev Disabil Res Rev 2002;8:46-50

25. Gluckman PD, Hanson MA, Cooper C, Thornburg KL. Effect of in utero and early-life conditions on adult health and disease. N Engl J Med 2008;359:61-73

26. Sibai B, Dekker G, Kupferminc M. Pre-eclampsia. Lancet 2005;365:785-99

27. Chaouat G, Ledee-bataille N, Zourbas S, Dubanchet S, Sandra O, Martal J, Ostojojic S, Frydman R. Implantation: can immunological parameters of implantation failure be of interest for pre-eclampsia? J Reprod Immunol 2003;59:205-17

28. Goldenberg RL, Hauth JC, Andrews WW. Intrauterine infection and preterm delivery. $N$ Engl J Med 2000;342:1500-7

29. Faye-Petersen OM. The placenta in preterm birth. J Clin Pathol 2008;61:1261-75

30. Annells MF, Hart PH, Mullighan CG, Heatley SL, Robinson JS, McDonald HM. Polymorphisms in immunoregulatory genes and the risk of histologic chorioamnionitis in Caucasoid women: a case control study. BMC Pregnancy Childbirth 2005;5:4

31. Holst D, Garnier Y. Preterm birth and inflammation-The role of genetic polymorphisms. Eur J Obstet Gynecol Reprod Biol 2008;141:3-9 
32. Sfakianaki AK, Buhimschi IA, Ravishankar V, Bahtiyar MO, Dulay AT, Buhimschi CS. Relationships of maternal serum levels of vascular endothelial growth factor and tensile strength properties of the cervix in a rat model of chronic hypoxia. Am J Obstet Gynecol 2008;198:223 e1-7

33. Holst RM, Laurini R, Jacobsson B, Samuelsson E, Savman K, Doverhag C, Wennerholm UB, Hagberg H. Expression of cytokines and chemokines in cervical and amniotic fluid: relationship to histological chorioamnionitis. J Matern Fetal Neonatal Med 2007;20:885-93

34. DiGiulio DB, Romero R, Amogan HP, Kusanovic JP, Bik EM, Gotsch F, Kim CJ, Erez O, Edwin S, Relman DA. Microbial prevalence, diversity and abundance in amniotic fluid during preterm labor: a molecular and culture-based investigation. PLOS ONE 2008;3:e3056

35. Han YW, Shen T, Chung P, Buhimschi IA, Buhimschi CS. Uncultivated Bacteria as Etiologic Agents of IntraAmniotic Inflammation Leading to Preterm Birth. J Clin Microbiol 2008

36. Redline RW. Inflammatory responses in the placenta and umbilical cord. Semin Fetal Neonatal Med 2006;11:296-301

37. Kayem G, Maillard F, Schmitz T, Jarreau PH, Cabrol D, Breart G, Goffinet F. Prediction of clinical infection in women with preterm labour with intact membranes: A score based on ultrasonographic, clinical and biological markers. Eur J Obstet Gynecol Reprod Biol 2009;145:36-40

38. Buhimschi CS, Dulay AT, Abdel-Razeq S, Zhao G, Lee S, Hodgson EJ, Bhandari V, Buhimschi IA. Fetal inflammatory response in women with proteomic biomarkers characteristic of intra-amniotic inflammation and preterm birth. BJOG 2009;116:257-67

39. Guoyang L, Morgan T, Bahtiyar MO, Snegovskikh VV, Schatz F, Kuczynski E, Funai EF, Dulay AT, Huang ST, Buhimschi CS, Buhimschi IA, Fortunato SJ, Menon R, Lockwood CJ, Norwitz ER. Single nucleotide polymorphisms in the human progesterone receptor gene and spontaneous preterm birth. Reprod Sci 2008;15:147-55

40. Chaudhari BP, Plunkett J, Ratajczak CK, Shen TT, DeFranco EA, Muglia LJ. The genetics of birth timing: insights into a fundamental component of human development. Clin Genet 2008;74:493-501

41. Murphy SP, Hanna NN, Fast LD, Shaw SK, Berg G, Padbury JF, Romero R, Sharma S. Evidence for participation of uterine natural killer cells in the mechanisms responsible for spontaneous preterm labor and delivery. Am J Obstet Gynecol 2009;200:308 e1-9

42. Harding R, Hooper SB. Regulation of lung expansion and lung growth before birth. J Appl Physiol 1996;81:209-24

43. Scholand MB, McDonald JA. Lung growth and development. In: Mason RJ, Courtney Broaddus V, Murray JF, Nadel JA eds, Murray And Nadel's Textbook Of Respiratory Medicine. 4th ed: Elsevier; 2005:30-40

44. Galambos C, Demello DE. Regulation of alveologenesis: clinical implications of impaired growth. Pathology 2008;40:124-40

45. Compernolle V, Brusselmans K, Acker T, Hoet P, Tjwa M, Beck H, Plaisance S, Dor Y, Keshet E, Lupu F, Nemery B, Dewerchin M, Van Veldhoven P, Plate K, Moons L, Collen D, Carmeliet P. Loss of HIF-2alpha and inhibition of VEGF impair fetal lung maturation, whereas treatment with VEGF prevents fatal respiratory distress in premature mice. Nat Med 2002;8:702-10

46. Breen EC. VEGF in biological control. J Cell Biochem 2007;102:1358-67

47. Bourbon J, Boucherat O, Chailley-Heu B, Delacourt C. Control mechanisms of lung alveolar development and their disorders in bronchopulmonary dysplasia. Pediatr Res 2005;57:38R-46R

48. Bolt RJ, van Weissenbruch MM, Lafeber HN, Delemarre-van de Waal HA. Glucocorticoids and lung development in the fetus and preterm infant. Pediatr Pulmonol 2001;32:76-91

49. Giedion A, Haefliger H, Dangel P. Acute pulmonary X-ray changes in hyaline membrane disease treated with artificial ventilation and positive end-expiratory pressure (PEP). Pediatr Radiol 1973;1:145-52

50. Ryan RM, Ahmed Q, Lakshminrusimha S. Inflammatory mediators in the immunobiology of bronchopulmonary dysplasia. Clin Rev Allergy Immunol 2008;34:174-90

51. Saugstad OD. Bronchopulmonary dysplasia-oxidative stress and antioxidants. Semin Neonatol 2003;8:3949

52. Ambalavanan N, Carlo WA. Bronchopulmonary dysplasia: new insights. Clin Perinatol 2004;31:613-28

53. Northway WH, Jr., Rosan RC, Porter DY. Pulmonary disease following respirator therapy of hyalinemembrane disease. Bronchopulmonary dysplasia. N Engl J Med 1967;276:357-68 
54. Jobe AH, Bancalari E. Bronchopulmonary dysplasia. Am J Respir Crit Care Med 2001;163:1723-9

55. Ehrenkranz RA, Walsh MC, Vohr BR, Jobe AH, Wright LL, Fanaroff AA, Wrage LA, Poole K. Validation of the National Institutes of Health consensus definition of bronchopulmonary dysplasia. Pediatrics 2005;116:1353-60

56. Bhandari A, Panitch HB. Pulmonary Outcomes in Bronchopulmonary Dysplasia. Semin Perinatol 2006;30:219-26

57. Akram Khan M, Kuzma-O'Reilly B, Brodsky NL, Bhandari V. Site-specific characteristics of infants developing bronchopulmonary dysplasia. J Perinatol 2006;26:428-35

58. Van Marter L, Allred EN, Pagano M, Sanocka U, Parad R, Moore M, Susser M, Paneth N, Leviton A. Do clinical markers of barotrauma and oxygen toxicity explain interhospital variation in rates of chronic lung disease? The Neonatology Committee for the Developmental Network. Pediatrics 2000;105:1194-201

59. Laughon M, Allred EN, Bose C, O'Shea TM, Van Marter L, Ehrenkranz RA, Leviton A. Patterns of respiratory disease during the first 2 postnatal weeks in extremely premature infants. Pediatrics 2009;123:1124-31

60. Been JV, Zimmermann LJ. Histological chorioamnionitis and respiratory outcome in preterm infants. Arch Dis Child Fetal Neonatal Ed 2009;94:F218-25

61. Greenough A, Alexander J, Burgess S, Chetcuti PA, Cox S, Lenney W, Turnbull F, Shaw NJ, Woods A, Boorman J, Coles S, Turner J. Home oxygen status and rehospitalisation and primary care requirements of infants with chronic lung disease. Arch Dis Child 2002;86:40-3

62. Greenough A, Alexander J, Burgess S, Bytham J, Chetcuti PA, Hagan J, Lenney W, Melville S, Shaw NJ, Boorman J, Coles S, Pang F, Turner J. Preschool healthcare utilisation related to home oxygen status. Arch Dis Child Fetal Neonatal Ed 2006;91:F337-41

63. McLean A, Townsend A, Clark J, Sawyer MG, Baghurst P, Haslam R, Whaites L. Quality of life of mothers and families caring for preterm infants requiring home oxygen therapy: a brief report. J Paediatr Child Health 2000;36:440-4

64. Greenough A, Limb E, Marston L, Marlow N, Calvert S, Peacock J. Risk factors for respiratory morbidity in infancy after very premature birth. Arch Dis Child Fetal Neonatal Ed 2005;90:F320-3

65. Smith VC, Zupancic JA, McCormick MC, Croen LA, Greene J, Escobar GJ, Richardson DK. Rehospitalization in the first year of life among infants with bronchopulmonary dysplasia. J Pediatr 2004;144:799-803

66. Greenough A, Cox S, Alexander J, Lenney W, Turnbull F, Burgess S, Chetcuti PA, Shaw NJ, Woods A, Boorman J, Coles S, Turner J. Health care utilisation of infants with chronic lung disease, related to hospitalisation for RSV infection. Arch Dis Child 2001;85:463-8

67. Vrijlandt EJ, Gerritsen J, Boezen HM, Duiverman EJ. Gender differences in respiratory symptoms in 19year-old adults born preterm. Respir Res 2005;6:117

68. Dammann O, Leviton A, Bartels DB, Dammann CE. Lung and brain damage in preterm newborns. Are they related? How? Why? Biol Neonate 2004;85:305-13

69. Dammann O, Leviton A, Gappa M, Dammann CE. Lung and brain damage in preterm newborns, and their association with gestational age, prematurity subgroup, infection/inflammation and long term outcome. BJOG 2005;112 Suppl 1:4-9

70. Freeman BA, Crapo JD. Biology of disease: free radicals and tissue injury. Lab Invest 1982;47:412-26

71. Sullivan JL. Iron, plasma antioxidants, and the 'oxygen radical disease of prematurity'. Am J Dis Child 1988;142:1341-4

72. Clement A, Chadelat K, Sardet A, Grimfeld A, Tournier G. Alveolar macrophage status in bronchopulmonary dysplasia. Pediatr Res 1988;23:470-3

73. Schock BC, Sweet DG, Ennis M, Warner JA, Young IS, Halliday HL. Oxidative stress and increased type-IV collagenase levels in bronchoalveolar lavage fluid from newborn babies. Pediatr Res 2001;50:29-33

74. Horowitz S, Shapiro DL, Finkelstein JN, Notter RH, Johnston CJ, Quible DJ. Changes in gene expression in hyperoxia-induced neonatal lung injury. Am J Physiol 1990;258:L107-11

75. Wilborn AM, Evers LB, Canada AT. Oxygen toxicity to the developing lung of the mouse: role of reactive oxygen species. Pediatr Res 1996;40:225-32

76. Han RN, Buch S, Tseu I, Young J, Christie NA, Frndova H, Lye SJ, Post M, Tanswell AK. Changes in structure, mechanics, and insulin-like growth factor-related gene expression in the lungs of newborn rats exposed to air or 60\% oxygen. Pediatr Res 1996;39:921-9 
77. Van Marter LJ. Progress in discovery and evaluation of treatments to prevent bronchopulmonary dysplasia. Biol Neonate 2006;89:303-12

78. Baier RJ, Majid A, Parupia H, Loggins J, Kruger TE. CC chemokine concentrations increase in respiratory distress syndrome and correlate with development of bronchopulmonary dysplasia. Pediatr Pulmonol 2004;37:137-48

79. Munshi UK, Niu JO, Siddiq MM, Parton LA. Elevation of interleukin-8 and interleukin- 6 precedes the influx of neutrophils in tracheal aspirates from preterm infants who develop bronchopulmonary dysplasia. Pediatr Pulmonol 1997;24:331-6

80. Jobe $A H$, Ikegami M. Mechanisms initiating lung injury in the preterm. Early Hum Dev 1998;53:81-94

81. Froese $A B$, McCulloch PR, Sugiura M, Vaclavik S, Possmayer F, Moller F. Optimizing alveolar expansion prolongs the effectiveness of exogenous surfactant therapy in the adult rabbit. Am Rev Respir Dis 1993;148:569-77

82. Lista G, Castoldi F, Fontana P, Reali R, Reggiani A, Bianchi S, Compagnoni G. Lung inflammation in preterm infants with respiratory distress syndrome: effects of ventilation with different tidal volumes. Pediatr Pulmonol 2006;41:357-63

83. Halbertsma FJ, Vaneker M, Scheffer GJ, van der Hoeven JG. Cytokines and biotrauma in ventilator-induced lung injury: a critical review of the literature. Neth J Med 2005;63:382-92

84. Groneck P, Gotze-Speer B, Oppermann M, Eiffert H, Speer CP. Association of pulmonary inflammation and increased microvascular permeability during the development of bronchopulmonary dysplasia: a sequential analysis of inflammatory mediators in respiratory fluids of high-risk preterm neonates. Pediatrics 1994;93:712-8

85. Merritt TA, Stuard ID, Puccia J, Wood B, Edwards DK, Finkelstein J, Shapiro DL. Newborn tracheal aspirate cytology: classification during respiratory distress syndrome and bronchopulmonary dysplasia. $J$ Pediatr 1981;98:949-56

86. Ogden BE, Murphy SA, Saunders GC, Pathak D, Johnson JD. Neonatal lung neutrophils and elastase/proteinase inhibitor imbalance. Am Rev Respir Dis 1984;130:817-21

87. Kim BI, Lee HE, Choi CW, Jo HS, Choi EH, Koh YY, Choi JH. Increase in cord blood soluble E-selectin and tracheal aspirate neutrophils at birth and the development of new bronchopulmonary dysplasia. J Perinat Med 2004;32:282-7

88. Kotecha S, Chan B, Azam N, Silverman M, Shaw RJ. Increase in interleukin-8 and soluble intercellular adhesion molecule-1 in bronchoalveolar lavage fluid from premature infants who develop chronic lung disease. Arch Dis Child Fetal Neonatal Ed 1995;72:F90-6

89. Kotecha S, Silverman M, Shaw RJ, Klein N. Soluble L-selectin concentration in bronchoalveolar lavage fluid obtained from infants who develop chronic lung disease of prematurity. Arch Dis Child Fetal Neonatal Ed 1998;78:F143-7

90. Watterberg KL, Demers LM, Scott SM, Murphy S. Chorioamnionitis and early lung inflammation in infants in whom bronchopulmonary dysplasia develops. Pediatrics 1996;97:210-5

91. Zuo YY, Veldhuizen RA, Neumann AW, Petersen NO, Possmayer F. Current perspectives in pulmonary surfactant - Inhibition, enhancement and evaluation. Biochim Biophys Acta 2008;1778:1947-77

92. Jonsson B, Tullus K, Brauner A, Lu Y, Noack G. Early increase of TNF alpha and IL-6 in tracheobronchial aspirate fluid indicator of subsequent chronic lung disease in preterm infants. Arch Dis Child Fetal Neonatal Ed 1997;77:F198-201

93. Kakkera DK, Siddiq MM, Parton LA. Interleukin-1 balance in the lungs of preterm infants who develop bronchopulmonary dysplasia. Biol Neonate 2005;87:82-90

94. An H, Nishimaki S, Ohyama M, Haruki A, Naruto T, Kobayashi N, Sugai T, Kobayashi Y, Mori M, Seki K, Yokota S. Interleukin-6, interleukin-8, and soluble tumor necrosis factor receptor-l in the cord blood as predictors of chronic lung disease in premature infants. Am J Obstet Gynecol 2004;191:1649-54

95. Niu JO, Munshi UK, Siddiq MM, Parton LA. Early increase in endothelin-1 in tracheal aspirates of preterm infants: correlation with bronchopulmonary dysplasia. J Pediatr 1998;132:965-70

96. Choi CW, Kim BI, Kim HS, Park JD, Choi JH, Son DW. Increase of interleukin-6 in tracheal aspirate at birth: a predictor of subsequent bronchopulmonary dysplasia in preterm infants. Acta Paediatr 2006;95:38-43 
97. Paananen R, Husa AK, Vuolteenaho R, Herva R, Kaukola T, Hallman M. Blood Cytokines during the Perinatal Period in Very Preterm Infants: Relationship of Inflammatory Response and Bronchopulmonary Dysplasia. J Pediatr 2008;154:A2

98. Huang HC, Yang MY, Huang CB, Yang KD. Profiles of inflammatory cytokines in bronchoalveolar lavage fluid from premature infants with respiratory distress disease. J Microbiol Immunol Infect 2000;33:19-24

99. Jonsson B, Li YH, Noack G, Brauner A, Tullus K. Downregulatory cytokines in tracheobronchial aspirate fluid from infants with chronic lung disease of prematurity. Acta Paediatr 2000;89:1375-80

100. De Dooy J, leven M, Stevens W, De Clerck L, Mahieu L. High levels of CXCL8 in tracheal aspirate samples taken at birth are associated with adverse respiratory outcome only in preterm infants younger than 28 weeks gestation. Pediatr Pulmonol 2007;42:193-203

101. Romero R, Gomez R, Ghezzi F, Yoon BH, Mazor M, Edwin SS, Berry SM. A fetal systemic inflammatory response is followed by the spontaneous onset of preterm parturition. Am J Obstet Gynecol 1998;179:18693

102. Cayabyab RG, Jones CA, Kwong KY, Hendershott C, Lecart C, Minoo P, Ramanathan R. Interleukin-1beta in the bronchoalveolar lavage fluid of premature neonates: a marker for maternal chorioamnionitis and predictor of adverse neonatal outcome. J Matern Fetal Neonatal Med 2003;14:205-11

103. Schmidt B, Cao L, Mackensen-Haen S, Kendziorra H, Klingel K, Speer CP. Chorioamnionitis and inflammation of the fetal lung. Am J Obstet Gynecol 2001;185:173-7

104. Chaiworapongsa T, Romero R, Kim JC, Kim YM, Blackwell SC, Yoon BH, Gomez R. Evidence for fetal involvement in the pathologic process of clinical chorioamnionitis. Am J Obstet Gynecol 2002;186:1178-82

105. Cheah FC, Winterbourn CC, Darlow BA, Mocatta TJ, Vissers MC. Nuclear factor kappaB activation in pulmonary leukocytes from infants with hyaline membrane disease: associations with chorioamnionitis and Ureaplasma urealyticum colonization. Pediatr Res 2005;57:616-23

106. De Dooy J, Colpaert C, Schuerwegh A, Bridts C, Van Der Planken M, leven M, De Clerck L, Stevens W, Mahieu L. Relationship between histologic chorioamnionitis and early inflammatory variables in blood, tracheal aspirates, and endotracheal colonization in preterm infants. Pediatr Res 2003;54:113-9

107. Bourbia A, Cruz MA, Rozycki HJ. NF-kappaB in tracheal lavage fluid from intubated premature infants: association with inflammation, oxygen, and outcome. Arch Dis Child Fetal Neonatal Ed 2006;91:F36-9

108. Kramer BW. Antenatal inflammation and lung injury: prenatal origin of neonatal disease. J Perinatol 2008;28 Suppl 1:S21-7

109. Kramer BW, Kallapur S, Newnham J, Jobe AH. Prenatal inflammation and lung development. Semin Fetal Neonatal Med 2009;14:2-7

110. Shenai JP, Chytil F, Jhaveri A, Stahlman MT. Plasma vitamin A and retinol-binding protein in premature and term neonates. J Pediatr 1981;99:302-5

111. Brandt RB, Mueller DG, Schroeder JR, Guyer KE, Kirkpatrick BV, Hutcher NE, Ehrlich FE. Serum vitamin A in premature and term neonates. J Pediatr 1978;92:101-4

112. Bhatia J, Ziegler EE. Retinol-binding protein and prealbumin in cord blood of term and preterm infants. Early Hum Dev 1983;8:129-33

113. Darlow BA, Graham PJ. Vitamin A supplementation to prevent mortality and short and long-term morbidity in very low birthweight infants. Cochrane Database Syst Rev 2007:CD000501

114. Torday JS, Rehan VK. Developmental cell/molecular biologic approach to the etiology and treatment of bronchopulmonary dysplasia. Pediatr Res 2007;62:2-7

115. Asikainen TM, Waleh NS, Schneider BK, Clyman RI, White CW. Enhancement of angiogenic effectors through hypoxia-inducible factor in preterm primate lung in vivo. Am J Physiol Lung Cell Mol Physiol 2006;291:L588-95

116. Rajatapiti P, van der Horst IW, de Rooij JD, Tran MG, Maxwell PH, Tibboel D, Rottier R, de Krijger RR. Expression of hypoxia-inducible factors in normal human lung development. Pediatr Dev Pathol 2008;11:193-9

117. Asikainen TM, Chang LY, Coalson JJ, Schneider BK, Waleh NS, Ikegami M, Shannon JM, Winter VT, Grubb P, Clyman RI, Yoder BA, Crapo JD, White CW. Improved lung growth and function through hypoxia-inducible factor in primate chronic lung disease of prematurity. FASEB J 2006;20:1698-700 
118. Lassus P, Ristimaki A, Ylikorkala O, Viinikka L, Andersson S. Vascular endothelial growth factor in human preterm lung. Am J Respir Crit Care Med 1999;159:1429-33

119. Lassus P, Turanlahti M, Heikkila P, Andersson LC, Nupponen I, Sarnesto A, Andersson S. Pulmonary vascular endothelial growth factor and Flt-1 in fetuses, in acute and chronic lung disease, and in persistent pulmonary hypertension of the newborn. Am J Respir Crit Care Med 2001;164:1981-7

120. Bhatt AJ, Pryhuber GS, Huyck H, Watkins RH, Metlay LA, Maniscalco WM. Disrupted pulmonary vasculature and decreased vascular endothelial growth factor, FIt-1, and TIE-2 in human infants dying with bronchopulmonary dysplasia. Am J Respir Crit Care Med 2001;164:1971-80

121. Lecart C, Cayabyab R, Buckley S, Morrison J, Kwong KY, Warburton D, Ramanathan R, Jones CA, Minoo P. Bioactive transforming growth factor-beta in the lungs of extremely low birthweight neonates predicts the need for home oxygen supplementation. Biol Neonate 2000;77:217-23

122. Kotecha S, Wangoo A, Silverman M, Shaw RJ. Increase in the concentration of transforming growth factor beta-1 in bronchoalveolar lavage fluid before development of chronic lung disease of prematurity. $J$ Pediatr 1996;128:464-9

123. Lassus P, Heikkila P, Andersson LC, von Boguslawski K, Andersson S. Lower concentration of pulmonary hepatocyte growth factor is associated with more severe lung disease in preterm infants. $J$ Pediatr 2003;143:199-202

124. Thomas W, Seidenspinner S, Kramer BW, Kawczynska-Leda N, Chmielnicka-Kopaczyk M, Marx A, Wirbelauer J, Szymankiewicz M, Speer CP. Airway concentrations of angiopoietin-1 and endostatin in ventilated extremely premature infants are decreased after funisitis and unbalanced with bronchopulmonary dysplasia/death. Pediatr Res 2009;65:468-73

125. Dik WA, Versnel MA, Naber BA, Janssen DJ, van Kaam AH, Zimmermann LJ. Dexamethasone treatment does not inhibit fibroproliferation in chronic lung disease of prematurity. Eur Respir J 2003;21:842-7

126. Danan C, Franco ML, Jarreau PH, Dassieu G, Chailley-Heu B, Bourbon J, Delacourt C. High concentrations of keratinocyte growth factor in airways of premature infants predicted absence of bronchopulmonary dysplasia. Am J Respir Crit Care Med 2002;165:1384-7

127. Maniscalco WM, Watkins RH, Pryhuber GS, Bhatt A, Shea C, Huyck H. Angiogenic factors and alveolar vasculature: development and alterations by injury in very premature baboons. Am J Physiol Lung Cell Mol Physiol 2002;282:L811-23

128. Jakkula M, Le Cras TD, Gebb S, Hirth KP, Tuder RM, Voelkel NF, Abman SH. Inhibition of angiogenesis decreases alveolarization in the developing rat lung. Am J Physiol Lung Cell Mol Physiol 2000;279:L600-7

129. Thebaud B, Ladha F, Michelakis ED, Sawicka M, Thurston G, Eaton F, Hashimoto K, Harry G, Haromy A, Korbutt G, Archer SL. Vascular endothelial growth factor gene therapy increases survival, promotes lung angiogenesis, and prevents alveolar damage in hyperoxia-induced lung injury: evidence that angiogenesis participates in alveolarization. Circulation 2005;112:2477-86

130. Maniscalco WM, Watkins RH, D'Angio CT, Ryan RM. Hyperoxic injury decreases alveolar epithelial cell expression of vascular endothelial growth factor (VEGF) in neonatal rabbit lung. Am J Respir Cell Mol Biol 1997;16:557-67

131. Kunig AM, Balasubramaniam V, Markham NE, Morgan D, Montgomery G, Grover TR, Abman SH. Recombinant human VEGF treatment enhances alveolarization after hyperoxic lung injury in neonatal rats. Am J Physiol Lung Cell Mol Physiol 2005;289:L529-35

132. Kunig AM, Balasubramaniam V, Markham NE, Seedorf G, Gien J, Abman SH. Recombinant human VEGF treatment transiently increases lung edema but enhances lung structure after neonatal hyperoxia. Am J Physiol Lung Cell Mol Physiol 2006;291:L1068-78

133. Thibeault DW, Mabry SM, Ekekezie, II, Zhang X, Truog WE. Collagen scaffolding during development and its deformation with chronic lung disease. Pediatrics 2003;111:766-76

134. Kaarteenaho-Wiik R, Paakko P, Herva R, Risteli J, Soini Y. Type I and III collagen protein precursors and mRNA in the developing human lung. J Pathol 2004;203:567-74

135. Ohki Y, Kato M, Kimura H, Nako Y, Tokuyama K, Morikawa A. Elevated type IV collagen in bronchoalveolar lavage fluid from infants with bronchopulmonary dysplasia. Biol Neonate 2001;79:34-8 
136. Dik WA, De Krijger RR, Bonekamp L, Naber BA, Zimmermann LJ, Versnel MA. Localization and potential role of matrix metalloproteinase-1 and tissue inhibitors of metalloproteinase-1 and -2 in different phases of bronchopulmonary dysplasia. Pediatr Res 2001;50:761-6

137. Dik WA, van Kaam AH, Dekker T, Naber BA, Janssen DJ, Kroon AA, Zimmermann LJ, Versnel MA, Lutter R. Early Increased Levels of Matrix Metalloproteinase-9 in Neonates Recovering from Respiratory Distress Syndrome. Biol Neonate 2005;89:6-14

138. Danan C, Jarreau PH, Franco ML, Dassieu G, Grillon C, Abd Alsamad I, Lafuma C, Harf A, Delacourt C. Gelatinase activities in the airways of premature infants and development of bronchopulmonary dysplasia. Am J Physiol Lung Cell Mol Physiol 2002;283:L1086-93

139. Hadchouel A, Decobert F, Franco-Montoya ML, Halphen I, Jarreau PH, Boucherat O, Martin E, Benachi A, Amselem S, Bourbon J, Danan C, Delacourt C. Matrix metalloproteinase gene polymorphisms and bronchopulmonary dysplasia: identification of MMP16 as a new player in lung development. PLOS ONE 2008;3:e3188

140. Sweet DG, McMahon KJ, Curley AE, O'Connor CM, Halliday HL. Type I collagenases in bronchoalveolar lavage fluid from preterm babies at risk of developing chronic lung disease. Arch Dis Child Fetal Neonatal Ed 2001;84:F168-71

141. Curley AE, Sweet DG, Thornton CM, O'Hara MD, Chesshyre E, Pizzotti J, Wilbourn MS, Halliday HL, Warner JA. Chorioamnionitis and increased neonatal lung lavage fluid matrix metalloproteinase-9 levels: implications for antenatal origins of chronic lung disease. Am J Obstet Gynecol 2003;188:871-5

142. Curley AE, Sweet DG, MacMahon KJ, O'Connor CM, Halliday HL. Chorioamnionitis increases matrix metalloproteinase-8 concentrations in bronchoalveolar lavage fluid from preterm babies. Arch Dis Child Fetal Neonatal Ed 2004;89:F61-4

143. Cederqvist K, Haglund C, Heikkila P, Sorsa T, Tervahartiala T, Stenman UH, Andersson S. Pulmonary trypsin2 in the development of bronchopulmonary dysplasia in preterm infants. Pediatrics 2003;112:570-7

144. Cederqvist K, Haglund C, Heikkila P, Hollenberg MD, Karikoski R, Andersson S. High expression of pulmonary proteinase-activated receptor 2 in acute and chronic lung injury in preterm infants. Pediatr Res 2005;57:831-6

145. Lavoie PM, Pham C, Jang KL. Heritability of bronchopulmonary dysplasia, defined according to the consensus statement of the national institutes of health. Pediatrics 2008;122:479-85

146. Rova M, Haataja R, Marttila R, Ollikainen V, Tammela O, Hallman M. Data mining and multiparameter analysis of lung surfactant protein genes in bronchopulmonary dysplasia. Hum Mol Genet 2004;13:1095104

147. Kazzi SN, Quasney MW. Deletion allele of angiotensin-converting enzyme is associated with increased risk and severity of bronchopulmonary dysplasia. J Pediatr 2005;147:818-22

148. Manar MH, Brown MR, Gauthier TW, Brown LA. Association of glutathione-S-transferase-P1 (GST-P1) polymorphisms with bronchopulmonary dysplasia. J Perinatol 2004;24:30-5

149. Kazzi SN, Kim UO, Quasney MW, Buhimschi I. Polymorphism of tumor necrosis factor-alpha and risk and severity of bronchopulmonary dysplasia among very low birth weight infants. Pediatrics 2004;114:e243-8

150. Altshuler D, Daly MJ, Lander ES. Genetic mapping in human disease. Science 2008;322:881-8

151. Schmidt B, Roberts R, Millar D, Kirpalani H. Evidence-based neonatal drug therapy for prevention of bronchopulmonary dysplasia in very-low-birth-weight infants. Neonatology 2008;93:284-7 



\section{Chapter 2}

What's new in surfactant?

A clinical view on recent developments

in neonatology and paediatrics

Been JV, Zimmermann L

Eur J Pediatr 2007; 166: 889-99 


\begin{abstract}
Surfactant therapy has significantly changed clinical practice in neonatology over the last 25 years. Recent trials in infants with respiratory distress syndrome (RDS) have not shown superiority of any natural surfactant over another. Advancements in the development of synthetic surfactants are promising, yet to date none has been shown to be superior to natural preparations. Ideally, surfactant would be administered without requiring mechanical ventilation. An increasing number of studies investigate the roles of alternative modes of administration and the use of nasal continuous positive airway pressure to minimise the need for mechanical ventilation.

Whether children with other lung diseases benefit from surfactant therapy is less clear. Evidence suggests that infants with meconium aspiration syndrome and children with acute lung injury/acute respiratory distress syndrome may benefit, while no positive effect of surfactant is seen in infants with congenital diaphragmatic hernia. However, more research is needed to establish potential beneficial effects of surfactant administration in children with lung diseases other than RDS. Furthermore, genetic disorders of surfactant metabolism have recently been linked to respiratory diseases of formerly unknown origin. It is important to consider these disorders in the differential diagnosis of unexplained respiratory distress although no established treatment is yet available besides lung transplantation for the most severe cases.

Conclusion: Research around surfactant is evolving and recent developments include further evolution of synthetic surfactants, evaluation of surfactant as a therapeutic option in lung diseases other than RDS and the discovery of genetic disorders of surfactant metabolism. Ongoing research is essential to continue to improve therapeutic prospects for children with serious respiratory disease involving disturbances in surfactant.
\end{abstract}




\section{Introduction}

Surfactant is a complex mixture of lipids (90\%) and proteins (10\%) lining the epithelial surface of the lung. Four surfactant apoproteins have been described: the hydrophobic surfactant protein B (SP-B) and SP-C and the hydrophilic SP-A and SP-D. Surfactant is synthesised by alveolar type II cells, stored in lamellar bodies that are exocytosed and taken up into the monolayer lining the alveolar epithelium. Traditionally, surfactant is recognised for its surface tension-lowering properties, by which alveolar collapse is prevented and gas exchange is facilitated. More recently, surfactant has been shown to have an important additional role in innate defence of the lung. Key players in this role are SP-A and $D$, members of the collectin family of proteins. Among their functions are binding, opsonisation and clearance of microbes from the lung and regulation of immune cell activity. Several reviews have addressed their role in detail ${ }^{1,2}$. Evidence is now accumulating that SP-B, SP-C and the surfactant lipids may be involved in modulation of pulmonary inflammation as well ${ }^{3-8}$.

The relevance of surfactant for pulmonary physiology is highlighted by the respiratory distress syndrome (RDS) seen in preterm infants, caused by an absolute deficiency of surfactant. Affected infants experience respiratory insufficiency often requiring mechanical ventilation. The introduction of exogenous surfactant administration for these infants is generally regarded as one of the most important advancements in the field of neonatology, having significantly decreased neonatal mortality over the last 25 years. Nowadays, the potential benefit of surfactant therapy is evaluated in a wide range of respiratory disorders in both neonates and paediatric patients. Moreover, several disease entities of formerly unknown origin have recently been linked to genetic disorders of surfactant metabolism.

The purpose of this review is to give an overview of these and other recent developments in the field of surfactant, focusing on clinically relevant issues in neonatology and paediatrics.

\section{Surfactant in RDS}

In 1959 Avery and Mead established the relationship between surfactant deficiency and RDS seen in preterm infants ${ }^{9}$. Twenty years later, exogenous surfactant was successfully administered to preterm infants with RDS and shown to dramatically improve oxygenation in these babies ${ }^{10}$. In subsequent clinical trials, reductions in neonatal mortality and incidence of pneumothorax were found after surfactant administration ${ }^{11}$. Further trials found that early treatment is superior to late treatment ${ }^{12}$, multiple doses are better than a single dose ${ }^{13}$, and prophylactic surfactant is associated with better outcome than is rescue treatment ${ }^{14}$. Excellent reviews on the history of surfactant are available ${ }^{15,16}$. 
In recent years knowledge of the in vivo surfactant metabolism in RDS patients has increased as a result of metabolic studies. Preterm infants were shown to have a decreased surfactant pool size with decreased synthesis but increased recycling of surfactant when compared to term infants ${ }^{17}$. Furthermore, it was found that both prenatal steroids and exogenous surfactant administration after birth stimulate endogenous surfactant synthesis $^{18,19}$

Recent developments in surfactant treatment for RDS include new comparative trials of natural surfactants, exploration of alternative modes of administration and evaluation of the use of nasal continuous positive airway pressure (nCPAP) either to decrease the need for surfactant or as an adjuvant therapy following surfactant administration. Moreover, much effort is put into the development of synthetic surfactants for treatment of respiratory distress. This topic is discussed separately.

\section{Natural surfactant}

In recent years, several clinical trials have compared the efficacy of different natural surfactants in the treatment of RDS. Natural surfactants are generally derived from either lung lavage or minced lung of bovine or porcine origin.

Four studies have compared beractant (Survanta) and poractant- $\alpha$ (Curosurf) ${ }^{20-23}$. Curosurf was found to have a more rapid onset of action in most studies ${ }^{21-23}$. A metaanalysis of these studies plus one unpublished study suggested a significant decrease in neonatal mortality after Curosurf treatment ${ }^{16}$. However, three of these studies have compared a Curosurf dose of $200 \mathrm{mg} / \mathrm{kg}$ with a Survanta dose of $100 \mathrm{mg} / \mathrm{kg}^{21-23}$. When these studies were excluded from analysis, the difference in mortality after treatment with comparable doses of both surfactants was not statistically significant ${ }^{16}$. Malloy and colleagues reported a significant decrease in the incidence of persistent ductus arteriosus after Curosurf treatment ${ }^{21}$. None of the other studies found such an effect and it is unclear whether this difference may be explained by the dosing difference as well.

Baroutis and colleagues compared the effects of three different surfactant preparations: Curosurf, Survanta and Alveofact ${ }^{20}$. Treatment with either Curosurf or Alveofact was associated with a decrease in days on the ventilator, days on oxygen and hospital stay, but no significant improvement in morbidity and mortality. A more recent study comparing Survanta and Alveofact reported a decrease in chronic lung disease (CLD) with Survanta ${ }^{24}$. However, CLD was defined as oxygen need at 28 days of age, a definition that does not take into account the gestational age of the infant and is generally regarded to be imprecise and outdated. There was a decrease in days on the ventilator, days on oxygen and length of hospital stay with Survanta. The need for postnatal steroids was decreased in the Survanta group as well; however, their overall use was very high compared to current standards.

Two studies have compared Survanta and Infasurf (calfactant) for the treatment of RDS ${ }^{25,26}$. The largest study compared the efficacy of the two surfactants for prophylactic administration as well as for rescue treatment ${ }^{26}$. Infasurf was found to have a more rapid 
effect, without having an effect on overall incidence of bronchopulmonary dysplasia (BPD) or mortality. Subgroup analysis showed a decrease in mortality after prophylactic Survanta treatment in infants under $600 \mathrm{~g}$. A more recent, smaller study reported a decrease in number of doses required with Infasurf without any differences in outcome ${ }^{25}$.

One small comparative trial was reported on bovine lipid extract surfactant (bLES) and Survanta ${ }^{27}$. Treatment with bLES was associated with a more rapid improvement in oxygenation, yet no effect on short-term outcome was seen.

In summary, most differences in effectiveness between natural surfactant preparations are short-lived. On the basis of currently available evidence, no preparation can clearly be considered superior to another with regard to morbidity and mortality. More data would be needed and future studies should include comparison of long-term outcome parameters. However, the clinical relevance of these differences is likely to be minimal; therefore, future studies should focus on more relevant aspects of surfactant therapy.

\section{Timing of surfactant}

Many studies have investigated the ideal timing of surfactant administration. Systematic reviews of earlier studies have found a decrease in the incidence of pneumothorax, pulmonary interstitial emphysema, CLD and mortality with early (within $2 \mathrm{~h}$ after birth) versus delayed surfactant administration ${ }^{12}$, and a decrease in pneumothorax and mortality with prophylactic surfactant administration versus selective rescue therapy ${ }^{14}$.

As stressed by Horbar and colleagues, these trials were conducted at a time when the use of antenatal steroid administration was much lower than it is today. Therefore, the observed difference between early and delayed surfactant therapy may be smaller in current practice ${ }^{28}$. A more recent trial still suggests a positive effect of early surfactant administration in intubated infants, albeit without any effect on morbidity and mortality 29

\section{Surfactant and $n C P A P$}

An important issue is the use of nCPAP, either to prevent intubation and surfactant administration or to accelerate extubation after surfactant is given. A recent Cochrane review showed that intubation and early administration of surfactant followed by extubation to nCPAP was associated with decreased ventilator requirement, but an increase in number of surfactant administrations when compared to selective surfactant and continued ventilation ${ }^{30}$. No difference in BPD incidence was detected. Dani and colleagues later showed that, when intubated and given surfactant, infants may benefit from early extubation to nCPAP ${ }^{31}$. Whether intubation for the purpose of surfactant administration is favourable for larger preterms with mild to moderate RDS is questioned by a recent study showing an increase in median duration of ventilation with elective intubation and surfac$\operatorname{tant}^{32}$. 
The potential of the initial use of nCPAP to prevent intubation and administration of surfactant is the subject of current studies. Potential side effects of intubation and high costs of surfactant administration might thus be avoided. Retrospective studies suggest that, when compared to early initiation of mechanical ventilation, early nCPAP decreases the incidence of intraventricular haemorrhage and improves survival but may increase the risk for necrotising enterocolitis when nCPAP fails ${ }^{33,34}$. However, only part of the infants on early mechanical ventilation received surfactant. More recent data from Te Pas and colleagues suggest that even if early nCPAP fails, it may still result in a decreased BPD risk when compared to infants intubated in the delivery room ${ }^{35}$.

Ideally, avoidance of intubation and subsequent mechanical ventilation would involve early initiation of nCPAP in combination with an alternative mode of surfactant administration. The combined use of early nCPAP and surfactant administration through a thin endotracheal catheter was reported to decrease the need for mechanical ventilation in very low birth weight infants ${ }^{36}$. Other potential alternatives for endotracheal administration include aerosolisation ${ }^{37}$, bronchoscopic administration ${ }^{38}$, nasopharyngeal deposition ${ }^{39}$, and administration of surfactant via a laryngeal mask ${ }^{40,41}$. Clearly, controlled trials are needed to evaluate the safety of alternative modes of surfactant administration and the potential of a combined approach with early nCPAP to decrease the subsequent need for mechanical ventilation and improve outcome.

\section{Synthetic surfactant}

A major disadvantage of commercially available natural surfactants is their price. Therefore much effort has been put into development of synthetic surfactants. The basis of these preparations is a highly simplified phospholipid mixture. The lack of surfactant proteins is a disadvantage compared to natural surfactants. Natural surfactant preparations contain variable amounts of SP-B and SP-C that enhance surface tension-lowering properties and long favoured their use above synthetic preparations ${ }^{42}$. The potential of several additives with surfactant protein-like properties to increase the efficacy of synthetic surfactant preparations is currently under evaluation.

Two synthetic surfactants containing such additives have been tested in clinical trials. One is Venticute, which contains recombinant SP-C (rSP-C). However, no trials involving Venticute in preterms with RDS have yet been published. The other, lucinactant (Surfaxin), is characterised by the addition of KL4 (sinapultide), a non-natural polypeptide that was designed to resemble SP-B ${ }^{43}$. Two trials comparing prophylactic use of Surfaxin to a natural surfactant in the treatment of RDS showed no differences in relevant outcome parameters ${ }^{44,45}$. However, these trials were designed to show only 'noninferiority', and the study comparing three surfactant preparations was underpowered to detect a difference between Surfaxin and the natural surfactant Survanta ${ }^{46}$.

So although synthetic surfactants, especially those with surfactant protein-like additives, have theoretical advantages over natural surfactants, to date none has been shown to be superior to natural preparations in comparative trials ${ }^{43}$. Yet the search for new syn- 
thetic surfactant protein analogues goes on. Recent data from in vitro and animal studies are promising regarding efficacy of different SP-B peptides, modified $\mathrm{rSP}-\mathrm{C}$ with improved function and polymyxin $B$ as possible future additives to synthetic surfactants ${ }^{43}$. Moreover, a group of additives capable of decreasing surfactant inactivation is under investigation, showing promising results. These include chitosan ${ }^{47}$, hyaluronan ${ }^{48-50}$, dextran ${ }^{51}$, and polymyxin $B^{52,53}$. The potential of these additives lies in their use in RDS and meconium aspiration syndrome (MAS), where inactivation of surfactant by albumin and meconium respectively decreases its efficiency.

\section{Surfactant in other neonatal lung disease}

\section{Congenital diaphragmatic hernia $(\mathrm{CDH})$}

$\mathrm{CDH}$ is a serious disease associated with a mortality of $25-74 \%$, primarily due to respiratory insufficiency ${ }^{54}$. Surfactant deficiency and dysfunction have been found in a lamb CDH model and respiratory failure in these animals improved after exogenous surfactant administration ${ }^{55}$. Data on surfactant pool size and function in infants with $\mathrm{CDH}$ are inconclusive ${ }^{56-59}$. Only one small, randomised trial of surfactant in $\mathrm{CDH}$ patients on extracorporal membrane oxygenation (ECMO) is available, showing no benefit ${ }^{60}$. Incidental reports do suggest a beneficial effect ${ }^{61-63}$. Recently, the CDH study group has retrospectively compared the outcomes of $\mathrm{CDH}$ infants that did and did not receive exogenous surfactant during admission. No difference was observed in term infants ${ }^{64}$, while surfactant administration was associated with increased mortality in preterms ${ }^{59}$. However, this difference was not statistically significant after adjusting for gestational age and Apgar score. When only infants on ECMO were considered, surfactant still did not improve survival ${ }^{65}$.

In conclusion, although surfactant therapy is incorporated in $\mathrm{CDH}$ treatment protocols in many centres, this strategy is not supported by evidence and is advised to be used only in the context of a randomised trial ${ }^{54,66}$.

\section{Meconium aspiration syndrome (MAS)}

Perinatal meconium aspiration affects surfactant function and metabolism in several ways. Meconium has an extremely high surface tension ${ }^{67}$, inhibits surfactant function ${ }^{68-71}$, and causes pneumonitis with direct toxicity to alveolar type II cells ${ }^{72,73}$. Furthermore, we have recently found decreased alveolar surfactant content and synthesis in infants with MAS $^{74}$.

Possible treatment options for MAS involving surfactant include bolus surfactant administration and lung lavage using either saline or diluted surfactant. Initial case series reported temporary improvements in oxygenation and a decreased need for ECMO after bolus surfactant treatment ${ }^{75,76}$. Two randomised trials of bolus surfactant therapy have been published ${ }^{77,78}$. A meta-analysis of these studies showed a decreased need for ECMO in surfactant-treated infants without any relevant improvement in outcome ${ }^{79}$. An impor- 
tant difference between the two studies was the timing of surfactant administration. With early treatment (within $6 \mathrm{~h}$ after birth), Findlay and colleagues did report additional beneficial effects, such as decreased air leaks and shorter duration of ventilation ${ }^{77}$. Based on current evidence, Dargaville and Mills advocate early administration of a surfactant known to resist meconium inactivation in severely affected infants, with repeated doses when needed $^{80}$.

Meconium can be effectively removed from the lung by lavage ${ }^{81}$. Most studies report a subsequent improvement in oxygenation above pre-lavage baseline, with earlier extubation and a decrease in pneumothorax incidence ${ }^{80}$. Two randomised controlled trials (RCT) of lavage therapy in MAS have been reported. Only limited data are available from one study, suggesting that surfactant lavage is better than saline lavage ${ }^{82}$. No significant differences were found between infants lavaged with Surfaxin and nonlavaged infants in the other trial ${ }^{83}$. However, additional studies are underway ${ }^{80}$. Further trials should focus on the comparison between bolus surfactant therapy and surfactant lavage.

In conclusion, infants with MAS seem to benefit from surfactant therapy when started early and repeated when necessary. There is insufficient evidence as yet to support the use of surfactant lavage therapy for MAS outside the setting of a clinical trial ${ }^{80}$. As discussed earlier, the development of synthetic additives capable of decreasing meconiuminduced surfactant inhibition may help to increase future efficacy of surfactant therapy for MAS.

\section{Other neonatal lung diseases}

Decreases in alveolar surfactant pool size and surfactant recycling have been described in chronically ventilated infants progressing to or suffering from BPD ${ }^{84-86}$. Therefore, surfactant might be beneficial in treating these infants. Indeed, incidental reports suggest shortterm improvement after surfactant administration in chronically ventilated preterms, urging the need for further studies ${ }^{87-89}$. Other neonatal pulmonary disorders that may benefit from surfactant therapy include haemorrhagic pulmonary oedema ${ }^{90}$, and neonatal pneumonia ${ }^{91}$, yet once again only incidental reports addressing these issues are available.

\section{Surfactant in paediatrics}

Surfactant has been evaluated as a potential intervention in respiratory diseases beyond the neonatal period. Several reports have focused on the use of surfactant in acute respiratory distress syndrome (ARDS) or acute lung injury (ALI). In paediatric ARDS/ALI patients, acute improvement of oxygenation is seen with surfactant administration ${ }^{92-97}$. No additional effects on outcome were noted in the first $\mathrm{RCT}^{94}$. In a more recent $\mathrm{RCT}$ in ventilated children with respiratory failure and bilateral radiographic abnormalities, treatment with Infasurf was associated with a decrease in mortality ${ }^{96}$. The mortality effect was greatest in the subgroup of infants (age $<1$ year), yet overall mortality was not significantly different 
after adjustment for immunocompromised status. Concerns about the study being underpowered and the increased incidence of hypotension and transient hypoxaemia in the treatment group warrant further evaluation before surfactant administration can be routinely recommended in paediatric ARDS/ALI ${ }^{98}$. An important determinant of surfactant response seems to be the nature of the lung injury causing the respiratory failure. Patients with direct lung injury may benefit more than do patients with indirect lung injury ${ }^{96}$. Future studies should address differences in ALI aetiology in the patients studied.

Several studies have investigated a possible role for surfactant in treatment of bronchiolitis. A recent systematic review evaluating three trials reported a significant decrease in duration of ventilation and of hospital admission with surfactant therapy ${ }^{99}$. However, it is generally felt that current evidence is insufficient to establish the role of surfactant suppletion in bronchiolitis and that additional trials are needed ${ }^{99-101}$. Surfactant disturbances have been described in a wider range of paediatric lung diseases and recent case series suggest a potential beneficial role for surfactant in the treatment of lobar atelectasis ${ }^{102}$, intrapulmonary haemorrhage ${ }^{103}$, Pneumocystis carinii pneumonia ${ }^{104}$, and as an adjuvant therapy in ECMO patients ${ }^{105}$. Clearly, additional studies are needed to establish the safety and potential benefit of surfactant therapy in these disorders as well.

\section{Genetic disorders of surfactant}

\section{$\underline{S P-B \text { deficiency }}$}

In recent years, several genetic disorders affecting surfactant metabolism have been identified. SP-B deficiency, first described in $1993^{106}$, is the most serious of these. It is a rare autosomal recessively inherited disease, in the majority of patients caused by the 121 ins 2 mutation ${ }^{107}$. SP-B is critical for lowering alveolar surface tension. Adding to the surfactant dysfunction caused by the deficiency of SP-B is the associated incomplete processing of SP-C ${ }^{108}$. In almost all cases a total absence of SP-B is present, which is invariably lethal ${ }^{109}$. Babies present with respiratory failure shortly after birth, only partially and transiently being responsive to exogenous surfactant administration. To date, the only therapeutic option for these patients is lung transplantation, which should be performed within weeks to months ${ }^{110}$. Recently, Palomar and colleagues reported that the outcome for lung transplantation in SPB- deficient patients is comparable to patients transplanted for other reasons ${ }^{111}$. However, Hamvas reports that approximately half the families of children eligible for lung transplantation decline and another $30 \%$ of patients die awaiting transplantation $^{109}$.

\section{SP-C-associated disease}

In recent years, several mutations in the SP-C gene have been identified and connected to respiratory disease. The incidence of SP-C-associated disease appears to be considerably higher than that of SP-B deficiency ${ }^{109}$. This is partly due to the fact that SP-C mutations 
are inherited in a dominant manner ${ }^{109}$. On the other hand, approximately half of the disease-associated mutations are spontaneous mutations ${ }^{109}$. The most common mutation $173 \mathrm{~T}$, as well as most other mutations, results in production of misfolded SP-C that accumulates within the alveolar type II cell ${ }^{112-114}$.

The presentation and characteristics of respiratory diseases resulting from SP-C mutations are diverse and unpredictable ${ }^{109}$. Patients carrying mutations may present anywhere between the newborn period and adulthood. In a large cohort of term newborns with unexplained respiratory disease, the incidence of SP-C gene mutations was shown to approach $10 \%{ }^{115}$. Asymptomatic patients carrying SP-C mutations have also been identified 116,117. Newborns may present with RDS-like symptoms despite term birth. In paediatric patients interstitial lung disease may present with gradual onset of respiratory insufficiency, hypoxaemia and failure to thrive. Some patients remain stable or even improve, while others progress to respiratory insufficiency, eventually requiring lung transplantation.

No standard treatment for SP-C-associated disease is available. Some authors have seen clinical improvement after treatment with hydroxychloroquine ${ }^{118,119}$, or repeated lung lavage along with administration of corticosteroids and azathioprine ${ }^{120}$, while others have not ${ }^{121,122}$. Clearly, additional studies are needed to further investigate possible treatment options for SP-C-associated disease.

\section{ABCA3-associated disease}

The most recently discovered genetic disruption of surfactant metabolism is caused by mutations in the gene encoding for $A B C A 3{ }^{123}$. $A B C A 3$ is an ATP-binding cassette $(A B C)$ protein localised at the limiting membrane of lamellar bodies ${ }^{124,125}$. In vitro studies show that depending on the mutation present, the mutant $A B C A 3$ protein is either retained at the endoplasmic reticulum or is appropriately localised yet exhibits a decreased capacity to hydrolyse ATP ${ }^{126}$. The exact role of $A B C A 3$ is unknown; however, other members of the $A B C A$ protein family are involved in lipid transport ${ }^{127}$. A specific role for ABCA3 in lipid metabolism is further supported by the detection of reduced lung levels of phosphatidylglycerol and phosphatidylcholine subtypes in ABCA3 knockout mice, while levels of other phospholipids and cholesterol were unaffected ${ }^{128}$. Along with other studies, this work further suggests a key role for ABCA3 in lamellar body formation ${ }^{128-130}$. Abnormal lamellar body formation, surfactant deficiency and surfactant dysfunction have indeed been found in patients carrying $A B C A 3$ mutations ${ }^{123,131-133}$.

Most patients with $A B C A 3$ mutations described thus far presented in the neonatal period with progressive respiratory distress, often being lethal. Hydroxychloroquine and corticosteroids have been used in the management of ABCA3-associated disease, yet their efficiency in treating the disorder is unclear ${ }^{132}$. For these patients, lung transplantation is currently the only treatment option ${ }^{133,134}$. However, Bullard and colleagues have recently stressed the fact that most patients described thus far were derived from highly selected populations of infants with unexplained severe respiratory distress ${ }^{132}$. The same group 
has identified $A B C A 3$ mutations in paediatric patients with interstitial lung disease, suggesting that defects in ABCA3 may be involved in a greater range of respiratory diseases ${ }^{134}$. Research on ABCA3-associated respiratory disease is clearly evolving and knowledge about the disorder will increase in the near future.

We wish to underline the importance of considering genetic disorders of surfactant metabolism in the differential diagnosis of both unexplained respiratory failure and interstitial lung disease in the newborn period and beyond. When such a disorder is suspected in a patient, one should turn to a specialised laboratory for establishment of the diagnosis.

\section{Surfactant protein polymorphisms and lung disease}

In addition to the mutations described above, more common polymorphisms in surfactant proteins have been linked to both increased and decreased risks of developing neonatal and paediatric pulmonary disease. Genetic variants of the SP-B gene have been linked to increased risks for both respiratory distress ${ }^{135,136}$, and BPD ${ }^{137}$. Common SP-A alleles, in interaction with the SP-B Ile131Thr genotype, have been associated with RDS susceptibility, while others seem to decrease RDS risk ${ }^{138,139}$. Recently, polymorphisms in SP-C genes have also been linked to RDS ${ }^{140}$. The susceptibility for respiratory syncytial virus (RSV) infection is altered by polymorphisms of SP-A and SP-D, known modulators of innate immunity. In addition, associations of surfactant protein polymorphisms with extrapulmonary diseases exist, such as recurrent ear infections ${ }^{141}$, and meningococcal disease ${ }^{142}$.

The relevance of these associations between surfactant protein haplotypes and neonatal and paediatric pulmonary and infectious diseases remains unclear. Associations may differ between populations, hence the finding of contrasting risk associations between SP$B$ polymorphisms and RDS ${ }^{136}$. Larger studies are clearly needed to confirm current findings. Possible future applications include individual risk determination and subsequent surfactant protein administration.

\section{Future directions and conclusion}

As highlighted in this review, substantial progression has been made in recent years considering the role of surfactant therapy in neonatal and paediatric lung diseases. However, many questions remain unanswered. Efforts should be made to investigate the roles of nCPAP and alternative administration routes for surfactant in the treatment of preterm infants. Further development of synthetic surfactants to enhance their surface tensionlowering properties and capacity to withstand inactivation may increase future efficacy of surfactant therapy. More ideally, one should be able to stimulate endogenous surfactant synthesis in preterm infants, preferably antenatally. A potential candidate drug would be docosahexaenoic acid, which has been shown to stimulate synthesis of dipalmitoyl phosphatidylcholine, the major phospholipid in surfactant, in preterm mice when administered

to the mother during pregnancy ${ }^{143}$. Another promising future application for surfactant is 
its use as a carrier for drug administration directly into the lung. In this way drugs are allowed to act locally with minimisation of unwanted systemic effects. Possible candidate drugs include immunosuppressants ${ }^{144}$, vasodilators ${ }^{145}$, and $\beta$-sympathicomimetics ${ }^{146}$. Investigational drugs that have been administered in animal models using surfactant as a carrier include a 5 -lipoxygenase inhibitor ${ }^{147}$, and recombinant human Clara cell secretory protein (rhCC10) ${ }^{148}$. Both agents have been shown to decrease experimental lung injury in these models. The antiinflammatory and antimicrobial characteristics of SP-A and SP-D make them attractive potential therapeutic agents as well. Administration of recombinant SP-D fragments in animal models results in enhanced pulmonary clearance of RSV ${ }^{69}$, a reduced allergic response ${ }^{149-151}$, and prevention of endotoxin shock ${ }^{152}$. However, SP-A and SP-D are very large and complex molecules, making construction of functional recombinant whole proteins extremely difficult if not impossible. Much more research is needed to evaluate a possible role for surfactant proteins in the treatment of inflammatory diseases. Furthermore, the general evolution of gene therapy involves potential applications in the genetic disorders of surfactant metabolism, primarily SP-B deficiency.

More than 25 years after the introduction of exogenous surfactant therapy, research around surfactant is still evolving. Surfactant remains a hallmark in the treatment of RDS, especially in very preterm infants. Future research should focus on potential ways to avoid intubation and mechanical ventilation and give surfactant via an alternative route. The therapeutic role of surfactant in other neonatal and paediatric lung diseases is less clear and needs further evaluation. Finally, genetic disorders of surfactant metabolism should be taken into account in the differential diagnosis of respiratory distress and interstitial lung disease in children.

\section{References}

1. Kingma PS, Whitsett JA. In defense of the lung: surfactant protein A and surfactant protein D. Curr Opin Pharmacol 2006;6:277-83

2. Wright JR. Immunoregulatory functions of surfactant proteins. Nat Rev Immunol 2005;5:58-68

3. Bridges JP, Xu Y, Na CL, Wong HR, Weaver TE. Adaptation and increased susceptibility to infection associated with constitutive expression of misfolded SP-C. J Cell Biol 2006;172:395-407

4. Chiba H, Piboonpocanun S, Mitsuzawa H, Kuronuma K, Murphy RC, Voelker DR. Pulmonary surfactant proteins and lipids as modulators of inflammation and innate immunity. Respirology 2006;11 Suppl:S2-6

5. Epaud R, Ikegami M, Whitsett JA, Jobe AH, Weaver TE, Akinbi HT. Surfactant protein B inhibits endotoxininduced lung inflammation. Am J Respir Cell Mol Biol 2003;28:373-8

6. Ikegami M, Whitsett JA, Martis PC, Weaver TE. Reversibility of lung inflammation caused by SP-B deficiency. Am J Physiol Lung Cell Mol Physiol 2005;289:L962-70

7. Mulugeta S, Beers MF. Surfactant protein C: its unique properties and emerging immunomodulatory role in the lung. Microbes Infect 2006;8:2317-23

8. Ryan MA, Akinbi HT, Serrano AG, Perez-Gil J, Wu H, McCormack FX, Weaver TE. Antimicrobial activity of native and synthetic surfactant protein B peptides. J Immunol 2006;176:416-25

9. Avery ME, Mead J. Surface properties in relation to atelectasis and hyaline membrane disease. AMA J Dis Child 1959;97:517-23 
10. Fujiwara T, Maeta H, Chida S, Morita T, Watabe Y, Abe T. Artificial surfactant therapy in hyaline-membrane disease. Lancet 1980;1:55-9

11. Surfactant replacement therapy for severe neonatal respiratory distress syndrome: an international randomized clinical trial. Collaborative European Multicenter Study Group. Pediatrics 1988;82:683-91

12. Yost CC, Soll RF. Early versus delayed selective surfactant treatment for neonatal respiratory distress syndrome. Cochrane Database Syst Rev 2000:CD001456

13. Soll RF. Multiple versus single dose natural surfactant extract for severe neonatal respiratory distress syndrome. Cochrane Database Syst Rev 2000:CD000141

14. Soll RF, Morley CJ. Prophylactic versus selective use of surfactant in preventing morbidity and mortality in preterm infants. Cochrane Database Syst Rev 2001:CD000510

15. Obladen M. History of surfactant up to 1980 . Biol Neonate 2005;87:308-16

16. Halliday HL. History of surfactant from 1980. Biol Neonate 2005;87:317-22

17. Zimmermann LJ, Janssen DJ, Tibboel D, Hamvas A, Carnielli VP. Surfactant metabolism in the neonate. Biol Neonate 2005;87:296-307

18. Bunt JE, Carnielli VP, Darcos Wattimena JL, Hop WC, Sauer PJ, Zimmermann L. The effect in premature infants of prenatal corticosteroids on endogenous surfactant synthesis as measured with stable isotopes. Am J Respir Crit Care Med 2000;162:844-9

19. Bunt JE, Carnielli VP, Janssen DJ, Wattimena JL, Hop WC, Sauer PJ, Zimmermann L. Treatment with exogenous surfactant stimulates endogenous surfactant synthesis in premature infants with respiratory distress syndrome. Crit Care Med 2000;28:3383-8

20. Baroutis G, Kaleyias J, Liarou T, Papathoma E, Hatzistamatiou Z, Costalos C. Comparison of three treatment regimens of natural surfactant preparations in neonatal respiratory distress syndrome. Eur $J$ Pediatr 2003;162:476-80

21. Malloy CA, Nicoski P, Muraskas JK. A randomized trial comparing beractant and poractant treatment in neonatal respiratory distress syndrome. Acta Paediatr 2005;94:779-84

22. Ramanathan R, Rasmussen MR, Gerstmann DR, Finer N, Sekar K. A randomized, multicenter masked comparison trial of poractant alfa (Curosurf) versus beractant (Survanta) in the treatment of respiratory distress syndrome in preterm infants. Am J Perinatol 2004;21:109-19

23. Speer CP, Gefeller O, Groneck P, Laufkotter E, Roll C, Hanssler L, Harms K, Herting E, Boenisch H, Windeler J. Randomised clinical trial of two treatment regimens of natural surfactant preparations in neonatal respiratory distress syndrome. Arch Dis Child Fetal Neonatal Ed 1995;72:F8-13

24. Hammoud M, Al-Kazmi N, Alshemmiri M, Thalib L, Ranjani VT, Devarajan LV, Elsori H. Randomized clinical trial comparing two natural surfactant preparations to treat respiratory distress syndrome. J Matern Fetal Neonatal Med 2004;15:167-75

25. Attar MA, Becker MA, Dechert RE, Donn SM. Immediate changes in lung compliance following natural surfactant administration in premature infants with respiratory distress syndrome: a controlled trial. J Perinatol 2004;24:626-30

26. Bloom BT, Kattwinkel J, Hall RT, Delmore PM, Egan EA, Trout JR, Malloy MH, Brown DR, Holzman IR, Coghill $\mathrm{CH}$, Carlo WA, Pramanik AK, McCaffree MA, Toubas PL, Laudert S, Gratny LL, Weatherstone KB, Seguin JH, Willett LD, Gutcher GR, Mueller DH, Topper WH. Comparison of Infasurf (calf lung surfactant extract) to Survanta (Beractant) in the treatment and prevention of respiratory distress syndrome. Pediatrics 1997;100:31-8

27. Lam BC, Ng YK, Wong KY. Randomized trial comparing two natural surfactants (Survanta vs. bLES) for treatment of neonatal respiratory distress syndrome. Pediatr Pulmonol 2005;39:64-9

28. Horbar JD, Carpenter JH, Buzas J, Soll RF, Suresh G, Bracken MB, Leviton LC, Plsek PE, Sinclair JC. Timing of initial surfactant treatment for infants 23 to 29 weeks' gestation: is routine practice evidence based? Pediatrics 2004;113:1593-602

29. Lefort S, Diniz EM, Vaz FA. Clinical course of premature infants intubated in the delivery room, submitted or not to porcine-derived lung surfactant therapy within the first hour of life. J Matern Fetal Neonatal Med 2003;14:187-96 
30. Stevens TP, Blennow M, Soll RF. Early surfactant administration with brief ventilation vs selective surfactant and continued mechanical ventilation for preterm infants with or at risk for respiratory distress syndrome. Cochrane Database Syst Rev 2004:CD003063

31. Dani C, Bertini G, Pezzati M, Cecchi A, Caviglioli C, Rubaltelli FF. Early extubation and nasal continuous positive airway pressure after surfactant treatment for respiratory distress syndrome among preterm infants <30 weeks' gestation. Pediatrics 2004;113:e560-3

32. Escobedo MB, Gunkel JH, Kennedy KA, Shattuck KE, Sanchez PJ, Seidner S, Hensley G, Cochran CK, Moya F, Morris B, Denson S, Stribley R, Naqvi M, Lasky RE. Early surfactant for neonates with mild to moderate respiratory distress syndrome: a multicenter, randomized trial. J Pediatr 2004;144:804-8

33. Aly H, Massaro AN, Patel K, El-Mohandes AA. Is it safer to intubate premature infants in the delivery room? Pediatrics 2005;115:1660-5

34. Ammari A, Suri M, Milisavljevic V, Sahni R, Bateman D, Sanocka U, Ruzal-Shapiro C, Wung JT, Polin RA. Variables associated with the early failure of nasal CPAP in very low birth weight infants. $J$ Pediatr 2005;147:341-7

35. Te Pas AB, Lopriore E, Engbers MJ, Walther FJ. Early respiratory management of respiratory distress syndrome in very preterm infants and bronchopulmonary dysplasia: a case-control study. PLOS ONE 2007;2:e192

36. Kribs A. Is it safer to intubate premature infants in the delivery room? Pediatrics 2006;117:1858-9

37. Finer NN, Merritt TA, Bernstein G, Job L, Mazela J, Liu G. A multicenter, pilot study of Aerosurf delivered via nasal CPAP to prevent RDS in pre-term neonates. E-PAS 2006;59:4840.138 (abstract)

38. Biban P, Benedetti M, Soffiati M, Ghizzi C, Zaglia F, Bolognani M, Bonetti P, Santuz P. Surfactant instillation via bronchoscopy in preterm infants with respiratory distress syndrome. Europaediatrics (abstract) 2006

39. Kattwinkel J, Robinson M, Bloom BT, Delmore P, Ferguson JE. Technique for intrapartum administration of surfactant without requirement for an endotracheal tube. J Perinatol 2004;24:360-5

40. Brimacombe J, Gandini D, Keller C. The laryngeal mask airway for administration of surfactant in two neonates with respiratory distress syndrome. Paediatr Anaesth 2004;14:188-90

41. Trevisanuto D, Grazzina N, Ferrarese P, Micaglio M, Verghese C, Zanardo V. Laryngeal mask airway used as a delivery conduit for the administration of surfactant to preterm infants with respiratory distress syndrome. Biol Neonate 2005;87:217-20

42. Soll RF, Blanco F. Natural surfactant extract versus synthetic surfactant for neonatal respiratory distress syndrome. Cochrane Database Syst Rev 2001:CD000144

43. Curstedt T, Johansson J. New synthetic surfactant - how and when? Biol Neonate 2006;89:336-9

44. Moya FR, Gadzinowski J, Bancalari E, Salinas V, Kopelman B, Bancalari A, Kornacka MK, Merritt TA, Segal R, Schaber CJ, Tsai H, Massaro J, d'Agostino R. A multicenter, randomized, masked, comparison trial of lucinactant, colfosceril palmitate, and beractant for the prevention of respiratory distress syndrome among very preterm infants. Pediatrics 2005;115:1018-29

45. Sinha SK, Lacaze-Masmonteil T, Valls i Soler A, Wiswell TE, Gadzinowski J, Hajdu J, Bernstein G, SanchezLuna M, Segal R, Schaber CJ, Massaro J, d'Agostino R. A multicenter, randomized, controlled trial of lucinactant versus poractant alfa among very premature infants at high risk for respiratory distress syndrome. Pediatrics 2005;115:1030-8

46. Kattwinkel J. Synthetic surfactants: the search goes on. Pediatrics 2005;115:1075-6

47. Zuo YY, Alolabi H, Shafiei A, Kang N, Policova Z, Cox PN, Acosta E, Hair ML, Neumann AW. Chitosan enhances the in vitro surface activity of dilute lung surfactant preparations and resists albumin-induced inactivation. Pediatr Res 2006;60:125-30

48. Lu KW, Goerke J, Clements JA, Taeusch HW. Hyaluronan reduces surfactant inhibition and improves rat lung function after meconium injury. Pediatr Res 2005;58:206-10

49. Lu KW, Goerke J, Clements JA, Taeusch HW. Hyaluronan decreases surfactant inactivation in vitro. Pediatr Res 2005;57:237-41

50. Wang X, Sun Z, Qian L, Guo C, Yu W, Wang W, Lu KW, Taeusch HW, Sun B. Effects of hyaluronan-fortified surfactant in ventilated premature piglets with respiratory distress. Biol Neonate 2006;89:15-24

51. Ochs M, Schuttler M, Stichtenoth G, Herting E. Morphological alterations of exogenous surfactant inhibited by meconium can be prevented by dextran. Respir Res 2006;7:86 
52. Calkovska A, Some M, Linderholm B, Johansson J, Curstedt T, Robertson B. Biophysical and physiological properties of porcine surfactant enriched with polymyxin B. Biol Neonate 2005;88:101-8

53. Stichtenoth G, Jung P, Walter G, Johansson J, Robertson B, Curstedt T, Herting E. Polymyxin B/pulmonary surfactant mixtures have increased resistance to inactivation by meconium and reduce growth of gramnegative bacteria in vitro. Pediatr Res 2006;59:407-11

54. Doyle NM, Lally KP. The CDH Study Group and advances in the clinical care of the patient with congenital diaphragmatic hernia. Semin Perinatol 2004;28:174-84

55. Wilcox DT, Glick PL, Karamanoukian H, Rossman J, Morin FC, 3rd, Holm BA. Pathophysiology of congenital diaphragmatic hernia. V. Effect of exogenous surfactant therapy on gas exchange and lung mechanics in the lamb congenital diaphragmatic hernia model. J Pediatr 1994;124:289-93

56. Cogo PE, Zimmermann L, Meneghini L, Mainini N, Bordignon L, Suma V, Buffo M, Carnielli VP. Pulmonary surfactant disaturated-phosphatidylcholine (DSPC) turnover and pool size in newborn infants with congenital diaphragmatic hernia (CDH). Pediatr Res 2003;54:653-8

57. Cogo PE, Zimmermann LJ, Verlato G, Midrio P, Gucciardi A, Ori C, Carnielli VP. A dual stable isotope tracer method for the measurement of surfactant disaturated-phosphatidylcholine net synthesis in infants with congenital diaphragmatic hernia. Pediatr Res 2004;56:184-90

58. Janssen DJ, Tibboel D, Carnielli VP, van Emmen E, Luijendijk IH, Darcos Wattimena JL, Zimmermann LJ. Surfactant phosphatidylcholine pool size in human neonates with congenital diaphragmatic hernia requiring ECMO. J Pediatr 2003;142:247-52

59. Lally KP, Lally PA, Langham MR, Hirschl R, Moya FR, Tibboel D, Van Meurs K. Surfactant does not improve survival rate in preterm infants with congenital diaphragmatic hernia. J Pediatr Surg 2004;39:829-33

60. Lotze A, Knight GR, Anderson KD, Hull WM, Whitsett JA, O'Donnell RM, Martin G, Bulas DI, Short BL. Surfactant (beractant) therapy for infants with congenital diaphragmatic hernia on ECMO: evidence of persistent surfactant deficiency. J Pediatr Surg 1994;29:407-12

61. Bae CW, Jang CK, Chung SJ, Choi YM, Oh SM, Lee TS, Shin OY. Exogenous pulmonary surfactant replacement therapy in a neonate with pulmonary hypoplasia accompanying congenital diaphragmatic hernia--a case report. J Korean Med Sci 1996;11:265-70

62. Bos AP, Tibboel D, Hazebroek FW, Molenaar JC, Lachmann B, Gommers D. Surfactant replacement therapy in high-risk congenital diaphragmatic hernia. Lancet 1991;338:1279

63. Glick PL, Leach CL, Besner GE, Egan EA, Morin FC, Malanowska-Kantoch A, Robinson LK, Brody A, Lele AS, McDonnell $M$, et al. Pathophysiology of congenital diaphragmatic hernia. III: Exogenous surfactant therapy for the high-risk neonate with CDH. J Pediatr Surg 1992;27:866-9

64. Van Meurs K. Is surfactant therapy beneficial in the treatment of the term newborn infant with congenital diaphragmatic hernia? J Pediatr 2004;145:312-6

65. Colby CE, Lally KP, Hintz SR, Lally PA, Tibboel D, Moya FR, VanMeurs KP. Surfactant replacement therapy on ECMO does not improve outcome in neonates with congenital diaphragmatic hernia. J Pediatr Surg 2004;39:1632-7

66. Moya FR, Lally KP. Evidence-based management of infants with congenital diaphragmatic hernia. Semin Perinatol 2005;29:112-7

67. Rubin BK, Tomkiewicz RP, Patrinos ME, Easa D. The surface and transport properties of meconium and reconstituted meconium solutions. Pediatr Res 1996;40:834-8

68. Bae CW, Takahashi A, Chida S, Sasaki M. Morphology and function of pulmonary surfactant inhibited by meconium. Pediatr Res 1998;44:187-91

69. Hickling TP, Bright H, Wing K, Gower D, Martin SL, Sim RB, Malhotra R. A recombinant trimeric surfactant protein $\mathrm{D}$ carbohydrate recognition domain inhibits respiratory syncytial virus infection in vitro and in vivo. Eur J Immunol 1999;29:3478-84

70. Moses D, Holm BA, Spitale P, Liu MY, Enhorning G. Inhibition of pulmonary surfactant function by meconium. Am J Obstet Gynecol 1991;164:477-81

71. Sun B, Curstedt T, Robertson B. Surfactant inhibition in experimental meconium aspiration. Acta Paediatr 1993;82:182-9

72. Higgins ST, Wu AM, Sen N, Spitzer AR, Chander A. Meconium increases surfactant secretion in isolated rat alveolar type II cells. Pediatr Res 1996;39:443-7 
73. Oelberg DG, Downey SA, Flynn MM. Bile salt-induced intracellular Ca++ accumulation in type II pneumocytes. Lung 1990;168:297-308

74. Janssen DJ, Carnielli VP, Cogo P, Bohlin K, Hamvas A, Luijendijk IH, Bunt JE, Tibboel D, Zimmermann L. Surfactant phosphatidylcholine metabolism in neonates with meconium aspiration syndrome. $J$ Pediatr 2006;149:634-9

75. Auten RL, Notter RH, Kendig JW, Davis JM, Shapiro DL. Surfactant treatment of full-term newborns with respiratory failure. Pediatrics 1991;87:101-7

76. Khammash H, Perlman M, Wojtulewicz J, Dunn M. Surfactant therapy in full-term neonates with severe respiratory failure. Pediatrics 1993;92:135-9

77. Findlay RD, Taeusch HW, Walther FJ. Surfactant replacement therapy for meconium aspiration syndrome. Pediatrics 1996;97:48-52

78. Lotze A, Mitchell BR, Bulas DI, Zola EM, Shalwitz RA, Gunkel JH. Multicenter study of surfactant (beractant) use in the treatment of term infants with severe respiratory failure. Survanta in Term Infants Study Group. J Pediatr 1998;132:40-7

79. Soll RF, Dargaville P. Surfactant for meconium aspiration syndrome in full term infants. Cochrane Database Syst Rev 2000:CD002054

80. Dargaville PA, Mills JF. Surfactant therapy for meconium aspiration syndrome: current status. Drugs 2005;65:2569-91

81. Lam BC, Yeung CY. Surfactant lavage for meconium aspiration syndrome: a pilot study. Pediatrics 1999;103:1014-8

82. Ogawa Y. Bronchial lavage with surfactant solution for the treatment of meconium aspiration syndrome. Hot topics in Neonatology '97 Conference Proceedings. Columbus (OH): Professional Services Dept, Ross Products: 259-64. 1997

83. Wiswell TE, Knight GR, Finer NN, Donn SM, Desai H, Walsh WF, Sekar KC, Bernstein G, Keszler M, Visser VE, Merritt TA, Mannino FL, Mastrioianni L, Marcy B, Revak SD, Tsai H, Cochrane CG. A multicenter, randomized, controlled trial comparing Surfaxin (Lucinactant) lavage with standard care for treatment of meconium aspiration syndrome. Pediatrics 2002;109:1081-7

84. Cogo PE, Toffolo GM, Gucciardi A, Benetazzo A, Cobelli C, Carnielli VP. Surfactant disaturated phosphatidylcholine kinetics in infants with bronchopulmonary dysplasia measured with stable isotopes and a twocompartment model. J Appl Physiol 2005;99:323-9

85. Cogo PE, Zimmermann LJ, Pesavento R, Sacchetto E, Burighel A, Rosso F, Badon T, Verlato G, Carnielli VP. Surfactant kinetics in preterm infants on mechanical ventilation who did and did not develop bronchopulmonary dysplasia. Crit Care Med 2003;31:1532-8

86. Spence KL, Zozobrado JC, Patterson BW, Hamvas A. Substrate utilization and kinetics of surfactant metabolism in evolving bronchopulmonary dysplasia. J Pediatr 2005;147:480-5

87. Bissinger R, Carlson C, Hulsey T, Eicher D. Secondary surfactant deficiency in neonates. J Perinatol 2004;24:663-6

88. Katz LA, Klein JM. Repeat surfactant therapy for postsurfactant slump. J Perinatol 2006;26:414-22

89. Merrill JD, Ballard PL, Hibbs AM, Godinez RI, Godinez MH, Luan X, Ryan R, Reynolds AM, Hamvas A, Spence K, Courtney S, Truog WE, Posencheg M, Ades A, Lisby DA, Ballard RA. Booster surfactant therapy beyond the first week of life in ventilated extremely low gestational age infants. E-PAS 2006;59:2635.1 (abstract)

90. Amizuka T, Shimizu H, Niida Y, Ogawa Y. Surfactant therapy in neonates with respiratory failure due to haemorrhagic pulmonary oedema. Eur J Pediatr 2003;162:697-702

91. Herting E, Gefeller O, Land M, van Sonderen L, Harms K, Robertson B. Surfactant treatment of neonates with respiratory failure and group $B$ streptococcal infection. Members of the Collaborative European Multicenter Study Group. Pediatrics 2000;106:957-64

92. Herting E, Moller O, Schiffmann JH, Robertson B. Surfactant improves oxygenation in infants and children with pneumonia and acute respiratory distress syndrome. Acta Paediatr 2002;91:1174-8

93. Marraro GA, Luchetti M, Galassini EM, Abbiati G. Natural surfactant supplementation in ARDS in paediatric age. Minerva Anestesiol 1999;65:92-7

94. Moller JC, Schaible T, Roll C, Schiffmann JH, Bindl L, Schrod L, Reiss I, Kohl M, Demirakca S, Hentschel R, Paul T, Vierzig A, Groneck P, von Seefeld H, Schumacher H, Gortner L. Treatment with bovine surfactant in 
severe acute respiratory distress syndrome in children: a randomized multicenter study. Intensive Care Med 2003;29:437-46

95. Willson DF, Jiao JH, Bauman LA, Zaritsky A, Craft H, Dockery K, Conrad D, Dalton H. Calf's lung surfactant extract in acute hypoxemic respiratory failure in children. Crit Care Med 1996;24:1316-22

96. Willson DF, Thomas NJ, Markovitz BP, Bauman LA, DiCarlo JV, Pon S, Jacobs BR, Jefferson LS, Conaway MR, Egan EA. Effect of exogenous surfactant (calfactant) in pediatric acute lung injury: a randomized controlled trial. JAMA 2005;293:470-6

97. Willson DF, Zaritsky A, Bauman LA, Dockery K, James RL, Conrad D, Craft H, Novotny WE, Egan EA, Dalton $H$. Instillation of calf lung surfactant extract (calfactant) is beneficial in pediatric acute hypoxemic respiratory failure. Members of the Mid-Atlantic Pediatric Critical Care Network. Crit Care Med 1999;27:188-95

98. Czaja AS. A critical appraisal of a randomized controlled trial: Willson et al: Effect of exogenous surfactant (calfactant) in pediatric acute lung injury (JAMA 2005, 293: 470-476). Pediatr Crit Care Med 2007;8:50-3

99. Ventre K, Haroon M, Davison C. Surfactant therapy for bronchiolitis in critically ill infants. Cochrane Database Syst Rev 2006;3:CD005150

100. Davison C, Ventre KM, Luchetti M, Randolph AG. Efficacy of interventions for bronchiolitis in critically ill infants: a systematic review and meta-analysis. Pediatr Crit Care Med 2004;5:482-9

101. Kneyber MC, Plotz FB, Kimpen JL. Bench-to-bedside review: Paediatric viral lower respiratory tract disease necessitating mechanical ventilation--should we use exogenous surfactant? Crit Care 2005;9:550-5

102. Krause MF, von Bismarck P, Oppermann HC, Ankermann T. Bronchoscopic surfactant administration in pediatric patients with persistent lobar atelectasis. Respiration 2008;75:100-4

103. Haas NA, Kulasekaran K, Camphausen CK. Successful use of surfactant to treat severe intrapulmonary hemorrhage after iatrogenic lung injury--A case report. Pediatr Crit Care Med 2006;7:583-5

104. Creery WD, Hashmi A, Hutchison JS, Singh RN. Surfactant therapy improves pulmonary function in infants with Pneumocystis carinii pneumonia and acquired immunodeficiency syndrome. Pediatr Pulmonol 1997;24:370-3

105. Hermon M, Burda G, Male C, Boigner H, Ponhold W, Khoss A, Strohmaier W, Trittenwein G. Surfactant application during extracorporeal membrane oxygenation improves lung volume and pulmonary mechanics in children with respiratory failure. Crit Care 2005;9:R718-24

106. Nogee LM, de Mello DE, Dehner LP, Colten HR. Brief report: deficiency of pulmonary surfactant protein B in congenital alveolar proteinosis. N Engl J Med 1993;328:406-10

107. Nogee LM, Wert SE, Proffit SA, Hull WM, Whitsett JA. Allelic heterogeneity in hereditary surfactant protein B (SP-B) deficiency. Am J Respir Crit Care Med 2000;161:973-81

108. Vorbroker DK, Profitt SA, Nogee LM, Whitsett JA. Aberrant processing of surfactant protein C in hereditary SP-B deficiency. Am J Physiol 1995;268:L647-56

109. Hamvas A. Inherited surfactant protein-B deficiency and surfactant protein- $C$ associated disease: clinical features and evaluation. Semin Perinatol 2006;30:316-26

110. Hamvas A, Nogee LM, Mallory GB, Jr., Spray TL, Huddleston CB, August A, Dehner LP, deMello DE, Moxley $\mathrm{M}$, Nelson R, Cole FS, Colten HR. Lung transplantation for treatment of infants with surfactant protein $B$ deficiency. J Pediatr 1997;130:231-9

111. Palomar LM, Nogee LM, Sweet SC, Huddleston CB, Cole FS, Hamvas A. Long-term outcomes after infant lung transplantation for surfactant protein B deficiency related to other causes of respiratory failure. J Pediatr 2006;149:548-53

112. Beers MF, Mulugeta S. Surfactant protein C biosynthesis and its emerging role in conformational lung disease. Annu Rev Physiol 2005;67:663-96

113. Kabore AF, Wang WJ, Russo SJ, Beers MF. Biosynthesis of surfactant protein C: characterization of aggresome formation by EGFP chimeras containing propeptide mutants lacking conserved cysteine residues. J Cell Sci 2001;114:293-302

114. Wang WJ, Mulugeta S, Russo SJ, Beers MF. Deletion of exon 4 from human surfactant protein $C$ results in aggresome formation and generation of a dominant negative. J Cell Sci 2003;116:683-92

115. Wert S, Deutsch G, Hamvas A, Whitsett J, Nogee L. Mutations in the surfactant protein C gene (SFTPC) are associated with acute and chronic lung disease in full term infants. Am J Respir Crit Care Med Abstr 2 2005:A23 
116. Cameron HS, Somaschini M, Carrera P, Hamvas A, Whitsett JA, Wert SE, Deutsch G, Nogee LM. A common mutation in the surfactant protein $C$ gene associated with lung disease. J Pediatr 2005;146:370-5

117. Thomas AQ, Lane K, Phillips J, 3rd, Prince M, Markin C, Speer M, Schwartz DA, Gaddipati R, Marney A, Johnson J, Roberts R, Haines J, Stahlman M, Loyd JE. Heterozygosity for a surfactant protein C gene mutation associated with usual interstitial pneumonitis and cellular nonspecific interstitial pneumonitis in one kindred. Am J Respir Crit Care Med 2002;165:1322-8

118. Amin RS, Wert SE, Baughman RP, Tomashefski JF, Jr., Nogee LM, Brody AS, Hull WM, Whitsett JA. Surfactant protein deficiency in familial interstitial lung disease. J Pediatr 2001;139:85-92

119. Rosen DM, Waltz DA. Hydroxychloroquine and surfactant protein C deficiency. N Engl J Med 2005;352:2078

120. Tredano M, Griese M, Brasch F, Schumacher S, de Blic J, Marque S, Houdayer C, Elion J, Couderc R, Bahuau M. Mutation of SFTPC in infantile pulmonary alveolar proteinosis with or without fibrosing lung disease. Am J Med Genet A 2004;126A:18-26

121. Brasch F, Griese M, Tredano M, Johnen G, Ochs M, Rieger C, Mulugeta S, Muller KM, Bahuau M, Beers MF. Interstitial lung disease in a baby with a de novo mutation in the SFTPC gene. Eur Respir J 2004;24:30-9

122. Chibbar R, Shih F, Baga M, Torlakovic E, Ramlall K, Skomro R, Cockcroft DW, Lemire EG. Nonspecific interstitial pneumonia and usual interstitial pneumonia with mutation in surfactant protein $\mathrm{C}$ in familial pulmonary fibrosis. Mod Pathol 2004;17:973-80

123. Shulenin S, Nogee LM, Annilo T, Wert SE, Whitsett JA, Dean M. ABCA3 gene mutations in newborns with fatal surfactant deficiency. N Engl J Med 2004;350:1296-303

124. Mulugeta S, Gray JM, Notarfrancesco KL, Gonzales LW, Koval M, Feinstein SI, Ballard PL, Fisher AB, Shuman $\mathrm{H}$. Identification of LBM180, a lamellar body limiting membrane protein of alveolar type II cells, as the $A B C$ transporter protein ABCA3. J Biol Chem 2002;277:22147-55

125. Yamano G, Funahashi H, Kawanami O, Zhao LX, Ban N, Uchida Y, Morohoshi T, Ogawa J, Shioda S, Inagaki N. ABCA3 is a lamellar body membrane protein in human lung alveolar type II cells. FEBS Lett 2001;508:221-5

126. Matsumura Y, Ban N, Ueda K, Inagaki N. Characterization and classification of ATP-binding cassette transporter ABCA3 mutants in fatal surfactant deficiency. J Biol Chem 2006;281:34503-14

127. Stefkova J, Poledne R, Hubacek JA. ATP-binding cassette $(A B C)$ transporters in human metabolism and diseases. Physiol Res 2004;53:235-43

128. Fitzgerald ML, Xavier R, Haley KJ, Welti R, Goss JL, Brown CE, Zhuang DZ, Bell SA, Lu N, McKee M, Seed B, Freeman MW. ABCA3 inactivation in mice causes respiratory failure, loss of pulmonary surfactant and depletion of lung phosphatidylglycerol. J Lipid Res 2007;48:621-32

129. Cheong N, Madesh M, Gonzales LW, Zhao M, Yu K, Ballard PL, Shuman H. Functional and trafficking defects in ATP binding cassette A3 mutants associated with respiratory distress syndrome. J Biol Chem 2006;281:9791-800

130. Nagata K, Yamamoto A, Ban N, Tanaka AR, Matsuo M, Kioka N, Inagaki N, Ueda K. Human ABCA3, a product of a responsible gene for abca3 for fatal surfactant deficiency in newborns, exhibits unique ATP hydrolysis activity and generates intracellular multilamellar vesicles. Biochem Biophys Res Commun 2004;324:262-8

131. Brasch F, Schimanski S, Muhlfeld C, Barlage S, Langmann T, Aslanidis C, Boettcher A, Dada A, Schroten H, Mildenberger E, Prueter E, Ballmann M, Ochs M, Johnen G, Griese M, Schmitz G. Alteration of the pulmonary surfactant system in full-term infants with hereditary ABCA3 deficiency. Am J Respir Crit Care Med 2006;174:571-80

132. Bullard JE, Wert SE, Nogee LM. ABCA3 Deficiency: Neonatal Respiratory Failure and Interstitial Lung Disease. Semin Perinatol 2006;30:327-34

133. Garmany TH, Moxley MA, White FV, Dean M, Hull WM, Whitsett JA, Nogee LM, Hamvas A. Surfactant composition and function in patients with ABCA3 mutations. Pediatr Res 2006;59:801-5

134. Bullard JE, Wert SE, Whitsett JA, Dean M, Nogee LM. ABCA3 mutations associated with pediatric interstitial lung disease. Am J Respir Crit Care Med 2005;172:1026-31

135. Floros J, Thomas NJ, Liu W, Papagaroufalis C, Xanthou M, Pereira S, Fan R, Guo X, Diangelo S, Pavlovic J. Family-based association tests suggest linkage between surfactant protein B (SP-B) (and flanking region) 
and respiratory distress syndrome (RDS): SP-B haplotypes and alleles from SP-B-linked loci are risk factors for RDS. Pediatr Res 2006;59:616-21

136. Hamvas A, Wegner DJ, Trusgnich MA, Madden K, Heins H, Liu Y, Rice T, An P, Watkins-Torry J, Cole FS. Genetic variant characterization in intron 4 of the surfactant protein B gene. Hum Mutat 2005;26:494-5

137. Rova M, Haataja R, Marttila R, Ollikainen V, Tammela O, Hallman M. Data mining and multiparameter analysis of lung surfactant protein genes in bronchopulmonary dysplasia. Hum Mol Genet 2004;13:1095104

138. Haataja R, Ramet M, Marttila R, Hallman M. Surfactant proteins A and B as interactive genetic determinants of neonatal respiratory distress syndrome. Hum Mol Genet 2000;9:2751-60

139. Hallman M, Haataja R. Genetic basis of respiratory distress syndrome. Front Biosci 2007;12:2670-82

140. Lahti M, Marttila R, Hallman M. Surfactant protein C gene variation in the Finnish population - association with perinatal respiratory disease. Eur J Hum Genet 2004;12:312-20

141. Ramet M, Lofgren J, Alho OP, Hallman M. Surfactant protein-A gene locus associated with recurrent otitis media. J Pediatr 2001;138:266-8

142. Jack DL, Cole J, Naylor SC, Borrow R, Kaczmarski EB, Klein NJ, Read RC. Genetic polymorphism of the binding domain of surfactant protein-A2 increases susceptibility to meningococcal disease. Clin Infect Dis 2006;43:1426-33

143. Blanco PG, Freedman SD, Lopez MC, Ollero M, Comen E, Laposata M, Alvarez JG. Oral docosahexaenoic acid given to pregnant mice increases the amount of surfactant in lung and amniotic fluid in preterm fetuses. Am J Obstet Gynecol 2004;190:1369-74

144. Gommers D, Haitsma JJ, Lachmann B. Surfactant as a carrier: influence of immunosuppressive agents on surfactant activity. Clin Physiol Funct Imaging 2006;26:357-61

145. Obaid L, Johnson ST, Bigam DL, Cheung PY. Intratracheal administration of sildenafil and surfactant alleviates the pulmonary hypertension in newborn piglets. Resuscitation 2006;69:287-94

146. Yeh TF, Su BH, Chang CH, Lin HS, Tsai CH, Pyati S, Kamat M. Early intratracheal instillation of budesonide (B) by using surfactant (Survanta) (S) as a vehicle to preterm infants at risk for chronic lung disease (CLD) A double blind trial. 2006;59:3724.1 (abstract)

147. Ankermann T, Reisner A, Wiemann T, Koehler H, Krams M, Krause MF. Intrapulmonary application of a 5lipoxygenase inhibitor using surfactant as a carrier reduces lung edema in a piglet model of airway lavage. Pediatr Pulmonol 2006;41:452-62

148. Shashikant BN, Miller TL, Welch RW, Pilon AL, Shaffer TH, Wolfson MR. Dose response to rhCC10augmented surfactant therapy in a lamb model of infant respiratory distress syndrome: physiological, inflammatory, and kinetic profiles. J Appl Physiol 2005;99:2204-11

149. Erpenbeck VJ, Ziegert M, Cavalet-Blanco D, Martin C, Baelder R, Glaab T, Braun A, Steinhilber W, Luettig B, Uhlig S, Hoymann HG, Krug N, Hohlfeld JM. Surfactant protein D inhibits early airway response in Aspergillus fumigatus-sensitized mice. Clin Exp Allergy 2006;36:930-40

150. Singh M, Madan T, Waters P, Parida SK, Sarma PU, Kishore U. Protective effects of a recombinant fragment of human surfactant protein $D$ in a murine model of pulmonary hypersensitivity induced by dust mite allergens. Immunol Lett 2003;86:299-307

151. Strong P, Townsend P, Mackay R, Reid KB, Clark HW. A recombinant fragment of human SP-D reduces allergic responses in mice sensitized to house dust mite allergens. Clin Exp Immunol 2003;134:181-7

152. Ikegami M, Carter K, Bishop K, Yadav A, Masterjohn E, Brondyk W, Scheule RK, Whitsett JA. Intratracheal recombinant surfactant protein $d$ prevents endotoxin shock in the newborn preterm lamb. Am J Respir Crit Care Med 2006;173:1342-7 



\section{Chapter 3}

Histological chorioamnionitis and respiratory outcome in preterm infants

Been JV, Zimmermann LJ

Arch Dis Child Fetal Neonatal Ed 2009; 194: F218-25 


\begin{abstract}
A considerable body of human and animal experimental evidence links antenatal inflammation to both accelerated maturation and adverse development of the lung. Initial reports suggest that in preterm infants histological chorioamnionitis is associated with a decreased incidence of respiratory distress syndrome (RDS), while the incidence of bronchopulmonary dysplasia (BPD) is increased. Considerable variation exists in the findings of subsequent human studies, largely dependent on differences in inclusion and exclusion criteria. Taking these differences into account, recent studies generally seem to confirm the effect of chorioamnionitis on RDS incidence, while no effect on BPD is seen. The increased use of antenatal steroids and the diminished effects of secondary proinflammatory hits seem to explain part of this change. Additional research is needed to explore these complex interactions and their underlying mechanisms, and evaluate the long term pulmonary effects of antenatal inflammation.
\end{abstract}




\section{Introduction}

The effects of antenatal inflammation on both short and long term outcome in preterm infants have received increasing attention over the last few years. Chorioamnionitis is clearly associated with preterm birth and its incidence in preterm infants increases with decreasing gestational age ${ }^{1-3}$. The primary process in the aetiology of intrauterine inflammation is believed to be ascending bacterial invasion from the cervicovaginal tract 4,5 , although several other routes have been postulated ${ }^{5}$. Bacteria may then spread across the chorioamniotic membranes and cause chorioamnionitis ${ }^{4,5}$. In a subset of patients intrauterine inflammation is accompanied by a fetal response, believed to reflect the more serious end of the continuum. Initial signs of fetal inflammation in preterm infants are seen in the chorionic plate, followed by involvement of the umbilical cord vessels, often referred to as "funisitis" ${ }^{4}$.

Both clinical and histopathological definitions of chorioamnionitis have been used as indicators of intrauterine inflammation, but numerous studies have shown these to be poorly correlated. Clinical indicators of maternal inflammation are unspecific and probably mainly identify cases of acute chorioamnionitis. Conversely, histological criteria for chorioamnionitis based upon the identification of polymorphonuclear cellular infiltrates, are clearly defined, although different grading systems exist. It is generally felt that a histological definition of intrauterine inflammation more closely reflects antenatal inflammatory exposure than the clinical definition ${ }^{5}$.

Exposure to antenatal inflammation has mainly been associated with alterations in brain and lung development. Intrauterine inflammation has quite consistently been shown to adversely affect short term neurological outcome by increasing the incidences of intraventricular haemorrhage, white matter abnormalities, cystic periventricular leucomalacia and cerebral palsy, as reviewed in Dammann et $a l^{6}$. While several follow-up studies show neurodevelopmental outcome to be unaffected ${ }^{7-11}$, others have reported histological chorioamnionitis to be associated with developmental delay ${ }^{12,13}$, abnormal neurological outcome ${ }^{14}$, speech delay ${ }^{15}$, and autism ${ }^{16}$. As regards pulmonary outcome, Watterberg and colleagues were the first to report a decrease in the incidence of respiratory distress syndrome (RDS), while the incidence of chronic lung injury, marked by the presence of bronchopulmonary dysplasia (BPD), was increased in infants with chorioamnionitis ${ }^{17}$. This paradoxical effect of prenatal inflammation on pulmonary outcome has been referred to as the "Watterberg effect". Numerous larger cohort studies in preterm infants have since tried to reproduce and explain these findings, yielding seemingly inconsistent results. The interpretation of many of these studies is further complicated by the fact that important confounders such as gestational age have not been adjusted for in the analyses.

The purpose of this review is to provide a synopsis of the human evidence on pulmonary outcome after exposure to intrauterine inflammation defined solely on histopathological grounds. Findings of cohort studies will be summarised, with special 
emphasis on identifying differences and similarities, and exploring potential explanations for paradoxical findings among these studies. Separation of the effects of chorioamnionitis with and without fetal involvement, and the interaction with antenatal steroid administration will receive special attention.

\section{Respiratory outcome after chorioamnionitis}

In the Watterberg study, 53 mechanically ventilated infants with a birth weight below $2000 \mathrm{~g}$ were divided into two groups based on the presence or absence of RDS ${ }^{17}$. None of the infants received surfactant or antenatal steroids. The incidence of chorioamnionitis was significantly higher in the group without RDS. Conversely, chorioamnionitis-exposed patients who survived were more likely to develop BPD. Although infants with chorioamnionitis were of significantly lower gestational age, possibly explaining the increased incidence of BPD, the data were not adjusted for this. On the other hand, gestational age adjustment would probably have augmented the decreased RDS risk.

These observations have led many research groups to conduct cohort studies on respiratory outcome in preterm newborns exposed to histological chorioamnionitis. The general characteristics of these studies are summarised in table 1 . Incidences of histological chorioamnionitis varied between $33 \%$ and $71 \%$, largely depending on variation in criteria used for inclusion and exclusion. Two studies comprised patients included in randomised controlled trials. One was designed to evaluate the effect of antenatal $\mathrm{MgSO}_{4}$ on the development of cerebral palsy ${ }^{18}$, while the other randomised mechanically ventilated infants to either hydrocortisone or placebo to evaluate the effect on BPD development ${ }^{19}$. While antenatal $\mathrm{MgSO}_{4}$ was shown not to alter respiratory outcome in preterm infants ${ }^{20}$, the hydrocortisone trial should obviously be interpreted with care.

The association of chorioamnionitis with relevant respiratory outcome parameters is shown in table 2. Chorioamnionitis-exposed patients had either similar ${ }^{7,21-25}$, or decreased 2,3,26,27 RDS incidences in most studies. While Elimian and colleagues reported an increase in RDS incidence, the difference disappeared after multivariate analysis ${ }^{28}$. Interpretation of this study is further complicated by the exclusion of patients with clinical chorioamnionitis. Four other large reports adjusted their data for confounding factors, invariably showing chorioamnionitis to be associated with significantly decreased RDS risk $2,3,27,29$

Table 1 (next page). Study characteristics of cohort studies reporting short-term pulmonary outcome in preterm infants with and without histologic chorioamnionitis (CA). PPROM=premature prolonged rupture of membranes; $\mathrm{PL}=$ preterm labour; cong=congenital; $\mathrm{GA}=$ gestational age; $\mathrm{BW}=$ birth weight; $\mathrm{PDA}=$ patent ductus arteriosus; $M V=$ mechanical ventilation; IUGR=intrauterine growth retardation; $A G A=$ appropriate for gestational age; AS=Apgar score; MMP-9=matrix metalloproteinase-9; ${ }^{\text {a }}$ randomised controlled trial (RCT) of postnatal hydrocorti-

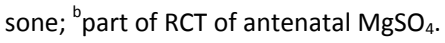




\begin{tabular}{|c|c|c|c|c|c|c|}
\hline Author & $\begin{array}{l}\text { Study } \\
\text { period }\end{array}$ & $\begin{array}{l}\text { Inclusion } \\
\text { criteria }\end{array}$ & $\begin{array}{l}\text { Exclusion } \\
\text { criteria }\end{array}$ & $\begin{array}{l}\text { Cohort } \\
\text { size }\end{array}$ & $\begin{array}{l}\text { Antenatal } \\
\text { steroids }\end{array}$ & $\begin{array}{l}\text { Factors in multivariate } \\
\text { model }\end{array}$ \\
\hline $\begin{array}{l}\text { Dexter } \\
2000^{7}\end{array}$ & $\begin{array}{l}1990- \\
1994\end{array}$ & $\begin{array}{l}<1250 \mathrm{~g}+ \\
\text { PPROM / PL }\end{array}$ & $>1^{\text {st }}$ born of multiples & $\begin{array}{l}C A+164 \\
C A-123\end{array}$ & $22 \%$ & \\
\hline $\begin{array}{l}\text { Elimian } \\
2000^{28}\end{array}$ & $\begin{array}{l}1990- \\
1997\end{array}$ & $500-1750 \mathrm{~g}$ & Clinical CA & $\begin{array}{l}\text { CA: } 527 \\
\text { CA- } 733\end{array}$ & $33 \%$ & $?$ \\
\hline $\begin{array}{l}\text { Kosuge } \\
2000^{26}\end{array}$ & $\begin{array}{l}1993- \\
1997\end{array}$ & $24-32 w$ & $\begin{array}{l}\text { Lethal cong } \\
\text { anomalies }\end{array}$ & $\begin{array}{l}C A+37 \\
C A-44\end{array}$ & $17 \%$ & \\
\hline $\begin{array}{l}\text { Redline } \\
2002^{31}\end{array}$ & $\begin{array}{l}1995- \\
1997\end{array}$ & $\begin{array}{l}<32 \mathrm{w}+ \\
<1250 \mathrm{~g}\end{array}$ & Death $<36$ w & $\begin{array}{l}C A+169 \\
C A-202\end{array}$ & $65 \%$ & $\begin{array}{l}\text { GA; BW Z-score; race; air } \\
\text { leak; PDA; atherosis; } \\
\text { sepsis; respiratory dis- } \\
\text { tress }\end{array}$ \\
\hline $\begin{array}{l}\text { Ogunyemi } \\
2003^{21}\end{array}$ & $\begin{array}{l}1992- \\
2000\end{array}$ & $24-32 w$ & - & $\begin{array}{l}C A+254 \\
C A-520\end{array}$ & $53 \%$ & \\
\hline $\begin{array}{l}\text { Kent } \\
2004^{30}\end{array}$ & $\begin{array}{l}1996- \\
2001\end{array}$ & $<30 w$ & - & $\begin{array}{l}C A+80 \\
C A-161\end{array}$ & $\begin{array}{l}94 \% \\
(71 \% 2 x)\end{array}$ & $\begin{array}{l}\text { GA, BW, sex, surfactant, } \\
\text { antenatal steroids }\end{array}$ \\
\hline $\begin{array}{l}\text { Holcroft } \\
2004^{22}\end{array}$ & $\begin{array}{l}1999- \\
2002\end{array}$ & $23-34 w$ & Cong anomalies & $\begin{array}{l}C A+146 \\
C A-208\end{array}$ & $?$ & \\
\hline $\begin{array}{l}\text { Watterberg } \\
2004^{a 19}\end{array}$ & $\begin{array}{l}2001- \\
2003\end{array}$ & $\begin{array}{l}500-999 \mathrm{~g} \\
+\mathrm{MV} 12-48 \mathrm{hrs} \\
\text { after birth }\end{array}$ & $\begin{array}{l}\text { Cong anomalies; cong } \\
\text { sepsis; >twins; postnatal } \\
\text { steroids }\end{array}$ & $\begin{array}{l}C A+149 \\
C A-211\end{array}$ & $79 \%$ & \\
\hline $\begin{array}{l}\text { de Felice } \\
2005^{23}\end{array}$ & $?$ & $<1250 \mathrm{~g}$ & Cong anomalies & $\begin{array}{l}C A+67 \\
C A-49\end{array}$ & $?$ & \\
\hline $\begin{array}{l}\text { Dempsey } \\
2005^{3}\end{array}$ & $\begin{array}{l}1989- \\
1999\end{array}$ & $<30 w$ & - & $\begin{array}{l}C A+140 \\
C A-202\end{array}$ & $63 \%$ & $?$ \\
\hline $\begin{array}{l}\text { Mittendorf } \\
2005^{b 18}\end{array}$ & $\begin{array}{l}1995- \\
1997\end{array}$ & $\begin{array}{l}24-34 \mathrm{w}+\mathrm{PL}+ \\
\text { reassuring fetal } \\
\text { assessment }\end{array}$ & $\begin{array}{l}\text { Clinical signs of maternal } \\
\text { infection; preeclampsia }\end{array}$ & $\begin{array}{l}C A+60 \\
C A-63\end{array}$ & $90 \%$ & \\
\hline $\begin{array}{l}\text { Andrews } \\
2006^{29}\end{array}$ & $\begin{array}{l}1996- \\
2001\end{array}$ & $23-32 w$ & - & $\begin{array}{l}C A+222 \\
C A-224\end{array}$ & $\pm 87 \%$ & GA; race; sex \\
\hline $\begin{array}{l}\text { Mehta } \\
2006^{32}\end{array}$ & $\begin{array}{l}1999- \\
2001\end{array}$ & $<34 w$ & - & $\begin{array}{l}C A+64 \\
C A-100\end{array}$ & $?$ & \\
\hline $\begin{array}{l}\text { Richardson } \\
2006^{24}\end{array}$ & $\begin{array}{l}1995- \\
2003\end{array}$ & $\begin{array}{l}25-34 \mathrm{w}+\mathrm{PL} / \\
\text { suspected CA }\end{array}$ & $\begin{array}{l}\text { Multiples; cong anoma- } \\
\text { lies }\end{array}$ & $\begin{array}{l}C A+292 \\
C A-368\end{array}$ & $?$ & $\begin{array}{l}\text { GA; delivery mode; DM; } \\
\text { hypertension; abruption; } \\
\text { IUGR<3\% }\end{array}$ \\
\hline $\begin{array}{l}M u \\
2008^{25}\end{array}$ & $\begin{array}{l}2000- \\
2004\end{array}$ & $<1250 \mathrm{~g}$ & Cong anomalies & $\begin{array}{l}C A+64 \\
C A-55\end{array}$ & $45 \%$ & $\mathrm{GA}$ \\
\hline $\begin{array}{l}\text { Kewitz } \\
2008^{33}\end{array}$ & $\begin{array}{l}1996- \\
2000\end{array}$ & $<28 w+A G A$ & Cong anomalies & $\begin{array}{l}C A+87 \\
C A-35\end{array}$ & ? & \\
\hline $\begin{array}{l}\text { Lahra } \\
2009^{2}\end{array}$ & $\begin{array}{l}1991- \\
2001\end{array}$ & $<30 w$ & - & $\begin{array}{l}C A+357 \\
C A-367\end{array}$ & $\begin{array}{l}94 \% \\
(57 \% 2 x)\end{array}$ & $\begin{array}{l}\text { GA; } 1 \text { min AS<4; multiple } \\
\text { gestation; hypertension }\end{array}$ \\
\hline $\begin{array}{l}\text { Kaukola } \\
2008^{27}\end{array}$ & $\begin{array}{l}1998- \\
2002\end{array}$ & $<32 w$ & $\begin{array}{l}\text { Cong anomalies; neona- } \\
\text { tal mortality; general- } \\
\text { ised viral / protozoal } \\
\text { infection }\end{array}$ & $\begin{array}{l}C A+68 \\
C A-99\end{array}$ & $86 \%$ & GA \\
\hline
\end{tabular}


Table 2. Association of histologic chorioamnionitis with respiratory outcome parameters in cohort studies. $\uparrow$, $\downarrow$ and $=$ indicate increased, decreased, or unchanged risk after chorioamnionitis, respectively. Abbreviations: RDS=respiratory distress syndrome; $B P D=$ bronchopulmonary dysplasia; dexa=postnatal dexamethasone; surf=surfactant; MV=mechanical ventilation. ${ }^{a}$ duration of therapy; ${ }^{b}$ adjustment for GA and BW Z-score; ${ }^{c}$ additional adjustment for race, air leak, patent ductus arteriosus, atherosis, sepsis and respiratory distress; ${ }^{d}$ physiologic BPD definition at $36 \mathrm{w}$ postconceptional age (PCA); ${ }^{e}$ physiologic BPD definition at $36 \mathrm{w}$ PCA with correction for altitude; ${ }^{f} \mathrm{BPD}$ defined as $\mathrm{O}_{2}$ at 28 days postnatal age; ${ }^{g} \mathrm{BPD}$ definition not mentioned.

$$
\text { Outcome (unadjusted) Outcome (adjusted) }
$$

\begin{tabular}{|c|c|c|c|c|c|c|c|c|c|}
\hline Study & $\stackrel{\varkappa}{\approx}$ & ০ & 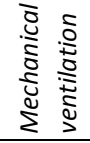 & $0^{2}$ & 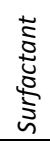 & $\frac{\bar{d}}{\frac{1}{0}}$ & ֻิ & ০ & $\begin{array}{l}\bar{\Xi} \\
\text { ठँ }\end{array}$ \\
\hline Dexter $2000^{7}$ & $=$ & $=$ & $={ }^{a}$ & $={ }^{a}$ & & & & & \\
\hline Elimian $2000^{28}$ & $\uparrow$ & & & & $\uparrow$ & & $=$ & & \\
\hline Kosuge $2000^{26}$ & $\downarrow$ & & $=$ & & $\downarrow$ & & & & \\
\hline Redline $2002^{31}$ & & $=$ & & & & & & $\downarrow^{b} /=^{c}$ & \\
\hline Ogunyemi $2003^{21}$ & $=$ & $\uparrow$ & & & & & & & \\
\hline Kent $2004^{30}$ & & $=$ & & & $=$ & $=$ dexa & & $=$ & \\
\hline Holcroft $2004^{22}$ & $=$ & & & & & & & & \\
\hline Watterberg $2004^{19}$ & & $\uparrow /=^{\mathrm{d}, \mathrm{e}}$ & & & & & & & \\
\hline de Felice $2005^{23}$ & $=$ & $\uparrow^{f}$ & $\uparrow$ & $\uparrow$ & & & & & \\
\hline Dempsey $2005^{3}$ & $\downarrow$ & $=^{\mathrm{g}}$ & & & & 个pneumonia & $\downarrow$ & $=^{g}$ & 个pneumonia \\
\hline Mittendorf $2005^{18}$ & & $\uparrow^{f}$ & & & & & & & \\
\hline Andrews $2006^{29}$ & & & & & & & $\downarrow$ & $=$ & \\
\hline Mehta $2006^{32}$ & & $\uparrow$ & & & & & & & \\
\hline Richardson $2006^{24}$ & $=$ & $\uparrow$ & & & & & & & \\
\hline Mu $2008^{25}$ & $=$ & $\uparrow$ & $=/ \uparrow^{a}$ & & $\uparrow$ & & $=$ & $\uparrow$ & $=$ surf $/ \uparrow M V$ \\
\hline Kewitz $2008^{33}$ & & $=$ & & & & & & & \\
\hline Lahra $2009^{2}$ & $\downarrow$ & & & & & & $\downarrow$ & & \\
\hline Kaukola $2009^{27}$ & $\downarrow$ & $=$ & & & & & $\downarrow$ & $=$ & \\
\hline
\end{tabular}

Data on the need for respiratory support after chorioamnionitis differ greatly between studies. Often parallel to RDS incidence, chorioamnionitis has been reported to increase 25,28 and decrease ${ }^{26}$, as well as not to affect the need for surfactant administration ${ }^{30}$. Moreover, while some report no effect on the need for mechanical ventilation ${ }^{25,26}$, time spent on the ventilator ${ }^{7}$, and time on additional oxygen supplementation ${ }^{7}$, others report increased need for ventilatory support or oxygen ${ }^{23,25}$.

The increased incidence of BPD was reproduced in six of the 18 studies ${ }^{18,21,23-25,32}$. However, gestational age adjustment was performed in only one of these ${ }^{25}$. Curiously, the risk remained although gestational age was significantly lower in chorioamnionitis infants 25 . Moreover, two of these studies used the old BPD definition of oxygen need at 28 days postnatally ${ }^{18,23}$. In the remaining reports, multivariate adjustment generally showed no 
difference in BPD risk or BPD-free survival ${ }^{3,19,27,29,30}$, while chorioamnionitis even decreased BPD risk in one study ${ }^{31}$.

Incidental reports suggest that chorioamnionitis may be associated with increased risks for neonatal pneumonia ${ }^{3}$, and severe pulmonary haemorrhage ${ }^{34}$. Additional studies are needed to investigate these potential associations.

\section{Respiratory outcome after fetal involvement}

Fetal signs of inflammation accompanying chorioamnionitis are generally felt to reflect a more serious inflammatory state. Recent evidence suggests that amnionitis may be another marker of severe intrauterine inflammation, although data linking amnionitis to neonatal respiratory outcome are currently lacking ${ }^{35}$. Matsuda and colleagues were the first to link severe fetal inflammation to BPD development ${ }^{36}$. Several studies have since addressed the question as to whether fetal inflammation may have additional consequences for neonatal outcome. Reported differences in respiratory outcome parameters between chorioamnionitis-exposed patients with and without fetal involvement are shown in table 3.

Fetal inflammation was defined as either chorionic vasculitis ${ }^{32}$, umbilical vasculitis ${ }^{2}$, funisitis ${ }^{18,22,24,30}$, "fetal response" 31 , or subdivided into polymorphonuclear leukocyte (PMN) infiltration of the chorionic plate or the umbilical cord ${ }^{29}$. Two studies showed that RDS incidence was further decreased in infants with fetal involvement when compared to those with only maternal signs of inflammation ${ }^{2,22}$, while no additional effect was seen in another ${ }^{24}$. Multivariate analysis invariably confirmed the association between fetal inflammation and decreased RDS incidence ${ }^{2,24,29}$, an effect that appears to be additive to that of chorioamnionitis alone ${ }^{2}$. None of the studies found fetal inflammation to increase the risk of developing BPD when compared to only maternal inflammation. Also, no overall effect of fetal involvement on BPD risk was seen after adjustment for potential confounders ${ }^{29,31}$, although in non-white infants severe fetal involvement was associated with decreased BPD risk in one study ${ }^{31}$.

Not included in the table is a small case-control study comparing the effects of severe acute chorioamnionitis, severe subacute chorioamnionitis (defined by the presence of additional mononuclear cells) and subacute necrotising funisitis on neonatal outcome ${ }^{37}$. Each of these histological states was associated with decreased RDS incidence when compared to matched patients without placental inflammation. Interestingly, BPD incidence was greatly increased only in the subacute chorioamnionitis group ${ }^{37}$. This suggests that both the timing and duration of intrauterine exposure to inflammation may modulate its effect on neonatal respiratory outcome. However, the definition of BPD used was not mentioned, complicating interpretation of the data. Moreover, others have found no association between mononuclear infiltrates and neonatal outcome ${ }^{29}$. 
Table 3. Association of histologic fetal inflammation with respiratory outcome parameters in cohort studies. $\downarrow$ and $=$ indicate either decreased or unchanged risk after fetal inflammation $(C A+F+)$ versus maternal inflammation only (CA+F-). Abbreviations: RDS=respiratory distress syndrome; BPD=bronchopulmonary dysplasia; $\mathrm{MV}=$ mechanical ventilation; $\mathrm{FP}=$ involvement of fetal plate; $\mathrm{UC}=$ involvement of umbilical cord.

\begin{tabular}{|c|c|c|c|c|c|c|c|}
\hline \multirow[b]{2}{*}{ Study } & \multirow[b]{2}{*}{ Cohort size } & \multicolumn{2}{|c|}{$\begin{array}{l}\text { Outcome } \\
\text { (unadjusted) }\end{array}$} & \multirow[b]{2}{*}{ Other } & & \multicolumn{2}{|c|}{ Outcome (adjusted) } \\
\hline & & $R D S$ & $B P D$ & & & $R D S$ & $B P D$ \\
\hline Redline $2002^{31}$ & $\begin{array}{l}\mathrm{CA}+\mathrm{F}+? \\
\mathrm{CA}+\mathrm{F}-?\end{array}$ & & $=$ & & & & $=$ \\
\hline Kent $2004^{30}$ & $\begin{array}{l}C A+F+40 \\
C A+F-40\end{array}$ & & $=$ & $\begin{array}{l}=\mathrm{O}_{2} \text { days } \\
=\text { Surf }\end{array}$ & $\begin{array}{l}=\text { MV days } \\
=\text { Dexa }\end{array}$ & & \\
\hline Holcroft $2004^{22}$ & $\begin{array}{l}C A+F+87 \\
C A+F-59\end{array}$ & $\downarrow$ & & & & & \\
\hline Mittendorf $2005^{18}$ & $\begin{array}{l}C A+F+22 \\
C A+F-38\end{array}$ & & $={ }^{a}$ & & & & \\
\hline Andrews $2006^{29}$ & $\begin{array}{l}\mathrm{CA}+215 \\
\mathrm{CA}+\mathrm{FP}+178 \\
\mathrm{CA}+\mathrm{UC}+136\end{array}$ & & & & & $\begin{array}{l}\downarrow(\mathrm{FP}) \\
\downarrow(\mathrm{UC})\end{array}$ & $\begin{array}{l}=(F P) \\
=(U C)\end{array}$ \\
\hline Mehta $2006^{32}$ & $\begin{array}{l}C A+F+45 \\
C A+F-19\end{array}$ & & $=$ & & & & \\
\hline Richardson $2006^{24}$ & $\begin{array}{l}C A+F+178 \\
C A+F-114\end{array}$ & $=$ & $=$ & & & $\downarrow$ & \\
\hline Lahra $2009^{2}$ & $\begin{array}{l}C A+F+219 \\
C A+F-138\end{array}$ & $\downarrow$ & & & & $\downarrow$ & \\
\hline
\end{tabular}

\section{Chorioamnionitis and steroids}

\section{Antenatal steroids}

Although chorioamnionitis is an inflammatory state while steroids have an antiinflammatory effect, both are capable of enhancing lung maturation, probably partly through distinct mechanisms ${ }^{38,39}$. Concerns that maternal administration of corticosteroids would aggravate the alleged harmful response to intrauterine inflammation have initially limited their use in suspected chorioamnionitis. Over recent years, both animal experimental studies and clinical studies have provided support for the use of antenatal steroids in imminent preterm birth with suspected chorioamnionitis. The human evidence is discussed here, while animal experimental evidence has been reviewed recently ${ }^{38}$.

None of the patients reported in the initial Watterberg study received antenatal steroids ${ }^{17}$. It has been suggested that the inability of many later studies to confirm the increased BPD risk, may be attributed to the increased use of antenatal steroids over the last 15 years. Several of the aforementioned cohort studies have explored the effect of antenatal steroids in patients with histological chorioamnionitis to try to address this issue. 
In line with their established effects in the overall preterm population, antenatal steroids also seem to decrease RDS incidence in infants with histological chorioamnionitis. Although only Elimian and colleagues found the decrease to be significant ${ }^{28}$, a similar trend is clearly present in other reports as well ${ }^{3,40}$. These observations are supported by molecular studies showing increased surfactant protein B in amniotic fluid after antenatal steroids in women with intra-amniotic infection ${ }^{41}$. In addition, antenatal steroids seem to decrease neonatal mortality ${ }^{3,28}$ and the incidence of the systemic inflammatory response syndrome (SIRS) ${ }^{40}$ in chorioamnionitis-exposed infants.

Despite an apparent reduction in RDS, no significant effect of antenatal steroids on $B P D$ incidence has been reported ${ }^{40}$. In a logistic regression model to identify risk factors for BPD, Kent and Dahlstrom found neither chorioamnionitis nor antenatal steroids to be significant predictors ${ }^{30}$. On the other hand, all cohort studies with documented antenatal steroid exposure rates above 55\% have reported either decreased or unchanged incidences of RDS and BPD at 36 weeks post-menstrual age (PMA) after chorioamnionitis (table 1$)^{2,3,19,27,29-31}$. Thus, current high rates of prenatal steroid administration may partly explain why the initial observation of an association between chorioamnionitis and BPD is no longer reproduced. Taken together, these data further support liberal administration of antenatal steroids in case of imminent preterm birth ${ }^{42}$, and also when chorioamnionitis is present.

\section{Postnatal steroids}

In light of the association between steroid exposure, chorioamnionitis and respiratory outcome, the findings of the hydrocortisone trial are of particular interest. Although hydrocortisone did not improve outcome in the general population, subgroup analysis of infants with chorioamnionitis showed increased BPD-free survival and decreased mortality with postnatal hydrocortisone ${ }^{19}$. The effect remained after multivariate analysis and was most prominent in infants with fetal signs of inflammation. Thus, anti-inflammatory treatment may positively affect pulmonary outcome after antenatal exposure to inflammation. However, the particular study was stopped because of an increased incidence of spontaneous gastrointestinal perforations in the treatment group, complicating future exploration of this therapeutic option.

\section{Chorioamnionitis and long term respiratory outcome}

We are aware of only two human studies investigating the association between chorioamnionitis and pulmonary outcome beyond the neonatal period. No significant differences in the use of supplemental oxygen, bronchodilators and systemic or inhaled steroids were reported between patients with and without chorioamnionitis at 18-22 months' corrected age in the hydrocortisone trial, irrespective of neonatal hydrocortisone treatment ${ }^{43}$. A prospective study by Kumar and colleagues was specifically designed to 
investigate the effect of chorioamnionitis on respiratory outcome in early childhood ${ }^{44}$. Chorioamnionitis and prematurity were shown to have a joint predisposing effect on recurrent wheezing and physician-diagnosed asthma at a mean age of 2.2 years. The effect was most prominent in former extremely preterm infants and in African-American children. Chorioamnionitis was defined as the presence of either maternal fever or histological chorioamnionitis, complicating comparison with studies reporting only histological inflammation. Still this study suggests that antenatal inflammation may affect lung development beyond the neonatal period and further investigation of the long term pulmonary effects of antenatal exposure to inflammation is warranted ${ }^{45}$.

\section{Explaining the inconsistencies}

Reported effects of antenatal inflammation on respiratory outcome differ greatly between studies published to date. Figure 1 illustrates how numerous factors complicate interpretation of these associations and may explain at least part of the paradoxical nature of findings among different studies. Their potential contributions are discussed in order to try to explain the apparent inconsistencies.

\section{Inclusion and exclusion criteria}

Firstly, inclusion criteria differ greatly between studies. Differences in gestational age and the birth weight distributions of the study groups are likely to affect both adverse respiratory outcome and its association with chorioamnionitis, since the incidence of both is inversely related to gestational age (fig 1). Some studies further selected their cohort by including only ventilated infants ${ }^{17,19}$, or patients with premature prolonged rupture of membranes (PPROM) ${ }^{7}$, preterm labour ${ }^{7,18,24,36}$, and suspected clinical chorioamnionitis ${ }^{24,36}$. In contrast, cases of clinical chorioamnionitis or suspected maternal infection were excluded by others ${ }^{18,28}$. The resultant plausible exclusion of more seriously affected chorioamnionitis infants ${ }^{46}$ may underestimate the effect of chorioamnionitis on RDS reduction, since fetal inflammation has been shown to be associated with a more prominent reduction in RDS than maternal inflammation alone ${ }^{2}$. On the other hand, inclusion of mothers based on the presence of preterm labour will preselect mainly patients with histological chorioamnionitis, largely excluding the group of indicated preterm delivery consisting primarily of mothers with preeclampsia, HELLP syndrome (haemolysis, elevated liver enzymes and low platelets) and vaginal bleeding. This too is importance since these entities have been associated with increased RDS incidence (fig 1) ${ }^{47-50}$. Excluding these patients may thus underestimate the association between chorioamnionitis and RDS reduction and explain why studies doing so have failed to identify this association ${ }^{7,24}$.

The fact that preeclampsia and HELLP syndrome are associated with increased RDS incidence raises another fundamental question. Since these entities and chorioamnionitis rarely co-exist, their high incidence in the reference group is an important confounder 
when assessing the effect of chorioamnionitis on respiratory outcome. It raises the question as to whether the decrease in RDS incidence seen after chorioamnionitis may in fact reflect an increased risk in patients exposed to preeclampsia or HELLP syndrome. The notion that markers of lung maturation are decreased in patients with HELLP syndrome ${ }^{51}$, while animal studies invariably confirm the lung maturational effects of antenatal inflammation ${ }^{38,52}$, suggests that the effect is bidirectional.

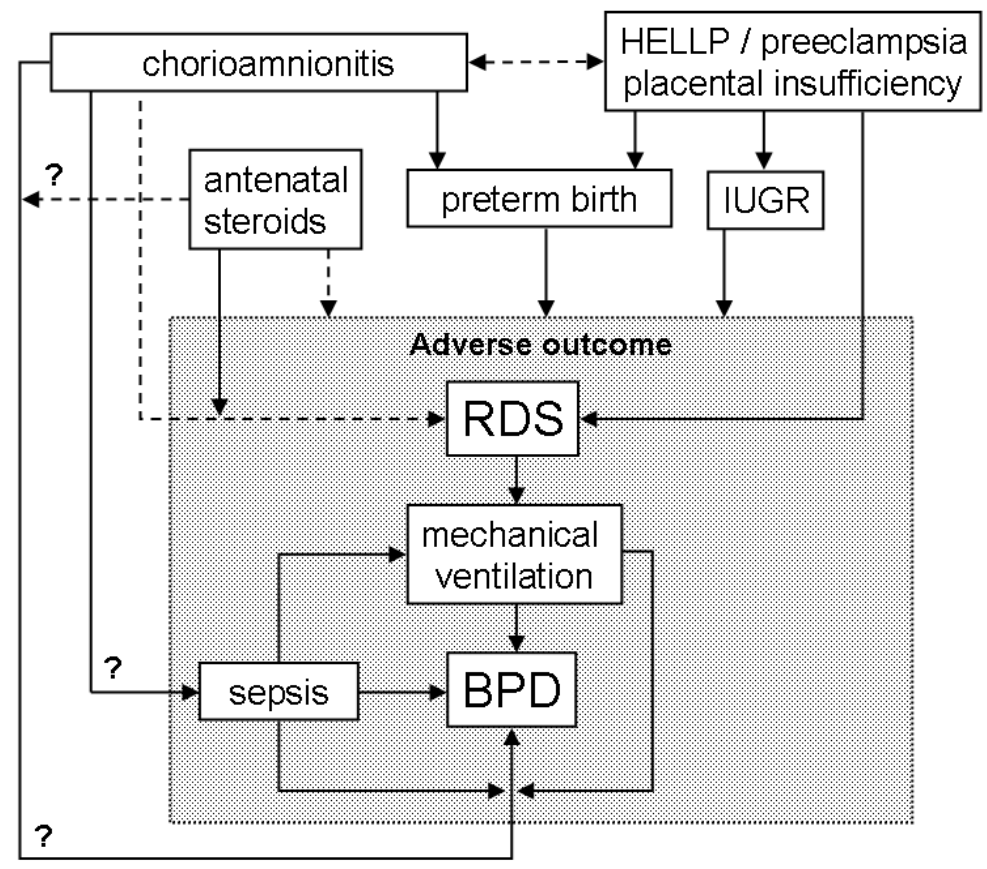

Figure 1. Diagram showing positive (--) and negative (- - -) correlations between clinical entities that complicate interpretation of reported associations between chorioamnionitis and neonatal respiratory outcome. Abbreviations: HELLP=haemolysis, elevated liver enzymes and low platelets; IUGR=intrauterine growth retardation; RDS=respiratory distress syndrome; BPD=bronchopulmonary dysplasia.

\section{Disease definitions}

Various histopathological criteria and grading systems for diagnosing chorioamnionitis or fetal inflammation exist and likewise, differ importantly between studies. Furthermore, the old definition of BPD used by some complicates comparison of this outcome parameter between studies ${ }^{18,23}$. Since the incidence of BPD defined as oxygen need at 28 days postnatally is more closely related to gestational age than is the more suitable definition of BPD at 36 weeks postconceptional age (PCA), the use of the former may account for the increased BPD incidence in the chorioamnionitis group through their lower gestational age in these studies ${ }^{23}$. 


\section{Confounding factors and covariates}

Since both chorioamnionitis and adverse neonatal outcome are inversely related to gestational age, adjusting for gestational age differences when exploring associations between the two is invaluable. Only a limited number of studies have appreciated this and performed multivariate adjustment to account for this effect $2,3,24,25,27,29-31$. Although additional inclusion of other confounding factors in multivariate models may have increased the relevance of the findings in individual studies ${ }^{2,3,24,29-31}$, it further complicates comparison of the data between them, as does the lack of mentioning the factors included in the model ${ }^{28}$. Although the fact that gestational age in itself is dependent on many additional confounding factors somewhat limits the accuracy of its use in multivariate models ${ }^{53}$, the magnitude of its confounding nature justifies its use as such.

Racial differences in chorioamnionitis prevalence and the pulmonary response to intrauterine inflammation may account for additional inconsistencies between studies. Chorioamnionitis and vaginal bacterial colonisation are more prevalent in non-white infants $31,54,55$, while white race is a risk factor for BPD ${ }^{31,56}$. Redline and colleagues showed that in non-white infants, chorioamnionitis was associated with decreased BPD incidence, most prominently in infants still ventilated on day $2^{31}$. Conversely, black race augmented the increased risk of wheezing and asthma after chorioamnionitis in a follow-up study ${ }^{44}$. Other important potential confounding variables have been shown to differ importantly between white and black mothers and complicate interpretation of the association between race, chorioamnionitis prevalence and neonatal outcome ${ }^{31,55}$.

Over the time period the cohort study data have been collected, important changes in general practice in neonatal intensive care have taken place. The widespread implementation of antenatal steroids is the most obvious and probably the most influential example ${ }^{42}$. Other practice changes include the increased use of exogenous surfactant ${ }^{57}$ and non-invasive modes of ventilatory support such as continuous positive airway pressure (CPAP) ${ }^{58}$. These may reduce secondary lung injury in chorioamnionitisexposed infants and partly account for the apparently diminishing association between chorioamnionitis and BPD over time ${ }^{59}$.

\section{Exploring the mechanisms}

Sufficient evidence links chorioamnionitis to altered lung maturation and development. In animals, antenatal inflammation clearly enhances lung maturation ${ }^{38,52}$. The effect has been shown to be much greater than that of antenatal steroids, suggesting that at least partly distinct mechanisms play a role ${ }^{39,60}$. On the other hand, normal lung development is disrupted and architectural changes resemble the pathological picture of new BPD currently seen in preterm infants ${ }^{38,61-63}$. Both inflammatory mediators and growth factors have been shown to play a role in this process ${ }^{38,64,65}$. 
As for human data two levels of mechanistic evidence may be considered: indirect data, investigating associations between covariables and the effect of chorioamnionitis on respiratory outcome, and direct data, investigating effects of chorioamnionitis on a functional, molecular or cellular level.

\section{Indirect mechanistic evidence}

Probably the most informative study concerning indirect mechanistic evidence is that reported by Van Marter and colleagues ${ }^{59}$. In a case-control design, very low birth weight infants with BPD were matched with infants without BPD on gestational age, birth weight and hospital specific treatment strategies. In these infants chorioamnionitis was associated with a decreased risk for BPD if infants were ventilated for less than 7 days. However, when infants were exposed to mechanical ventilation for more than 7 days or had sepsis, chorioamnionitis significantly increased BPD risk, the effect being most prominent in infants with all three risk factors present (fig 1). This suggests that, while antenatal exposure to inflammation in itself may reduce BPD risk, it increases the susceptibility of the lung to postnatal injurious events. This too may explain part of the Watterberg effect on BPD, since only ventilated children were included in their initial study ${ }^{17}$. Interestingly, in the Watterberg study mean airway pressures needed to ventilate infants were lower initially in those exposed to chorioamnionitis but rose above values for non-exposed infants over the second week ${ }^{17}$. This too is indicative of worsening pulmonary status during mechanical ventilation despite an apparently healthier initial condition.

Pointing in the same direction is the simple observation that chorioamnionitis probably lowers RDS risk without consistently affecting BPD incidence. In other words, given the better initial respiratory status reasonably requiring less invasive intervention, one would expect BPD risk to diminish as well, since invasive interventional strategies are clearly associated with BPD development ${ }^{66}$. The notion that this does not happen further supports the concept of increased susceptibility of the developing lung to secondary hits in the neonatal period following intrauterine exposure to inflammation ${ }^{67}$.

\section{Direct mechanistic evidence}

Not surprisingly, many studies have reported increased levels of pro-inflammatory cytokines, chemokines and other markers of inflammation in cord blood, fetal placental capillaries and lung-derived specimens in patients with histological evidence of intrauterine inflammation ${ }^{14,17,18,27,36,68-72}$. Chorioamnionitis and funisitis have also been associated with increased numbers of macrophages and lymphocytes in the lung ${ }^{73-75}$. Moreover, both maternal and fetal polymorphisms of immunoregulatory genes have been associated with both histological chorioamnionitis ${ }^{76-82}$ and neonatal sepsis ${ }^{81}$, while no association with neonatal pulmonary outcome was found ${ }^{81}$.

A considerable body of evidence links Ureaplasma urealyticum to chorioamnionitis, preterm birth and the development of chronic lung disease ${ }^{83,84}$, as reviewed elsewhere ${ }^{85,86}$. Awareness of the role of Ureaplasma species is invaluable, since its in vitro cultivation 
needs specific and complex nutritional requirements and regular culture techniques will often miss the organism. Molecular techniques may improve the detection of chorioamnionitis-associated pathogens including Ureaplasma ${ }^{87,88}$. The ability of Ureaplasma species to induce both lung maturation and injury has been confirmed in animal models ${ }^{89,90}$. However, antibiotic treatment aimed at eradicating Ureaplasma does not seem to improve respiratory outcome in preterm infants ${ }^{91}$. Worryingly, in women in threatened preterm labour antibiotic treatment is associated with an increased risk of cerebral palsy ${ }^{92}$. No difference in outcome is seen in a similar trial in women with PPROM 93.

In preterm infants not exposed to antenatal steroids, Watterberg and colleagues showed that chorioamnionitis was associated with increased serum cortisol levels ${ }^{94}$. Since corticoids are known stimulants of surfactant synthesis and lung maturation, this could partly account for the reduction in respiratory distress in these infants ${ }^{94}$, although animal data do not support this concept ${ }^{39}$.

In a pathological study in stillborn fetuses, those with chorioamnionitis had decreased pulmonary expression of serum and glucocorticoid-inducible kinase (SGK1), a known regulator of epithelial $\mathrm{Na}^{+}$channel $(\mathrm{EnaC})$ and $\mathrm{Na}^{+}-\mathrm{K}^{+}$-ATPase ${ }^{73}$. The authors suggest that this may decrease pulmonary fluid clearance and consequently affect gas exchange, predisposing infants to increased ventilatory support. The same group showed that proliferation of epithelial cells, endothelial cells and fibroblasts was decreased while apoptosis of distal lung epithelial cells was increased in fetuses with chorioamnionitis ${ }^{95}$. This provides a potential human link between chorioamnionitis and adverse lung development. Matrix metalloproteinase- 8 and -9 , neutrophil products capable of cleaving important matrix components, may also play a role in this process. Increased levels in cord blood and lung-derived fluid have been linked to both chorioamnionitis ${ }^{27,96,97}$ and the development of BPD ${ }^{97-101}$. Taken together, human studies on mechanistic evidence are scarce when compared to animal experimental studies. Additional human data are indispensable in exploring the underlying mechanisms of pulmonary developmental changes after chorioamnionitis.

\section{Conclusions}

Evidence is increasing that intrauterine inflammation decreases RDS risk in preterm infants through stimulation of lung maturation. Despite a reduction in RDS, the incidence of BPD is unchanged, while recent data suggest the susceptibility for subsequent asthma development to be increased. Both altered lung development and enhanced susceptibility to secondary injury may account for this effect. Antenatal steroids further decrease the incidence of RDS and possibly also that of BPD in chorioamnionitis-exposed infants.

Although current treatment strategies seem to diminish the adverse effects chorioamnionitis has on neonatal outcome in preterm infants, its impact on adverse 
outcome obviously remains substantial through its causal relationship with preterm birth itself. Future research should focus on the mechanisms of inflammation-induced lung injury, long term follow-up of pulmonary outcome after chorioamnionitis and ways to reduce its adverse effects on lung development and injury repair.

\section{References}

1. Lahra MM, Jeffery HE. A fetal response to chorioamnionitis is associated with early survival after preterm birth. Am J Obstet Gynecol 2004;190:147-51

2. Lahra MM, Beeby PJ, Jeffery HE. Maternal versus fetal inflammation and respiratory distress syndrome: a 10-year hospital cohort study. Arch Dis Child Fetal Neonatal Ed 2009;94:F13-6

3. Dempsey E, Chen MF, Kokottis T, Vallerand D, Usher R. Outcome of neonates less than 30 weeks gestation with histologic chorioamnionitis. Am J Perinatol 2005;22:155-9

4. Goldenberg RL, Hauth JC, Andrews WW. Intrauterine infection and preterm delivery. $N$ Engl J Med 2000;342:1500-7

5. Redline RW. Inflammatory responses in the placenta and umbilical cord. Semin Fetal Neonatal Med 2006;11:296-301

6. Dammann O, Leviton A, Bartels DB, Dammann CE. Lung and brain damage in preterm newborns. Are they related? How? Why? Biol Neonate 2004;85:305-13

7. Dexter SC, Pinar H, Malee MP, Hogan J, Carpenter MW, Vohr BR. Outcome of very low birth weight infants with histopathologic chorioamnionitis. Obstet Gynecol 2000;96:172-7

8. Polam S, Koons A, Anwar M, Shen-Schwarz S, Hegyi T. Effect of chorioamnionitis on neurodevelopmental outcome in preterm infants. Arch Pediatr Adolesc Med 2005;159:1032-5

9. Mu SC, Lin CH, Sung TC, Chen YL, Lin YC, Lee CC, Chen TJ, Lin MI, Jow GM. Neurodevelopmental outcome of very-low-birth-weight infants with chorioamnionitis. Acta Paediatr Taiwan 2007;48:207-12

10. Dexter SC, Malee MP, Pinar H, Hogan JW, Carpenter MW, Vohr BR. Influence of chorioamnionitis on developmental outcome in very low birth weight infants. Obstet Gynecol 1999;94:267-73

11. Andrews WW, Cliver SP, Biasini F, Peralta-Carcelen AM, Rector R, Alriksson-Schmidt Al, Faye-Petersen O, Carlo W, Goldenberg R, Hauth JC. Early preterm birth: association between in utero exposure to acute inflammation and severe neurodevelopmental disability at 6 years of age. Am J Obstet Gynecol 2008;198:466 e1- e11

12. Mittendorf R, Montag AG, MacMillan W, Janeczek S, Pryde PG, Besinger RE, Gianopoulos JG, Roizen N. Components of the systemic fetal inflammatory response syndrome as predictors of impaired neurologic outcomes in children. Am J Obstet Gynecol 2003;188:1438-4

13. Redline RW, Minich N, Taylor HG, Hack M. Placental lesions as predictors of cerebral palsy and abnormal neurocognitive function at school age in extremely low birth weight infants ( $<1 \mathrm{~kg})$. Pediatr Dev Pathol 2007;10:282-92

14. Kaukola T, Herva R, Perhomaa M, Paakko E, Kingsmore S, Vainionpaa L, Hallman M. Population cohort associating chorioamnionitis, cord inflammatory cytokines and neurologic outcome in very preterm, extremely low birth weight infants. Pediatr Res 2006;59:478-83

15. Suppiej A, Franzoi M, Vedovato S, Marucco A, Chiarelli S, Zanardo V. Neurodevelopmental outcome in preterm histological chorioamnionitis. Early Hum Dev 2009;85:187-9

16. Limperopoulos C, Bassan H, Sullivan NR, Soul JS, Robertson RL, Jr., Moore M, Ringer SA, Volpe JJ, du Plessis AJ. Positive screening for autism in ex-preterm infants: prevalence and risk factors. Pediatrics 2008;121:758-65

17. Watterberg KL, Demers LM, Scott SM, Murphy S. Chorioamnionitis and early lung inflammation in infants in whom bronchopulmonary dysplasia develops. Pediatrics 1996;97:210-5 
18. Mittendorf R, Covert R, Montag AG, elMasri W, Muraskas J, Lee KS, Pryde PG. Special relationships between fetal inflammatory response syndrome and bronchopulmonary dysplasia in neonates. J Perinat Med 2005;33:428-34

19. Watterberg KL, Gerdes JS, Cole CH, Aucott SW, Thilo EH, Mammel MC, Couser RJ, Garland JS, Rozycki HJ, Leach CL, Backstrom C, Shaffer ML. Prophylaxis of early adrenal insufficiency to prevent bronchopulmonary dysplasia: a multicenter trial. Pediatrics 2004;114:1649-57

20. Crowther CA, Hiller JE, Doyle LW, Haslam RR. Effect of magnesium sulfate given for neuroprotection before preterm birth: a randomized controlled trial. JAMA 2003;290:2669-76

21. Ogunyemi D, Murillo M, Jackson U, Hunter N, Alperson B. The relationship between placental histopathology findings and perinatal outcome in preterm infants. J Matern Fetal Neonatal Med 2003;13:102-9

22. Holcroft CJ, Askin FB, Patra A, Allen MC, Blakemore KJ, Graham EM. Are histopathologic chorioamnionitis and funisitis associated with metabolic acidosis in the preterm fetus? Am J Obstet Gynecol 2004;191:20105

23. De Felice C, Toti P, Parrini S, Del Vecchio A, Bagnoli F, Latini G, Kopotic RJ. Histologic chorioamnionitis and severity of illness in very low birth weight newborns. Pediatr Crit Care Med 2005;6:298-302

24. Richardson BS, Wakim E, daSilva O, Walton J. Preterm histologic chorioamnionitis: impact on cord gas and $\mathrm{pH}$ values and neonatal outcome. Am J Obstet Gynecol 2006;195:1357-65

25. Mu SC, Lin CH, Chen YL, Ma HJ, Lee JS, Lin MI, Lee CC, Chen TJ, Jow GM, Sung TC. Impact on neonatal outcome and anthropometric growth in very low birth weight infants with histological chorioamnionitis. $J$ Formos Med Assoc 2008;107:304-10

26. Kosuge S, Ohkuchi A, Minakami H, Matsubara S, Uchida A, Eguchi Y, Honma Y, Sato I. Influence of chorioamnionitis on survival and morbidity in singletons live-born at $<32$ weeks of gestation. Acta Obstet Gynecol Scand 2000;79:861-5

27. Kaukola T, Tuimala J, Herva R, Kingsmore S, Hallman M. Cord immunoproteins as predictors of respiratory outcome in preterm infants. Am J Obstet Gynecol 2009;200:100 e1-8

28. Elimian A, Verma U, Beneck D, Cipriano R, Visintainer P, Tejani N. Histologic chorioamnionitis, antenatal steroids, and perinatal outcomes. Obstet Gynecol 2000;96:333-6

29. Andrews WW, Goldenberg RL, Faye-Petersen O, Cliver S, Goepfert AR, Hauth JC. The Alabama Preterm Birth study: polymorphonuclear and mononuclear cell placental infiltrations, other markers of inflammation, and outcomes in 23- to 32-week preterm newborn infants. Am J Obstet Gynecol 2006;195:803-8

30. Kent A, Dahlstrom JE. Chorioamnionitis/funisitis and the development of bronchopulmonary dysplasia. J Paediatr Child Health 2004;40:356-9

31. Redline RW, Wilson-Costello D, Hack M. Placental and other perinatal risk factors for chronic lung disease in very low birth weight infants. Pediatr Res 2002;52:713-9

32. Mehta R, Nanjundaswamy S, Shen-Schwarz S, Petrova A. Neonatal morbidity and placental pathology. Indian J Pediatr 2006;73:25-8

33. Kewitz G, Wudel S, Hopp H, Hopfenmuller W, Vogel M, Roots I. Below median birth weight in appropriatefor-gestational-age preterm infants as a risk factor for bronchopulmonary dysplasia. J Perinat Med 2008;36:359-64

34. De Felice C, Latini G, Ginanneschi C, Santopietro R, Toti P, Fanetti G, La Gamma ML, Bagnoli F. Subclinical chorioamnionitis: an unrecognised risk factor for severe pulmonary haemorrhage in extremely low birth weight infants. Eur J Pediatr 2005;164:111-2

35. Park CW, Moon KC, Park JS, Jun JK, Romero R, Yoon BH. The involvement of human amnion in histologic chorioamnionitis is an indicator that a fetal and an intra-amniotic inflammatory response is more likely and severe: clinical implications. Placenta 2009;30:56-61

36. Matsuda T, Nakajima T, Hattori S, Hanatani K, Fukazawa Y, Kobayashi K, Fujimoto S. Necrotizing funisitis: clinical significance and association with chronic lung disease in premature infants. Am J Obstet Gynecol 1997;177:1402-7

37. Ohyama M, Itani Y, Yamanaka M, Goto A, Kato K, Ijiri R, Tanaka Y. Re-evaluation of chorioamnionitis and funisitis with a special reference to subacute chorioamnionitis. Hum Pathol 2002;33:183-90

38. Kramer BW. Antenatal inflammation and lung injury: prenatal origin of neonatal disease. J Perinatol 2008;28 Suppl 1:S21-7 
39. Jobe AH, Newnham JP, Willet KE, Moss TJ, Gore Ervin M, Padbury JF, Sly P, Ikegami M. Endotoxin-induced lung maturation in preterm lambs is not mediated by cortisol. Am J Respir Crit Care Med 2000;162:1656-61

40. Goldenberg RL, Andrews WW, Faye-Petersen OM, Cliver SP, Goepfert AR, Hauth JC. The Alabama preterm birth study: corticosteroids and neonatal outcomes in 23- to 32-week newborns with various markers of intrauterine infection. Am J Obstet Gynecol 2006;195:1020-4

41. Chaiworapongsa T, Hong JS, Hull WM, Romero R, Whitsett JA. Amniotic fluid concentration of surfactant proteins in intra-amniotic infection. J Matern Fetal Neonatal Med 2008;21:663-70

42. Roberts D, Dalziel S. Antenatal corticosteroids for accelerating fetal lung maturation for women at risk of preterm birth. Cochrane Database Syst Rev 2006;3:CD004454

43. Watterberg KL, Shaffer ML, Mishefske MJ, Leach CL, Mammel MC, Couser RJ, Abbasi S, Cole CH, Aucott SW, Thilo EH, Rozycki HJ, Lacy CB. Growth and neurodevelopmental outcomes after early low-dose hydrocortisone treatment in extremely low birth weight infants. Pediatrics 2007;120:40-8

44. Kumar R, Yu Y, Story RE, Pongracic JA, Gupta R, Pearson C, Ortiz K, Bauchner HC, Wang X. Prematurity, chorioamnionitis, and the development of recurrent wheezing: a prospective birth cohort study. J Allergy Clin Immunol 2008;121:878-84 e6

45. Been JV, Kramer BW, Zimmermann LJ. In utero and early-life conditions and adult health and disease. $N$ Engl J Med 2008;359:1523-4

46. Dammann O, Allred EN, Leviton A, Shen-Schwarz S, Heller D, Genest DR, Collins MH. Fetal vasculitis in preterm newborns: interrelationships, modifiers, and antecedents. Placenta 2004;25:788-96

47. Kurkinen-Raty $M$, Koivisto $M$, Jouppila P. Preterm delivery for maternal or fetal indications: maternal morbidity, neonatal outcome and late sequelae in infants. BJOG 2000;107:648-55

48. Baud O, Zupan V, Lacaze-Masmonteil T, Audibert F, Shojaei T, Thebaud B, Ville Y, Frydman R, Dehan M. The relationships between antenatal management, the cause of delivery and neonatal outcome in a large cohort of very preterm singleton infants. BJOG 2000;107:877-84

49. Banias BB, Devoe LD, Nolan TE. Severe preeclampsia in preterm pregnancy between 26 and 32 weeks' gestation. Am J Perinatol 1992;9:357-60

50. Ley D, Wide-Swensson D, Lindroth $M$, Svenningsen N, Marsal K. Respiratory distress syndrome in infants with impaired intrauterine growth. Acta Paediatr 1997;86:1090-6

51. Torrance HL, Voorbij HA, Wijnberger LD, van Bel F, Visser GH. Lung maturation in small for gestational age fetuses from pregnancies complicated by placental insufficiency or maternal hypertension. Early Hum Dev 2008;84:465-9

52. Kramer BW, Kallapur S, Newnham J, Jobe AH. Prenatal inflammation and lung development. Semin Fetal Neonatal Med 2009;14:2-7

53. Leviton A, Blair E, Dammann O, Allred E. The wealth of information conveyed by gestational age. J Pediatr 2005;146:123-7

54. Goldenberg RL, Klebanoff MA, Nugent R, Krohn MA, Hillier S, Andrews WW. Bacterial colonization of the vagina during pregnancy in four ethnic groups. Vaginal Infections and Prematurity Study Group. Am J Obstet Gynecol 1996;174:1618-21

55. Dammann O, Leviton A, Allred EN. What explains away the increased risk of histological chorioamnionitis in African-American mothers of very-low-birthweight infants? Developmental Epidemiology Network Investigators. Paediatr Perinat Epidemiol 2000;14:20-9

56. Akram Khan M, Kuzma-O'Reilly B, Brodsky NL, Bhandari V. Site-specific characteristics of infants developing bronchopulmonary dysplasia. J Perinatol 2006;26:428-35

57. Been JV, Zimmermann LJ. What's new in surfactant? A clinical view on recent developments in neonatology and paediatrics. Eur J Pediatr 2007;166:889-99

58. Morley CJ, Davis PG. Continuous positive airway pressure: scientific and clinical rationale. Curr Opin Pediatr 2008;20:119-24

59. Van Marter LJ, Dammann O, Allred EN, Leviton A, Pagano M, Moore M, Martin C. Chorioamnionitis, mechanical ventilation, and postnatal sepsis as modulators of chronic lung disease in preterm infants. J Pediatr 2002;140:171-6

60. Willet KE, Jobe AH, Ikegami M, Newnham J, Brennan S, Sly PD. Antenatal endotoxin and glucocorticoid effects on lung morphometry in preterm lambs. Pediatr Res 2000;48:782-8 
61. Husain AN, Siddiqui NH, Stocker JT. Pathology of arrested acinar development in postsurfactant bronchopulmonary dysplasia. Hum Pathol 1998;29:710-7

62. Jobe AJ. The new BPD: an arrest of lung development. Pediatr Res 1999;46:641-3

63. Ueda K, Cho K, Matsuda T, Okajima S, Uchida M, Kobayashi Y, Minakami H, Kobayashi K. A rat model for arrest of alveolarization induced by antenatal endotoxin administration. Pediatr Res 2006;59:396-400

64. Kallapur SG, Bachurski CJ, Le Cras TD, Joshi SN, Ikegami M, Jobe AH. Vascular changes after intra-amniotic endotoxin in preterm lamb lungs. Am J Physiol Lung Cell Mol Physiol 2004;287:L1178-85

65. Kunzmann S, Speer CP, Jobe AH, Kramer BW. Antenatal inflammation induced TGF-beta1 but suppressed CTGF in preterm lungs. Am J Physiol Lung Cell Mol Physiol 2007;292:L223-31

66. Ryan RM, Ahmed Q, Lakshminrusimha S. Inflammatory mediators in the immunobiology of bronchopulmonary dysplasia. Clin Rev Allergy Immunol 2008;34:174-90

67. Jobe AH. Antenatal associations with lung maturation and infection. J Perinatol 2005;25 Suppl 2:S31-5

68. De Dooy J, Colpaert C, Schuerwegh A, Bridts C, Van Der Planken M, leven M, De Clerck L, Stevens W, Mahieu L. Relationship between histologic chorioamnionitis and early inflammatory variables in blood, tracheal aspirates, and endotracheal colonization in preterm infants. Pediatr Res 2003;54:113-9

69. Cheah FC, Winterbourn CC, Darlow BA, Mocatta TJ, Vissers MC. Nuclear factor kappaB activation in pulmonary leukocytes from infants with hyaline membrane disease: associations with chorioamnionitis and Ureaplasma urealyticum colonization. Pediatr Res 2005;57:616-23

70. Baier RJ, Majid A, Parupia H, Loggins J, Kruger TE. CC chemokine concentrations increase in respiratory distress syndrome and correlate with development of bronchopulmonary dysplasia. Pediatr Pulmonol 2004;37:137-48

71. Kramer BW, Kaemmerer U, Kapp M, Herbst D, Marx A, Berg D, Groneck PA, Speer CP. Decreased expression of angiogenic factors in placentas with chorioamnionitis after preterm birth. Pediatr Res 2005;58:60712

72. D'Alquen D, Kramer BW, Seidenspinner S, Marx A, Berg D, Groneck P, Speer CP. Activation of umbilical cord endothelial cells and fetal inflammatory response in preterm infants with chorioamnionitis and funisitis. Pediatr Res 2005;57:263-9

73. Wirbelauer J, Schmidt B, Klingel K, Cao L, Lang F, Speer CP. Serum and glucocorticoid-inducible kinase in pulmonary tissue of preterm fetuses exposed to chorioamnionitis. Neonatology 2008;93:257-62

74. Schmidt B, Cao L, Mackensen-Haen S, Kendziorra H, Klingel K, Speer CP. Chorioamnionitis and inflammation of the fetal lung. Am J Obstet Gynecol 2001;185:173-7

75. Arai H, Matsuda T, Goto R, Takada G. Increased numbers of macrophages in tracheal aspirates in premature infants with funisitis. Pediatr Int 2008;50:184-8

76. Simhan HN, MacPherson T, Caritis SN, Krohn MA. Maternal and fetal Toll-like receptor 4 genotype and chorionic plate inflammatory lesions. Am J Obstet Gynecol 2008;199:400 e1-4

77. Kazzi SN, Jacques SM, Qureshi F, Quasney MW, Kim UO, Buhimschi IA. Tumor necrosis factor-alpha allele lymphotoxin-alpha+250 is associated with the presence and severity of placental inflammation among preterm births. Pediatr Res 2004;56:94-8

78. Kerk J, Dordelmann M, Bartels DB, Brinkhaus MJ, Dammann CE, Dork T, Dammann O. Multiplex measurement of cytokine/receptor gene polymorphisms and interaction between interleukin-10 (-1082) genotype and chorioamnionitis in extreme preterm delivery. J Soc Gynecol Investig 2006;13:350-6

79. Speer EM, Gentile DA, Zeevi A, Pillage G, Huo D, Skoner DP. Role of single nucleotide polymorphisms of cytokine genes in spontaneous preterm delivery. Hum Immunol 2006;67:915-23

80. Polydorides AD, Kalish RB, Witkin SS, Baergen RN. Fetal polymorphisms in anti-inflammatory cytokine and beta-adrenergic receptor genes associated with placental pathological lesions. Int J Gynecol Pathol 2008;27:79-85

81. Reiman M, Kujari H, Ekholm E, Lapinleimu H, Lehtonen L, Haataja L. Interleukin-6 polymorphism is associated with chorioamnionitis and neonatal infections in preterm infants. J Pediatr 2008;153:19-24

82. Annells MF, Hart PH, Mullighan CG, Heatley SL, Robinson JS, McDonald HM. Polymorphisms in immunoregulatory genes and the risk of histologic chorioamnionitis in Caucasoid women: a case control study. BMC Pregnancy Childbirth 2005;5:4 
83. Oue S, Hiroi M, Ogawa S, Hira S, Hasegawa M, Yamaoka S, Yasui M, Tamai H, Ogihara T. Association of gastric fluid microbes at birth with severe bronchopulmonary dysplasia. Arch Dis Child Fetal Neonatal Ed 2009;94:F17-22

84. Gerber S, Vial Y, Hohlfeld P, Witkin SS. Detection of Ureaplasma urealyticum in second-trimester amniotic fluid by polymerase chain reaction correlates with subsequent preterm labor and delivery. $J$ Infect Dis 2003;187:518-21

85. Waites KB, Katz B, Schelonka RL. Mycoplasmas and ureaplasmas as neonatal pathogens. Clin Microbiol Rev 2005;18:757-89

86. Schelonka RL, Waites KB. Ureaplasma infection and neonatal lung disease. Semin Perinatol 2007;31:2-9

87. DiGiulio DB, Romero R, Amogan HP, Kusanovic JP, Bik EM, Gotsch F, Kim CJ, Erez O, Edwin S, Relman DA. Microbial prevalence, diversity and abundance in amniotic fluid during preterm labor: a molecular and culture-based investigation. PLOS ONE 2008;3:e3056

88. Han YW, Shen T, Chung P, Buhimschi IA, Buhimschi CS. Uncultivated Bacteria as Etiologic Agents of IntraAmniotic Inflammation Leading to Preterm Birth. J Clin Microbiol 2008

89. Viscardi RM, Atamas SP, Luzina IG, Hasday JD, He JR, Sime PJ, Coalson JJ, Yoder BA. Antenatal Ureaplasma urealyticum respiratory tract infection stimulates proinflammatory, profibrotic responses in the preterm baboon lung. Pediatr Res 2006;60:141-6

90. Moss TJ, Knox CL, Kallapur SG, Nitsos I, Theodoropoulos C, Newnham JP, Ikegami M, Jobe AH. Experimental amniotic fluid infection in sheep: effects of Ureaplasma parvum serovars 3 and 6 on preterm or term fetal sheep. Am J Obstet Gynecol 2008;198:122 e1-8

91. Mabanta CG, Pryhuber GS, Weinberg GA, Phelps DL. Erythromycin for the prevention of chronic lung disease in intubated preterm infants at risk for, or colonized or infected with Ureaplasma urealyticum. Cochrane Database Syst Rev 2003:CD003744

92. Kenyon S, Pike K, Jones DR, Brocklehurst P, Marlow N, Salt A, Taylor DJ. Childhood outcomes after prescription of antibiotics to pregnant women with spontaneous preterm labour: 7-year follow-up of the ORACLE II trial. Lancet 2008;372:1319-27

93. Kenyon S, Pike K, Jones DR, Brocklehurst P, Marlow N, Salt A, Taylor DJ. Childhood outcomes after prescription of antibiotics to pregnant women with preterm rupture of the membranes: 7-year follow-up of the ORACLE I trial. Lancet 2008;372:1310-8

94. Watterberg KL, Scott SM, Naeye RL. Chorioamnionitis, cortisol, and acute lung disease in very low birth weight infants. Pediatrics 1997;99:E6

95. May M, Marx A, Seidenspinner S, Speer CP. Apoptosis and proliferation in lungs of human fetuses exposed to chorioamnionitis. Histopathology 2004;45:283-90

96. Curley AE, Sweet DG, MacMahon KJ, O'Connor CM, Halliday HL. Chorioamnionitis increases matrix metalloproteinase-8 concentrations in bronchoalveolar lavage fluid from preterm babies. Arch Dis Child Fetal Neonatal Ed 2004;89:F61-4

97. Curley AE, Sweet DG, Thornton CM, O'Hara MD, Chesshyre E, Pizzotti J, Wilbourn MS, Halliday HL, Warner JA. Chorioamnionitis and increased neonatal lung lavage fluid matrix metalloproteinase-9 levels: implications for antenatal origins of chronic lung disease. Am J Obstet Gynecol 2003;188:871-5

98. Maymon E, Romero R, Chaiworapongsa T, Berman S, Conoscenti G, Gomez R, Edwin S. Amniotic fluid matrix metalloproteinase-8 in preterm labor with intact membranes. Am J Obstet Gynecol 2001;185:114955

99. Sweet DG, McMahon KJ, Curley AE, O'Connor CM, Halliday HL. Type I collagenases in bronchoalveolar lavage fluid from preterm babies at risk of developing chronic lung disease. Arch Dis Child Fetal Neonatal Ed 2001;84:F168-71

100. Sweet DG, Curley AE, Chesshyre E, Pizzotti J, Wilbourn MS, Halliday HL, Warner JA. The role of matrix metalloproteinases -9 and -2 in development of neonatal chronic lung disease. Acta Paediatr 2004;93:7916

101. Dik WA, van Kaam AH, Dekker T, Naber BA, Janssen DJ, Kroon AA, Zimmermann LJ, Versnel MA, Lutter R. Early Increased Levels of Matrix Metalloproteinase-9 in Neonates Recovering from Respiratory Distress Syndrome. Biol Neonate 2005;89:6-14 



\section{Aims of the thesis}

As highlighted, the phenotype of BPD seems to be shifting. However, the underlying mechanisms are largely unclear, and human data on this issue are scarce. The current thesis aims to investigate perinatal factors that contribute to (adverse) lung development after preterm birth. Increased knowledge of the contribution of these early factors is important as it may facilitate better identification of the population at risk, as well as offer new possibilities for development of future preventive and therapeutic interventions. Given its modulatory role in lung maturation and high prevalence in preterm infants, chorioamnionitis will receive special attention. More specifically, the following aims apply to this thesis:

1. Determine the relative contributions of pulmonary inflammatory mediators (Chapter 4), growth factors (Chapter 6), and DNA damage (Chapter 8 ) in the early phase of BPD.

2. Investigate the effects of antenatal factors on prenatal lung development (Chapter 7) and postnatal epithelial repair potential (Chapter 5).

3. Evaluate the association between chorioamnionitis and neonatal (pulmonary) outcome (Chapter 9-12), with additional focus on the modulatory effect of antenatal steroids (Chapter 9-10).

4. Determine the role of the surfactant response and 'secondary hits' in the association between chorioamnionitis and BPD (Chapter 11-12). 


\section{Part 2}

Laboratory and translational observations 


\section{Chapter 4}

Bronchoalveolar lavage fluid

cytokine and chemokine profiles

in ventilated preterm infants

Been JV, van Iwaarden JF, de Jager W, Debeer A, Zimmermann L

Submitted 


\section{Abstract}

Background. Early pulmonary inflammation is historically regarded a key element in the pathophysiology of bronchopulmonary dysplasia (BPD). We sought to determine the feasibility of quantifying 32 inflammatory mediators in bronchoalveolar lavage fluid (BALF) and identify their associations with clinical variables in ventilated preterm infants during the first postnatal week.

Methods. BALF was performed in ventilated infants born before 32 weeks gestation at postnatal days $0,1,3$ and 7. Cytokine and chemokine levels were determined in $50 \mu \mathrm{l}$ of BALF using multiplex immunoassay. Associations between clinical variables and growth factor levels, normalised by log-transformation, were tested using Student's t-test.

Results. 93 BALF samples were obtained from 59 infants. Levels were within the detection range of the assay for the vast majority of mediators. Chorioamnionitis was highly associated with increased inflammatory mediator levels at several time points. IL-10, IL$1 \beta$, TNF- $\alpha$ and IL-1 $\alpha$ had the highest predictive ability for chorioamnionitis (area under ROC curve $=0.94,0.92,0.92$, and 0.91, respectively; all $p<0.01$ ). Surprisingly, increased cytokine or chemokine levels did not predict the development of bronchopulmonary dysplasia (BPD). Instead, several chemokines were decreased in infants developing BPD.

Conclusions. Using multiplex immunoassay it is feasible to quantify a wide range of inflammatory mediators in small amounts of BALF from preterm infants. Prior exposure to chorioamnionitis was the main determinant of postnatal pulmonary inflammation. The latter was not predictive of BPD, in line with the concept of 'new BPD' being a lung developmental disease rather than being due to secondary injury. 


\section{Introduction}

Chronic lung disease of prematurity (bronchopulmonary dysplasia; BPD) has been recognised as a serious pulmonary consequence of preterm birth for over 40 years. Important risk factors include mechanical ventilation, oxygen exposure, and infection. These and other factors such as antenatal exposure to chorioamnionitis may lead to pulmonary inflammation, historically considered a hallmark of BPD development ${ }^{1,2}$. In the late nineties, it was first recognised that the BPD phenotype may be shifting ${ }^{3}$. Whereas secondary lung injury was a hallmark of 'old' BPD, the current 'new' BPD appears to be characterised

mainly by a developmental arrest of the lung ${ }^{3}$. Increased survival of smaller and more immature infants, and the increased use of protective treatment strategies for respiratory distress after preterm birth, seem important modulators of this change ${ }^{4,5}$.

In line with the recognised role of inflammation in BPD development, numerous studies have shown associations between increased pulmonary levels of inflammatory markers and subsequent BPD development, as reviewed elsewhere ${ }^{2}$. Several factors complicate interpretation of these studies. In spite of the complexity of pulmonary inflammation and BPD pathophysiology, most studies have focused on either a single mediator or a small group of markers. In addition, associations between individual mediators and BPD often are not in agreement between studies. Finally, most studies of lung-derived fluid have primarily sampled the larger airways, whereas BPD is considered a disorder affecting the distant lung areas involved in gas-exchange.

Over recent years, newer techniques have allowed simultaneous detection of an increasing number of markers in small samples. Multiplex immunoassay (MIA) is an example of such a technique, which has been used to quantify inflammatory markers in several body fluids. Using this technique, others have shown associations between cytokine levels in blood and subsequent BPD development ${ }^{6-8}$. In the current study we simultaneously detected 32 inflammatory markers in BALF from ventilated preterm infants over the first postnatal week using MIA. Our aims were to determine the feasibility of this approach and relate the measurements to selected clinical variables (chorioamnionitis, antenatal and postnatal steroid and caffeine supplementation, sepsis, high frequency ventilation, development of BPD, and mortality) in a temporal fashion.

\section{Methods}

\section{Infant enrolment and characteristics}

Ventilated preterm infants born before 32 weeks gestational age were enrolled in the NICUs of the University Hospitals in Maastricht and Leuven. The Medical Ethical Committees of both hospitals approved the study and written parental consent was obtained. Histological chorioamnionitis was diagnosed when $>10$ neutrophils per high power field were present in the chorion or amnion. Betamethasone (2x $12 \mathrm{mg}$ i.m. $24 \mathrm{hrs}$ apart) was 
administered to the mother in case of imminent preterm delivery. Postnatal hydrocortisone $(1.25 \mathrm{mg} / \mathrm{kg}$ i.v. once every $6 \mathrm{hrs})$ was administered when persistent hypotension was present despite fluid administration and use of inotropics. High frequency ventilation (HFV) was generally used as a rescue ventilatory treatment. Caffeine base was given when extubation was anticipated (loading dose $10 \mathrm{mg} / \mathrm{kg}$ i.v., initial daily dose $2.5 \mathrm{mg} / \mathrm{kg}$ i.v.). Clinical sepsis was diagnosed when elevated C-reactive protein and clinical symptoms were present, with or without a positive blood culture. Patients were considered to have BPD when they were on supplemental oxygen, continuous positive airway pressure (CPAP) or mechanical ventilation at 36 weeks postmenstrual age (PMA).

\section{BALF collection and processing}

BAL was performed at postnatal days 0 (within 24 hrs after birth), 1, 3, and 7 as described earlier ${ }^{9,10}$. Obviously, no BALF was obtained when infants were not yet on or already off the ventilator, thus explaining 'missing' values. Briefly, after turning the infant's head to the left, a suction catheter was inserted through a side port of the Trachcare suctioning system until slight resistance was felt. One $\mathrm{ml}$ per $\mathrm{kg}$ birth weight of sterile isotonic saline was gently infused and suctioning was performed while slowly retracting the catheter. The procedure was repeated once and the collected fluid was pooled and placed on ice. After centrifugation for 10 minutes at $4{ }^{\circ} \mathrm{C}$ and $300 \times g$, the supernatant was aliquoted and stored at $-80^{\circ} \mathrm{C}$ until analysis.

\section{Multiplex analysis}

Various inflammatory mediators were measured in BALF using a multiplex immunoassay as described previously ${ }^{11,12}$. Measurements and data analysis of all assays were performed using the Bio-Plex system in combination with the Bio-Plex Manager software version 4.1 using five parametric curve fitting (Bio-Rad Laboratories, Hercules CA, USA). In house quality control acquisition was performed as described elsewhere ${ }^{13}$. Mediator levels were expressed per ml BALF retrieved, according to European Respiratory Society task force guidelines ${ }^{14}$. Undetectable levels were assigned the value ' 0 ', while levels above the upper limit of detection were assigned the highest value on the standard curve.

\section{$\underline{\text { Statistics }}$}

Continuous variables are expressed as mean $\pm S D$, or median (IQR) in case of nonnormality. Between-group differences were assessed by ANOVA or Kruskall-Wallis test, respectively. Dichotomous variables are expressed as $n / N(\%)$ and tested using $\chi^{2}$-test. For statistical testing of inflammatory mediator levels, these were transformed using the formula [ $\operatorname{Ln}$ (mediator level + 1)] to account both for non-normality and non-detectable levels. For graphical display, mean transformed subgroup levels were transformed back into $\mathrm{pg} / \mathrm{ml}$ and assigned a color according to a semi-logarithmic color grading scale. ROC curves (area under the curve (AUC)) were computed using transformed mediator levels to investigate the predictive ability of individual mediator levels for certain clinical variables. Mul- 
tivariable models were not computed due to the high number of variables relative to the sample size. A two-tailed alpha level of .05 was applied in all analyses. Statistics were computed using SPSS 15.0 software.

\section{Results}

\section{General characteristics}

Ninety-three BALF samples obtained from 59 infants were included. General patient characteristics are shown in Table 1 . Significant differences in $\mathrm{FiO}_{2}$, and treatment with hydrocortisone and caffeine were present between distinct postnatal days.

Table 1. Population characteristics per postnatal day. Postnatal hydrocortisone, caffeine, sepsis, and high frequency ventilation were considered positive when present on that particular day. Continuous variables are expressed as mean $\pm S D$, or median (IQR) for skewed data. Dichotomous data are expressed as $\mathrm{n} / \mathrm{N}(\%)$. Overall $p$-values for between-day differences are presented (ANOVA, Kruskall-Wallis test or $\chi^{2}$-test, respectively). Abbreviations: $\mathrm{FiO}_{2}=$ fraction of inspired oxygen; $\mathrm{MAP}=$ mean airway pressure.

\begin{tabular}{|c|c|c|c|c|c|}
\hline & Day $0(n=27)$ & Day $1(n=21)$ & Day $3(n=31)$ & Day $7(n=14)$ & Pvalue \\
\hline Gestational age (wks) & $28.0 \pm 1.9$ & $28.2 \pm 2.0$ & $28.7 \pm 1.9$ & $27.4 \pm 2.0$ & .21 \\
\hline Birth weight (g) & $1059 \pm 206$ & $1084 \pm 237$ & $1073 \pm 258$ & $934 \pm 262$ & .27 \\
\hline Histological chorioamnionitis & $5 / 22(23)$ & 2/15 (13) & $5 / 23(22)$ & $3 / 11(27)$ & .84 \\
\hline Antenatal betamethasone & 19/27 (70) & $15 / 21(71)$ & 28/31 (90) & $12 / 14(86)$ & .19 \\
\hline $\begin{array}{l}\text { Last betamethasone } \\
\text { (days before birth) }\end{array}$ & $1(0-5)$ & $2(0-8)$ & $5(1-8)$ & $3(1-8)$ & .11 \\
\hline Postnatal hydrocortisone & $2 / 24(8)$ & $3 / 21(14)$ & $9 / 29(31)$ & $7 / 13(54)$ & .01 \\
\hline Caffeine & $0 / 23(0)$ & $1 / 21(5)$ & $6 / 29(21)$ & $0 / 13(0)$ & .02 \\
\hline Clinical sepsis & $1 / 24(4)$ & $4 / 21(19)$ & $2 / 29(7)$ & $1 / 13(8)$ & .34 \\
\hline High frequency ventilation & $8 / 27(30)$ & $7 / 21(33)$ & $6 / 28(21)$ & $5 / 13(39)$ & .68 \\
\hline $\begin{array}{l}\text { Mean } \mathrm{FiO}_{2} \text { 0-6 hrs before } \mathrm{BAL} \\
\text { (\%) }\end{array}$ & $41 \pm 22$ & $29 \pm 11$ & $25 \pm 6$ & $26 \pm 5$ & $<.001$ \\
\hline $\begin{array}{l}\text { Mean MAP 0-6 hrs before BAL } \\
\left(\mathrm{cmH}_{2} \mathrm{O}\right)\end{array}$ & $8.7 \pm 2.3$ & $8.6 \pm 2.6$ & $7.8 \pm 2.1$ & $8.1 \pm 1.7$ & .47 \\
\hline Bronchopulmonary dysplasia & $5 / 24(21)$ & $8 / 20(40)$ & $10 / 29(35)$ & 4/14 (29) & .55 \\
\hline Mortality & $6 / 27(22)$ & $1 / 21(5)$ & $3 / 31(10)$ & $1 / 14(7)$ & .24 \\
\hline
\end{tabular}

\section{BALF inflammatory mediator levels: detectability}

The levels of each individual mediator were within the detection range of the assay in the majority of BALF samples. Undetectable levels were present only for IL-4 (4\% and 7\% on days 0 and 7 , respectively), IL-13 (11\%, 10\%, 19\%, and 7\% on days $0,1,3$, and 7 , respectively), and $\operatorname{CXCL} 12$ (7\%,52\%, $13 \%$, and $14 \%$ on days $0,1,3$, and 7 , respectively). In con- 
trast, some mediators had levels above the upper detection limit: IL-6 (5\% on day 1), CCL2 ( $7 \%, 5 \%$, and $10 \%$ on days 0,1 , and 3 respectively), CCL3 (3\% on day 3 ), CCL18 ( $4 \%, 10 \%$, $74 \%$, and $93 \%$ on days $0,1,3$, and 7 , respectively), and CXCL8 ( $11 \%$ and $19 \%$ on days 0 and 3 , respectively).

\section{BALF inflammatory mediator levels: general profiles}

Inflammatory mediator profiles in BALF obtained at different postnatal days are shown in Table 2 and visualised in Figure 1. When significant differences over time were present, essentially three distinct patterns could be identified: a general increase over time (CCL2, CCL18, CCL22), a U-shaped pattern with high initial values, followed by a temporary decrease and subsequent increase (IL1- $\alpha$, IL-1 $\beta$, IL-7, IL-10, IL-17, IL-18, TNF- $\alpha$, OSM, CCL3), and a biphasic pattern with high levels on days 0 and 3 and lower levels on days 1 and 7 (IL-2, IL-15, IL-22, IL-23, MIF, CCL11, CXCL8, CXCL9, CXCL12).

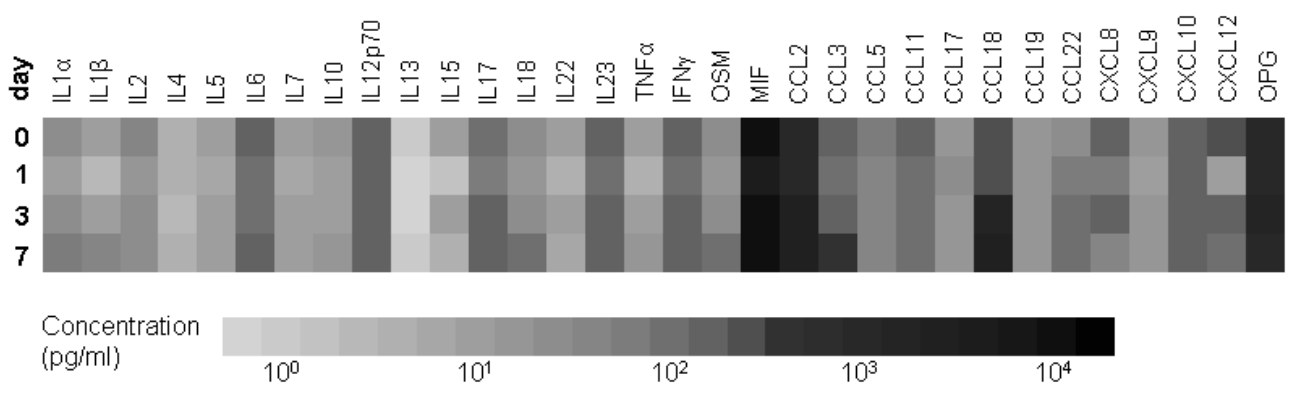

Figure 1. Bronchoalveolar lavage fluid inflammatory mediator profile in total population. Colors represent mean log-transformed levels, back transformed into $\mathrm{pg} / \mathrm{ml}$ for visual display of time-dependent profile. Abbreviations: IL=interleukin; TNF=tumour necrosis factor; IFN=interferon; OSM=oncostatin M; MIF=macrophage migration inhibitory factor; OPG=osteoprotegerin.

\section{BALF inflammatory mediator levels: clinical associations}

Associations between BALF levels of inflammatory mediators and various clinical variables are shown in Table 3. It is important to note the low number of infants in several group comparisons. Despite this, significant and clinically plausible associations between several clinical variables and BALF inflammatory mediator levels were observed. Most prominently, histological chorioamnionitis was associated with increased levels of several mediators on day 0 (IL-1 $\alpha$, IL-1 $\beta$, IL-2, IL-5, IL-7, IL-10, IL-12p70, IL17, IL23, TNF- $\alpha$, IFN- $\gamma$, OSM, CCL3, CCL5, CCL11, CCL19), and to a lesser extent on days 1 (CXCL12) and 3 (IL-2, IL-7, IL12p70, IL-22, IFN- $\gamma$, CCL5, CCL11, CXCL10; Table 3; Figure 2). As shown in Figure 3, BALF levels of several mediators carry substantial diagnostic potential for histological chorioamnionitis within 24 hours after birth. Increased levels were also found in infants with sepsis (IL-6 and IL-17), although IL-4 was decreased on day 3 (Table 3). Conversely, both antenatal and postnatal steroid exposure were associated with decreased inflamma- 
tory mediator levels on day 7 predominantly. HFV and caffeine treatment showed little association with BALF inflammatory mediator levels.

Table 2. Bronchoalveolar lavage fluid inflammatory mediator levels per postnatal day. Levels are presented as median (IQR). Overall p-values for between-day differences are presented (Kruskall-Wallis test). Abbreviations: $\mathrm{IL}=$ interleukin; TNF=tumour necrosis factor; IFN=interferon; OSM=oncostatin $\mathrm{M}$; MIF=macrophage migration inhibitory factor; OPG=osteoprotegerin.

\begin{tabular}{|c|c|c|c|c|c|}
\hline & \multicolumn{4}{|l|}{ Concentration $(\mathrm{pg} / \mathrm{ml})$} & \multirow{2}{*}{$\begin{array}{l}P \\
\text { value }\end{array}$} \\
\hline & Day $0(n=27)$ & Day $1(n=21)$ & Day $3(n=31)$ & Day $7(n=14)$ & \\
\hline$I L-1 \alpha$ & $36(15-115)$ & $17(12-24)$ & $52(20-117)$ & $128(19-442)$ & .001 \\
\hline$I L-16$ & $8(4-16)$ & $4(3-8)$ & $9(5-21)$ & $112(6-508)$ & .001 \\
\hline IL-2 & $64(34-104)$ & $34(30-44)$ & $38(29-62)$ & $38(30-67)$ & .03 \\
\hline IL-4 & $8(6-11)$ & $7(6-8)$ & $6(4-8)$ & $6(5-7)$ & .14 \\
\hline IL-5 & $11(7-26)$ & $8(5-11)$ & $10(7-18)$ & $11(7-25)$ & .23 \\
\hline$I L-6$ & 279 (99-727) & $115(32-242)$ & $170(71-551)$ & $528(62-1105)$ & .07 \\
\hline IL-7 & $16(7-35)$ & $8(6-10)$ & $13(7-22)$ & $10(7-28)$ & .03 \\
\hline IL-10 & $21(15-28)$ & $14(13-17)$ & $19(14-23)$ & $20(14-43)$ & .002 \\
\hline$I L-12 p 70$ & $306(222-483)$ & $226(192-251)$ & $239(176-338)$ & $212(159-312)$ & .06 \\
\hline IL-13 & $1.3(0.8-2.8)$ & $0.8(0.7-1.3)$ & $0.8(0.3-1.7)$ & $0.9(0.5-1.5)$ & .14 \\
\hline IL-15 & $9(5-18)$ & $4(2-5)$ & $8(4-15)$ & $5(4-8)$ & $<.001$ \\
\hline $\mid L-17$ & $210(80-407)$ & 73 (52-149) & 227 (159-467) & $209(172-314)$ & .001 \\
\hline IL-18 & $37(25-65)$ & $26(18-34)$ & $65(35-131)$ & $125(60-207)$ & $<.001$ \\
\hline$I L-22$ & $15(8-21)$ & $7(6-10)$ & $10(8-14)$ & $8(6-10)$ & .002 \\
\hline IL-23 & $323(132-673)$ & $124(109-155)$ & $258(124-550)$ & $187(116-498)$ & .005 \\
\hline$T N F-\alpha$ & $13(6-41)$ & $6(5-10)$ & $15(7-36)$ & $32(6-229)$ & .003 \\
\hline$I F N-\gamma$ & $294(165-577)$ & $192(150-209)$ & $206(142-343)$ & $177(144-556)$ & .15 \\
\hline OSM & $40(21-107)$ & $16(15-22)$ & $40(19-107)$ & $105(20-625)$ & $<.001$ \\
\hline MIF & 9254 (6793-14737) & 6409 (3894-9802) & 12668 (8514-16630) & $11226(9690-12727)$ & $<.001$ \\
\hline$C C L 2$ & $1459(602-3644)$ & $1479(837-2246)$ & $3930(2076-8741)$ & 4945 (1841-7777) & $<.001$ \\
\hline CCL3 & $302(166-770)$ & $151(135-195)$ & $257(143-512)$ & $629(131-2960)$ & .02 \\
\hline$C C L 5$ & $72(57-120)$ & $57(56-66)$ & $60(52-77)$ & $56(45-141)$ & .14 \\
\hline CCL11 & $232(124-444)$ & $101(89-122)$ & $207(113-292)$ & $159(103-253)$ & $<.001$ \\
\hline CCL17 & $20(13-43)$ & $61(22-83)$ & $28(14-76)$ & $18(9-38)$ & .09 \\
\hline CCL18 & $552(112-1295)$ & $711(196-1525)$ & $4500(4493-4500)$ & $4500(4500-4500)$ & $<.001$ \\
\hline CCL19 & $42(12-90)$ & $18(15-26)$ & $21(12-49)$ & $19(15-39)$ & .82 \\
\hline CCL22 & $62(21-150)$ & $76(42-133)$ & $197(53-372)$ & $137(64-252)$ & .01 \\
\hline CXCL8 & $120(53-1894)$ & $85(68-110)$ & 109 (78-1739) & $73(56-80)$ & .006 \\
\hline CXCL9 & $30(24-45)$ & $16(14-24)$ & $19(14-34)$ & $16(13-25)$ & $<.001$ \\
\hline CXCL10 & $98(75-477)$ & $183(125-321)$ & $236(109-735)$ & $307(144-655)$ & .21 \\
\hline CXCL12 & $882(263-1687)$ & $0(0-199)$ & 646 (298-953) & $314(60-1023)$ & $<.001$ \\
\hline$O P G$ & $2079(1105-2741)$ & $1496(1045-2133)$ & $1871(1242-3453)$ & $2140(1208-2733)$ & .48 \\
\hline
\end{tabular}


Table 3. Associations of bronchoalveolar lavage fluid inflammatory mediator levels with clinical variables. 'None' indicates no association, '-' indicates no statistical testing due to presence of the clinical variable in $<2$ infants. $\uparrow / \downarrow=p<.05 ; \uparrow \uparrow / \downarrow \downarrow=p<.01 ; \uparrow \uparrow \uparrow / \downarrow \downarrow \downarrow=p<.001$. Abbreviations: IL=interleukin; TNF=tumour necrosis factor; IFN=interferon; OSM=oncostatin $\mathrm{M}$; MIF=macrophage migration inhibitory factor; HFV=high frequency ventilation (as opposed to conventional ventilation).

\begin{tabular}{|c|c|c|c|c|c|c|c|}
\hline & Day 0 & & Day 1 & Day 3 & & Day 7 & \\
\hline $\begin{array}{l}\text { Histological } \\
\text { chorioamnionitis }\end{array}$ & $\begin{array}{l}\text { IL-1 } \alpha \uparrow \uparrow \\
\text { IL-1 } \uparrow \\
\text { IL-2 } \uparrow \\
\text { IL-5 } \\
\text { IL-7 } \\
\text { IL-10 } \\
\text { IL-12p70 } \\
\text { IL-17 个个 }\end{array}$ & $\begin{array}{l}\text { IL-23 } \uparrow \\
\text { TNF- } \alpha \uparrow \uparrow \\
\text { IFN- } \gamma \uparrow \\
\text { OSM } \uparrow \uparrow \\
\text { CCL3 } \uparrow \uparrow \\
\text { CCL5 } \\
\text { CCL11 } \uparrow \\
\text { CCL19 } \uparrow\end{array}$ & $\begin{array}{l}\text { IL-2 个 } \\
\text { IL-7 个 } \\
\text { IL-12p70个 } \\
\text { IL-22 个 }\end{array}$ & $\begin{array}{l}\text { IFN- } \gamma \uparrow \\
\text { CCL5 } \uparrow \\
\text { CCL11 } \uparrow \\
\text { CXCL10 } \uparrow \uparrow\end{array}$ & & None & \\
\hline $\begin{array}{l}\text { Antenatal } \\
\text { betamethasone }\end{array}$ & None & & None & CCL18 $\downarrow$ & & $\begin{array}{l}\text { IL5 } \downarrow \\
\text { IFN } \gamma \downarrow \\
\text { CCL3 } \downarrow\end{array}$ & \\
\hline $\begin{array}{l}\text { Postnatal } \\
\text { hydrocortisone }\end{array}$ & 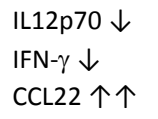 & & $\begin{array}{l}\mathrm{IL}-2 \downarrow \\
\mathrm{IL}-6 \uparrow \\
\mathrm{CXCL} 12 \uparrow \uparrow \uparrow\end{array}$ & MIF $\uparrow$ & & $\begin{array}{l}\text { IL-2 } \downarrow \\
\text { IL-10 } \\
\text { IL-12p70 } \downarrow\end{array}$ & $\begin{array}{l}\text { IL-13 } \downarrow \\
\text { IFN } \gamma \downarrow \\
\operatorname{CCL} 11 \downarrow\end{array}$ \\
\hline Caffeine & - & & - & CCL18 个 & & - & \\
\hline Sepsis & - & & $\begin{array}{l}\text { IL-6 } \\
\text { IL-17 } \uparrow \uparrow\end{array}$ & IL-4 $\downarrow$ & & - & \\
\hline$H F V$ & CXCL9 $\downarrow$ & & None & None & & CXCL10 $\downarrow$ & \\
\hline $\begin{array}{l}\text { Bronchopulmo- } \\
\text { nary dysplasia }\end{array}$ & $\begin{array}{l}\text { CCL19 } \downarrow \downarrow \downarrow \\
\text { CCL22 } \downarrow \\
\text { CXCL8 } \downarrow\end{array}$ & & None & $\begin{array}{l}\text { CCL19 } \downarrow \\
\text { MIF } \downarrow \\
\text { CXCL8 } \downarrow\end{array}$ & & CCL5 $\downarrow$ & \\
\hline Mortality & None & & - & $\begin{array}{l}\text { IL-4 } \downarrow \downarrow \\
\text { IL-5 } \downarrow \\
\text { IL-12p70 } \downarrow\end{array}$ & $\begin{array}{l}\text { CCL5 } \downarrow \downarrow \\
\text { CCL18 } \uparrow \\
\text { CXCL8 } \uparrow \uparrow \uparrow \\
\text { CXCL10 } \downarrow \downarrow\end{array}$ & - & \\
\hline
\end{tabular}

Surprisingly, development of BPD was not preceded by increased BALF levels of inflammatory mediators (Table 3; Figure 4). Instead, BPD was associated with decreased levels of several factors on distinct postnatal days (day 0: CCL19, CCL22, CXCL8; day 3: CCL19, MIF, CXCL8; day 7: CCL5). Likewise, decreased levels of several mediators on day 3 were associated with neonatal mortality (IL-4, IL-5, IL-12p70, CCL5, CXCL10), although CCL18 and CXCL8 were elevated in these infants. 


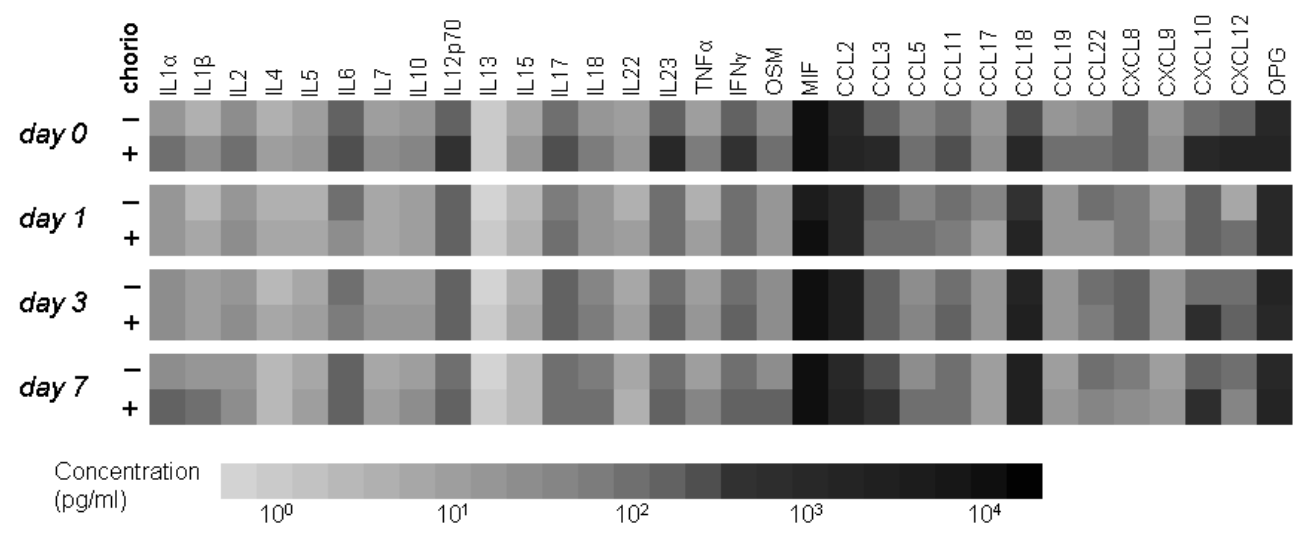

Figure 2. Bronchoalveolar lavage fluid inflammatory mediator profile according to chorioamnionitis exposure. Colors represent mean log-transformed subgroup levels, back transformed into $\mathrm{pg} / \mathrm{ml}$ for visual display of timedependent profiles. Abbreviations: chorio=chorioamnionitis; IL=interleukin; TNF=tumour necrosis factor; IFN=interferon; OSM=oncostatin M; MIF=macrophage migration inhibitory factor; OPG=osteoprotegerin.

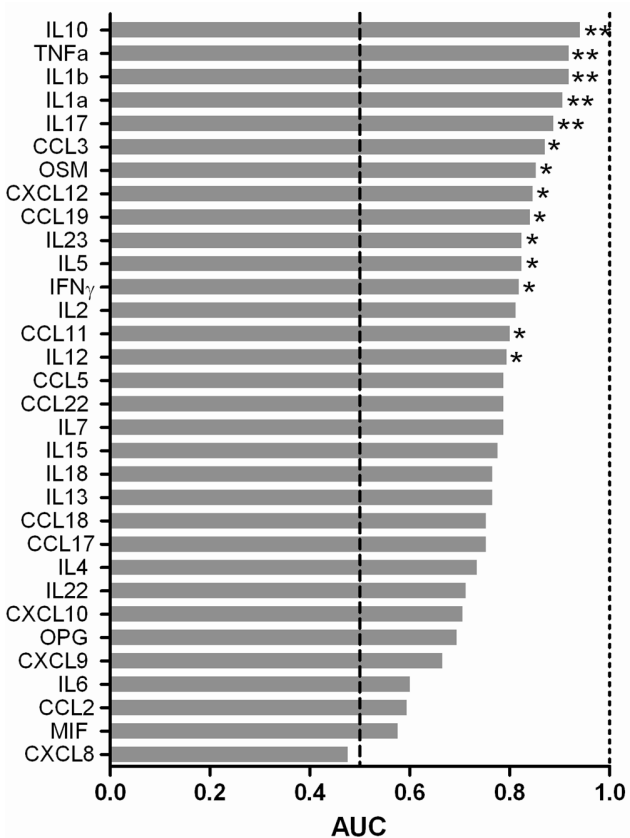

Figure 3. Predictive ability of day $\mathbf{0}$ bronchoalveolar lavage fluid inflammatory mediators for histological chorioamnionitis. Bars represent area under the curve (AUC) of ROC curves for chorioamnionitis prediction for each individual mediator. ${ }^{*} \mathrm{p}<.05 ;{ }^{* *} \mathrm{p}<.01$. Abbreviations: chorio=chorioamnionitis; IL=interleukin; TNF=tumour necrosis factor; IFN=interferon; OSM=oncostatin $\mathrm{M}$; $\mathrm{MIF}=$ macrophage migration inhibitory factor; OPG=osteoprotegerin. 


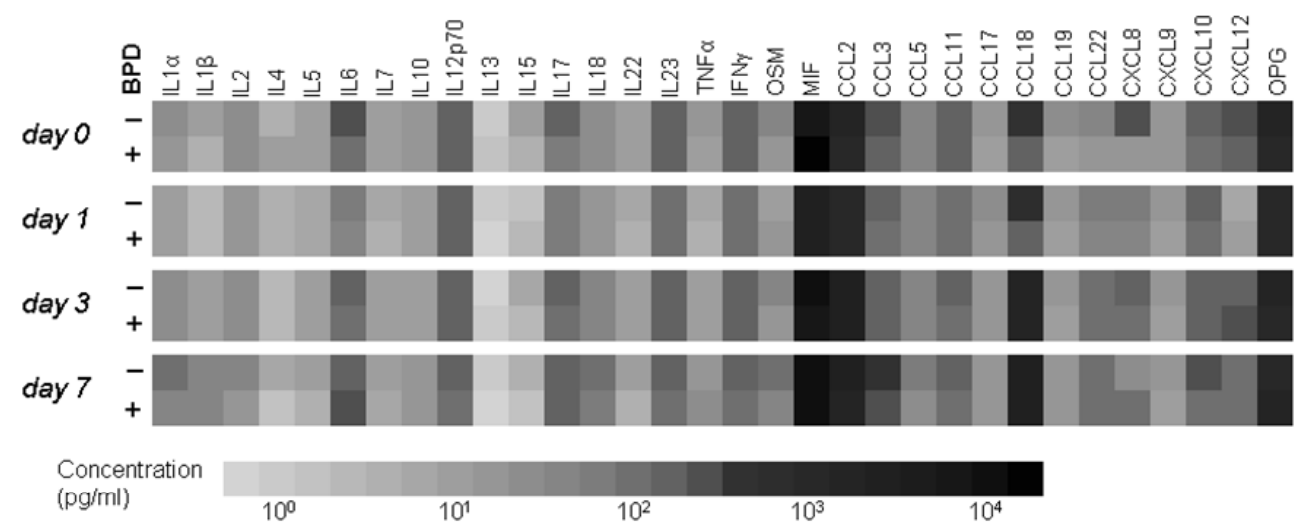

Figure 3. Bronchoalveolar lavage fluid inflammatory mediator profile according to development of bronchopulmonary dysplasia. Colors represent mean log-transformed subgroup levels, back transformed into $\mathrm{pg} / \mathrm{ml}$ for visual display of time-dependent profiles. Abbreviations: BPD=bronchopulmonary dysplasia; IL=interleukin; $\mathrm{TNF}=$ tumour necrosis factor; IFN=interferon; OSM=oncostatin $\mathrm{M}$; MIF=macrophage migration inhibitory factor; OPG=osteoprotegerin.

\section{Discussion}

Using MIA, it is feasible to detect 32 inflammatory mediators in small samples of BALF obtained from ventilated preterm infants. Levels were outside the detection range of the assay for very few markers, and in only a small number of samples. Further analyses suggest important correlations of BALF inflammatory mediator levels with several clinical variables, most prominently so with histological chorioamnionitis. Development of BPD was preceded by decreased rather than increased pulmonary chemokine levels.

Previous studies of inflammatory mediators in lung-derived fluid samples from preterm infants have analysed individual markers or at best small groups of markers. Over recent years new analysis techniques have become available allowing for detection of an increasing number of factors in increasingly small samples. MIA has proven a powerful tool to simultaneously quantify individual levels of up to a hundred protein markers in both human and animal-derived samples ${ }^{15}$. To our knowledge, the current study is the first to investigate the feasibility of MIA in lung-derived fluid from preterm infants. We demonstrate very good detectability of almost all inflammatory mediators studied in as little as $50 \mu$ l of BALF. Using this technique we were able to adequately quantify mediators previously reported undetectable in lung derived specimens for preterm infants ${ }^{16,17}$.

BALF inflammatory mediator levels were shown to be of clinical relevance, that is, important correlations were present between their levels and several clinical variables. Antenatal exposure to chorioamnionitis resulted in a clear inflammatory pulmonary profile, involving both cytokines and chemokines. This is in accordance with earlier human reports and animal experimental evidence ${ }^{1,18}$. The effect was most prominent directly after birth 
and was still present three days later. It is interesting to note that IL-10, classically regarded an anti-inflammatory cytokine, was the most discriminative determinant of chorioamnionitis. This suggests a strong anti-inflammatory response to chorioamnionitisinduced pulmonary inflammation, despite earlier suggestions of defective antiinflammatory mechanisms in preterm infants ${ }^{19}$. Importantly, the observed profile after chorioamnionitis also involved IL-1, a key modulator of the pulmonary maturational response after intrauterine inflammation ${ }^{20}$.

Relative to the prominent inflammatory profile observed after chorioamnionitis, very little association between BALF inflammatory mediator levels and sepsis was observed. Possible explanations include primarily pulmonary versus systemic inflammation in chorioamnionitis versus sepsis, and small group numbers in the sepsis comparisons. Conversely, anti-inflammatory effects probably account for the associations between both antenatal and postnatal steroid exposure and decreased inflammatory mediator levels in BALF. The early association between increased inflammatory markers and postnatal hydrocortisone probably represents the particular need for blood pressure support (e.g. hydrocortisone) in sicker infants with more pronounced inflammation. We were able to confirm a previously reported association between decreased pulmonary levels of IL12 p70 and neonatal mortality ${ }^{21}$. This intriguing link warrants further study.

Possibly the most striking observation is the absence of any association between increased BALF levels of inflammatory markers and subsequent BPD development. We believe this is in accordance with the current concept that the pathophysiology of BPD is shifting ${ }^{3}$. Pulmonary inflammation, along with secondary lung injury, was clearly a hallmark of the 'old' BPD phenotype ${ }^{3}$. In accordance, many early studies have reported associations between increased markers of lung inflammation and subsequent development of $B P D$, as reviewed elsewhere ${ }^{2}$. As noted earlier, treatment changes have accounted for increased survival of more immature infants and a more gentle approach towards treatment of their respiratory problems. These factors contributed to development of 'new' $B P D$, thought to represent an arrest in lung development rather than secondary lung injury ${ }^{3}$. In accordance, we previously demonstrated significant associations between pulmonary expression of several growth factors with essential roles in lung development, and subsequent BPD development ${ }^{10}$. The findings of the current study, involving the same cohort, further support a role for lung developmental changes rather than early lung inflammation in the pathophysiology of BPD.

Several studies have identified chorioamnionitis as an important risk factor for BPD development. However, in general findings regarding this association are contradictory ${ }^{1}$. More recent studies support a 'second hit' hypothesis, suggesting that prolonged mechanical ventilation, postnatal sepsis and decreased surfactant efficacy all modulate the association between chorioamnionitis and BPD ${ }^{22-25}$. The current finding of early postnatal inflammation being associated with chorioamnionitis but not with BPD, further adds to the increasing evidence for postnatal modulation of this association rather than it being a direct mechanism. 
While cytokine levels had no relationship whatsoever with BPD, several chemokines showed a negative rather than positive correlation with BPD on several postnatal days. Although due to the low number of infants no firm conclusions can be made, these observations appeal for speculation. Decreased levels on days 0 and 3 of both CCL19 and CXCL8 were associated with BPD. CCL19 is a developmental regulator of lymphoid tissue. Decreased pulmonary CCL19 has been associated with allergic airway inflammation in mice ${ }^{26}$, and post-transplantation bronchiolitis obliterans in humans ${ }^{27}$, supporting a potential role of CCL19 deficiency in adverse pulmonary outcome. Paradoxically, CXCL8 has previously been reported to be positively associated with the BPD phenotype ${ }^{28,29}$. However, more recent reports have not been able to reproduce this ${ }^{30-32}$. Other chemokines negatively associated with development of BPD were CCL5, CCL22 and MIF. Decreased MIF expression may indicate a decreased potential for alveolar epithelial repair ${ }^{33}$, while chemokines such as CXCL8 and the CC chemokines, have been implicated in the regulation of angiogenesis ${ }^{34}$. Proper angiogenesis is invaluable for normal lung development and has been implicated in the pathophysiology of new BPD ${ }^{35}$. The association between decreased chemokine expression and subsequent BPD development may thus reflect modulation of pulmonary angiogenesis, although additional research is needed to investigate this.

The current study has several limitations. Although considerable in size in its sort, the presented cohort is too small to draw firm conclusions with regard to most associations between mediator levels and clinical variables. For the same reason no attempt was made to perform multivariable analyses by adjusting for potential confounders, or combining levels of different mediators in predictive models. Thus, we cannot exclude confounding effects in our results. However, as a feasibility study it may guide future research on the topic. A second limitation is that BALF can only be derived from ventilated infants, introducing bias. Others have shown the feasibility of detection of inflammatory markers using MIA in exhaled breath condensate ${ }^{36}$. Future studies should evaluate the feasibility of marker detection in lung-derived fluid obtained by non-invasive techniques, allowing the evaluation of cytokine and chemokine profiles in healthier, non-ventilated neonates.

In conclusion, we have demonstrated the feasibility of quantifying individual levels of up to 32 molecular markers in as little as $50 \mu$ of BALF. Given the low yield of BAL from ventilated preterm infants, and the evolving potential of collecting lung-derived specimens in a less invasive manner, these results are promising. Chorioamnionitis was found to be associated with upregulation of a wide range of pulmonary inflammatory mediators shortly after birth. We were unable to detect any association between pulmonary inflammation and BPD, whereas BPD was preceded by alterations in pulmonary growth factor profiles in the same cohort. These observations are in line with the current concept of a shifting pathophysiology of BPD. 


\section{References}

1. Been JV, Zimmermann LJ. Histological chorioamnionitis and respiratory outcome in preterm infants. Arch Dis Child Fetal Neonatal Ed 2009;94:F218-25

2. Bose $\mathrm{CL}$, Dammann $\mathrm{CE}$, Laughon $\mathrm{MM}$. Bronchopulmonary dysplasia and inflammatory biomarkers in the premature neonate. Arch Dis Child Fetal Neonatal Ed 2008;93:F455-61

3. Jobe AJ. The new BPD: an arrest of lung development. Pediatr Res 1999;46:641-3

4. Ramanathan R. Optimal ventilatory strategies and surfactant to protect the preterm lungs. Neonatology 2008;93:302-8

5. Been JV, Zimmermann LJ. What's new in surfactant? A clinical view on recent developments in neonatology and paediatrics. Eur J Pediatr 2007;166:889-99

6. Paananen R, Husa AK, Vuolteenaho R, Herva R, Kaukola T, Hallman M. Blood cytokines during the perinatal period in very preterm infants: relationship of inflammatory response and bronchopulmonary dysplasia. $J$ Pediatr 2009;154:39-43 e3

7. Ambalavanan N, Carlo WA, D'Angio CT, McDonald SA, Das A, Schendel D, Thorsen P, Higgins RD. Cytokines associated with bronchopulmonary dysplasia or death in extremely low birth weight infants. Pediatrics 2009;123:1132-41

8. Kaukola T, Tuimala J, Herva R, Kingsmore S, Hallman M. Cord immunoproteins as predictors of respiratory outcome in preterm infants. Am J Obstet Gynecol 2009;200:100 e1-8

9. Been JV, Zimmermann L, Debeer A, Kloosterboer N, Van Iwaarden JF. Bronchoalveolar lavage fluid from preterm infants with chorioamnionitis inhibits alveolar epithelial repair. Respir Res 2009;10:116

10. Been JV, Debeer A, van Iwaarden JF, Kloosterboer N, Passos VL, Naulaers G, Zimmermann LJ. Early alterations of growth factor patterns in bronchoalveolar lavage fluid from preterm infants developing bronchopulmonary dysplasia. Pediatr Res 2010;67:83-9.

11. de Jager W, te Velthuis H, Prakken BJ, Kuis W, Rijkers GT. Simultaneous detection of 15 human cytokines in a single sample of stimulated peripheral blood mononuclear cells. Clin Diagn Lab Immunol 2003;10:133-9

12. de Jager W, Prakken BJ, Bijlsma JW, Kuis W, Rijkers GT. Improved multiplex immunoassay performance in human plasma and synovial fluid following removal of interfering heterophilic antibodies. J Immunol Methods 2005;300:124-35

13. de Jager W, Bourcier K, Rijkers GT, Prakken BJ, Seyfert-Margolis V. Prerequisites for cytokine measurements in clinical trials with multiplex immunoassays. BMC Immunol 2009;10:52

14. de Blic J, Midulla F, Barbato A, Clement A, Dab I, Eber E, Green C, Grigg J, Kotecha S, Kurland G, Pohunek P, Ratjen F, Rossi G. Bronchoalveolar lavage in children. ERS Task Force on bronchoalveolar lavage in children. European Respiratory Society. Eur Respir J 2000;15:217-31

15. de Jager W, Prakken B, Rijkers GT. Cytokine multiplex immunoassay: methodology and (clinical) applications. Methods Mol Biol 2009;514:119-33

16. Jonsson B, Li YH, Noack G, Brauner A, Tullus K. Downregulatory cytokines in tracheobronchial aspirate fluid from infants with chronic lung disease of prematurity. Acta Paediatr 2000;89:1375-80

17. Kwong KY, Jones CA, Cayabyab R, Lecart C, Khuu N, Rhandhawa I, Hanley JM, Ramanathan R, deLemos RA, Minoo P. The effects of IL-10 on proinflammatory cytokine expression (IL-1beta and IL-8) in hyaline membrane disease (HMD). Clin Immunol Immunopathol 1998;88:105-13

18. Kramer BW. Antenatal inflammation and lung injury: prenatal origin of neonatal disease. J Perinatol 2008;28 Suppl 1:S21-7

19. Jones CA, Cayabyab RG, Kwong KY, Stotts C, Wong B, Hamdan H, Minoo P, deLemos RA. Undetectable interleukin (IL)-10 and persistent IL-8 expression early in hyaline membrane disease: a possible developmental basis for the predisposition to chronic lung inflammation in preterm newborns. Pediatr Res 1996;39:966-75

20. Kallapur SG, Nitsos I, Moss TJ, Polglase GR, Pillow JJ, Cheah FC, Kramer BW, Newnham JP, Ikegami M, Jobe AH. IL-1 mediates pulmonary and systemic inflammatory responses to chorioamnionitis induced by lipopolysaccharide. Am J Respir Crit Care Med 2009;179:955-61 
21. Mahieu LM, De Dooy JJ, leven MM, Bridts CH, Stevens WJ. Increased levels of tumor necrosis factor-alpha and decreased levels of interleukin-12 p 70 in tracheal aspirates, within $2 \mathrm{hrs}$ after birth, are associated with mortality among ventilated preterm infants. Pediatr Crit Care Med 2005;6:682-9

22. Van Marter LJ, Dammann O, Allred EN, Leviton A, Pagano M, Moore M, Martin C. Chorioamnionitis, mechanical ventilation, and postnatal sepsis as modulators of chronic lung disease in preterm infants. $J$ Pediatr 2002;140:171-6

23. Been JV, Rours IG, Kornelisse RF, Jonkers F, de Krijger RR, Zimmermann L. Chorioamnionitis alters the response to surfactant in preterm infants. J Pediatr 2010;156:10-15.e1

24. Lahra MM, Beeby PJ, Jeffery HE. Intrauterine inflammation, neonatal sepsis, and chronic lung disease: a 13-year hospital cohort study. Pediatrics 2009;123:1314-19

25. Been JV, Zimmermann LJ. Chorioamnionitis and chronic lung disease in preterm infants. Pediatrics 2009; http://pediatrics.aappublications.org/cgi/eletters/123/5/1314

26. Xu B, Aoyama K, Kusumoto M, Matsuzawa A, Butcher EC, Michie SA, Matsuyama T, Takeuchi T. Lack of lymphoid chemokines CCL19 and CCL21 enhances allergic airway inflammation in mice. Int Immunol 2007;19:775-84

27. Meloni F, Solari N, Miserere S, Morosini M, Cascina A, Klersy C, Arbustini E, Pellegrini C, Vigano M, Fietta AM. Chemokine redundancy in BOS pathogenesis. A possible role also for the CC chemokines: MIP3-beta, MIP3-alpha, MDC and their specific receptors. Transpl Immunol 2008;18:275-80

28. Tullus K, Noack GW, Burman LG, Nilsson R, Wretlind B, Brauner A. Elevated cytokine levels in tracheobronchial aspirate fluids from ventilator treated neonates with bronchopulmonary dysplasia. Eur $J$ Pediatr 1996;155:112-6

29. Munshi UK, Niu JO, Siddiq MM, Parton LA. Elevation of interleukin-8 and interleukin-6 precedes the influx of neutrophils in tracheal aspirates from preterm infants who develop bronchopulmonary dysplasia. Pediatr Pulmonol 1997;24:331-6

30. Truog WE, Ballard PL, Norberg M, Golombek S, Savani RC, Merrill JD, Parton LA, Cnaan A, Luan X, Ballard RA. Inflammatory markers and mediators in tracheal fluid of premature infants treated with inhaled nitric oxide. Pediatrics 2007;119:670-8

31. Bourbia A, Cruz MA, Rozycki HJ. NF-kappaB in tracheal lavage fluid from intubated premature infants: association with inflammation, oxygen, and outcome. Arch Dis Child Fetal Neonatal Ed 2006;91:F36-9

32. Beresford MW, Shaw NJ. Detectable IL-8 and IL-10 in bronchoalveolar lavage fluid from preterm infants ventilated for respiratory distress syndrome. Pediatr Res 2002;52:973-8

33. Marsh LM, Cakarova L, Kwapiszewska G, von Wulffen W, Herold S, Seeger W, Lohmeyer J. Surface expression of CD74 by type II alveolar epithelial cells: a potential mechanism for macrophage migration inhibitory factor-induced epithelial repair. Am J Physiol Lung Cell Mol Physiol 2009;296:L442-52

34. Rosenkilde MM, Schwartz TW. The chemokine system -- a major regulator of angiogenesis in health and disease. APMIS 2004;112:481-95

35. Abman SH. Bronchopulmonary dysplasia: "a vascular hypothesis". Am J Respir Crit Care Med 2001;164:1755-6

36. Rosias PP, Robroeks CM, van de Kant KD, Rijkers GT, Zimmermann LJ, van Schayck CP, Heynens JW, Jobsis $\mathrm{Q}$, Dompeling E. Feasibility of a new method to collect exhaled breath condensate in pre-school children. Pediatr Allergy Immunol 2009; [Epub ahead of print] 


\section{Chapter 5}

Bronchoalveolar lavage fluid from preterm infants with chorioamnionitis inhibits alveolar epithelial repair

Been JV, Zimmermann L, Debeer A, Kloosterboer $N$, van Iwaarden JF

Respir Res 2009; 10: 116 


\section{Abstract}

Background: Preterm infants are highly susceptible to lung injury. While both chorioamnionitis and antenatal steroids induce lung maturation, chorioamnionitis is also associated with adverse lung development. We investigated the ability of bronchoalveolar lavage fluid (BALF) from ventilated preterm infants to restore alveolar epithelial integrity after injury in vitro, depending on whether or not they were exposed to chorioamnionitis or antenatal steroids. For this purpose, a translational model for alveolar epithelial repair was developed and characterised.

Methods: BALF was added to mechanically wounded monolayers of A549 cells. Wound closure was quantified over time and compared between preterm infants (gestational age $<32 \mathrm{wks}$ ) exposed or not exposed to chorioamnionitis and antenatal steroids ( $\geq$ 1 dose). Furthermore, keratinocyte growth factor (KGF) and vascular endothelial growth factor (VEGF) were quantified in BALF, and their ability to induce alveolar epithelial repair was evaluated in the model.

Results: On day $0 / 1$, BALF from infants exposed to antenatal steroids significantly increased epithelial repair ( $40.3 \pm 35.5$ vs. $-6.3 \pm 75.0 \%$ above control/mg protein), while chorioamnionitis decreased woundhealing capacity of BALF (-2.9 \pm 87.1 vs. $40.2 \pm 36.9 \%$ above control/mg protein). BALF from patients with chorioamnionitis contained less KGF (11 (0-27) vs. 0 (0-4) pg/ml) and less detectable VEGF (66 vs. 95\%) on day 0. BALF levels of VEGF and KGF correlated with its ability to induce wound repair. Moreover, KGF stimulated epithelial repair dose-dependently, although the low levels in BALF suggest KGF is not a major modulator of BALF-induced wound repair. VEGF also stimulated alveolar epithelial repair, an effect that was blocked by addition of soluble VEGF receptor-1 (sVEGFr1/FIt-1). However, BALF-induced wound repair was not significantly affected by addition of sVEGFr1.

Conclusion: Antenatal steroids improve the ability of BALF derived from preterm infants to stimulate alveolar epithelial repair in vitro. Conversely, chorioamnionitis is associated with decreased wound-healing capacity of BALF. A definite role for KGF and VEGF in either process could not be established. Decreased ability to induce alveolar epithelial repair after injury may contribute to the association between chorioamnionitis and adverse lung development in mechanically ventilated preterm infants. 


\section{Background}

Antenatal steroid administration and intrauterine inflammation are two important factors capable of promoting lung maturation before birth. Maternal administration of corticosteroids in case of anticipated preterm delivery enhances structural lung maturation and stimulates surfactant secretion in the fetus, and has become standard of care in current obstetric practice ${ }^{1,2}$. Intrauterine inflammation, represented histopathologically by chorioamnionitis, stimulates lung maturation and decreases the incidence of the respiratory distress syndrome (RDS) ${ }^{3-6}$.

Although both chorioamnionitis and antenatal steroids induce lung maturation, a single course of antenatal steroids does not seem to affect longer term lung development while chorioamnionitis does ${ }^{1,3,4}$. Several studies have shown an association between chorioamnionitis and subsequent development of chronic lung disease of prematurity (bronchopulmonary dysplasia; BPD) ${ }^{3}$. Experimental chorioamnionitis in animals, besides inducing lung maturation, also results in a pathological picture of alveolar simplification similar to that of BPD currently seen in preterm infants ${ }^{4}$. This suggests that, although the short term effect appears similar, both entities induce different responses affecting subsequent lung development. The notion that antenatal steroid administration further reduces RDS incidence in preterm infants exposed to intrauterine inflammation, also suggests that both processes exert their effects at least partially through distinct mechanisms 3 .

The mechanisms by which the differential effects of antenatal exposure to steroids and inflammation induce lung maturation and affect lung development are incompletely understood. Different effects of both antecedents on pulmonary growth factor expression

have been demonstrated ${ }^{2,4,7}$. However, lung development is a dynamic, complex and tightly regulated process involving multiple cell types, effector molecules and interactions. By quantifying biological activity of human lung-derived specimens, all potential modulators present are allowed to conduct their effects. An available model for this purpose is the epithelial wound healing model. After induction of a mechanical defect in cultured epithelial cells, the effect of a modulator on the ability of the epithelium to restore its integrity is evaluated. A translational approach can be made by evaluating the effect of human lung-derived fluid obtained in vivo on alveolar wound healing capacity in vitro ${ }^{8}$. Using this approach relevant differences between distinct patient groups have been reported $^{9,10}$.

This model has not been applied in neonatal pulmonary medicine, while it offers comparison of biological activity of lung-derived fluid between patients that were or were not exposed to either antenatal steroids or chorioamnionitis to evaluate their effects on the ability to restore alveolar epithelial injury. This is of particular interest for chorioamnionitis, since the relationship between chorioamnionitis and adverse lung development has been shown to be predominantly modulated by postnatal injury. Clinical data suggest that chorioamnionitis in itself is not a risk factor for adverse lung development and may actu- 
ally even be protective, while subsequent postnatal exposure to either sepsis, mechanical ventilation or both highly increases BPD risk ${ }^{11-14}$.

We hypothesised that chorioamnionitis reduces the ability of lung-derived fluid to restore alveolar epithelial integrity after injury, while antenatal steroids would have a stimulatory effect. To test this hypothesis, we developed a translational in vivo-in vitro model for alveolar epithelial repair. By collecting bronchoalveolar lavage fluid (BALF) at consecutive postnatal time points, we evaluated the time-dependent postnatal effect of both antenatal modulators on BALF biological activity. We further investigated a potential underlying role of two growth factors in the BALF-modulated repair process. Vascular endothelial growth factor (VEGF) is invaluable for normal lung development and is decreased in lung-derived fluid from infants developing BPD ${ }^{15-18}$, and in sheep lungs after experimental chorioamnionitis ${ }^{7}$. Keratinocyte growth factor (KGF) is a potent stimulant of alveolar repair after lung injury ${ }^{19-25}$ and high KGF in tracheal aspirate fluid (TAF) has been associated with absence of BPD ${ }^{26}$. Importantly, both growth factors have been shown to enhance in vitro alveolar epithelial wound healing ${ }^{27-29}$.

\section{Methods}

\section{Patient characteristics and enrolment}

Patients were eligible for the study when born before 32 weeks gestational age and ventilated for RDS. Patients were enrolled in the NICUs in the University Hospitals of Maastricht and Leuven. The Medical Ethical Committees of both hospitals approved the study and written parental consent was obtained. Chorioamnionitis was diagnosed histologically when $>10$ neutrophils per high-power field were present in the chorion or amnion. Steroids were administered to the mother in case of anticipated preterm delivery by giving two intramuscular doses of betamethasone acetate $12 \mathrm{mg} 24 \mathrm{hrs}$ apart.

\section{BALF collection and processing}

BALF was performed at postnatal days $0-1,3-4$, and 7 according to a standard procedure. After turning the infant's head to the left, a 6 French suction catheter was inserted through a side port of the Trachcare ${ }^{\circledR}$ closed suctioning system until slight resistance was felt. Then, one $\mathrm{ml}$ per kg birth weight of sterile isotonic saline solution was gently infused into the lung. After five seconds, suctioning was performed while slowly retracting the catheter. The procedure was repeated once after which the collected fluid was pooled and placed on ice. After centrifugation for 10 minutes at $4^{\circ} \mathrm{C}$ and $300 \times g$, the supernatant was collected, aliquoted and stored at $-80^{\circ} \mathrm{C}$ until analysis.

\section{In vitro alveolar epithelial wound healing assay}

A549 cells (Sigma-Aldrich, St. Louis, MO, USA) were seeded in 24-well plates (BD, Franklin Lakes NJ, USA; approximately 200.000 cells per well) and grown to confluence at $37^{\circ} \mathrm{C}$ and 
a 5\% CO2-95\% air atmosphere in RPMI 1640 medium (Dutch modification; Invitrogen, Carlsbad CA, USA) supplied with $10 \%(\mathrm{v} / \mathrm{v})$ fetal bovine serum (FBS; Greiner Bio-One, Kremsmünster, Austria), $200 \mu \mathrm{M}$ L-glutamine (L-glut; Invitrogen, Carslbad CA, USA) and 10 $\mathrm{U}$ penicillin $+10 \mu \mathrm{g}$ streptomycin per $\mathrm{ml}(\mathrm{P} / \mathrm{S}$; Invitrogen, Carslbad CA, USA). A black grid printed on a plastic sheet was attached to the bottom of each plate, positioning a $2 \times 2$ $\mathrm{mm}$ square underneath the centre of each well. Between the lines of each square a rectangular wound was created by gently scratching the monolayer with a sterile $1 \mathrm{ml}$ pipette tip. By visualisation, scratches of poor quality were excluded from further analysis before start of the experiment. After wounding, each well was washed with $1 \mathrm{ml}$ of phosphatebuffered saline (PBS ( $\mathrm{pH} 7.4$ ); Invitrogen, Carslbad CA, USA) to remove cellular debris.

For model validation experiments, effects of FBS and albumin on wound healing were evaluated by adding various concentrations of FBS to RPMI 1640 medium + L-glut + P/S or human serum albumin (A1887, Sigma-Aldrich, St. Louis MO, USA) to control medium (RPMI $1640+0.1 \%(v / v)$ FBS + L-glut $+P / S)$, using $300 \mu$ l medium per well. Various concentrations of BALF diluted in control medium were added to wounded monolayers, using $300 \mu \mathrm{l}$ medium per well, to evaluate the effect of BALF dilution on wound healing. For this purpose, BALF was obtained from a term newborn ventilated for non-pulmonary reasons.

\section{Effect of BALF, KGF and VEGF on in vitro alveolar epithelial wound healing}

For BALF experiments, BALF was diluted 1:10 in control medium and each well was supplied with $300 \mu \mathrm{l}$ of this mixture from one BALF specimen after wounding. Control wells were supplied with isotonic saline 1:10 in control medium. All experiments were performed in triplicate and each 24-well plate contained three controls. Moreover, each plate included one positive control containing $10 \%(\mathrm{v} / \mathrm{v})$ FBS. In additional experiments, various concentrations of human KGF (R\&D systems, Minneapolis MN, USA) diluted in control medium were added to wounded monolayers in 24-well plates. VEGF (10 pg/ml; R\&D systems, Minneapolis MN, USA), soluble VEGF receptor 1 (sVEGFr1/Flt1; R\&D systems, Minneapolis MN, USA) $(6 \mathrm{ng} / \mathrm{ml})$ and $\operatorname{BALF}(1: 10(\mathrm{v} / \mathrm{v}))$ diluted in control medium were added in distinct experiments, both solitary and combined, to evaluate their effects on alveolar epithelial wound repair. For this purpose BALF from several patients was pooled to obtain a large and uniform sample. Each plate contained three controls and quadruplicates for each growth factor/receptor concentration.

\section{Assessment of wound healing}

Using a Leica DC 300 F camera coupled to a Leica MZ FL III stereomicroscope, each wound was photographed at a magnification of $3.15 \times$ directly after scratching $(t=0)$ and at subsequent time points ( 6 and 24 hours for BALF experiments). Each well was repeatedly photographed within the central square of the grid to ensure wound surface measurements were performed at a fixed position.

The wounded surface was quantified by tracing the wound edge and calculating the denuded surface area using Image J software. The assessor was blinded for the experi- 
mental condition of the photograph. Wound healing was assessed by subtracting the wound area at a given time point from the wound area at time point zero and expressed as the percentage of wound healing of each BALF specimen above the wound healing of the control wells (containing $0.1 \% \mathrm{FBS}(\mathrm{v} / \mathrm{v})$ ) on the same culture plate.

\section{Quantification of total protein, KGF, VEGF, sVEGFr1, and $M 30$}

Total protein in BALF was quantified using the NanoOrange ${ }^{\circledR}$ protein quantitation kit (Molecular Probes, Eugene, OR, USA) according to the manufacturer's instructions. KGF, VEGF and SVEGFr1 in BALF were quantified by ELISA (R\&D systems, Minneapolis MN) according to the manufacturer's instructions, in half-area 96-well ELISA plates (Greiner Bio-One, Kremsmünster, Austria). To assess the effect of BALF on induction of apoptosis in A549 cells, M30 (CK18Asp396-NE; a soluble marker of epithelial cell apoptosis) was quantified in the cell culture supernatant at the end of the wound healing experiment $(t=24)$ using ELISA (Peviva AB, Bromma, Sweden). For this purpose, triplicates from the culture experiments were pooled to represent a single patient sample.

\section{$\underline{\text { Statistics }}$}

Continuous data are expressed as mean \pm standard deviation if normally distributed, and median plus interquartile range otherwise. Differences between groups were tested using student t-test and ANOVA with post-hoc Bonferroni correction for comparison of two or three groups, respectively. Mann-Whitney $U$ test was used for comparison of nonparametric data and dichotomous variables were tested using $\chi^{2}$-test. Correlations were determined using Pearson's correlation coefficient. A test result of $p<0.05$ was considered significant (two-tailed). All analyses were performed using SPSS 15.0 software.

\section{Results}

\section{FBS stimulates in vitro alveolar epithelial wound healing}

The effect on wound healing of addition of increasing FBS concentrations to culture medium was evaluated in order to validate the model (Figure 1A). Addition of FBS concentration-dependently stimulated wound closure. A large number of cells detached from the culture plate during incubation without FBS over 24 hours, while cell attachment was conserved and partial wound closure occurred during incubation in $0.1 \%$ FBS. Thus, this concentration was used as the optimal concentration to preserve cell viability and determine the effect of subsequent addition of BALF.

\section{Wound closure rate}

To evaluate wound closure rate, wounded monolayers were incubated in control medium $(0.1 \%$ FBS $(v / v))$ and positive control medium (10\% FBS $(v / v))$ with serial photographs taken over a 24-hour period (Figure 1B). In control medium, wound closure rate decreased 
over time, stabilising between four and six hours of incubation. A more gradual decrease was observed during incubation with positive control medium.

A

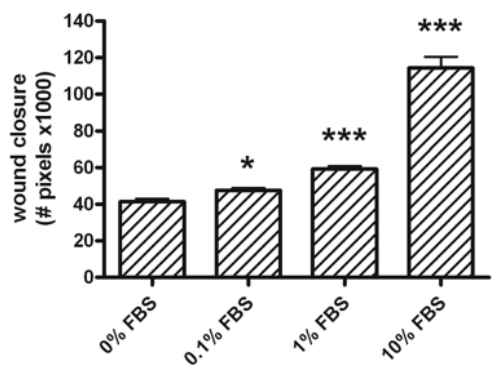

C

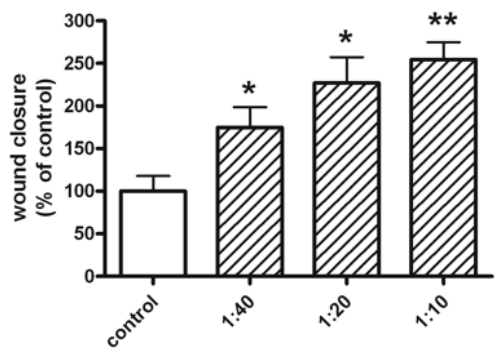

B

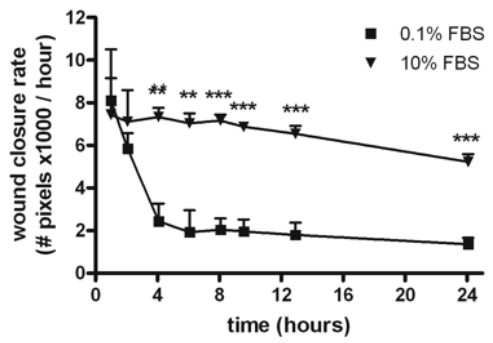

D

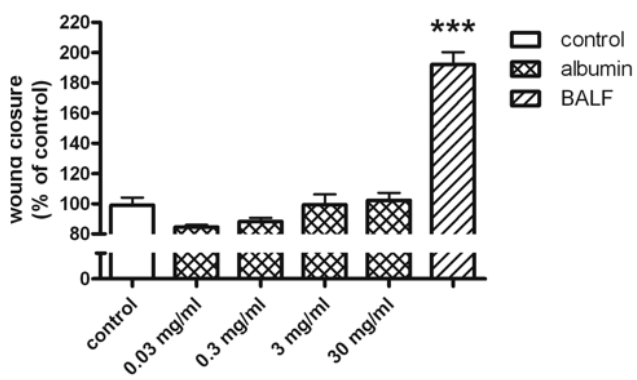

Figure 1. Characterisation of the alveolar epithelial wound repair model. A. Effect of addition of various concentrations of fetal bovine serum (FBS) to culture medium on in vitro alveolar epithelial wound healing $(A ; t=24$ hours). Bars represent mean wound closure + SEM (number of pixels $\times 1000)$ of triplicate experiments $\left({ }^{*} p<0.05\right.$; $* * * p<0.001$ vs. control). B. Differences in wound closure rate over time between incubation in control medium $(0.1 \% \mathrm{FBS})$ and positive control medium (10\% FBS). Points represent mean wound closure rate + SEM of triplicate experiments ( ${ }^{*} p<0.01 ; * * p<0.001$ vs control). C. Effect of addition of various concentrations of bronchoalveolar lavage fluid (BALF) from a term newborn diluted in control medium ( $0.1 \%$ FBS) on in vitro alveolar epithelial wound healing ( $t=24$ hours). Bars represent mean wound closure + SEM (\% of control) of triplicate experiments $\left({ }^{*} p<0.05 ;{ }^{* *} p<0.01\right.$ vs. control). D. Effects of various concentrations of albumin and BALF (diluted 1:10) from a term newborn (total protein in the original BALF specimen was $1.7 \mathrm{mg} / \mathrm{ml}$ ). Bars represent mean wound closure + SEM relative to control medium of triplicate experiments ( $* * * p<0.001$ vs. control).

\section{BALF has a concentration-dependent effect on wound closure}

To evaluate the optimal dilution factor for BALF addition to the model, and evaluate the concentration dependency of the BALF effect on wound healing, BALF obtained from a term newborn was added in various concentrations to the model (Figure 1C). Addition of BALF to control medium had a concentration-dependent stimulatory effect on wound closure. For further experiments BALF was diluted 1:10. 


\section{Albumin does not affect wound closure}

Albumin is the most abundant protein in BALF and may be increased in serious lung injury as a result of distortion of the blood-air barrier. We evaluated the effect of addition of albumin to control medium on wound closure in order to determine whether this would affect our model (Figure 1D). Albumin did not significantly affect wound closure, while wound closure was significantly enhanced by addition of BALF, which contained less protein than the highest albumin concentration used in the experiment.

\section{BALF characteristics and wound healing}

74 BALF specimens were collected from 45 ventilated preterm infants. There was no significant difference in total protein or wound closure between different postnatal days when all patients were considered (not shown). No significant differences in gestational age or birth weight were present between the different patient groups (Table 1). Patients with chorioamnionitis had significantly increased BALF total protein at day 7 when compared to patients without chorioamnionitis. No other differences in total protein were observed at any postnatal day. Wound closure correlated significantly with BALF total protein content $\left(R^{2}=0.44 ; p<0.001\right)$ and wound closure data are corrected for total BALF protein content in further analyses. Neither wound closure nor BALF total protein correlated with either gestational age or birth weight. There was a close correlation between wound closure at $t=6$ and $t=24\left(R^{2}=0.80 ; p<0.001\right)$, yet the majority of the effect was reached within 6 hours after wound induction. Further analyses were performed only at $t$ $=6$.

To evaluate the effects of chorioamnionitis and antenatal steroids, the capacity of BALF to stimulate alveolar epithelial repair in vitro was compared between infants with and without chorioamnionitis and infants that had and had not received antenatal steroids.

\section{Chorioamnionitis decreases wound healing capacity of BALF}

BALF obtained from infants with histological chorioamnionitis demonstrated a significantly decreased capacity to stimulate in vitro wound healing when compared to BALF from infants without histological chorioamnionitis at day $0 / 1$ (Figure 2A). No significant differences were observed between infants with and without chorioamnionitis on postnatal days $3 / 4$ and 7 .

\section{Prenatal steroids stimulate wound healing capacity of BALF}

BALF from infants exposed to antenatal steroids demonstrated a significantly increased capacity to stimulate wound healing at day $0 / 1$ when compared to BALF from nonexposed infants (Figure 2B). No significant differences were observed after day $0 / 1$, although it should be noted that at these time points the no steroids group comprised only two patients. 
Table 1. General characteristics of different patient groups included in the cell culture experiments and the total population (including VEGF and KGF quantification). ${ }^{*} p<0.05$ vs no chorioamnionitis day 7 . Abbreviations: chorio = chorioamnionitis; IQR = interquartile range; $S D=$ standard deviation.

\begin{tabular}{|c|c|c|c|c|}
\hline $\begin{array}{l}\text { Wound healing } \\
\text { experimental group }\end{array}$ & $\begin{array}{l}\text { Chorio } \\
(n=7)\end{array}$ & $\begin{array}{l}\text { No chorio } \\
(n=30)\end{array}$ & $\begin{array}{l}\text { Steroids } \\
(n=35)\end{array}$ & $\begin{array}{l}\text { No steroids } \\
(n=10)\end{array}$ \\
\hline $\begin{array}{l}\text { Gestational age in weeks } \\
\text { (median (IQR)) }\end{array}$ & $\begin{array}{l}26.9 \\
(25.6-28.7)\end{array}$ & $\begin{array}{l}28.6 \\
(27.0-39.3)\end{array}$ & $\begin{array}{l}28.6 \\
(26.9-29.4)\end{array}$ & $\begin{array}{l}27.5 \\
(26.2-29.7)\end{array}$ \\
\hline $\begin{array}{l}\text { Birth weight in grams } \\
\text { (mean } \pm S D)\end{array}$ & $1027 \pm 246$ & $1069 \pm 221$ & $1091 \pm 223$ & $1028 \pm 268$ \\
\hline $\begin{array}{l}\text { BALF total protein day } 0 / 1 \\
\text { in } \mathrm{mg} / \mathrm{ml} \text { (mean } \pm S D)\end{array}$ & $\begin{array}{l}0.75 \pm 0.49 \\
(n=7)\end{array}$ & $\begin{array}{l}0.76 \pm 0.47 \\
(n=28)\end{array}$ & $\begin{array}{l}0.82 \pm 0.57 \\
(n=32)\end{array}$ & $\begin{array}{l}0.62 \pm 0.46 \\
(n=9)\end{array}$ \\
\hline $\begin{array}{l}\text { BALF total protein day } 3 / 4 \\
\text { in } \mathrm{mg} / \mathrm{ml} \text { (mean } \pm S D)\end{array}$ & $\begin{array}{l}1.47 \pm 2.38 \\
(n=5)\end{array}$ & $\begin{array}{l}1.25 \pm 1.34 \\
(n=14)\end{array}$ & $\begin{array}{l}1.09 \pm 1.22 \\
(n=19)\end{array}$ & $\begin{array}{l}3.21 \pm 3.53 \\
(n=2)\end{array}$ \\
\hline $\begin{array}{l}\text { BALF total protein day } 7 \\
\text { in } \mathrm{mg} / \mathrm{ml} \text { (mean } \pm S D)\end{array}$ & $\begin{array}{l}0.84 \pm 0.39 * \\
(n=3)\end{array}$ & $\begin{array}{l}0.44 \pm 0.18 \\
(n=7)\end{array}$ & $\begin{array}{l}0.51 \pm 0.28 \\
(n=9)\end{array}$ & $\begin{array}{l}0.95 \pm 0.03 \\
(n=2)\end{array}$ \\
\hline Total population & $\begin{array}{l}\text { Chorio } \\
(n=8)\end{array}$ & $\begin{array}{l}\text { No chorio } \\
(n=37)\end{array}$ & $\begin{array}{l}\text { Steroids } \\
(n=51)\end{array}$ & $\begin{array}{l}\text { No steroids } \\
(n=11)\end{array}$ \\
\hline $\begin{array}{l}\text { Gestational age in weeks } \\
\text { (median (IQR)) }\end{array}$ & $\begin{array}{l}26.5 \\
(25.7-28.4)\end{array}$ & $\begin{array}{l}28.4 \\
(26.8-29.4)\end{array}$ & $\begin{array}{l}28.6 \\
(26.9-29.4)\end{array}$ & $\begin{array}{l}27.6 \\
(26.3-29.7)\end{array}$ \\
\hline $\begin{array}{l}\text { Birth weight in grams } \\
\text { (mean } \pm S D)\end{array}$ & $1014 \pm 231$ & $1045 \pm 228$ & $1079 \pm 236$ & $1045 \pm 260$ \\
\hline
\end{tabular}

To further investigate the possible mechanisms of the effects of chorioamnionitis and antenatal steroids on the ability of BALF to repair alveolar epithelial injury in vitro, we focused on BALF-induced apoptosis and possible roles for KGF and VEGF, known modulators of lung development and lung injury repair. KGF and VEGF were quantified in BALF and added to the model in various concentrations.

\section{BALF-induced apoptosis is not influenced by chorioamnionitis or antenatal steroids}

To investigate whether the effects of chorioamnionitis and antenatal steroids on day $0 / 1$ could be explained by differential effects on BALF-induced apoptosis in A549 cells, we quantified $\mathrm{M} 30$, a soluble marker of epithelial apoptosis, in the cell culture supernatant at the end of the wound healing experiment. No significant differences were observed between culture supernatants of day $0 / 1$ experiments from infants with or without chorioamnionitis ( $841 \pm 338$ vs. $1085 \pm 316 \mathrm{U} / \mathrm{L}, \mathrm{p}=0.08$; Figure $3 \mathrm{~A}$ ), and from infants exposed or not exposed to antenatal betamethasone (1028 \pm 314 vs. $1041 \pm 389 \mathrm{U} / \mathrm{L}, \mathrm{p}=$ 0.42; Figure 3B). 

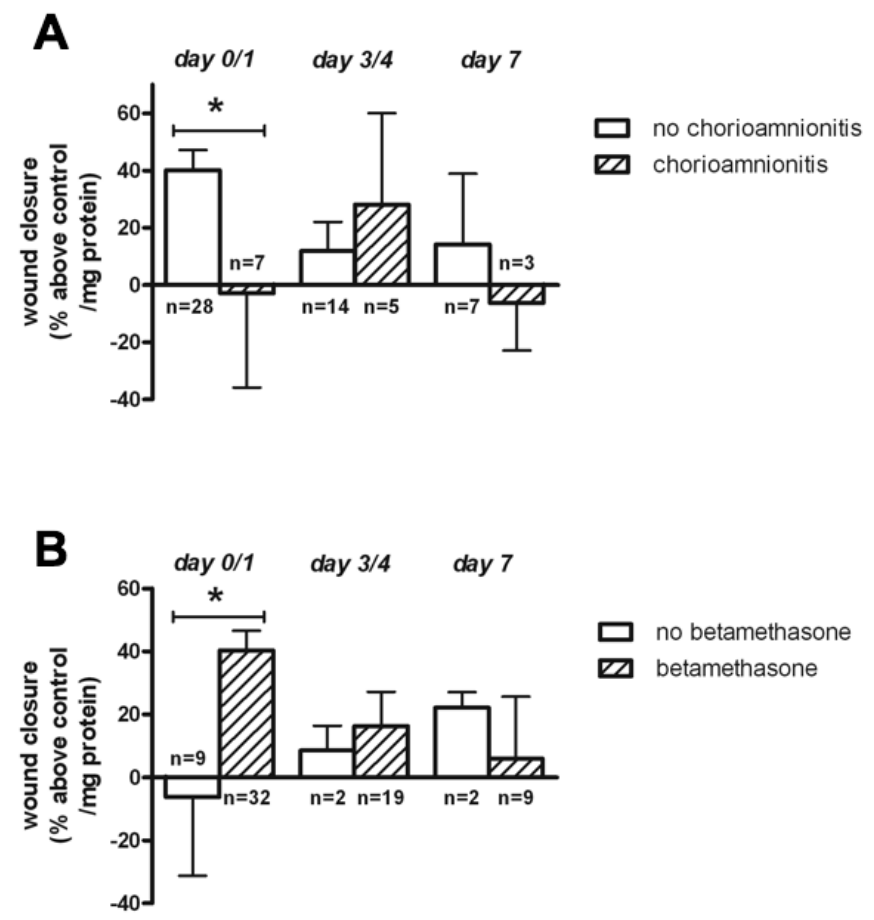

Figure 2. Effects of chorioamnionitis and antenatal steroids on bronchoalveolar lavage fluid (BALF) wound healing capacity. Effect of BALF obtained at different postnatal days from patients with and without chorioamnionitis (A), and from patients with and without antenatal steroid exposure (B) on in vitro alveolar epithelial wound healing. Bars represent mean wound closure +/- SEM (\% above control/mg total protein in BALF) of triplicate experiments $\left({ }^{*} p<0.05\right)$.

A

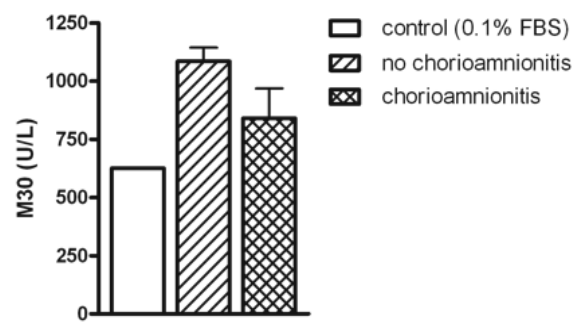

B

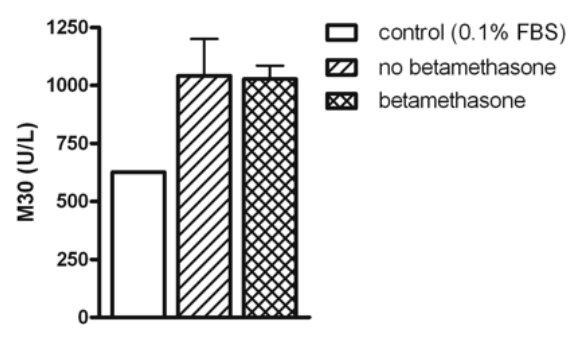

Figure 3. M30 detected in culture supernatant after day 0/1 wound healing experiment according to chorioamnionitis or betamethasone exposure. Bars represent mean wound closure + SEM per group. No significant differences between groups were present. 


\section{Chorioamnionitis is associated with decreased KGF and less detectable VEGF in BALF}

KGF and VEGF were quantified in 121 BALF specimens from 62 patients, including all BALF specimens tested in the in vitro wound healing experiments. KGF was detected in $63 \%$, $53 \%, 71 \%$ and $56 \%$ of BALF specimens obtained on day $0,1,3 / 4$ and 7 , respectively. KGF in BALF correlated positively with gestational age on day 0 , but not thereafter $\left(R^{2}=0.17, p<\right.$ $0.05)$. VEGF was detected in $88 \%, 97 \%, 94 \%$ and $100 \%$ of BALF specimens obtained on day $0,1,3 / 4$ and 7 , respectively.

KGF concentrations in BALF obtained on day 0 from patients with chorioamnionitis were significantly lower than those in BALF from patients without chorioamnionitis $(010-$ 5) vs. 11 (0-27), p <.05; Figure 4A). Furthermore, no KGF was detectable in chorioamnionitis-exposed infants at day 7 , while $75 \%$ of non-exposed infants had detectable KGF ( $p<$ 0.05). BALF from infants with chorioamnionitis was significantly less likely to contain detectable levels of VEGF on day 0 when compared to BALF from infants without chorioamnionitis $(67 \%$ versus $95 \%, p<0.05)$. Absolute VEGF concentrations were not significantly different between infants with or without chorioamnionitis on day 0 (9 (0-17) vs. 17 (729), $p=0.14$ ), or on any other day (Figure 4B).
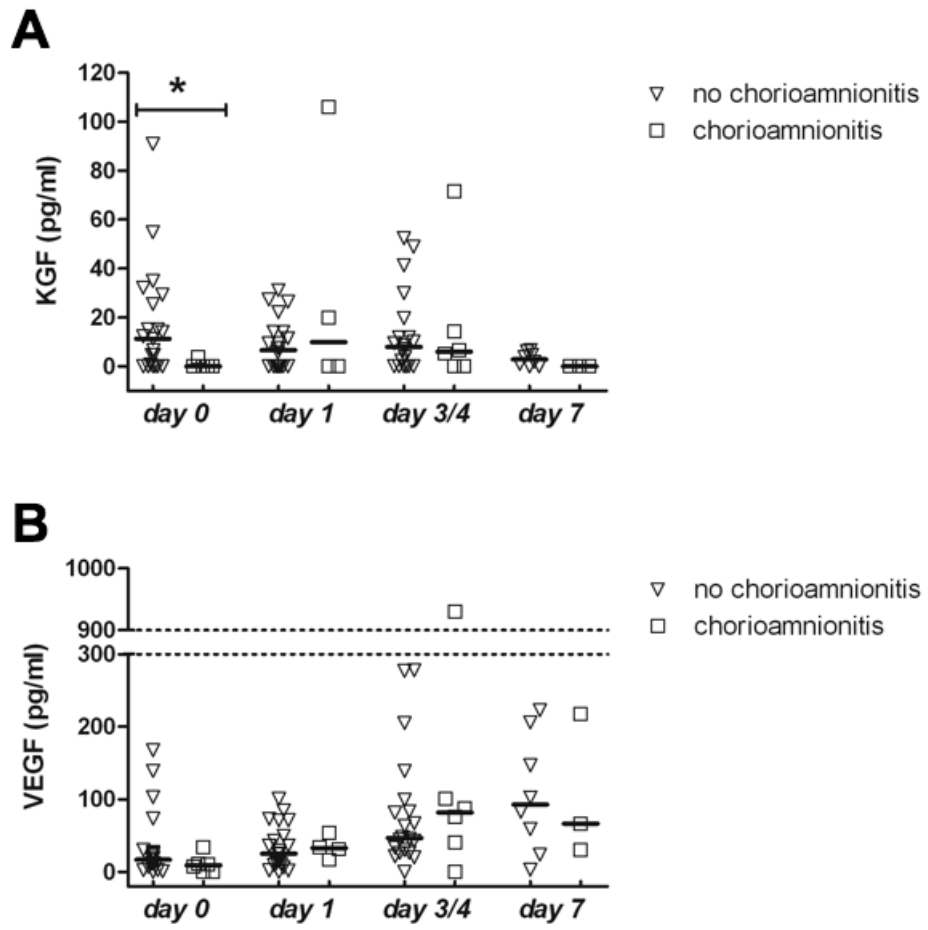

Figure 4. Keratinocyte growth factor (KGF) and vascular endothelial growth factor (VEGF) levels in bronchoalveolar lavage fluid (BALF). KGF (A) and VEGF (B) levels in bronchoalveolar lavage fluid (BALF) obtained at different postnatal days from patients with and without chorioamnionitis. Points represent individual BALF growth factor concentrations, horizontal lines represent medians $\left({ }^{*} p<0.05\right)$. 
Concentrations of both KGF and VEGF in BALF correlated significantly with the ability of BALF to stimulate alveolar epithelial repair in vitro albeit with low $R^{2}$ values $\left(R^{2}=0.08, p<\right.$ 0.05 ; and $R^{2}=0.10, p<0.01$, respectively). This illustrates that small part of the decreased ability of BALF obtained from patients with chorioamnionitis to stimulate alveolar epithelial repair may result from the decreased availability of these growth factors. No significant differences in BALF VEGF or KGF concentrations were detected on any day between patients that had or had not received antenatal steroids.

\section{$K G F, V E G F$ and in vitro wound healing}

Remaining BALF was pooled for further experiments aimed at evaluating the roles of KGF and VEGF in BALF on wound repair. The pooled BALF contained $40 \mathrm{pg} / \mathrm{ml} \mathrm{VEGF,} \mathrm{but} \mathrm{unde-}$ tectable levels of KGF. In the absence of BALF, VEGF stimulated alveolar epithelial repair, an effect that was blocked by addition of sVEGFr1 (Figure 5A). However, addition of the same concentrations of SVEGFr1, VEGF, or a combination of both to BALF did not significantly alter its effect on wound healing (Figure $5 \mathrm{~A}$ ). To evaluate whether natural abundance of SVEGFr1 in BALF could explain the inability to detect a VEGF-mediated effect on BALF-induced alveolar epithelial wound repair, we quantified SVEGFr1 in a subset of remaining BALF samples $(n=10)$. sVEGFr1 was present in significant amounts in all evaluated samples (median [range] = $5.39[1.28 ;>10] \mathrm{ng} / \mathrm{l}$ ).

Given the undetectable levels of KGF in the BALF pool, no attempts to antagonise the effect of KGF in BALF were made. Nevertheless, KGF was shown to have a concentration dependent stimulatory effect on wound healing (Figure 5B).
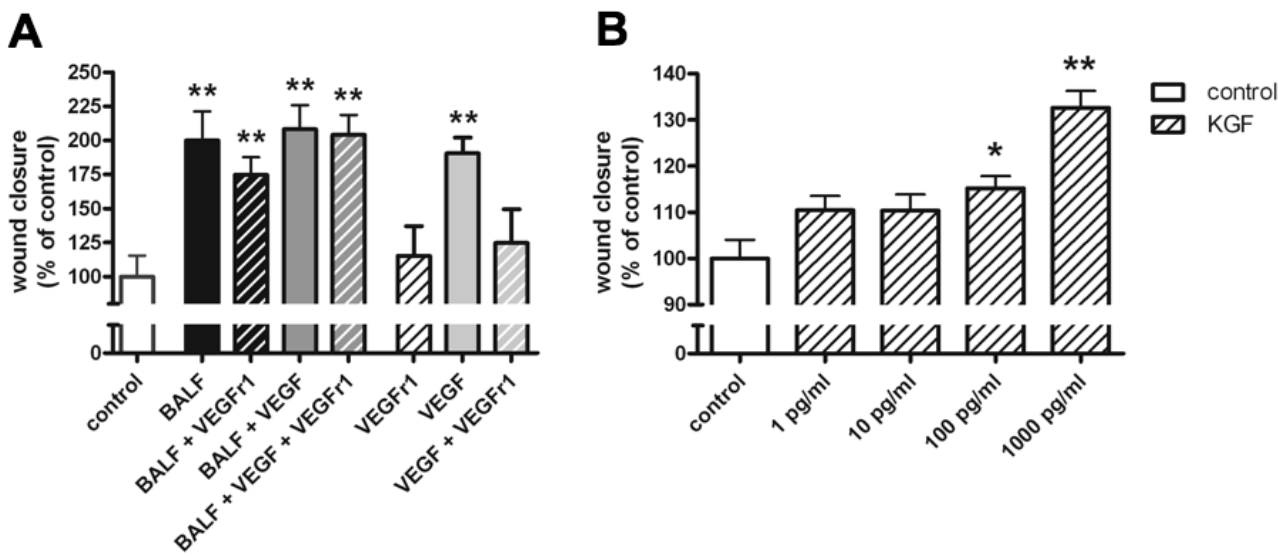

Figure 5. Vascular endothelial growth factor (VEGF) and keratinocyte growth factor (KGF) effects on alveolar epithelial wound repair. Effect of addition of different combinations of bronchoalveolar lavage fluid (BALF), VEGF (10 pg/ml), and soluble VEGF-receptor 1 (sVEGFr1; $6 \mathrm{ng} / \mathrm{ml})(\mathrm{A})$, or various concentrations of KGF (B) on in vitro alveolar epithelial wound healing. Bars represent mean wound closure + SEM (\% of control) of triplicate experiments $\left(* p<0.05\right.$, and ${ }^{*} p<0.01$ vs control). No significant differences are present between BALF alone and BALF with any addition. Significant differences between VEGF, and both sVEGFr1 and VEGF + sVEGFr1 are present (both $\mathrm{p}<.05$ ). 


\section{Discussion}

We report the development and characterisation of a translational in vivo/in vitro model for alveolar epithelial repair. Wound repair was quantified after mechanical wounding of a monolayer of A549 cells. FBS and BALF stimulated alveolar epithelial wound healing in this model in a concentration-dependent manner. Physiological concentrations of albumin, the most abundant protein in BALF, did not affect wound repair indicating that the effect of BALF results from actions of specific mediators rather than a general protein or dilutional effect. BALF from patients with chorioamnionitis had a significantly reduced capacity to induce alveolar epithelial wound healing, while exposure to antenatal steroids was associated with increased wound healing capacity of BALF shortly after birth. These effects were not attributable to alterations in BALF-induced apoptosis. BALF from patients exposed to chorioamnionitis contained lower levels of KGF and less detectable VEGF on postnatal day 0 . BALF wound healing capacity correlated with levels of both of these and addition of these factors to our model resulted in stimulation of alveolar epithelial repair. However, results from subsequent experiments suggest that, at the concentrations present, their contribution to BALF-induced wound repair is at best around $10 \%$, although significant effects could not be demonstrated.

Evaluation of epithelial wound healing in vitro is an established model for epithelial repair after injury and has been applied and characterised for many different epithelial types, including the alveolar epithelium ${ }^{8}$. Many investigators have used primary cultures of alveolar type II cells isolated from animal lungs in epithelial repair models since A549 cells do not hold all characteristics of type II cells and freshly isolated human type II cells are not readily available ${ }^{8,27,28}$. Still, of all human cell-lines available A549 cells share most characteristics with alveolar type II cells and are most widely used in human in vitro models of alveolar physiology. More importantly, in testing the biological activity of human BALF, we refrained from using animal-derived type II cells because of concerns regarding loss or modulation of biological signal due to species difference, in accordance with previous reports $^{9,10}$.

We are aware of only two earlier reports evaluating the effect of human lung-derived fluid on alveolar epithelial repair in vitro ${ }^{9,10}$. Perkins et al. recently showed that in patients ventilated for acute respiratory distress syndrome (ARDS), treatment with salbutamol, a $\beta 2$-agonist, significantly increased the ability of BALF to stimulate wound healing in A549cells ${ }^{10}$. Interestingly, BALF derived from salbutamol-treated patients also contained higher levels of VEGF, although the authors show evidence that in their study interleukin-1 $\beta$ (IL$1 \beta$ ) and not VEGF was the main contributor to epithelial repair ${ }^{10}$. In an earlier report, pulmonary edema fluid from ventilated adult patients with acute lung injury (ALI)/ARDS enhanced wound repair when compared to plasma or edema fluid from ventilated patients with hydrostatic edema ${ }^{9}$. Additional experiments suggested that IL-1 $\beta$ accounted for part of this effect, although edema fluid IL-1 $\beta$ concentrations were not reported. IL-1 $\beta$ was not evaluated in our model since BALF levels were increased rather than decreased 
after chorioamnionitis in our cohort (unpublished observations), arguing against its contribution to the decreased wound healing ability of BALF. IL-1 receptor antagonist (IL-1ra) induced by BALF in A549 cells or present in the alveolar space may further modulate the effects of IL-1 $\beta$, complicating assessment of its contribution to our findings. Considering the inflammatory nature of both ALI/ARDS and chorioamnionitis, one might expect that these conditions have similar effects on wound repair. However, chorioamnionitis was associated with decreased wound healing in our model whereas BALF from ALI/ARDS patients increased wound repair ${ }^{9}$. Total protein concentrations in edema fluid from ALI/ARDS patients were also significantly higher ${ }^{9}$, possibly explaining part of its increased wound healing potential. Furthermore age-related differences, differences in specimen used (BALF versus edema fluid) and growth factor patterns may partly account for differences.

A unique aspect of our study is the evaluation of the differential effect of BALF collected consecutively within distinct patient groups. We observed clear effects of the antenatal antecedents studied on wound healing capacity of BALF early after birth, whereas no significant effects were present later on. Thus, the effects of modulators of wound healing present in BALF on epithelial repair appear to vary over time. Multiple studies have shown that short term exposure to injury may induce important and sustained lung damage ${ }^{30,31}$. Therefore, modulation of lung injury repair by antenatal events seen in our study is likely to be of clinical importance, even though the effects are only observed shortly after birth. A larger time window between the antecedent and its effect, and possible interference of other factors influencing repair capacity may explain disappearance of the association over time $^{32}$.

The decreased capacity of BALF from patients previously exposed to chorioamnionitis to restore epithelial integrity provides a novel link between antenatal inflammation and adverse lung development ${ }^{3,4,33}$. Our model is unique in comparing biological activity of human BALF between patients with and without chorioamnionitis. The data suggest that prenatal exposure to inflammation results in BALF that is less efficient in repairing lung injury. This may explain why chorioamnionitis alone may not predispose to adverse lung development, while additional exposure to postnatal injurious factors such as mechanical ventilation and sepsis highly augments its association with chronic lung disease ${ }^{11,12}$. Experimental chorioamnionitis in preterm sheep increases the inflammatory response to postnatal mechanical ventilation, suggesting that inflammatory factors play a role ${ }^{34}$. Paradoxically, classic inflammatory cytokines known to be upregulated in chorioamnionitis have previously been shown to stimulate wound repair ${ }^{8,9}$. The finding of decreased epithelial repair after chorioamnionitis in our model suggests an additional role for other modulators. Although our initial experiments suggest that decreased levels of VEGF and KGF after chorioamnionitis may explain part of the decreased ability of BALF to induce alveolar epithelial repair, a definite contribution of neither factor could be established. We were able confirm earlier reports of stimulatory effects of VEGF and KGF on in vitro alveolar epithelial wound healing ${ }^{27-29}$, and decreased availability of VEGF after chorioamnionitis 
${ }^{7}$. Moreover, both KGF and VEGF levels in BALF are linked to development of BPD in previous reports ${ }^{15-17,26}$, as well as in our sample ${ }^{18}$. A considerable amount of animal experimental data further supports a pivotal role of both factors in lung development and repair 19-25,27,28,35. Thus, the early decrease in BALF levels of KGF and VEGF is likely to contribute to adverse lung development seen after chorioamnionitis, although our experiments suggest that their effects are primarily exerted through mechanisms other than BALF-induced alveolar epithelial repair. The overall low levels of VEGF and KGF as compared to adult studies may reflect developmental regulation as well as differences in BAL technique (e.g. non-bronchoscopic versus bronchoscopic). Furthermore, the potential role of the apparent abundance of SVEGFr1 in the alveolar space in decreasing VEGF bioavailability warrants further investigation ${ }^{36}$.

Although antenatal steroids reduce RDS incidence, enhance structural maturity of the lung and improve lung function ${ }^{1,2,37}$, BPD incidence seems unaffected ${ }^{1}$. However, when only studies using betamethasone are considered, BPD is significantly reduced ${ }^{1}$. By demonstrating an association between antenatal betamethasone and enhanced alveolar epithelial repair, our data provide a potential link between betamethasone exposure and improved lung development.

An earlier study found no effect of corticosteroids on airway epithelial repair ${ }^{38}$, while another showed dexamethasone to inhibit wound repair initially, while inducing extended subsequent wound-healing potential in bronchial epithelial cells ${ }^{39}$. Thus, the direct effect induced by corticosteriods seems to differ from the longer term changes that affect the cellular response to injury. In sheep, maternal betamethasone acetate administration results in peak fetal plasma concentrations after 3 hours, dropping below the detection limit within 8 hours ${ }^{40}$. Since infants in our study were exposed to maternal steroids hours to weeks before birth, indirect mechanisms most likely explain the increased BALF wound healing capacity seen in our model. We were unable to detect betamethasone effects on BALF-induced apoptosis, and VEGF or KGF levels, suggesting that other factors play a role in this process.

Our model obviously is a simplified representation of the in vivo situation, since the alveolar space consist of a combination of different cell types. Communication between these cells cannot be investigated in our current model. Still we feel this model is an important first step in the identification of risk factors and protective factors in lung injury repair and of the underlying mechanisms at a molecular level. Larger patient groups are needed to further evaluate possible other modulating factors, such as oxygen exposure, mechanical ventilation characteristics and the combined effects of chorioamnionitis and antenatal steroids ${ }^{3,41}$. 


\section{Conclusion}

A translational in vivo/in vitro model for alveolar epithelial repair using BALF as a reflection of the in vivo pulmonary environment, was characterised and applied. The evaluation of alveolar epithelial repair capacity of BALF serially collected in distinct patient groups provides a unique means by which biological activity of human specimens can be linked to clinical parameters over time. BALF obtained shortly after birth from preterm infants exposed to chorioamnionitis had a significantly decreased ability to restore alveolar epithelial integrity in vitro, providing a biological link between chorioamnionitis and adverse lung development. Our data suggest that the contribution of VEGF and KGF in BALF to this effect is probably small, although their decrease after chorioamnionitis may well modulate the susceptibility for adverse lung development. Conversely, prenatal steroid administration was shown to significantly increase wound-healing capacity of BALF in preterm infants. Additional research is needed to study the underlying mechanisms of modulation of alveolar epithelial repair by chorioamnionitis and antenatal steroids. Further evaluation of biological activity of human specimens in translational models like the one presented here carries great potential to study mechanisms underlying disease associations.

\section{References}

1. Roberts D, Dalziel S. Antenatal corticosteroids for accelerating fetal lung maturation for women at risk of preterm birth. Cochrane Database Syst Rev 2006;3:CD004454

2. Bolt RJ, van Weissenbruch MM, Lafeber HN, Delemarre-van de Waal HA. Glucocorticoids and lung development in the fetus and preterm infant. Pediatr Pulmonol 2001;32:76-91

3. Been JV, Zimmermann LJ. Histological chorioamnionitis and respiratory outcome in preterm infants. Arch Dis Child Fetal Neonatal Ed 2009;94:F218-25

4. Kramer BW. Antenatal inflammation and lung injury: prenatal origin of neonatal disease. J Perinatol 2008;28 Suppl 1:S21-7

5. Kramer BW, Ladenburger A, Kunzmann S, Speer CP, Been JV, van Iwaarden JF, Zimmermann LJ, Gantert M, Garnier Y. Intravenous lipopolysaccharide-induced pulmonary maturation and structural changes in fetal sheep. Am J Obstet Gynecol 2009;200:195 e1-10

6. Been JV, Rours IG, Kornelisse RF, Lima Passos V, Kramer BW, Schneider TA, de Krijger RR, Zimmermann LJ. Histologic chorioamnionitis, fetal involvement, and antenatal steroids: effects on neonatal outcome in preterm infants. Am J Obstet Gynecol 2009;201:587 e1-8

7. Kallapur SG, Bachurski CJ, Le Cras TD, Joshi SN, Ikegami M, Jobe AH. Vascular changes after intra-amniotic endotoxin in preterm lamb lungs. Am J Physiol Lung Cell Mol Physiol 2004;287:L1178-85

8. Geiser T. Mechanisms of alveolar epithelial repair in acute lung injury--a translational approach. Swiss Med Wkly 2003;133:586-90

9. Geiser T, Atabai K, Jarreau PH, Ware LB, Pugin J, Matthay MA. Pulmonary edema fluid from patients with acute lung injury augments in vitro alveolar epithelial repair by an IL-1beta-dependent mechanism. Am J Respir Crit Care Med 2001;163:1384-8

10. Perkins GD, Gao F, Thickett DR. In vivo and in vitro effects of salbutamol on alveolar epithelial repair in acute lung injury. Thorax 2008;63:215-20

11. Lahra MM, Beeby PJ, Jeffery HE. Intrauterine inflammation, neonatal sepsis, and chronic lung disease: a 13-year hospital cohort study. Pediatrics 2009;123:1314-19 
12. Van Marter LJ, Dammann O, Allred EN, Leviton A, Pagano M, Moore M, Martin C. Chorioamnionitis, mechanical ventilation, and postnatal sepsis as modulators of chronic lung disease in preterm infants. J Pediatr 2002;140:171-6

13. Been JV, Rours IG, Kornelisse RF, Jonkers F, de Krijger RR, Zimmermann LJ. Chorioamnionitis Alters the Response to Surfactant in Preterm Infants. J Pediatr 2010;156:10-5

14. Been JV, Zimmermann LJ. Chorioamnionitis and chronic lung disease in preterm infants. Pediatrics 2009;http://pediatrics.aappublications.org/cgi/eletters/123/5/1314

15. Lassus P, Ristimaki A, Ylikorkala O, Viinikka L, Andersson S. Vascular endothelial growth factor in human preterm lung. Am J Respir Crit Care Med 1999;159:1429-33

16. Lassus P, Turanlahti M, Heikkila P, Andersson LC, Nupponen I, Sarnesto A, Andersson S. Pulmonary vascular endothelial growth factor and Flt-1 in fetuses, in acute and chronic lung disease, and in persistent pulmonary hypertension of the newborn. Am J Respir Crit Care Med 2001;164:1981-7

17. Bhatt AJ, Pryhuber GS, Huyck H, Watkins RH, Metlay LA, Maniscalco WM. Disrupted pulmonary vasculature and decreased vascular endothelial growth factor, FIt-1, and TIE-2 in human infants dying with bronchopulmonary dysplasia. Am J Respir Crit Care Med 2001;164:1971-80

18. Been JV, Debeer A, van Iwaarden JF, Kloosterboer N, Passos VL, Naulaers G, Zimmermann LJ. Early alterations of growth factor patterns in bronchoalveolar lavage fluid from preterm infants developing bronchopulmonary dysplasia. Pediatr Res 2010;67:83-9

19. Panos RJ, Bak PM, Simonet WS, Rubin JS, Smith LJ. Intratracheal instillation of keratinocyte growth factor decreases hyperoxia-induced mortality in rats. J Clin Invest 1995;96:2026-33

20. Barazzone C, Donati YR, Rochat AF, Vesin C, Kan CD, Pache JC, Piguet PF. Keratinocyte growth factor protects alveolar epithelium and endothelium from oxygen-induced injury in mice. Am J Pathol 1999;154:1479-87

21. Yano T, Deterding RR, Simonet WS, Shannon JM, Mason RJ. Keratinocyte growth factor reduces lung damage due to acid instillation in rats. Am J Respir Cell Mol Biol 1996;15:433-42

22. Ulrich K, Stern M, Goddard ME, Williams J, Zhu J, Dewar A, Painter HA, Jeffery PK, Gill DR, Hyde SC, Geddes DM, Takata M, Alton EW. Keratinocyte growth factor therapy in murine oleic acid-induced acute lung injury. Am J Physiol Lung Cell Mol Physiol 2005;288:L1179-92

23. Ray P. Protection of epithelial cells by keratinocyte growth factor signaling. Proc Am Thorac Soc 2005;2:221-5

24. Yi ES, Williams ST, Lee H, Malicki DM, Chin EM, Yin S, Tarpley J, Ulich TR. Keratinocyte growth factor ameliorates radiation- and bleomycin-induced lung injury and mortality. Am J Pathol 1996;149:1963-70

25. Deterding RR, Havill AM, Yano T, Middleton SC, Jacoby CR, Shannon JM, Simonet WS, Mason RJ. Prevention of bleomycin-induced lung injury in rats by keratinocyte growth factor. Proc Assoc Am Physicians 1997;109:254-68

26. Danan C, Franco ML, Jarreau PH, Dassieu G, Chailley-Heu B, Bourbon J, Delacourt C. High concentrations of keratinocyte growth factor in airways of premature infants predicted absence of bronchopulmonary dysplasia. Am J Respir Crit Care Med 2002;165:1384-7

27. Atabai K, Ishigaki M, Geiser T, Ueki I, Matthay MA, Ware LB. Keratinocyte growth factor can enhance alveolar epithelial repair by nonmitogenic mechanisms. Am J Physiol Lung Cell Mol Physiol 2002;283:L1639

28. Roberts JR, Perkins GD, Fujisawa T, Pettigrew KA, Gao F, Ahmed A, Thickett DR. Vascular endothelial growth factor promotes physical wound repair and is anti-apoptotic in primary distal lung epithelial and A549 cells. Crit Care Med 2007;35:2164-70

29. Galiacy S, Planus E, Lepetit H, Fereol S, Laurent V, Ware L, Isabey D, Matthay M, Harf A, d'Ortho MP. Keratinocyte growth factor promotes cell motility during alveolar epithelial repair in vitro. Exp Cell Res 2003;283:215-29

30. Bjorklund $\mathrm{J}$, Ingimarsson J, Curstedt T, John J, Robertson B, Werner O, Vilstrup CT. Manual ventilation with a few large breaths at birth compromises the therapeutic effect of subsequent surfactant replacement in immature lambs. Pediatr Res 1997;42:348-55 
31. Hillman NH, Moss TJ, Kallapur SG, Bachurski C, Pillow JJ, Polglase GR, Nitsos I, Kramer BW, Jobe AH. Brief, large tidal volume ventilation initiates lung injury and a systemic response in fetal sheep. Am J Respir Crit Care Med 2007;176:575-81

32. Ryan RM, Ahmed Q, Lakshminrusimha S. Inflammatory mediators in the immunobiology of bronchopulmonary dysplasia. Clin Rev Allergy Immunol 2008;34:174-90

33. Kramer BW, Kallapur S, Newnham J, Jobe AH. Prenatal inflammation and lung development. Semin Fetal Neonatal Med 2009;14:2-7

34. Ikegami $\mathrm{M}$, Jobe $\mathrm{AH}$. Postnatal lung inflammation increased by ventilation of preterm lambs exposed antenatally to Escherichia coli endotoxin. Pediatr Res 2002;52:356-62

35. Thebaud B, Abman SH. Bronchopulmonary dysplasia: where have all the vessels gone? Roles of angiogenic growth factors in chronic lung disease. Am J Respir Crit Care Med 2007;175:978-85

36. Perkins GD, Roberts J, McAuley DF, Armstrong L, Millar A, Gao F, Thickett DR. Regulation of vascular endothelial growth factor bioactivity in patients with acute lung injury. Thorax 2005;60:153-8

37. McEvoy C, Bowling S, Williamson K, Stewart M, Durand M. Functional residual capacity and passive compliance measurements after antenatal steroid therapy in preterm infants. Pediatr Pulmonol 2001;31:42530

38. Dorscheid DR, Patchell BJ, Estrada O, Marroquin B, Tse R, White SR. Effects of corticosteroid-induced apoptosis on airway epithelial wound closure in vitro. Am J Physiol Lung Cell Mol Physiol 2006;291:L794801

39. Wadsworth SJ, Nijmeh HS, Hall IP. Glucocorticoids increase repair potential in a novel in vitro human airway epithelial wounding model. J Clin Immunol 2006;26:376-87

40. Schwab M, Coksaygan T, Samtani MN, Jusko WJ, Nathanielsz PW. Kinetics of betamethasone and fetal cardiovascular adverse effects in pregnant sheep after different doses. Obstet Gynecol 2006;108:617-25

41. Been JV, Kramer BW, Zimmermann LJ. Antenatal corticosteroids to prevent preterm birth. Lancet 2009;373:894 


\section{Chapter 6}

Early alterations of growth factor patterns

in bronchoalveolar lavage fluid from preterm

infants developing bronchopulmonary

dysplasia

Been JV, Debeer A, van Iwaarden JF, Kloosterboer $N$,

Lima Passos $V$, Naulaers $G$, Zimmermann $L J$

Pediatr Res 2010; 67: 83-9 


\section{Abstract}

Chronic lung disease of prematurity (bronchopulmonary dysplasia; BPD) is characterized by an arrest in lung development. We hypothesized that early alterations in pulmonary expression of growth factors important for normal lung development would precede development of BPD.

Bronchoalveolar lavage fluid (BALF) was obtained from ventilated preterm infants $(n=$ 62) on postnatal d 0, 1, 3, and 7 and analyzed for total phospholipids (PL), VEGF, PDGF-BB, TGF- $\alpha$ and $-\beta 1$, granulocyte macrophage colony stimulating factor (GM-CSF), and keratinocyte growth factor (KGF). Levels (Ln transformed) were compared between infants developing BPD and BPD-free survivors, adjusted for potential confounders.

BPD was associated with higher overall GM-CSF $(\beta(95 \% \mathrm{Cl})=0.69(0.13 ; 1.25) ; p<$ $0.05)$, lower overall latent TGF- $\beta 1(\beta(95 \% \mathrm{Cl})=-1.19(-1.87,-0.39) ; p<0.01)$ and total PL $(\beta(95 \% \mathrm{Cl})=-0.64(-1.23,-0.05) ; p<0.05)$, and lower $d 0$ and 3 levels of VEGF (mean difference $(95 \% \mathrm{Cl})=-1.75(-2.72,-0.77), p<0.001$; and $-1.18(-2.30,-0.06), p<0.05$, respectively) and TGF- $\alpha$ (mean difference $(95 \% \mathrm{Cl})=-0.73(-1.42,-0.04), p<0.05$; and $1.01(-1.64,-0.38), p<0.01$, respectively). Day 0 VEGF levels had the highest predictive value for BPD (area under receiver operating characteristic curve $=0.87 ; p<0.01$ ).

In conclusion, substantial alterations in BALF growth factor levels are present in infants developing BPD. An early imbalance in pulmonary growth factors may contribute to the developmental arrest of the lung seen in BPD. 


\section{Introduction}

Bronchopulmonary dysplasia (BPD) is a chronic lung disease seen in preterm infants, affecting around $35 \%$ of extremely low-birth weight infants. BPD is associated with recurrent respiratory infections, frequent rehospitalization, and adverse neurodevelopmental outcome. The classical BPD picture of emphysema, inflammation, and fibrosis, as originally described by Northway et al. ${ }^{1}$, has been replaced by one best characterized as an arrest in lung development ${ }^{2}$. This shift coincided with the introduction of surfactant replacement therapy and antenatal steroid administration, which have allowed smaller and less mature infants to survive.

The pathophysiology of BPD is complex and is an interplay between iatrogenic injury due to both mechanical ventilation and oxygen supplementation and other factors such as genetic predisposition and inflammation ${ }^{3}$. The latter has been shown to predispose the infant to BPD already before birth, as indicated by the relationship between chorioamnionitis and adverse lung development ${ }^{4,5}$. In recent years, accumulating evidence indicates that growth factors play an important role in the developmental arrest of the lung seen in "new BPD" 3,6. However, much of this evidence is derived from experimental animal data. Studies on pulmonary growth factor concentrations and indicators of lung maturation in preterm infants are scarce. Most of them report on analyses on tracheal aspirate fluid (TAF), retrieving epithelial lining fluid of more proximal origin than bronchoalveolar lavage $(B A L)^{7}$. Moreover, very few studies have investigated concurrent coexpression of various growth factors in human specimens.

The objective of this study was to simultaneously quantify concentrations of several growth factors in BAL fluid (BALF) obtained from ventilated preterm infants during the first week after birth. Growth factors were selected based on their previously demonstrated roles in lung development and chronic lung injury. VEGF is a known stimulant of alveolarization and vascularization and is invaluable for normal lung development ${ }^{3,8}$. Keratinocyte growth factor (KGF) is an epithelial mitogen with an important role in lung injury repair ${ }^{9}$, while PDGF-BB has been linked to compensatory lung growth ${ }^{10}$, in addition to adverse lung development and fibrosis ${ }^{11}$. The hematopoietic cytokine granulocyte macrophage colony stimulating factor (GM-CSF) is up-regulated by inflammation ${ }^{12}$ and plays an important role in surfactant homeostasis ${ }^{13}$. TGF- $\alpha$ disrupts lung morphogenesis in mice ${ }^{14}$ and has been implicated in the pathogenesis of BPD ${ }^{15}$. Finally, TGF- $\beta 1$ is a cytokine essential for normal lung development ${ }^{16}$, although its overexpression decreases alveolarization in animal models ${ }^{17}$. It was hypothesized that early differences in BALF expression patterns of these growth factors would be present between infants who eventually developed BPD and those who did not. In addition, we quantified BALF total phospholipids (PL) as a general measure of lung maturation. 


\section{Materials and methods}

\section{Patient characteristics and enrolment}

Patients were eligible for the study if they were born before 32-wk gestational age and ventilated for respiratory distress syndrome (RDS). Patients were enrolled in the NICUs of the University Hospitals in Maastricht and Leuven. The Medical Ethical Committees of both hospitals have approved the study and written parental consent was obtained. BPD was diagnosed according to Jobe and Bancalari ${ }^{18}$. Chorioamnionitis was diagnosed histologically when $>10$ neutrophils per high power field were present in the chorion or amnion. Betamethasone ( $2 \times 12 \mathrm{mg}$ i.m., $24 \mathrm{~h}$ apart) was administered to the mother in case of imminent preterm delivery.

\section{BALF collection and processing}

BAL was performed at postnatal d 0 (within $24 \mathrm{~h}$ after birth), 1, 3-4, and 7 according to a standard procedure. After turning the infant's head to the left, a $6 \mathrm{~F}$ suction catheter was inserted through a side port of the Trachcare closed suctioning system until slight resistance was felt. Then, $1 \mathrm{~mL} / \mathrm{kg}$ birth weight of sterile isotonic saline was gently infused into the lung. After $5 \mathrm{~s}$, suctioning was performed while slowly retracting the catheter. The procedure was repeated once after which the collected fluid was pooled and placed on ice. After centrifugation for $10 \mathrm{~min}$ at $4^{\circ} \mathrm{C}$ and $300 \times \mathrm{g}$, the supernatant was collected, aliquoted, and stored at $-80^{\circ} \mathrm{C}$ until analysis.

\section{Quantification of growth factors and total $P L$ in BALF}

VEGF, KGF, PDGF-BB, GM-CSF, TGF- $\alpha$, and TGF- $\beta 1$ and were quantified by ELISA (R\&D systems, Minneapolis, MN) according to the manufacturer's instructions, in half-area 96well ELISA plates (Greiner Bio-one, Alphen a/d Rijn, The Netherlands). Both active and total (latent + active) TGF- $\beta 1$ were quantified. The concentration of latent TGF- $\beta 1$ was obtained by subtracting the amount of active TGF- $\beta 1$ from the total TGF- $\beta 1$, quantified after acid activation of each individual sample. As a general measure of BALF surfactant content, total PL were quantified according to Stewart ${ }^{19}$, with minor modifications to analyze small quantities. Briefly, fluid was evaporated from $15 \mu \mathrm{L}$ of BALF by heating at $50^{\circ} \mathrm{C}$ under continuous nitrogen gas flow. The dried material was reconstituted in $100 \mu \mathrm{L}$ of chloroform and vortexed. Then, $50 \mu \mathrm{L}$ of ammonium ferrothiocyanate was added, and the mixture was vortexed thoroughly for $30 \mathrm{~s}$. The organic phase (containing the stained $\mathrm{PL}$ ) was separated from the inorganic phase by centrifugation (10 $\mathrm{min}, 2000 \mathrm{rpm}$ ). Then, $75 \mu \mathrm{L}$ of the organic phase of each sample was transferred into a 96-well glass-coated microtiter plate (Instrument Solutions, Nieuwegein, The Netherlands), and extinction was measured at $488 \mathrm{~nm}$ in a Spectra Max M2 photospectrometer using a phosphatidylcholine standard curve (range, 0-200 $\mu \mathrm{g} / \mathrm{mL}$ ). Growth factor and PL concentrations were considered detectable when they were above background levels of their respective assays. All 
concentrations are expressed per milliliter of BALF retrieved according to European Respiratory Society task force guidelines ${ }^{20}$.

\section{Univariable analyses}

Data are expressed as mean \pm SD or median with interquartile range (IQR) where appropriate. Correspondingly, differences between groups were tested using either $t$ test or Mann-Whitney $U$ test. Dichotomous variables were tested using $\chi^{2}$ test. Correlations between variables were determined using Spearman's $\rho$ correlation coefficient.

\section{Multivariable analyses - the marginal model}

To obtain a more symmetric distribution of the positively skewed growth factor levels while appreciating undetectable levels (which were entered as “ 0 "), concentrations were transformed using the following formula: Ln ([growth factor] + 1). Marginal models were fitted to evaluate average changes in transformed growth factor concentrations over time between infants with or without BPD, adjusting for other potential confounders (21). Individual infants were taken as random factor and time (categorized) as well as the other explanatory variables constituted the model's fixed effect part. A top down procedure was handled for variable selection, except for BPD and gestational age, which were always kept in the model. Model parameters were estimated via the restricted maximum likelihood method. The final variance-covariance matrix was selected via likelihood ratio tests. Based on the estimated mean transformed growth factor values, Bonferroni post hoc analysis was applied for multiple pairwise comparisons between groups and time points. For marginal model analysis, infants with mild, moderate, and severe BPD were clustered in a single BPD category. Antenatal betamethasone exposure was categorized according to time between exposure and birth ( $<24 \mathrm{~h}, 2-7 \mathrm{~d}$, and $>7 \mathrm{~d}$ ). One of the advantages of the marginal model analysis is that all individual data are used for the parameters estimation, not only of those subjects with complete data ${ }^{21}$. To check whether the occurrence of missing values depended on the predictors at stake, a logistic regression model was applied. Explanatory variables significantly associated with missingness were kept in the final marginal model.

\section{Multivariable analyses-logistic regression for prediction of $B P D$}

Backward logistic regression analysis was performed to evaluate which combination of growth factors in BALF best predicted the development of BPD at each postnatal day. Receiver operating characteristic (ROC) curves for BPD prediction were computed using individual predicted probabilities derived from the final logistic regression model. In all analyses, an alpha level of 0.05 was applied (two-tailed). All analyses were performed using SPSS 15.0 software. 


\section{Results}

\section{General characteristics}

One hundred twenty-one BALF specimens were obtained from 62 patients. At 36-wk PMA, 34 patients fulfilled the diagnostic criteria of BPD. In further analyses, the latter are compared with patients alive without BPD at 36-wk PMA $(n=21)$. Seven patients had died and were excluded from further analyses. General characteristics, ventilatory settings, and oxygen requirement for patients with and without BPD are shown in Table 1. Infants who developed BPD were more often born to mothers with preeclampsia, had lower birth weight, and had higher oxygen requirement just before BALF collection on $\mathrm{d} 0$ and 1 .

Table 1. General characteristics and ventilatory requirements of infants included in the study. ${ }^{*} p<0.001 .^{\dagger} p<$ 0.05 . ${ }^{\ddagger} \mathrm{p}<0.01$. $\mathrm{FiO}_{2}$, fraction of inspired oxygen; MAP, mean airway pressure.

\begin{tabular}{|c|c|c|c|}
\hline & & No $B P D(n=21)$ & $B P D(n=34)$ \\
\hline \multicolumn{2}{|l|}{ Gestational age (wks) } & $29.0 \pm 1.8$ & $28.0 \pm 1.8$ \\
\hline \multicolumn{2}{|l|}{ Birth weight (g) } & $1212 \pm 136$ & $1005 \pm 263^{*}$ \\
\hline \multicolumn{2}{|l|}{ Histological chorioamnionitis (\%) } & 19 & 17 \\
\hline \multicolumn{2}{|l|}{ Preeclampsia (\%) } & 10 & $38^{+}$ \\
\hline \multicolumn{2}{|r|}{$<24$ hrs before birth } & 33 & 24 \\
\hline \multirow[t]{3}{*}{ Antenatal steroids } & 1-7 days before birth & 14 & 38 \\
\hline & >7 days before birth & 33 & 27 \\
\hline & day 0 & $28 \pm 10$ & $52 \pm 25^{\ddagger}$ \\
\hline \multirow{4}{*}{$\begin{array}{l}\text { Mean } \mathrm{FiO}_{2} \\
0-6 \text { hrs before BAL (\%) }\end{array}$} & day 1 & $25 \pm 5$ & $32 \pm 10^{\dagger}$ \\
\hline & day 3 & $25 \pm 7$ & $27 \pm 6$ \\
\hline & day 7 & $24 \pm 3$ & $26 \pm 6$ \\
\hline & day 0 & $8.8 \pm 2.4$ & $8.6 \pm 2.4$ \\
\hline \multirow{3}{*}{$\begin{array}{l}\text { Mean MAP } \\
0-6 \text { hrs before } B A L\left(\mathrm{~cm} \mathrm{H}_{2} \mathrm{O}\right)\end{array}$} & day 1 & $8.2 \pm 2.7$ & $8.3 \pm 2.4$ \\
\hline & day 3 & $7.9 \pm 2.0$ & $8.2 \pm 2.4$ \\
\hline & day 7 & $8.3 \pm 2.0$ & $9.2 \pm 1.9$ \\
\hline \multirow{4}{*}{ BALF specimens collected ( $n$ ) } & day 0 & 11 & 14 \\
\hline & day 1 & 9 & 24 \\
\hline & day 3 & 13 & 20 \\
\hline & day 7 & 3 & 13 \\
\hline
\end{tabular}

\section{Univariable analyses}

Growth factor and total PL concentrations for infants who did and those who did not develop BPD are shown in Table 2. In unadjusted analyses, patients developing BPD had lower VEGF on $d 0$ and 3 , lower TGF- $\alpha$ on $d 0$, and latent TGF- $\beta 1$ on $d 0$. Conversely, both GM-CSF and active TGF- $\beta 1$ were more likely to be detected in infants developing BPD on $d$ 
7. Infants with BPD had a higher active versus latent TGF- $\beta 1$ ratio on $\mathrm{d} 3$ [mean $(\mathrm{Cl})=0.06$ (0.02-0.27) vs 0.01 (0.01-0.03); not shown]. Significant positive correlations were observed between BALF levels of several growth factors on each postnatal day (Table 3 ). Moreover, total PL correlated with levels of VEGF and both active and latent TGF- $\beta 1$ on several days.

\section{Multivariable analyses - the marginal model}

Figure 1 shows BALF growth factor and total PL concentrations as predicted by the marginal model for infants with BPD and those without. For ease of graphical display, model predicted values were transformed back to represent growth factor levels in picograms per milliliter. Model parameter estimates for each growth factor are shown in Table 4. For all marginal models, a diagonal covariance matrix of the outcome responses was selected as the most appropriate.

BPD was associated with increased GM-CSF but lower latent TGF- $\beta 1$ and total PL during the entire study period in these analyses (Fig. 1D, E, and $H$ ). For VEGF and TGF- $\alpha$, the interaction term (BPD $\times$ time) was retained in the model because of its significant contribution, thus allowing for time dependent effect of BPD status on growth factor concentration (Table 4). Pairwise comparisons for individual time points showed BPD to be associated with decreased levels of both VEGF and TGF- $\alpha$ on $d 0$ and 3 [VEGF: mean difference $(95 \% \mathrm{Cl})=-1.75(-2.72,-0.77), p<0.001$; and $-1.18(-2.30,-0.06), p=0.04$, respectively (Fig. $1 A)$; TGF- $\alpha$ : mean difference $(95 \% \mathrm{Cl})=-0.73(-1.42,-0.04), p=0.04$; and $-1.01(-$ $1.64,-0.38), p=0.003$, respectively (Fig. 1E)]. Marginal model analysis showed no significant association between BPD and BALF concentrations of KGF, PDGF-BB, and active TGF$\beta 1$.

From the marginal model analyses, several other variables emerged as significant independent predictors of bronchoalveolar growth factor concentrations (Table 4). KGF and VEGF concentrations were shown to increase with advancing gestational age. Conversely, preeclampsia was associated with decreased VEGF, KGF, and GM-CSF. Both antenatal steroid exposure $>7 \mathrm{~d}$ before birth and exposure to high fraction of inspired oxygen were associated with increased levels of PDGF-BB. Importantly, no explanatory variable was associated with whether data were missing (BALF not obtained).

\section{Multivariate analyses-ROC curves}

Development of BPD was best predicted using a combination of VEGF and TGF- $\alpha$ levels on $\mathrm{d} O$ [area under the ROC curve $(A \cup C)=0.92(0.82-1.03) ; p<0.001$ ]. A slightly lower predictive value was obtained using VEGF, TGF- $\alpha$, and latent TGF- $\beta 1$ levels on d 3 [AUC $=0.88$ $(0.74-1.01) ; p<0.001$ ]. The best single predictor was VEGF on $d 0$ ( $A \cup C=0.87, p=0.002$ ). 
Table 2. Growth factor and total phospholipids concentrations in bronchoalveolar lavage fluid from infants who did or did not develop bronchopulmonary dysplasia (BPD and no BPD, respectively). ${ }^{*} p<0.01$ vs no BPD. $+p<0.05$.

\begin{tabular}{|c|c|c|c|c|c|}
\hline & \multirow[b]{2}{*}{ Day } & \multicolumn{2}{|c|}{ Concentration (median (IQR)) } & \multicolumn{2}{|c|}{ Detectable (\%) } \\
\hline & & no $B P D$ & $B P D$ & no $B P D$ & $B P D$ \\
\hline \multirow{4}{*}{$\begin{array}{l}V E G F \\
(p g / m l)\end{array}$} & 0 & $28(12-73)$ & $5(1-15)^{*}$ & 100 & 79 \\
\hline & 1 & $43(16-60)$ & $27(10-61)$ & 100 & 96 \\
\hline & 3 & $205(91-291)$ & $47(26-98)^{*}$ & 100 & 90 \\
\hline & 7 & $223(30-469)$ & $102(59-212)$ & 100 & 100 \\
\hline \multirow{4}{*}{$\begin{array}{l}K G F \\
(p g / m l)\end{array}$} & 0 & $5(0-29)$ & $4(0-15)$ & 64 & 57 \\
\hline & 1 & $0(0-8)$ & $6(0-18)$ & 33 & 58 \\
\hline & 3 & $8(0-28)$ & $9(1-18)$ & 69 & 75 \\
\hline & 7 & $0(0-6)$ & $2(0-9)$ & 33 & 62 \\
\hline \multirow{3}{*}{$\begin{array}{l}P D G F-B B \\
(\mathrm{pg} / \mathrm{ml})\end{array}$} & 0 & $0(0-8)$ & $2(0-6)$ & 46 & 64 \\
\hline & 1 & $0(0-7)$ & $0(0-4)$ & 44 & 33 \\
\hline & 3 & $10(4-22)$ & $5(2-16)$ & 100 & 95 \\
\hline \multirow{5}{*}{$\begin{array}{l}\text { GM-CSF } \\
(\mathrm{pg} / \mathrm{ml})\end{array}$} & 7 & $0(0-7)$ & $5(3-11)$ & 33 & 85 \\
\hline & 0 & $2(1-5)$ & $2(1-8)$ & 82 & 93 \\
\hline & 1 & $6(2-8)$ & $3(1-13)$ & 89 & 88 \\
\hline & 3 & $53(21-123)$ & 65 (13-162) & 100 & 95 \\
\hline & 7 & $15(0-38)$ & 29 (7-97) & 67 & $100^{+}$ \\
\hline \multirow{3}{*}{$\begin{array}{l}\text { TGF- } \alpha \\
(\mathrm{pg} / \mathrm{ml})\end{array}$} & 0 & $7(5-16)$ & $4(1-7)$ & 100 & 100 \\
\hline & 1 & $2(1-7)$ & $3(2-5)$ & 100 & 100 \\
\hline & 3 & $5(2-8)$ & $2(0-2)^{*}$ & 100 & 85 \\
\hline \multirow{5}{*}{$\begin{array}{l}\text { active TGF- } \beta 1 \\
(\mathrm{pg} / \mathrm{ml})\end{array}$} & 7 & $3(1-4)$ & $2(0-5)$ & 100 & 85 \\
\hline & 0 & $4(1-6)$ & $2(0-4)$ & 91 & 57 \\
\hline & 1 & $5(4-6)$ & $4(0-9)$ & 100 & 71 \\
\hline & 3 & $8(5-8)$ & $9(4-16)$ & 92 & 95 \\
\hline & 7 & $0(0-21)$ & $11(7-21)$ & 33 & $100 *$ \\
\hline \multirow{3}{*}{$\begin{array}{l}\text { latent TGF- } \beta 1 \\
(\mathrm{pg} / \mathrm{ml})\end{array}$} & 0 & $132(60-176)$ & $17(2-47)^{*}$ & 100 & 79 \\
\hline & 1 & 95 (51-249) & $72(15-132)$ & 100 & 92 \\
\hline & 3 & $260(53-566)$ & $58(11-213)$ & 77 & 80 \\
\hline \multirow{5}{*}{$\begin{array}{l}\text { Total PL } \\
(\mu \mathrm{g} / \mathrm{ml})\end{array}$} & 7 & $276(44-348)$ & $256(128-475)$ & 100 & 100 \\
\hline & 0 & $161(43-246)$ & $22(0-162)$ & 91 & 71 \\
\hline & 1 & $37(19-195)$ & $44(18-89)$ & 100 & 100 \\
\hline & 3 & $85(55-221)$ & $73(31-120)$ & 100 & 96 \\
\hline & 7 & $92(70-115)$ & $55(32-118)$ & 100 & 100 \\
\hline
\end{tabular}


Table 3. Significant correlations between bronchoalveolar lavage levels of individual growth factors and total phospholipids (PL) on different postnatal days. Numbers represent $R^{2}$ values. ${ }^{*} p<0.001 .{ }^{\dagger} p<0.01 .{ }^{\ddagger} p<0.05$.

\begin{tabular}{|c|c|c|c|c|c|c|c|c|}
\hline & Day & $\begin{array}{l}\text { latent } \\
\text { TGF- } \beta 1\end{array}$ & $\begin{array}{l}\text { active } \\
\text { TGF- } \beta 1\end{array}$ & $T G F-\alpha$ & GM-CSF & PDGF-BB & $K G F$ & VEGF \\
\hline \multirow[t]{4}{*}{ Total PL } & 0 & $.34^{*}$ & $.25^{\dagger}$ & $.19^{\ddagger}$ & - & - & - & - \\
\hline & 1 & - & - & - & - & - & - & - \\
\hline & 3 & - & - & - & - & - & - & $.13^{\ddagger}$ \\
\hline & 7 & $.56^{\dagger}$ & - & - & - & - & - & $.38^{\ddagger}$ \\
\hline \multirow[t]{4}{*}{ VEGF } & 0 & $.36^{*}$ & $.29^{+}$ & $.13^{\ddagger}$ & - & - & $.18^{\ddagger}$ & \\
\hline & 1 & $.15^{\ddagger}$ & $.14^{\ddagger}$ & $.14^{\ddagger}$ & - & - & - & \\
\hline & 3 & $.12^{\ddagger}$ & - & $.24^{+}$ & $.24^{+}$ & $.20^{+}$ & - & \\
\hline & 7 & $.48^{+}$ & $.25^{\ddagger}$ & - & $.62^{*}$ & - & - & \\
\hline \multirow[t]{4}{*}{$K G F$} & 0 & $.17^{\ddagger}$ & $.22^{+}$ & $.25^{+}$ & - & $.25^{+}$ & & \\
\hline & 1 & - & - & - & - & - & & \\
\hline & 3 & - & - & - & $.27^{+}$ & $.46^{*}$ & & \\
\hline & 7 & - & - & - & - & $.36^{\ddagger}$ & & \\
\hline \multirow[t]{4}{*}{ PDGF-BB } & 0 & - & $.14^{\ddagger}$ & $.31^{+}$ & - & & & \\
\hline & 1 & $.23^{+}$ & - & $.48 *$ & - & & & \\
\hline & 3 & - & - & - & $.38^{*}$ & & & \\
\hline & 7 & - & $.48^{+}$ & - & - & & & \\
\hline \multirow[t]{4}{*}{ GM-CSF } & 0 & - & - & - & & & & \\
\hline & 1 & - & - & - & & & & \\
\hline & 3 & - & - & - & & & & \\
\hline & 7 & $.28^{\ddagger}$ & $.43^{+}$ & - & & & & \\
\hline \multirow[t]{4}{*}{$T G F-\alpha$} & 0 & $.62^{*}$ & $.15^{+}$ & & & & & \\
\hline & 1 & $.60^{*}$ & $.14^{\ddagger}$ & & & & & \\
\hline & 3 & $.38^{*}$ & - & & & & & \\
\hline & 7 & - & - & & & & & \\
\hline \multirow[t]{4}{*}{ active TGF- $\beta 1$} & 0 & $.32^{+}$ & & & & & & \\
\hline & 1 & $.44 *$ & & & & & & \\
\hline & 3 & - & & & & & & \\
\hline & 7 & $.39^{\dagger}$ & & & & & & \\
\hline
\end{tabular}


Table 4 (part 1). Parameter estimates and Cls from the marginal models for individual growth factors and total $\mathrm{PL}$ in bronchoalveolar lavage fluid. Figures represent $\beta(95 \% \mathrm{Cl})$ per unit increase for continuous factors or vs the reference group for nominal factors. ${ }^{*} \mathrm{p}<0.05{ }^{\dagger} \mathrm{p}<0.01 . \mathrm{FiO}_{2}$, fraction of inspired oxygen.

\begin{tabular}{|c|c|c|c|c|}
\hline Parameter & VEGF & $K G F$ & $P D G F-B B$ & $G M-C S F$ \\
\hline Intercept & $\begin{array}{l}-0.82 \\
(-5.04 ; 3.41)\end{array}$ & $\begin{array}{l}-4.68 \\
(-9.98 ; 0.61)\end{array}$ & $\begin{array}{l}-1.55 \\
(-5.70 ; 2.57)\end{array}$ & $\begin{array}{l}-1.58 \\
(-5.61 ; 2.44)\end{array}$ \\
\hline Day 1 (vs. day 0) & $\begin{array}{l}-0.11 \\
(-1.21 ; 0.98)\end{array}$ & $\begin{array}{l}-0.03 \\
(-0.89 ; 0.84)\end{array}$ & $\begin{array}{l}0.01 \\
(-0.75 ; 0.75)\end{array}$ & $\begin{array}{l}0.40 \\
(-0.22 ; 1.02)\end{array}$ \\
\hline Day 3 (vs. day 0) & $\begin{array}{l}1.54 \\
(0.49 ; 2.60)^{\dagger}\end{array}$ & $\begin{array}{l}0.46 \\
(-0.41 ; 1.34)\end{array}$ & $\begin{array}{l}1.29 \\
(0.50 ; 2.08)^{\dagger}\end{array}$ & $\begin{array}{l}2.44 \\
(1.71 ; 3.17)^{\dagger}\end{array}$ \\
\hline Day 7 (vs. day 0) & $\begin{array}{l}1.18 \\
(-0.58 ; 2.94)\end{array}$ & $\begin{array}{l}-0.31 \\
(-1.19 ; 0.58)\end{array}$ & $\begin{array}{l}1.08 \\
(-0.16 ; 2.01)\end{array}$ & $\begin{array}{l}1.51 \\
(0.69 ; 2.33)^{\dagger}\end{array}$ \\
\hline$B P D$ & $\begin{array}{l}-1.74 \\
(-2.72 ;-0.77)^{+}\end{array}$ & $\begin{array}{l}0.53 \\
(-0.15 ; 1.21)\end{array}$ & $\begin{array}{l}-0.13 \\
(-0.70 ; 0.43)\end{array}$ & $\begin{array}{l}0.69 \\
(0.13 ; 1.25)^{*}\end{array}$ \\
\hline$B P D x$ day 1 & $\begin{array}{l}1.89 \\
(0.51 ; 3.27)^{+}\end{array}$ & - & - & - \\
\hline$B P D \times$ day 3 & $\begin{array}{l}0.57 \\
(-0.82 ; 1.95)\end{array}$ & - & - & - \\
\hline$B P D x$ day 7 & $\begin{array}{l}2.01 \\
(0.01 ; 4.01)^{*}\end{array}$ & - & - & - \\
\hline $\begin{array}{l}\text { GA } \\
\text { (per wk increase) }\end{array}$ & $\begin{array}{l}0.15 \\
(0.01 ; 0.30)^{*}\end{array}$ & $\begin{array}{l}0.23 \\
(0.04 ; 0.41)^{*}\end{array}$ & $\begin{array}{l}0.05 \\
(-0.09 ; 0.26)\end{array}$ & $\begin{array}{l}0.10 \\
(-0.04 ; 0.23)\end{array}$ \\
\hline Chorioamnionitis & - & $\begin{array}{l}-0.74 \\
(-1.52 ; 0.04)\end{array}$ & - & - \\
\hline Preeclampsia & $\begin{array}{l}-0.93 \\
(-1.52 ;-0.34)^{+}\end{array}$ & $\begin{array}{l}-0.96 \\
(-1.66 ;-0.25)^{+}\end{array}$ & $\begin{array}{l}-0.63 \\
(-1.27 ; 0.01)\end{array}$ & $\begin{array}{l}-1.09 \\
(-1.66 ;-0.53)^{\dagger}\end{array}$ \\
\hline $\begin{array}{l}\text { Antenatal steroids } \\
<24 \text { hrs before birth }\end{array}$ & - & - & $\begin{array}{l}0.43 \\
(-0.32 ; 1.17)\end{array}$ & - \\
\hline $\begin{array}{l}\text { Antenatal steroids } \\
\text { 2-7 days before birth }\end{array}$ & - & - & $\begin{array}{l}0.46 \\
(-0.43 ; 1.35)\end{array}$ & - \\
\hline $\begin{array}{l}\text { Antenatal steroids } \\
\text { >7 days before birth }\end{array}$ & - & - & $\begin{array}{l}1.25 \\
(0.44 ; 1.35)^{\dagger}\end{array}$ & - \\
\hline $\begin{array}{l}\mathrm{FiO}_{2} \\
\text { (per } 0.1 \text { increase) }\end{array}$ & - & - & $\begin{array}{l}0.25 \\
(0.04 ; 0.46)^{*}\end{array}$ & - \\
\hline
\end{tabular}


Table 4 (part 2). Parameter estimates and Cls from the marginal models for individual growth factors and total $\mathrm{PL}$ in bronchoalveolar lavage fluid. Figures represent $\beta(95 \% \mathrm{Cl})$ per unit increase for continuous factors or vs the reference group for nominal factors. ${ }^{*} \mathrm{p}<0.05{ }^{\dagger} \mathrm{p}<0.01$. $\mathrm{FiO}_{2}$, fraction of inspired oxygen.

\begin{tabular}{|c|c|c|c|c|}
\hline Parameter & $T G F-\alpha$ & active TGF- $\beta 1$ & latent TGF- $\beta 1$ & total $P L$ \\
\hline Intercept & $\begin{array}{l}3.40 \\
(0.77 ; 6.03)^{*}\end{array}$ & $\begin{array}{l}1.18 \\
(-2.84 ; 5.20)\end{array}$ & $\begin{array}{l}1.62 \\
(-4.00 ; 7.23)\end{array}$ & $\begin{array}{l}0.89 \\
(-3.52 ; 5.29)\end{array}$ \\
\hline Day 1 (vs. day 0) & $\begin{array}{l}-1.00 \\
(-1.68 ;-0.31)^{\dagger}\end{array}$ & $\begin{array}{l}0.15 \\
(-0.38 ; 0.69)\end{array}$ & $\begin{array}{l}0.90 \\
(0.03 ; 1.77)^{*}\end{array}$ & $\begin{array}{l}0.21 \\
(-0.78 ; 1.19)\end{array}$ \\
\hline Day 3 (vs. day 0) & $\begin{array}{l}-0.34 \\
(-0.99 ; 0.32)\end{array}$ & $\begin{array}{l}0.97 \\
(0.43 ; 1.51)^{+}\end{array}$ & $\begin{array}{l}0.61 \\
(-0.47 ; 1.69)\end{array}$ & $\begin{array}{l}0.46 \\
(-0.54 ; 1.46)\end{array}$ \\
\hline Day 7 (vs. day 0) & $\begin{array}{l}-1.15 \\
(-2.32 ;-0.01)\end{array}$ & $\begin{array}{l}1.03 \\
(0.30 ; 1.76)^{+}\end{array}$ & $\begin{array}{l}2.21 \\
(1.17 ; 3.24)^{+}\end{array}$ & $\begin{array}{l}0.66 \\
(-0.35 ; 1.66)\end{array}$ \\
\hline$B P D$ & $\begin{array}{l}-0.73 \\
(-1.42 ;-0.04)^{*}\end{array}$ & $\begin{array}{l}-0.05 \\
(-0.54 ; 0.43)\end{array}$ & $\begin{array}{l}-1.19 \\
(-1.87 ;-0.39)^{+}\end{array}$ & $\begin{array}{l}-0.64 \\
(-1.23 ;-0.05)^{*}\end{array}$ \\
\hline$B P D \times$ day 1 & $\begin{array}{l}0.86 \\
(-0.02 ; 1.75)\end{array}$ & - & - & - \\
\hline$B P D \times$ day 3 & $\begin{array}{l}-0.29 \\
(-1.16 ; 0.59)\end{array}$ & - & - & - \\
\hline$B P D \times$ day 7 & $\begin{array}{l}0.36 \\
(-0.98 ; 1.69)\end{array}$ & - & - & - \\
\hline $\begin{array}{l}\text { GA } \\
\text { (per wk increase) }\end{array}$ & $\begin{array}{l}-0.04 \\
(-0.13 ; 0.05)\end{array}$ & $\begin{array}{l}0.01 \\
(-0.12 ; 0.14)\end{array}$ & $\begin{array}{l}0.10 \\
(-0.10 ; 0.29)\end{array}$ & $\begin{array}{l}0.11 \\
(-0.04 ; 0.26)\end{array}$ \\
\hline Chorioamnionitis & - & $\begin{array}{l}-0.58 \\
(-1.17 ; 0.01)\end{array}$ & - & - \\
\hline Preeclampsia & $\begin{array}{l}-0.33 \\
(-0.69 ; 0.03)\end{array}$ & - & $\begin{array}{l}-1.33 \\
(-2.14 ;-0.51)^{+}\end{array}$ & - \\
\hline $\begin{array}{l}\text { Antenatal steroids } \\
<24 \text { hrs before birth }\end{array}$ & - & $\begin{array}{l}0.08 \\
(-0.60 ; 0.76)\end{array}$ & - & - \\
\hline $\begin{array}{l}\text { Antenatal steroids } \\
\text { 2-7 days before birth }\end{array}$ & - & $\begin{array}{l}-0.55 \\
(-1.28 ; 0.17)\end{array}$ & - & - \\
\hline $\begin{array}{l}\text { Antenatal steroids } \\
>7 \text { days before birth }\end{array}$ & - & $\begin{array}{l}0.54 \\
(-0.19 ; 1.27)\end{array}$ & - & - \\
\hline $\begin{array}{l}\mathrm{FiO}_{2} \\
\text { (per } 0.1 \text { increase) }\end{array}$ & - & - & - & - \\
\hline
\end{tabular}


A

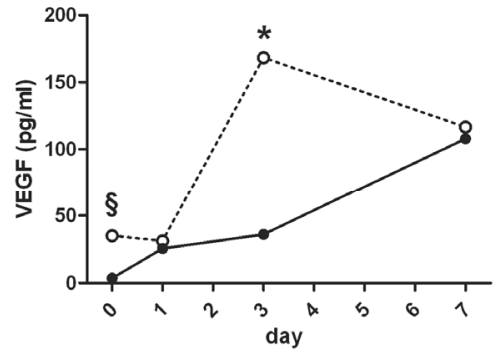

C

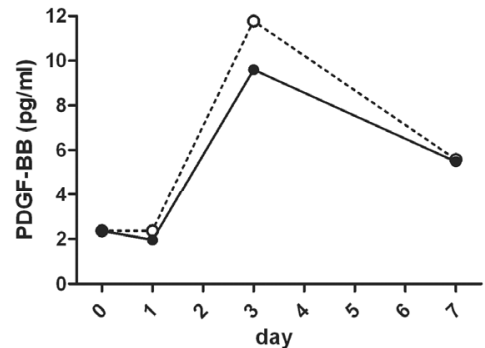

E
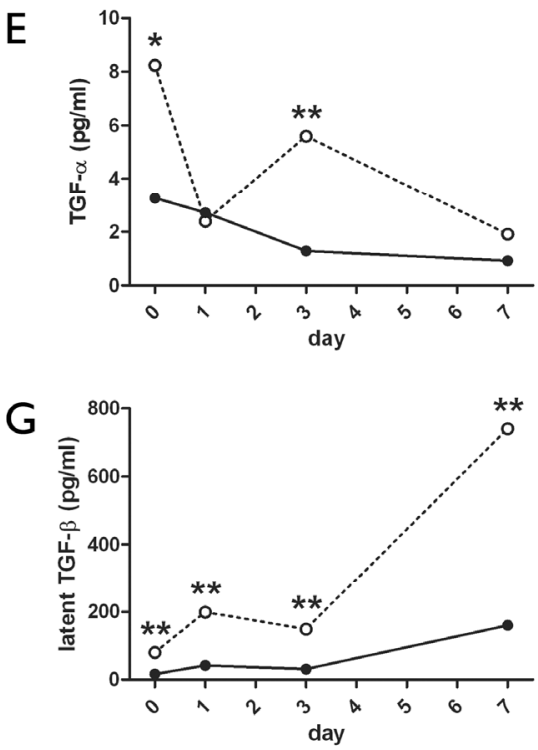

B

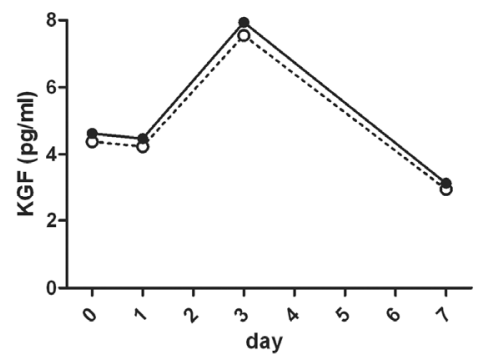

D

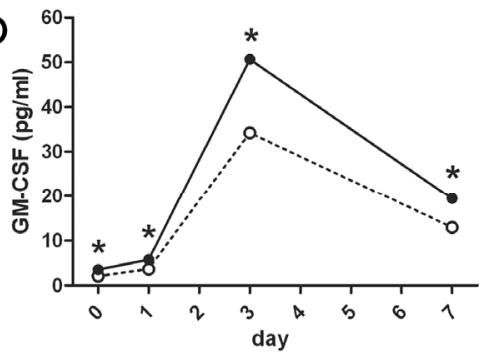

F
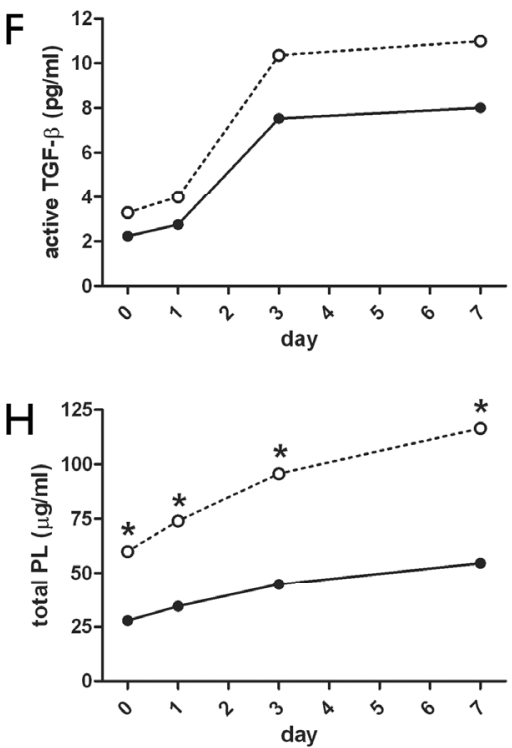

Figure 1. (A-H): Temporal growth factor and total PL patterns in bronchoalveolar lavage fluid for infants developing bronchopulmonary dysplasia (BPD; •,continuous line) and infants surviving without BPD (o, dashed line) as predicted by the marginal models with adjustment for confounders. Points represent mean predictives, and $p$ values relate to the model estimate for the BPD effect (Table $4 ;{ }^{*} p<0.05$ and $* * p<0.01$ for individual time points). 


\section{Discussion}

We describe the dynamic patterns of various growth factors and total PL in BALF during the first postnatal week in ventilated preterm infants. Distinct expression patterns were observed for different growth factors. Substantial differences in BALF growth factor concentrations were present during the first postnatal week between infants who developed BPD and those who did not. Moreover, it was shown that VEGF concentrations entail important predictive value for BPD development already within $24 \mathrm{~h}$ after birth.

The most prominent differences in BALF concentrations between infants with and without BPD were observed for VEGF. In the lung, VEGF is produced by endothelial cells as well as bronchial and type II alveolar epithelial cells ${ }^{3,8}$. Inhibition of VEGF during lung development results in disruption of vascular and alveolar development and a pathologic picture similar to that of new BPD ${ }^{8}$. Thus, the lower initial VEGF concentrations found in our study in infants eventually developing BPD could well reflect a mechanistic process of adverse lung development and are in agreement with previous human studies ${ }^{22,23}$. BALF VEGF levels may be used to identify individuals at particular risk for BPD at an early stage, which could facilitate future implementation of individualized preventive strategies for BPD in preterm infants.

Moreover, VEGF may be a marker of lung development, supported by the positive association between VEGF and gestational age, and the correlation between VEGF and PL concentrations in BALF. The latter observation corresponds to animal experimental evidence indicating a stimulatory effect of VEGF on pulmonary surfactant synthesis ${ }^{24,25}$. The association between lower alveolar VEGF and total PL concentrations and subsequent BPD development supports the concept that a developmental arrest of the lung is a critical mechanism in the development of new BPD ${ }^{2}$.

Besides VEGF and PL, TGF- $\alpha$ was also decreased in infants developing BPD. We are unaware of earlier reports of TGF- $\alpha$ quantification in BALF from preterm infants. Given the low overall levels, reducing accuracy of the measurements, it is surprising that significant differences were detected. TGF- $\alpha$ is a known stimulant of angiogenesis and alveolar epithelial differentiation. Pulmonary overexpression of TGF- $\alpha$ disrupts lung morphology in mice ${ }^{14}$, while paradoxically TGF- $\alpha$ knockout also results in a reduction of the terminal gas exchange area ${ }^{26}$. The latter corresponds to our findings of reduced TGF- $\alpha$ being associated with the development of BPD. Together, the available data on the role of TGF- $\alpha$ within the lung indicate that tight regulation of its expression is vital for proper lung development.

GM-CSF is a stimulator of proliferation and differentiation of granulocytes and macrophages, and a regulator of surfactant homeostasis ${ }^{12,13}$. GM-CSF overexpression leads to exaggerated macrophage proliferation and activation ${ }^{27}$, while GM-CSF null mice experience excessive accumulation of surfactant constituents in the alveolar space ${ }^{28}$. The sudden increase in BALF levels of GM-CSF by the third postnatal day as found in our study is in line with earlier reports ${ }^{29}$. We hypothesize that the increase in GM-CSF in infants develop- 
ing BPD is a marker of increased influx and activation of inflammatory cells in the alveolar space.

TGF- $\beta 1$ is an ubiquitous regulator of embryonic development. It is secreted as an inactive precursor protein consisting of mature TGF- $\beta 1$ and the latency associated peptide (LAP) ${ }^{16}$. Latent TGF- $\beta 1$ can be activated in various ways, including by acidification as performed in this study ${ }^{16}$. Our study shows that in ventilated preterm newborns, the inactive precursor protein comprises the vast majority of TGF- $\beta 1$ in the alveolar space. Why such an abundance of the latent TGF- $\beta 1$ form is present in the lung remains unknown, although our data indicate that increased TGF- $\beta 1$ activation may be implicated in the pathophysiology of BPD. TGF- $\beta 1$ overexpression decreases alveolarization in newborn murine models on the one hand ${ }^{17}$, whereas TGF- $\beta 1$ diminishes apoptosis and promotes repair in alveolar type II cells after hyperoxia ${ }^{30}$. The ambivalent nature of TGF- $\beta 1$ in pulmonary physiology complicates interpretation of its contribution to BPD development.

Earlier reports indicate a role in the pathogenesis of BPD for TGF- $\beta 1$ and other classic growth factors involved in fibrosis and lung repair such as PDGF-BB and KGF ${ }^{3,6}$. In this study, we were unable to reproduce previous associations between BALF levels of these factors and development of BPD in multivariable analysis. Instead, significant associations were detected between BPD and levels of total PL and growth factors involved in lung maturation and development (e.g., VEGF and TGF- $\alpha$ ). These findings are in agreement with the current concept of a shift in pathophysiology from old to new BPD ${ }^{2,4}$. Secondary lung injury and fibrosis are replaced by a picture depicted as a developmental arrest of the lung. Although, to date, the pathophysiology of this change has primarily been studied in animals, this study provides an additional supportive evidence of a molecular basis for this shift in humans.

Positive correlations were observed between individual levels of various growth factors on each day, in line with earlier studies in $\mathrm{TAF}^{31}$, suggesting important interaction or costimulation. Moreover, it was striking to see a strong negative correlation between preeclampsia and almost any growth factor in BALF after multivariable adjustment. Interpretation of this association is complicated, because preeclampsia may be a proxy for being small for gestational age as well as for absence of chorioamnionitis ${ }^{5}$. Both factors are associated with changes in growth factor expression as well as BPD risk ${ }^{5}$. Additional studies are needed to explore the effect of maternal preeclampsia on fetal lung development and growth factor expression.

Particular strengths of this study include the simultaneous quantification of several growth factors in one population and the application of a marginal model approach. The former enables a composite picture of the several growth factors to be obtained, to find possible differential expression patterns. The latter allows for temporal comparisons of mean changes in growth factor concentrations with adjustment for potential confounders. It is important to emphasize that the model parameters and associated conclusions are only valid under the condition that, given all relevant covariates, missingness occurred at 
random. We had no apparent reason to dismiss this assumption, and as such we believe that the results are unbiased.

The underlying mechanisms responsible for the demonstrated effects were not studied and remain open to speculation. Similarly, alterations in growth factor expression observed in patients developing BPD do not provide information on the causality of this association. Additional research is needed to evaluate whether these alterations have a causal role in BPD development or are merely markers of the process of adverse lung development leading to BPD. The developmental regulation and differential temporal expression of certain growth factors in relation to BPD observed in this study suggest that time-dependent effects need consideration when designing additional studies.

In conclusion, we have described general postnatal dynamics of BALF levels of various growth factors important for lung development and studied simultaneously in ventilated preterm infants. Important differences in BALF growth factor expression over time were demonstrated between infants developing BPD and healthy infants already from $\mathrm{d} 0$. Disturbance of the normal growth factor response to injury may explain part of the adverse lung development seen in BPD patients. Increased understanding of time dependent growth factor regulation of lung development may open up new perspectives for related interventions to prevent or treat BPD in the future.

\section{References}

1. Northway WH, Jr., Rosan RC, Porter DY. Pulmonary disease following respirator therapy of hyalinemembrane disease. Bronchopulmonary dysplasia. N Engl J Med 1967;276:357-68

2. Jobe AJ. The new BPD: an arrest of lung development. Pediatr Res 1999;46:641-3

3. Ambalavanan N, Carlo WA. Bronchopulmonary dysplasia: new insights. Clin Perinatol 2004;31:613-28

4. Kramer BW. Antenatal inflammation and lung injury: prenatal origin of neonatal disease. $J$ Perinatol 2008;28 Suppl 1:S21-7

5. Been JV, Zimmermann LJ. Histological chorioamnionitis and respiratory outcome in preterm infants. Arch Dis Child Fetal Neonatal Ed 2009;94:F218-25

6. Jankov RP, Tanswell KA. Growth factors, postnatal lung growth and bronchopulmonary dysplasia. Paediatr Respir Rev 2004;5 Suppl A:S265-75

7. Dargaville PA, South M, McDougall PN. Comparison of two methods of diagnostic lung lavage in ventilated infants with lung disease. Am J Respir Crit Care Med 1999;160:771-7

8. Thebaud B, Abman SH. Bronchopulmonary dysplasia: where have all the vessels gone? Roles of angiogenic growth factors in chronic lung disease. Am J Respir Crit Care Med 2007; 175:978-85

9. Ray P. Protection of epithelial cells by keratinocyte growth factor signaling. Proc Am Thorac Soc 2005;2:221-5

10. Yuan S, Hannam V, Belcastro R, Cartel N, Cabacungan J, Wang J, Diambomba Y, Johnstone L, Post M, Tanswell AK. A role for platelet-derived growth factor-BB in rat postpneumonectomy compensatory lung growth. Pediatr Res 2002;52:25-33

11. Hoyle GW, Li J, Finkelstein JB, Eisenberg T, Liu JY, Lasky JA, Athas G, Morris GF, Brody AR. Emphysematous lesions, inflammation, and fibrosis in the lungs of transgenic mice overexpressing platelet-derived growth factor. Am J Pathol 1999;154:1763-75

12. Hamilton JA. Colony-stimulating factors in inflammation and autoimmunity. Nat Rev Immunol 2008;8:53344 
13. Trapnell BC, Whitsett JA. Gm-CSF regulates pulmonary surfactant homeostasis and alveolar macrophagemediated innate host defense. Annu Rev Physiol 2002;64:775-802

14. Kramer EL, Deutsch GH, Sartor MA, Hardie WD, Ikegami M, Korfhagen TR, Le Cras TD. Perinatal increases in TGF-\{alpha\} disrupt the saccular phase of lung morphogenesis and cause remodeling: microarray analysis. Am J Physiol Lung Cell Mol Physiol 2007;293:L314-27

15. Strandjord TP, Clark JG, Guralnick DE, Madtes DK. Immunolocalization of transforming growth factoralpha, epidermal growth factor (EGF), and EGF-receptor in normal and injured developing human lung. Pediatr Res 1995;38:851-6

16. Gordon KJ, Blobe GC. Role of transforming growth factor-beta superfamily signaling pathways in human disease. Biochim Biophys Acta 2008;1782:197-228

17. Gauldie J, Galt T, Bonniaud P, Robbins C, Kelly M, Warburton D. Transfer of the active form of transforming growth factor-beta 1 gene to newborn rat lung induces changes consistent with bronchopulmonary dysplasia. Am J Pathol 2003;163:2575-84

18. Jobe AH, Bancalari E. Bronchopulmonary dysplasia. Am J Respir Crit Care Med 2001;163:1723-9

19. Stewart JC. Colorimetric determination of phospholipids with ammonium ferrothiocyanate. Anal Biochem 1980;104:10-4

20. de Blic J, Midulla F, Barbato A, Clement A, Dab I, Eber E, Green C, Grigg J, Kotecha S, Kurland G, Pohunek P, Ratjen F, Rossi G. Bronchoalveolar lavage in children. ERS Task Force on bronchoalveolar lavage in children. European Respiratory Society. Eur Respir J 2000;15:217-31

21. Fitzmaurice G, Laird N, Ware J. Applied longitudinal analysis. 1 ed. Malden MA: John Wiley \& Sons; 2004:536

22. Hasan J, Beharry KD, Valencia AM, Strauss A, Modanlou HD. Soluble vascular endothelial growth factor receptor 1 in tracheal aspirate fluid of preterm neonates at birth may be predictive of bronchopulmonary dysplasia/chronic lung disease. Pediatrics 2009;123:1541-7

23. Lassus P, Turanlahti M, Heikkila P, Andersson LC, Nupponen I, Sarnesto A, Andersson S. Pulmonary vascular endothelial growth factor and Flt-1 in fetuses, in acute and chronic lung disease, and in persistent pulmonary hypertension of the newborn. Am J Respir Crit Care Med 2001;164:1981-7

24. Compernolle V, Brusselmans K, Acker T, Hoet P, Tjwa M, Beck H, Plaisance S, Dor Y, Keshet E, Lupu F, Nemery B, Dewerchin M, Van Veldhoven P, Plate K, Moons L, Collen D, Carmeliet P. Loss of HIF-2alpha and inhibition of VEGF impair fetal lung maturation, whereas treatment with VEGF prevents fatal respiratory distress in premature mice. Nat Med 2002;8:702-10

25. Been JV, Zoer B, Kloosterboer N, Kessels CG, Zimmermann LJ, van Iwaarden JF, Villamor E. Pulmonary Vascular Endothelial Growth Factor Expression and Disaturated Phospholipid Content in a Chicken Model of Hypoxia-Induced Fetal Growth Restriction. Neonatology 2010;97:183-9

26. Minami S, Iwamoto R, Mekada E. HB-EGF decelerates cell proliferation synergistically with TGFalpha in perinatal distal lung development. Dev Dyn 2008;237:247-58

27. Metcalf D, Moore JG. Divergent disease patterns in granulocyte-macrophage colony-stimulating factor transgenic mice associated with different transgene insertion sites. Proc Natl Acad Sci U S A 1988;85:776771

28. Dranoff G, Crawford AD, Sadelain M, Ream B, Rashid A, Bronson RT, Dickersin GR, Bachurski CJ, Mark EL, Whitsett JA. Involvement of granulocyte-macrophage colony-stimulating factor in pulmonary homeostasis. Science 1994;264:713-6

29. Bry K, Hallman M, Teramo K, Waffarn F, Lappalainen U. Granulocyte-macrophage colony-stimulating factor in amniotic fluid and in airway specimens of newborn infants. Pediatr Res 1997;41:105-9

30. Buckley S, Shi W, Barsky L, Warburton D. TGF-beta signaling promotes survival and repair in rat alveolar epithelial type 2 cells during recovery after hyperoxic injury. Am J Physiol Lung Cell Mol Physiol 2008;294:L739-48

31. Vento G, Matassa PG, Ameglio F, Capoluongo E, Zecca E, Tortorolo L, Martelli M, Romagnoli C. HFOV in premature neonates: effects on pulmonary mechanics and epithelial lining fluid cytokines. A randomized controlled trial. Intensive Care Med 2005;31:463-70 


\section{Chapter 7}

Pulmonary vascular endothelial growth

factor expression and disaturated

phospholipid content in a chicken model

of hypoxia-induced fetal growth restriction

Been JV, Zoer B, Kloosterboer $N$, Kessels CG, Zimmermann $L$, van Iwaarden JF, Villamor $E$

Neonatology 2010; 97: 183-9 


\section{Abstract}

Background: Prenatal hypoxia is an important cause of intrauterine growth retardation that affects fetal lung maturation, although previous studies have rendered conflicting results. The fetal chicken model allows the study of the isolated effects of hypoxia during development.

Objectives: We hypothesized that prenatal hypoxia would differentially affect surfactant synthesis, depending on timing and duration of hypoxia. Pulmonary vascular endothelial growth factor (VEGF) expression was analyzed as a possible link between oxygen sensing and surfactant production.

Methods: Fertilized White Leghorn eggs were incubated in normoxia, hyperoxia $(60 \%$ $\mathrm{O}_{2}$ ) from day 15 or hypoxia $\left(15 \% \mathrm{O}_{2}\right)$ from either day 6 or day 15 of incubation. Whole lung disaturated phospholipids (DSPL) and mRNA expression of VEGF isoforms were quantified at day 16 and 19 .

Results: Lung DSPL content increased approximately threefold between day 16 and 19 in control animals. Both hypoxia and hyperoxia from day 15 significantly increased DSPL content at day 19 versus control (103 \pm 22 and $116 \pm 18$ vs. $81 \pm 15 \mu \mathrm{g} / \mathrm{mg}$ protein, $\mathrm{p}<$ 0.01 and $p<0.001$, respectively), while long-term hypoxia tended to decrease DSPL content $(65 \pm 17 \mu \mathrm{g} / \mathrm{mg}$ protein, $\mathrm{p}=0.056)$. No differences in DSPL content were observed at day 16. Short-term hypoxia transiently up-regulated VEGF146 1.5 -fold at day 16 ( $p<0.05$ ). A similar trend was observed for VEGF122 ( $p=0.058)$ and VEGF190 ( $p=0.08)$, while no differences were present at day 19.

Conclusions: Both prenatal hypoxia and hyperoxia induced during critical windows of lung development differentially modulate surfactant synthesis. Our data support the concept that fetal oxygen tension is a key signal in the regulation of the surfactant system. 


\section{Introduction}

Pulmonary surfactant is a complex mixture of phospholipids and proteins; it lowers surface tension at the air-water interface and prevents alveolar collapse. Surfactant deficiency due to lung immaturity causes respiratory distress syndrome (RDS) in preterm neonates that is rescued by exogenous surfactant administration ${ }^{1}$.

Intrauterine growth retardation is most frequently the consequence of placental insufficiency resulting in decreased availability of nutrients and oxygen ${ }^{2,3}$. As normal pulmonary development takes place in the relatively hypoxic environment of the uterus, it has classically been suggested that increased hypoxic intrauterine stress may accelerate lung maturity and protect the preterm infant from RDS ${ }^{4}$. However, there is conflicting evidence in the literature regarding this accelerated pulmonary maturation. Elevated amniotic fluid lecitin/sphingomyelin ratios have been reported in preterm infants with placental insufficiency, suggesting accelerated lung maturation ${ }^{5}$. Accordingly, investigators have found decreased rates of RDS in infants with intrauterine growth retardation ${ }^{6}$. However, others have found no difference ${ }^{7,8}$ or even increased rates of RDS ${ }^{9-11}$ in infants with intrauterine growth retardation.

Vascular endothelial growth factor (VEGF) has been shown in numerous studies to play a critical role in lung development ${ }^{12}$. VEGF is highly expressed in alveolar type II cells and stimulates surfactant synthesis ${ }^{12-14}$. Indeed, high levels of VEGF in tracheal aspirate fluid from preterm infants have been associated with a decreased need for exogenous surfactant administration ${ }^{15}$. VEGF is under hypoxic control through upstream regulation by hypoxia-inducible factor $2 \alpha^{13}$ and hypoxia has been shown to increase alveolar VEGF content ${ }^{16}$.

The chicken fetus is an excellent model for the study of the developmental consequences of hypoxia and other prenatal insults ${ }^{17-21}$. Hypoxia is easily induced by incubating the egg in a low-oxygen environment, and its effects can be studied without interferences of maternal hormonal, metabolic, or hemodynamic alterations. In the present study, we hypothesized that exposure of chicken fetuses to hypoxia would have modulatory effects on pulmonary VEGF expression and surfactant production. The latter was quantified by analyzing disaturated phospholipids (DSPL), the most surface-active lipid fraction of surfactant and the main constituent of both mammalian and avian surfactant ${ }^{22}$. We evaluated the effects of two different regimes of hypoxia: $15 \% \mathrm{O}_{2}$ during either the last two thirds or the last third of incubation. The effects of hyperoxia $\left(60 \% \mathrm{O}_{2}\right.$ during the last third of the incubation) were also analyzed. 


\section{Methods}

\section{Experimental protocol}

Experiments were performed in accordance with Dutch law for animal experimentation. Fertilized eggs of White Leghorn chickens were incubated at $37.8^{\circ} \mathrm{C}$ and $45 \%$ humidity and turned over an angle of $90^{\circ}$ once per hour (Incubator model 25HS; Masalles Comercial, Ripollet, Spain). Control eggs were incubated under normoxic conditions $\left(21 \% \mathrm{O}_{2}\right)$. For the hypoxia protocol, eggs were incubated under normoxic conditions until day 6 (long term hypoxia) or day 15 (short-term hypoxia) of incubation, when they were transferred to an incubator where $15.0 \pm 0.3 \% \mathrm{O}_{2}$ was maintained. For the hyperoxia protocol, eggs were incubated under normoxia until day 15 and then transferred to an incubator where $60 \pm$ $1 \% \mathrm{O}_{2}$ was maintained. The $\mathrm{O}_{2}$ concentrations in the incubators were monitored with a DrDAQ $\mathrm{O}_{2}$ sensor (Pico Technology, Eaton Socon, UK). Eggs were incubated for either 16 (normoxia and hypoxia groups) or 19 days (all experimental groups). On the experimental day the fetuses were killed by decapitation and weighed; afterwards both lungs were excised. None of the fetuses had internally pipped ${ }^{20,23}$. The right lung was weighed and homogenized in phosphate-buffered saline using a 2-ml dounce. The left lung was used for mRNA analysis (see below).

\section{Total protein quantification, DSPL isolation and quantification}

Total protein was quantified in the right lung homogenate using the Micro BCA protein assay kit (Thermo Fisher Scientific, Rockford, III., USA) according to the manufacturer's instructions. Next, the lung homogenate was suspended 1:10 in 1-butanol and vortexed. The mixture was centrifuged at $800 \mathrm{~g}$ for $10 \mathrm{~min}$ after which the supernatant was evaporated at $50{ }^{\circ} \mathrm{C}$ under continuous nitrogen gas flow. The pellet was redissolved in carbon tetrachloride $+100 \mathrm{mg} / \mathrm{ml}$ osmium tetroxide and DSPL were isolated according to Mason et al. ${ }^{24}$. DSPL were dissolved in chloroform and quantified according to Stewart ${ }^{25}$, with slight modifications. Briefly, ammonium ferrothiocyanate was added 1:2 to DSPL in chloroform and vortexed thoroughly for $30 \mathrm{~s}$. The organic phase (containing the stained DSPL) was separated from the inorganic phase by centrifugation $(10 \mathrm{~min}, 800 \mathrm{~g}$ ). Then, $125 \mu \mathrm{l}$ of the organic phase of each sample was transferred into a 96-well glass-coated microtiter plate (Instrument Solutions, Nieuwegein, The Netherlands) and extinction was measured at $488 \mathrm{~nm}$ in a Spectra Max M2 photospectrometer using a phosphatidylcholine standard curve (range: $0-200 \mu \mathrm{g} / \mathrm{ml}$ ).

\section{RNA isolation and measurement of VEGF $m R N A$ expression}

The chicken VEGF-A gene gives rise to four isoforms generated by alternative splicing of exons (VEGF122, VEGF146, VEGF166, and VEGF190, homologous to human VEGF121, VEGF145, VEGF165, and VEGF189, respectively) ${ }^{26,27}$. We examined the expression of the VEGF-A isoforms by RT-PCR of total RNA isolated from fetal chicken lung. The left lung was cut into pieces and tissue RNAs were stabilized in RNAlater ${ }^{\mathrm{TM}}$ (Qiagen, Venlo, The Nether- 
lands) for 1 day at $4{ }^{\circ} \mathrm{C}$, after which the samples were stored at $-80{ }^{\circ} \mathrm{C}$ until use. After thawing, total RNA was isolated using the RNeasy ${ }^{\circledR}$ minikit (Qiagen) according to the manufacturer's protocol, including a DNase treatment step (RNase-free DNase set for use with RNeasy columns; Qiagen).

Total RNA was quantified using a Thermo Scientific NanoDrop ${ }^{\mathrm{TM}} 1000$ Spectrophotometer. Part of the RNA was denatured at $65{ }^{\circ} \mathrm{C}$ for $10 \mathrm{~min}$ and immediately placed on ice. Then, 500 ng of RNA was translated to cDNA using Ready-To-Go ${ }^{\text {TM }}$ You-Prime FirstStrand beads (GE Healthcare, Eindhoven, The Netherlands) and $200 \mathrm{pmol} p d(\mathrm{~N})_{6}$ random hexamer primers (GE Healthcare) in a total volume of $25 \mu \mathrm{l}$. RT-PCR was performed at 37 ${ }^{\circ} \mathrm{C}$ for $1 \mathrm{~h}$, after which the samples were heated to $95{ }^{\circ} \mathrm{C}$ for 3 min to stop the reaction. Subsequently, samples were cooled to $4{ }^{\circ} \mathrm{C}$ and stored at $4{ }^{\circ} \mathrm{C}$ until use.

PCR was performed with chicken VEGF primers (FW 5'-caggccatcctgtgtgcctct-3', RV 5'ttccgctgctcaccgtctccgg- $3^{\prime}$ ) designed to yield the four isoforms of chicken VEGF. PureTaq ${ }^{\mathrm{TM}}$ Ready-To-Go ${ }^{\text {TM }}$ PCR beads (GE Healthcare) were used with $10 \mathrm{pmol}$ of each primer and 1 $\mu \mathrm{l}$ of cDNA per reaction with a total volume of $25 \mu \mathrm{l}$. PCR steps were as follows: denaturation $3 \mathrm{~min}$ at $94{ }^{\circ} \mathrm{C}$ (denaturation at $94{ }^{\circ} \mathrm{C} 30 \mathrm{~s}$, annealing at $60{ }^{\circ} \mathrm{C} 1 \mathrm{~min}$, elongation at 72 ${ }^{\circ} \mathrm{C} 1 \mathrm{~min}$ ). Ribosomal $18 \mathrm{~S}$ was used as an internal standard and analyzed by the same procedure (primer sequences: FW: $3^{\prime}$-ccatccaatcggtagtagcg-3' and RV: 5'cgataacgaacgagactctgg- $\left.3^{\prime}\right)$. PCR products in the exponential phase of the PCR reaction were yielded after 18 cycles. PCR products were visualized at a $2 \%$ agarose gel stained with ethidium bromide and band densities were measured using ImageQuant ${ }^{\mathrm{TM}}$ software (GE Healthcare).

\section{Statistics}

Data are expressed as mean and standard deviation (SD), while for clarity standard error of the mean (SEM) is used in figures. Differences between groups were tested using oneway analysis of variance (ANOVA) with Dunnett's post-hoc analysis. A test result of $p<$ 0.05 was considered significant (two-tailed). All analyses were performed using SPSS 15.0 software (SPSS Inc., Chigaco, III., USA).

\section{Results}

\section{Fetal body and lung masses}

Exposure to $15 \% \mathrm{O}_{2}$ during middle (from day 6 onward) or late (from day 15 onward) incubation resulted in decreased mass of the 19-day chicken fetus (table 1). However, this effect of hypoxia was not observed in the 16-day fetus. Exposure to $60 \% \mathrm{O}_{2}$ during late incubation (day 15-19) did not significantly affect fetal body mass (table 1). Neither hypoxia nor hyperoxia significantly affected lung mass or the proportion lung mass:fetal mass. 
Table 1. Morphometric parameters after incubation in normoxia, hyperoxia $\left(60 \% \mathrm{O}_{2}\right.$ from day 15$)$ or long-term (LT; from day 6) or short-term (ST; from day 15) hypoxia $\left(15 \% \mathrm{O}_{2}\right)$ at days 16 and 19. Data are shown as mean \pm SD. $* * * p<0.001$ vs. normoxia.

\begin{tabular}{llllllll}
\hline & $\begin{array}{l}\text { Day 16 } \\
\text { Normoxia } \\
(n=15)\end{array}$ & $\begin{array}{l}\text { LT hypoxia } \\
(n=15)\end{array}$ & $\begin{array}{l}\text { ST hypoxia } \\
(n=11)\end{array}$ & $\begin{array}{l}\text { Normoxia } \\
(n=15)\end{array}$ & $\begin{array}{l}\text { LT hypoxia } \\
(n=14)\end{array}$ & $\begin{array}{l}\text { ST hypoxia } \\
(n=16)\end{array}$ & $\begin{array}{l}\text { Hyperoxia } \\
(n=15)\end{array}$ \\
\hline Body mass (g) & 17.0 & 16.3 & 16.3 & 29.9 & 25.8 & 26.4 & 29.6 \\
& \pm 1.0 & \pm 0.9 & \pm 1.2 & \pm 2.3 & $\pm 1.2^{* * *}$ & $\pm 1.8^{* * *}$ & \pm 2.5 \\
Lung mass (mg) & $80 \pm 14$ & $74 \pm 13$ & $76 \pm 7$ & $137 \pm 18$ & $123 \pm 22$ & $122 \pm 16$ & $130 \pm 20$ \\
Lung mass /body & 4.7 & 4.6 & 4.7 & 4.6 & 4.8 & 4.6 & 4.4 \\
mass (\%o) & \pm 0.8 & \pm 0.8 & \pm 0.5 & \pm 0.5 & \pm 0.9 & \pm 0.6 & \pm 0.7 \\
\hline
\end{tabular}

\section{Lung DSPL}

There were no differences in whole lung total phospholipids and total protein content between experimental groups at any time point. As shown in figure 1, whole lung DSPL content increased between day 16 and day 19 in control animals, reflecting the physiologic increase in surfactant production during development. Incubation under hypoxic conditions did not affect whole lung DSPL content by day 16, irrespective of hypoxia duration. However, hypoxia from day 15 significantly increased whole lung surfactant content by day $19(\mathrm{p}<0.01)$. Long-term hypoxia induced a nonsignificant decrease of DSPL content in the 19-day fetal lung $(p=0.058)$. Hyperoxic incubation from day 15 significantly increased whole lung DSPL content at day $19(p<0.001)$.

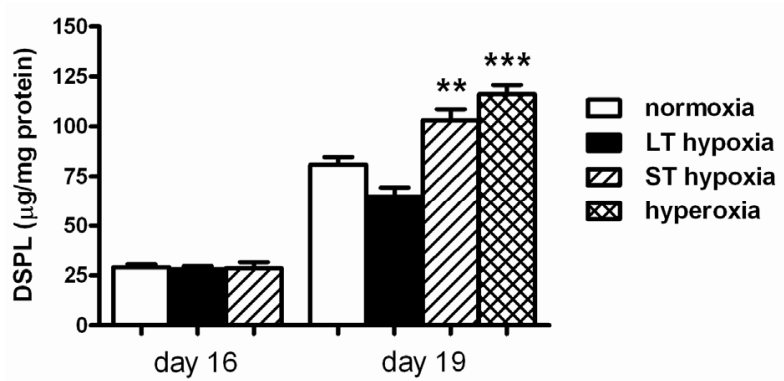

Fig. 1. Whole lung DSPL content after incubation in normoxia, hyperoxia $\left(60 \% \mathrm{O}_{2}\right.$ from day 15$)$ or long-term (LT; from day 6) or short-term (ST; from day 15$)$ hypoxia $\left(15 \% \mathrm{O}_{2}\right)$ at days 16 and 19 . Bars represent mean + SEM ( $* * p<0.01$ and $* * * p<0.001$ vs. normoxia).

\section{Pulmonary VEGF mRNA expression}

When the pulmonary mRNA expression of the VEGF-A isoforms was examined by RT-PCR, we detected three bands corresponding to VEGF122, VEGF146, and VEGF190 isoforms (fig. 2). No signal was detected for the VEGF166 isoform. As shown in figure 3, short-term hy- 
poxia induced a transient increase in the expression of the VEGF146 isoform (i.e., the expression was augmented at day 16 but not at day 19). A similar trend, although not statistically significant, was observed towards a transient increase in the expression of the VEGF122 and VEGF190 isofoms in the 16-day lungs exposed to short-term hypoxia ( $p=$ 0.057 and $p=0.08$, respectively). Neither long-term hypoxia nor hyperoxia significantly changed the pattern of development of VEGF mRNA expression (fig. 3).

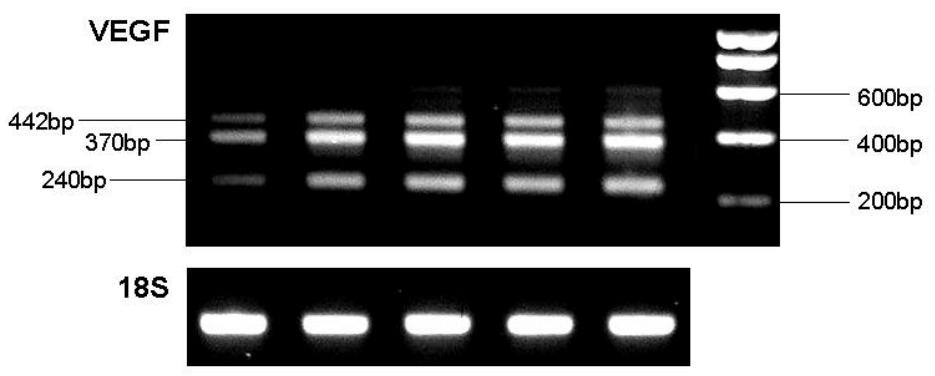

Fig. 2. mRNA expression of VEGF isoforms in the fetal chicken lung. VEGF isoforms 190 (442 bp), 146 (370 bp) and 122 (240 bp) were detected, but not isoform 166 (310 bp).

\section{Discussion}

This is the first study to examine how chronic hypoxic exposure started during middle or late incubation differentially affects surfactant synthesis in the chicken fetus. Hypoxia during late incubation (from day 15 onward) was found to increase surfactant synthesis in the 19-day fetus, while conversely, long-standing (from day 6 onward) hypoxia tended to decrease whole lung surfactant content. The increase in surfactant content induced by late hypoxic exposure was preceded by a transient upregulation of the VEGF isoform VEGF146. Interestingly, hyperoxia during late incubation also increased surfactant production, but without a significant effect on VEGF expression. Our data support the concept that fetal oxygen tension is a key signal in the regulation of the surfactant system.

Previous studies that focused on the effect of hypoxia on lung development and surfactant production using mammalian models have rendered conflicting results ${ }^{28-33}$. In fetal sheep, both maternal hypoxia between gestation day 108 and 130 (term = 147 days) as well as embolization- induced fetal hypoxemia from day 134 to 136 up-regulated mRNA for surfactant protein (SP)-A and $-B$ but not $-C^{28,29}$. Conversely, maternal hypoxia from gestation day 14 suppressed pulmonary SP-A, -B and -C mRNA expression in preterm fetal mice (day 17.5; term $=21$ days) ${ }^{32}$. In near-term fetal rats, intermittent maternal hypoxia reduced fetal lung disaturated phosphatidylcholine content when started at day 7 of gestation (term = 21 days), while continuous hypoxia from day 14 had no effect on either lung morphology ${ }^{33}$ or surfactant content ${ }^{31}$. The results of the latter study point in the same direction as our data, suggesting the existence of 'critical windows' during which environ- 
mental perturbation would exert different effects. The main limitation of these mammalian studies is the interference of maternal alterations induced by hypoxia. In addition, exposure to hypoxia generally induces a marked reduction in maternal food intake that may result in a cumulative substrate deficit and thus constituted a dual insult (i.e. hypoxia and malnutrition) for the offspring ${ }^{34}$. In the last years, the use of the chicken fetus model has allowed the isolation of the effects of prenatal hypoxia and undernutrition ${ }^{20,21}$.

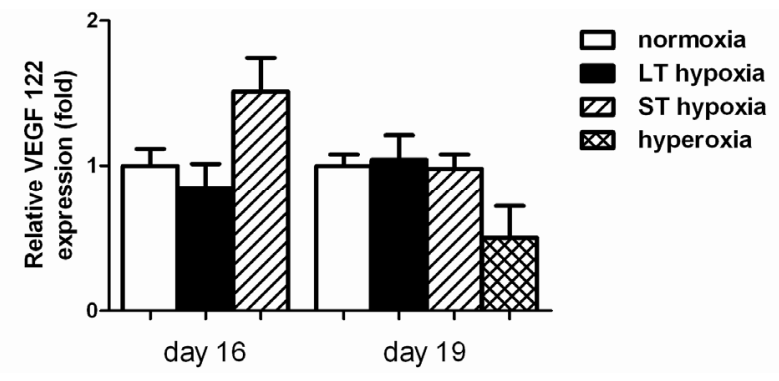

A

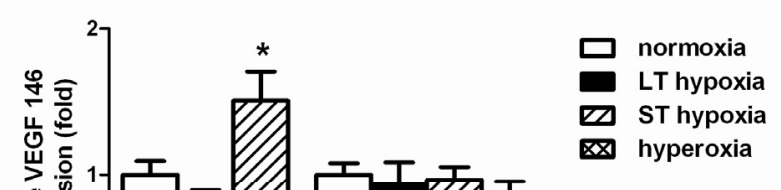

B

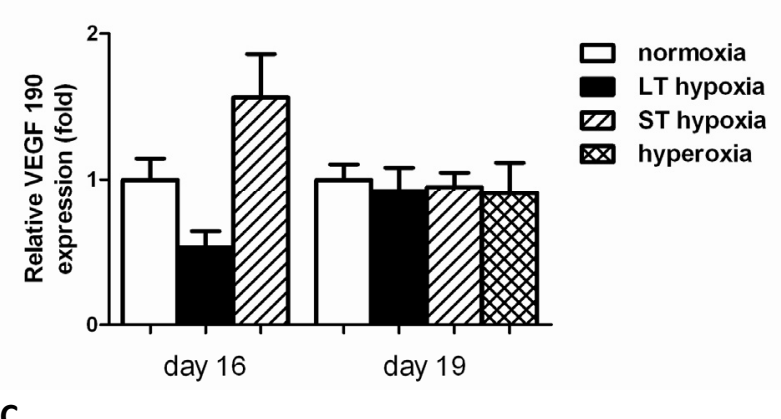

Fig. 3. a-c VEGF isoform expression patterns after incubation in normoxia, hyperoxia $\left(60 \% \mathrm{O}_{2}\right.$ from day 15$)$ or long-term (LT; from day 6) or short-term (ST; from day 15) hypoxia $\left(15 \% \mathrm{O}_{2}\right)$ at days 16 and 19 . Bars represent mean + SEM ( $* p<0.05$ vs. normoxia). 
When interpreting the data presented, it is important to take into account the differences and similarities between human and avian lung development and structure. Surfactant has a crucial role in preventing alveolar collapse in the human lung during respiration ${ }^{1}$. In contrast, the chicken lung consists of air capillaries rather than alveoli, that connect to tubular structures (parabronchi) with a unidirectional laminar airflow ${ }^{35}$. These dissimilarities have been suggested to imply functional differences of pulmonary surfactant between humans and chickens ${ }^{22,35,36}$. It appears that SP-C and SP-D are absent in chicken lungs, while debate exists around SP-B ${ }^{22,36-38}$. Despite these differences, the phospholipid composition and the fetal developmental pattern of surfactant in the chicken are very similar to those of mammals and other vertebrates ${ }^{22,23,35}$. Type II cells develop within the atrial walls of the parabronchi between the 14 th and 15 th day of incubation ${ }^{38}$, and lamellar bodies appear on day 16 and increase in number to a maximum at day $18^{39}$. Concomitantly, the amount of total phospholipids and DSPL increases in the final stages of incubation, and the DSPL:total phospholipid ratio becomes maximal at days $19-20^{40}$. Around this time, the chicken fetus internally pips by piercing the air cell inner membrane with its beak and begins lung ventilation ${ }^{23}$. Although during internal pipping, gas exchange is still partly dependent on the chorioallantoic membrane, the fetal lung is considered structurally and functionally mature ${ }^{35,41}$. Whether changes in prenatal oxygen environment would affect the structural maturation of the developing chicken lung warrants further investigation.

Our data show relatively low pulmonary surfactant content on day 16 , while DSPL content approximately tripled by day 19. In addition, we demonstrated that the developmental increase in surfactant production was differentially affected by hypoxia and that this effect was dependent on the timing and the duration of the stimulus. We are aware of one earlier report of surfactant measurements after hypoxic incubation in the chicken fetus. Blacker et al. ${ }^{23}$ quantified surfactant lipids in bronchoalveolar lavage fluid from fetal chicks after incubation in $17 \% \mathrm{O}_{2}$ from day 10 . Hypoxia was shown to significantly increase phospholipid concentration by day 16 and of both phospholipids and DSPL by day 19. No significant differences were observed at days 20 and 21, suggesting that the effect was temporary. Only one hypoxic exposure period was used, therefore a timing-dependent differential effect could not be evaluated. Comparison to our data is difficult due to the differences in duration and severity of hypoxia. However, it should be noted that in contrast to $15 \% \mathrm{O}_{2}{ }^{20,21}, 17 \% \mathrm{O}_{2}$ did not induce a significant delay in fetal growth in the study by Blacker et al. ${ }^{23}$.

The molecular mechanisms that regulate lung development differ to some extent between species, including humans and chickens ${ }^{39,42}$. On the other hand, important similarities are present, such as the stimulatory effect of corticosteroids on surfactant production 23,42 . Regarding the role of growth factors in the regulation of avian lung development, there is an important lack of data, as stressed by Maina ${ }^{35}$. Our study thus contributes to an increased knowledge on pulmonary growth factor responses to hypoxia and hyperoxia in the chicken fetus. One of the most potent responses to tissue hypoxia is the induction of an angiogenic reaction that is partly mediated by expression of VEGF and its receptors 
. Recent evidence indicates that VEGF is not only involved in angiogenesis but also in epithelial cell growth and proliferation in the fetal lung ${ }^{12}$. Moreover, type II cells express VEGF receptors and respond to VEGF by increasing surfactant production ${ }^{13}$. We therefore examined the expression of VEGF mRNA in the developing chicken lung. Exposure to hypoxia from day 6 of incubation did not significantly affect VEGF expression, but when the fetuses were made hypoxic from day 15, an increase in the mRNA expression of the VEGF146 isoform was observed at day 16 . However, this increase was transient and was no longer observed at day 19. Whether the increase in surfactant production induced by hypoxia is related to the transient increase of VEGF or to up-regulation of other stressinduced stimulators of surfactant production such as corticosteroids ${ }^{23,42}$ warrants further investigation.

Since hyperoxia is one of the main contributors to neonatal chronic lung disease ${ }^{44}$, numerous studies have analyzed the effects of postnatal alveolar hyperoxia on lung development. In general, these studies demonstrate that hyperoxia stimulates surfactant synthesis ${ }^{45-47}$ but impairs surfactant function ${ }^{48}$. Moreover, both VEGF and the expression of VEGF receptors are decreased by hyperoxia ${ }^{49,50}$. We are aware of one earlier study evaluating the effect of prenatal hyperoxia on surfactant, showing increased synthesis after intermittent maternal exposure to $100 \% \mathrm{O}_{2}$ from day 7 of gestation in rats ${ }^{31}$. Our data show that continuous hyperoxic $\left(60 \% \mathrm{O}_{2}\right)$ incubation of chicken fetuses during the physiologic window of surfactant synthesis increases pulmonary surfactant content, but does not affect VEGF mRNA expression. Although we studied only one period of hyperoxia, Xu and Mortola ${ }^{51}$ have shown that hyperoxia from day 14 to day 18 had more pronounced effects on lung mass and DNA content than did hyperoxia from day 7 to day 18 . Moreover, van Golde et al. ${ }^{52}$ demonstrated that exposure of the chicken fetus to $60 \% \mathrm{O}_{2}$ induced a transient increase in the activity of superoxide dismutase, catalase and glutathione peroxidase in several organs, including the lungs. This effect was much more marked when hyperoxic exposure occurred on incubation days 10-11 than when it took place on incubation days $14-15$ or 18-19, stressing again the relevance of stimulus timing ${ }^{52}$.

Critical time windows exist during development, and if environmental changes are experienced in the window of vulnerability, then the trajectory of development of the responding organ may be changed in ways that result in transient or persistent alterations 53. The present study provides evidence for the high level of plasticity of the surfactant system within its maturation and for the critical role of fetal oxygenation in controlling this process. Both hypoxia and hyperoxia during the critical window of surfactant production trigger an increase in surfactant development that may represent an acceleration in the pattern of maturation ${ }^{23}$.

\section{References}

1. Been JV, Zimmermann LJ. What's new in surfactant? A clinical view on recent developments in neonatology and paediatrics. Eur J Pediatr 2007;166:889-99 
2. Aucott SW, Donohue PK, Northington FJ. Increased morbidity in severe early intrauterine growth restriction. J Perinatol 2004;24:435-40

3. Bernstein IM, Horbar JD, Badger GJ, Ohlsson A, Golan A. Morbidity and mortality among very-low-birthweight neonates with intrauterine growth restriction. The Vermont Oxford Network. Am J Obstet Gynecol 2000;182:198-206

4. Procianoy RS, Garcia-Prats JA, Adams JM, Silvers A, Rudolph AJ. Hyaline membrane disease and intraventricular haemorrhage in small for gestational age infants. Arch Dis Child 1980;55:502-5

5. Torrance HL, Voorbij HA, Wijnberger LD, van Bel F, Visser GH. Lung maturation in small for gestational age fetuses from pregnancies complicated by placental insufficiency or maternal hypertension. Early Hum Dev 2008;84:465-9

6. Bartels DB, Kreienbrock L, Dammann O, Wenzlaff P, Poets CF. Population based study on the outcome of small for gestational age newborns. Arch Dis Child Fetal Neonatal Ed 2005;90:F53-9

7. Gortner L, Wauer RR, Stock GJ, Reiter HL, Reiss I, Jorch G, Hentschel R, Hieronimi G. Neonatal outcome in small for gestational age infants: do they really better? J Perinat Med 1999;27:484-9

8. Simchen MJ, Beiner ME, Strauss-Liviathan N, Dulitzky M, Kuint J, Mashiach S, Schiff E. Neonatal outcome in growth-restricted versus appropriately grown preterm infants. Am J Perinatol 2000;17:187-92

9. Ley D, Wide-Swensson D, Lindroth M, Svenningsen N, Marsal K. Respiratory distress syndrome in infants with impaired intrauterine growth. Acta Paediatr 1997;86:1090-6

10. Gilbert WM, Danielsen B. Pregnancy outcomes associated with intrauterine growth restriction. Am J Obstet Gynecol 2003;188:1596-9

11. Tyson JE, Kennedy K, Broyles S, Rosenfeld CR. The small for gestational age infant: accelerated or delayed pulmonary maturation? Increased or decreased survival? Pediatrics 1995;95:534-8

12. Breen EC. VEGF in biological control. J Cell Biochem 2007;102:1358-67

13. Compernolle V, Brusselmans K, Acker T, Hoet P, Tjwa M, Beck H, Plaisance S, Dor Y, Keshet E, Lupu F, Nemery B, Dewerchin M, Van Veldhoven P, Plate K, Moons L, Collen D, Carmeliet P. Loss of HIF-2alpha and inhibition of VEGF impair fetal lung maturation, whereas treatment with VEGF prevents fatal respiratory distress in premature mice. Nat Med 2002;8:702-10

14. Been JV, Debeer A, van Iwaarden JF, Kloosterboer N, Passos VL, Naulaers G, Zimmermann LJ. Early alterations of growth factor patterns in bronchoalveolar lavage fluid from preterm infants developing bronchopulmonary dysplasia. Pediatr Res 2010;67:83-9

15. Lassus P, Turanlahti M, Heikkila P, Andersson LC, Nupponen I, Sarnesto A, Andersson S. Pulmonary vascular endothelial growth factor and Flt-1 in fetuses, in acute and chronic lung disease, and in persistent pulmonary hypertension of the newborn. Am J Respir Crit Care Med 2001;164:1981-7

16. Pham I, Uchida T, Planes C, Ware LB, Kaner R, Matthay MA, Clerici C. Hypoxia upregulates VEGF expression in alveolar epithelial cells in vitro and in vivo. Am J Physiol Lung Cell Mol Physiol 2002;283:L1133-42

17. Van der Sterren S, Agren P, Zoer B, Kessels L, Blanco CE, Villamor E. Morphological and functional alterations of the ductus arteriosus in a chicken model of hypoxia-induced fetal growth retardation. Pediatr Res 2009;65:279-84

18. Carlo WF, Villamor E, Ambalavanan N, DeMey JG, Blanco CE. Chronic exposure to cigarette smoke extract impairs endothelium-dependent relaxation of chicken embryo pulmonary arteries. Biol Neonate 2001;80:247-50

19. Villamor E, Kessels CG, van Suylen RJ, De Mey JG, Blanco CE. Cardiopulmonary effects of chronic administration of the NO synthase inhibitor L-NAME in the chick embryo. Biol Neonate 2005;88:156-63

20. Villamor E, Kessels CG, Ruijtenbeek K, van Suylen RJ, Belik J, de Mey JG, Blanco CE. Chronic in ovo hypoxia decreases pulmonary arterial contractile reactivity and induces biventricular cardiac enlargement in the chicken embryo. Am J Physiol Regul Integr Comp Physiol 2004;287:R642-51

21. Ruijtenbeek K, Kessels LC, De Mey JG, Blanco CE. Chronic moderate hypoxia and protein malnutrition both induce growth retardation, but have distinct effects on arterial endothelium-dependent reactivity in the chicken embryo. Pediatr Res 2003;53:573-9

22. Bernhard W, Gebert A, Vieten G, Rau GA, Hohlfeld JM, Postle AD, Freihorst J. Pulmonary surfactant in birds: coping with surface tension in a tubular lung. Am J Physiol Regul Integr Comp Physiol 2001;281:R327-37 
23. Blacker HA, Orgeig S, Daniels CB. Hypoxic control of the development of the surfactant system in the chicken: evidence for physiological heterokairy. Am J Physiol Regul Integr Comp Physiol 2004;287:R403-10

24. Mason RJ, Nellenbogen J, Clements JA. Isolation of disaturated phosphatidylcholine with osmium tetroxide. J Lipid Res 1976;17:281-4

25. Stewart JC. Colorimetric determination of phospholipids with ammonium ferrothiocyanate. Anal Biochem 1980;104:10-4

26. Sugishita Y, Takahashi T, Shimizu T, Yao A, Kinugawa K, Sugishita K, Harada K, Matsui H, Nagai R. Expression of genes encoding vascular endothelial growth factor and its Flk-1 receptor in the chick embryonic heart. J Mol Cell Cardiol 2000;32:1039-51

27. Tischer E, Mitchell R, Hartman T, Silva M, Gospodarowicz D, Fiddes JC, Abraham JA. The human gene for vascular endothelial growth factor. Multiple protein forms are encoded through alternative exon splicing. $J$ Biol Chem 1991;266:11947-54

28. Braems GA, Yao LJ, Inchley K, Brickenden A, Han VK, Grolla A, Challis JR, Possmayer F. Ovine surfactant protein cDNAs: use in studies on fetal lung growth and maturation after prolonged hypoxemia. Am J Physiol Lung Cell Mol Physiol 2000;278:L754-64

29. Gagnon R, Langridge J, Inchley K, Murotsuki J, Possmayer F. Changes in surfactant-associated protein mRNA profile in growth-restricted fetal sheep. Am J Physiol 1999;276:L459-65

30. Harding R, Cock ML, Louey S, Joyce BJ, Davey MG, Albuquerque CA, Hooper SB, Maritz GS. The compromised intra-uterine environment: implications for future lung health. Clin Exp Pharmacol Physiol 2000;27:965-74

31. Faridy EE, Sanii MR, Thliveris JA. Fetal lung growth: influence of maternal hypoxia and hyperoxia in rats. Respir Physiol 1988;73:225-41

32. Gortner L, Hilgendorff A, Bahner T, Ebsen M, Reiss I, Rudloff S. Hypoxia-induced intrauterine growth retardation: effects on pulmonary development and surfactant protein transcription. Biol Neonate 2005;88:129-35

33. Larson JE, Thurlbeck WM. The effect of experimental maternal hypoxia on fetal lung growth. Pediatr Res 1988;24:156-9

34. Williams SJ, Campbell ME, McMillen IC, Davidge ST. Differential effects of maternal hypoxia or nutrient restriction on carotid and femoral vascular function in neonatal rats. Am J Physiol Regul Integr Comp Physiol 2005;288:R360-7

35. Maina JN. Development, structure, and function of a novel respiratory organ, the lung-air sac system of birds: to go where no other vertebrate has gone. Biol Rev Camb Philos Soc 2006;81:545-79

36. Bernhard W, Haslam PL, Floros J. From birds to humans: new concepts on airways relative to alveolar surfactant. Am J Respir Cell Mol Biol 2004;30:6-11

37. Hughes AL. Evolution of the lung surfactant proteins in birds and mammals. Immunogenetics 2007;59:56572

38. Zeng X, Yutzey KE, Whitsett JA. Thyroid transcription factor-1, hepatocyte nuclear factor-3beta and surfactant protein A and B in the developing chick lung. J Anat 1998;193 ( Pt 3):399-408

39. Hylka VW, Doneen BA. Lung phospholipids in the embryonic and immature chicken: changes in lipid composition and biosynthesis during maturation of the surfactant system. J Exp Zool 1982;220:71-80

40. Johnston SD, Orgeig S, Lopatko OV, Daniels CB. Development of the pulmonary surfactant system in two oviparous vertebrates. Am J Physiol Regul Integr Comp Physiol 2000;278:R486-93

41. Maina JN. Developmental dynamics of the bronchial (airway) and air sac systems of the avian respiratory system from day 3 to day 26 of life: a scanning electron microscopic study of the domestic fowl, Gallus gallus variant domesticus. Anat Embryol (Berl) 2003;207:119-34

42. Hylka VW, Doneen BA. Ontogeny of embryonic chicken lung: effects of pituitary gland, corticosterone, and other hormones upon pulmonary growth and synthesis of surfactant phospholipids. Gen Comp Endocrinol 1983;52:108-20

43. Carmeliet P, Collen D. Molecular basis of angiogenesis. Role of VEGF and VE-cadherin. Ann N Y Acad Sci 2000;902:249-62

44. Saugstad OD. Optimal oxygenation at birth and in the neonatal period. Neonatology 2007;91:319-22 
45. ter Horst SA, Fijlstra M, Sengupta S, Walther FJ, Wagenaar GT. Spatial and temporal expression of surfactant proteins in hyperoxia-induced neonatal rat lung injury. BMC Pulm Med 2006;6:8

46. White CW, Greene KE, Allen CB, Shannon JM. Elevated expression of surfactant proteins in newborn rats during adaptation to hyperoxia. Am J Respir Cell Mol Biol 2001;25:51-9

47. Dombrowsky H, Tschernig T, Vieten G, Rau GA, Ohler F, Acevedo C, Behrens C, Poets CF, von der Hardt H, Bernhard W. Molecular and functional changes of pulmonary surfactant in response to hyperoxia. Pediatr Pulmonol 2006;41:1025-39

48. Andersson S, Kheiter A, Merritt TA. Oxidative inactivation of surfactants. Lung 1999;177:179-89

49. Klekamp JG, Jarzecka K, Perkett EA. Exposure to hyperoxia decreases the expression of vascular endothelial growth factor and its receptors in adult rat lungs. Am J Pathol 1999;154:823-31

50. Hosford GE, Olson DM. Effects of hyperoxia on VEGF, its receptors, and HIF-2alpha in the newborn rat lung. Am J Physiol Lung Cell Mol Physiol 2003;285:L161-8

51. Xu LJ, Mortola JP. Effects of hypoxia or hyperoxia on the lung of the chick embryo. Can J Physiol Pharmacol 1989;67:515-9

52. van Golde JC, Borm PJ, Wolfs MC, Rhijnsburger EH, Blanco CE. Induction of antioxidant enzyme activity by hyperoxia (60 \% 02) in the developing chick embryo. J Physiol 1998;509 ( Pt 1):289-96

53. Nathanielsz PW. Animal models that elucidate basic principles of the developmental origins of adult diseases. ILAR J 2006;47:73-82 



\section{Chapter 8}

Mitochondrial DNA damage analysis

in bronchoalveolar lavage fluid cells

of preterm infants

Zoer B, Been JV, Jongen E, Debeer A, Hendrickx A, Smeets $H$, Zimmermann $L$, Villamor $E$

Front Biosci (Elite Ed) 2010; 2: 361-8 


\begin{abstract}
In mechanically ventilated preterm infants, the combination of immaturity, volutrauma, oxidative stress, and inflammatory processes can lead to chronic lung injury. Mitochondrial DNA (mtDNA) is more susceptible to oxidative damage than nuclear DNA. We aimed to investigate the level of mtDNA damage (deletions, mutations and changes in copy number) in bronchoalveolar lavage (BAL) cells from 10 preterm infants (27-30 weeks). A first BAL (BAL1) was done within $24 \mathrm{~h}$ of endotracheal intubation and BAL2 was performed 30-103 $\mathrm{h}$ thereafter. Deletions were analyzed by long range PCR, point mutations by heteroduplex analysis of the D-loop region, and copy number changes by real-time PCR. Using these methods, no deletions were found in any of the BAL samples. When BAL1 and BAL2 samples were compared no new mutations were found. In contrast, a marked decrease in mtDNA copy number was observed in 5 patients.

In conclusion, we found that exposure of preterm infants to short term mechanical ventilation did not lead to detrimental consequences for the mtDNA in the form of mutations or deletions.
\end{abstract}




\section{Introduction}

In mechanically ventilated preterm infants, immaturity in combination with oxidative stress, volutrauma, and inflammatory processes can lead to chronic lung injury ${ }^{1-6}$. Oxidative damage is found very early in infants subsequently developing chronic lung disease and knowledge is now accumulating on how reactive oxygen species (ROS) trigger cellular and molecular changes that may impair normal pulmonary growth and development ${ }^{1,2}$.

Mitochondrial DNA (mtDNA) is more susceptible to oxidative damage and consequently acquires mutations at a higher rate than nuclear DNA ${ }^{7}$. This is due to exposure to high levels of ROS generated during respiration, lack of protective histones, and limited capacity for repair of DNA damage ${ }^{8}$. Significant damage to mtDNA will compromise cellular respiration, resulting in elevated levels of ROS that cause further injury to mitochondrial and nuclear DNA and, therefore, potentially contribute to chronic lung disease ${ }^{8,9}$. In this study, we hypothesized that mechanical ventilation would induce mtDNA damage in the lung of preterm infants. To test our hypothesis, we conducted a pilot study evaluating mtDNA deletions, mutations and changes in copy number in bronchoalveolar lavage (BAL) cells from preterm infants following endotracheal intubation and within 2-4 days of mechanical ventilation.

\section{Patients and methods}

The study was approved by the Maastricht University Medical Centre Ethics Committee and fully informed, written consent was obtained from the parents of each infant. The study population consisted of ten intubated, mechanically-ventilated preterm infants, whose clinical information is summarized in table 1 . The information about the characteristics of the mechanical ventilation used during the study period is summarized in table 2 . The ten children received surfactant (Curosurf $200 \mathrm{mg} / \mathrm{kg}$; Chiesi Farmaceutica, Parma, Italy) within $2 \mathrm{~h}$ after birth and at least $6 \mathrm{~h}$ before the first BAL. Patients 1, 8, 9, and 10 received a second surfactant dose between the two BAL procedures.

\section{BAL cell collection and processing}

A first BAL (BAL1) was done within $24 \mathrm{~h}$ of endotracheal intubation and a second (BAL2) was performed 30-103 $\mathrm{h}$ (median $48.5 \mathrm{~h}$ ) thereafter. BAL was performed as previously described ${ }^{10}$. Briefly, with the infant lying supine and the head turned to the left, a $6 \mathrm{~F}$ suction catheter was gently inserted into the endotracheal tube until resistance was felt. Then, $1 \mathrm{ml} / \mathrm{kg}$ birth weight of sterile isotonic saline was gently infused into the lung. After 5 $s$, suctioning was performed while slowly retracting the catheter. The procedure was repeated once after which the collected fluid was pooled and placed on ice. From the pooled aspirate, aliquots were taken for total and differential cell count. Haemocytometer counting was used to obtain total cell counts per $\mathrm{ml}$ of BAL fluid and a differential cell 
count was performed on cytospins of BAL cells using May-Grünwald-Giemsa stain. 500 cells were counted on each cytospin. The remainder of the BAL fluid was centrifuged at $300 \times g$ for 10 minutes at $4{ }^{\circ} \mathrm{C}$ and the supernatant and the cells were stored at $-80^{\circ} \mathrm{C}$ until analysis. All subsequent analyses were done by investigators who were blinded to the clinical features of the patients.

Table 1. General characteristics of the patients. $G A=$ gestational age; $H C=$ histologic chorioamnionitis; $\mathrm{AS}=$ antenatal steroids; $\mathrm{MV}=$ mechanical ventilation; $\mathrm{BPD}=$ bronchopulmonary dysplasia; $\mathrm{IVH}$ =intraventricular haemorrhage; Cord $\mathrm{pH}=$ umbilical artery blood $\mathrm{pH}$; $\mathrm{NA}=$ not available. * This child was born at home and transported to the hospital with cyanosis and hypothermia. Blood lactate was $7.9 \mathrm{mmol} / \mathrm{l}$.

\begin{tabular}{|c|c|c|c|c|c|c|c|c|c|c|c|}
\hline $\mathrm{Nr}$ & Sex & $G A(w k s)$ & $\begin{array}{l}\text { Birth } \\
\text { weight }(g)\end{array}$ & $H C$ & $A S$ & Cord $p H$ & $\mathrm{O}_{2} 28 d$ & $\mathrm{O}_{2} 36 \mathrm{w}$ & $\begin{array}{l}\text { Days on } \\
M V\end{array}$ & Died & $\begin{array}{l}\text { Cause of } \\
\text { death }\end{array}$ \\
\hline 1 & $M$ & $28+5$ & 1100 & - & + & 7.29 & - & - & 6 & - & \\
\hline 2 & $M$ & $30+2$ & 880 & - & + & 7.23 & died & died & 12 & day 11 & Sepsis \\
\hline 3 & $\mathrm{~F}$ & $28+0$ & 490 & - & + & 7.28 & + & + & 110 & day 112 & BPD \\
\hline 4 & $M$ & $29+2$ & 1290 & - & + & 7.35 & - & - & 3 & - & \\
\hline 5 & $M$ & $27+3$ & 1110 & + & - & $N A^{*}$ & - & - & 9 & - & \\
\hline 6 & $\mathrm{~F}$ & $27+4$ & 940 & - & - & 7.02 & + & died & 37 & day 50 & IVH \\
\hline 7 & $\mathrm{~F}$ & $28+6$ & 1240 & NA & + & 7.06 & - & - & 5 & - & \\
\hline 8 & $M$ & $29+3$ & 1180 & NA & + & 7.10 & + & - & 6 & - & \\
\hline 9 & $\mathrm{~F}$ & $27+2$ & 980 & NA & + & 7.39 & + & + & 10 & - & \\
\hline 10 & $M$ & $28+0$ & 1135 & - & + & 7.31 & + & + & 8 & - & \\
\hline
\end{tabular}

\section{Detection of deletions in the mitochondrial genome}

Total DNA was isolated according to the manufacturer's procedure using the QIAmp ${ }^{\circledR}$ DNA mini kit from Qiagen. A deletion PCR was performed for the whole mitochondrial DNA. Two primer pairs were used, yielding two mtDNA fragments of 16.1 and $16.0 \mathrm{~kb}$ in size, respectively. Primer sequences for fragment one were 5' CCGCTTCTGGCCACAGCACTTAAACACATC-3', at location 0314-0343, and 5'GGAGGATGGTGGTCAAGGGACCCCTATCTG-3', at location 16411-16382. For fragment 2 primers 5'-CAAGGTGTAGCCCATGAGGTGGCAAG-3', located at 01330-01355, and 5'GCTGCATTGCTGCGTGCTTGATG-3', located at 00778-00756, were used. The PCR mix consisted of Expand Long Template buffer (10x; $27.5 \mathrm{mM} \mathrm{MgCl}_{2}$ ), dNTP-mix containing 8.33 $\mathrm{mM}$ of each base, $100 \mathrm{ng}$ per microliter forward and reverse primer, $5 \mathrm{U}$ per microliter Expand Long Polymerase and 50 ng of DNA in a total volume of 50 microliter.

The PCR was performed using a PCR Perkin Elmer type 9700. First denaturation was achieved at $98{ }^{\circ} \mathrm{C}$ for $30 \mathrm{~s}$, followed by 30 cycles of $10 \mathrm{~s}$ of denaturation at $98^{\circ} \mathrm{C}$ and $8 \mathrm{~min}$ $15 \mathrm{~s}$ annealing at $72{ }^{\circ} \mathrm{C}$, followed by $10 \mathrm{~min}$ of elongation at $72{ }^{\circ} \mathrm{C}$. The PCR products were stored at $4{ }^{\circ} \mathrm{C}$ until use. 25 microliter PCR-products were loaded on ethidium bromide stained $0.7 \%$ agarose gels in TAE-buffer and run for 16 hours at $32 \mathrm{~V}$. After 16 hours a 
picture was taken of the PCR products in the gel and the gel was run for another 16 hours at $32 \mathrm{~V}$. Samples from the DNA bank of our institution were used as controls. The positive control was DNA obtained from muscle tissue of a 45-year-old female, whose mtDNA contained several deletions as a consequence of aging. The negative control was a DNA sample without mtDNA deletions.

Table 2. Ventilatory requirements during admission and between BAL procedures. For HFV ventilation, peak pressures represent amplitude values. $\mathrm{MAP}=$ mean airway pressure; $\mathrm{PIP}=$ peak inspiratory pressure; HFV=high frequency ventilation; SIMV= intermittent mandatory ventilation

\begin{tabular}{|c|c|c|c|c|c|c|c|c|c|}
\hline \multirow[b]{2}{*}{ Nr } & \multirow{2}{*}{$\begin{array}{l}\text { Before } \\
1^{\text {st }} B A L \\
\text { Max } \\
\mathrm{FiO}_{2}(\%)\end{array}$} & \multicolumn{8}{|c|}{ Between BAL procedures } \\
\hline & & $\begin{array}{l}\mathrm{Max} \\
\mathrm{FiO}_{2}(\%)\end{array}$ & $\begin{array}{l}\mathrm{FiO}_{2}>40 \% \\
\text { (\% of time) }\end{array}$ & $\begin{array}{l}\text { NO } \\
\text { (\% of time) }\end{array}$ & $\begin{array}{l}\text { Ventilator } \\
\text { mode }\end{array}$ & $\begin{array}{l}\text { Mean MAP } \\
\left(\mathrm{cm} \mathrm{H}_{2} \mathrm{O}\right)\end{array}$ & $\begin{array}{l}\text { Max MAP } \\
\left(\mathrm{cm} \mathrm{H}_{2} \mathrm{O}\right)\end{array}$ & $\begin{array}{l}\text { Mean PIP } \\
\left(\mathrm{cm} \mathrm{H}_{2} \mathrm{O}\right)\end{array}$ & $\begin{array}{l}\text { Max PIP } \\
\left(\mathrm{cm} \mathrm{H}_{2} \mathrm{O}\right)\end{array}$ \\
\hline 1 & 100 & 25 & 0 & 70 & HFV & 12 & 14 & 16 & 20 \\
\hline 2 & 100 & 30 & 0 & 0 & HFV & 8 & 10 & 14 & 17 \\
\hline 3 & 100 & 65 & 20 & 0 & SIMV & 9 & 10 & 16 & 19 \\
\hline 4 & 50 & 30 & 0 & 0 & SIMV & 9 & 10 & 15 & 20 \\
\hline 5 & 100 & 35 & 0 & 100 & HFV & 8 & 9 & 16 & 21 \\
\hline 6 & 35 & 30 & 0 & 0 & SIMV & 9 & 10 & 16 & 20 \\
\hline 7 & 45 & 25 & 0 & 0 & SIMV & 10 & 11 & 18 & 20 \\
\hline 8 & 30 & 35 & 0 & 0 & SIMV & 11 & 14 & 19 & 25 \\
\hline 9 & 80 & 35 & 0 & 0 & HFV & 11 & 13 & 24 & 27 \\
\hline 10 & 65 & 45 & 10 & 0 & $\mathrm{HFV} / \mathrm{SIMV}$ & 10 & 14 & 24 & 29 \\
\hline
\end{tabular}

\section{Mutation detection in the mitochondrial D-loop}

Another set of PCRs was performed to yield three fragments (fragment 1, 2 and 3 from the MitoScreen ${ }^{\mathrm{TM}}$ Assay Kit, Transgenomic, Elancourt, France) spanning the mutation hot spot D-loop region of the mtDNA, that were subjected to denaturing HPLC (DHPLC) analysis. The first primer pair (5'-CTCCACCATTAGCACCCAAAGC-3' and 5'GAGGATGGTGGTCAAGGGACC-3') was used to amplify the region between 15974$16409 \mathrm{bp}$, the second primer pair (5'-TACAGTCAAATCCCTTCTCGTCC-3' and 5'TCCAGCGTCTCGCAATGCTATC-3') was used to amplify the region between 102-16341bp, and the third primer pair (5'-CTCACGGGAGCTCTCCATGCAT-3' and 5'ATTAGTAGTATGGGAGTGGGAGG-3') was used to amplify the region between 29-480 bp. The PCR mix contained $10 *$ Optimase ${ }^{\circledR}$ reaction buffer with $\mathrm{MgSO}_{4}$, dNTP mix containing $10 \mathrm{mM}$ of each dNTP, Optimase Polymerase $2.5 \mathrm{U}, 100 \mathrm{ng}$ DNA, and $100 \mathrm{ng}$ of both primers in a total volume of $50 \mu \mathrm{l}$.

The PCR was performed using a Thermocycler (Perkin Elmer type 9700). Denaturation was achieved at $95{ }^{\circ} \mathrm{C}$ for $2 \mathrm{~min}$, then the samples were subjected to 30 cycles of $30 \mathrm{~s}$ of denaturation at $95{ }^{\circ} \mathrm{C}, 30 \mathrm{~s}$ of annealing at $56^{\circ} \mathrm{C}, 3 \mathrm{~min}$ of elongation at $72{ }^{\circ} \mathrm{C}$, followed by 
5 min of elongation at $72{ }^{\circ} \mathrm{C}$. PCR products were stored at $4{ }^{\circ} \mathrm{C}$ until use. Heteroduplex formation was achieved by heating the PCR products at $95{ }^{\circ} \mathrm{C}$ for $5 \mathrm{~min}$. Then the samples were cooled at a rate of $1.5{ }^{\circ} \mathrm{C} / \mathrm{min}$ until a temperature of $25^{\circ} \mathrm{C}$ was reached. Next, the samples were placed in the $\mathrm{WAVE}^{\circledR}$ nucleic acid fragment analysis system for analyses. The DNA was initially mixed with triethyl ammonium acetate, which functions as an ion pairing reagent. This enables size based binding of the hydrophilic DNA to the hydrophobic DNASep ${ }^{\circledR}$ Matrix.

Heat was used as a denaturant, in conjunction with the hydrophobic eluant acetonitrile, which lead to elution of the DNA from the matrix according to helicity and size. DNA containing a heteroduplex (and thus a mutation) will elute earlier from the matrix than the homoduplex species. In this way the chromatogram pattern changes and the presence of a mutation can be detected. WAVE ${ }^{\circledR}$ Control Standards were used to ensure quality during the analysis. This includes the WAVE ${ }^{\circledR}$ DNA Sizing Control Sample, the Low Range Mutation Control Standard, the Mid Range Mutation Control Sample and the High Range Mutation Control Standard. The temperatures at which $8 \mu$ of the PCR products was analyzed by DHPLC were optimized for each individual fragment: $50{ }^{\circ} \mathrm{C}$ and $58{ }^{\circ} \mathrm{C}$ for fragment 1,50 ${ }^{\circ} \mathrm{C}$ and $60^{\circ} \mathrm{C}$ for fragment 2 and $50{ }^{\circ} \mathrm{C}, 57{ }^{\circ} \mathrm{C}$ and $59{ }^{\circ} \mathrm{C}$ for fragment 3 . The resulting chromatograms from BAL1 and BAL2 were compared between each other and with standards.

\section{mtDNA copy number analysis}

To analyze potential changes in copy number of mtDNA as a consequence of mechanical ventilation, Real-Time PCR was performed for the nuclear RNase $P$ gene and the mtDNA encoded 12S-RNA gene. The PCR mix contained Taqman ${ }^{\circledR}$ Universal PCR Master Mix, $\operatorname{TaqMan}^{\circledR}$ RNase $\mathrm{P}$ Control Reagents Kit (VIC ${ }^{\mathrm{TM}}$ Probe), primers $12 \mathrm{~S}$ (3'CCCCAGGGTTGGTCAATTT-5' and 3'-CTATTGACTTGGGTTAATCGTGTGA-5') and Taqman ${ }^{\circledR}$ probe $12 S$ (3'-TGCCAGCCACCGCG-5') 6 pmol.

The PCR was performed in an ABI Prism 7000 Sequence Detection System. Amplitaq Gold activation was obtained at $95{ }^{\circ} \mathrm{C}$ for 10 minutes, followed by 40 cycles of denaturation for $15 \mathrm{~s}$ at $95^{\circ} \mathrm{C}$ and annealing and extension at $60^{\circ} \mathrm{C}$ for $1 \mathrm{~min}$. A standard DNA dilution was made to plot a standard curve to determine the efficiency of the PCR. Every sample was analyzed in duplicate. The efficiency was calculated by the formula Eff $=10-$ 1 slope. Relative copy number (Rc) was calculated by expressing threshold cycle number differences of the nuclear gene and the mitochondrial gene PCR, as described by Ritov et $a l^{11}: \mathrm{Rc}=2^{\text {(Ct nDNA-Ct mtDNA) }}$, where $\mathrm{Ct}$ is the threshold cycle number.

\section{Results}

Total and differential BAL cell counts are presented in Table 3. More detailed BAL cytospin data from patient 3, who experienced severe pneumonia, have previously been reported 12. When the mtDNA of the BAL cells was screened for deletions none of the samples 
showed positive results. Figure 1 shows an example of the PCR products that were exposed to gel electrophoresis for $32 \mathrm{~h}$. The positive control shows several bands, which indicate deletions in the DNA of this sample (muscle tissue from a 45-year-old female, whose mtDNA contained several deletions as a consequence of aging). In contrast, no extra bands are observed in the mtDNA of BAL1 and BAL2 samples, as well as in the negative control.

Table 3. Cell content in BAL-fluid.

\begin{tabular}{lllll}
\hline & BAL1 & & BAL2 & \\
& median & range & median & range \\
\hline Cell count $\left({ }^{*} 10^{-6}\right.$ cells $\left./ \mathrm{ml}\right)$ & 0.93 & $0.30-4.27$ & 0.80 & $0.46-8.82$ \\
Macrophages $(\%)$ & 25 & $5-88$ & 58 & $25-72$ \\
Neutrophils (\%) & 73 & $11-95$ & 38 & $10-73$ \\
Lymphocytes (\%) & 0.7 & $0-2.0$ & 0.8 & $0-19$ \\
Eosinophils (\%) & 0 & $0-1.0$ & 0 & $0-0$ \\
\hline
\end{tabular}

When BAL1 and BAL2 samples were compared, no newly formed mutations in the D-loop of the mtDNA were observed. Figure 2 shows an example of the DHPLC output from BAL1 and BAL2 DNA of two children. As can be seen in the figure, no new heteroduplexes were found in the analyzed products.

The results of the mtDNA copy number analysis are presented in Table 4. One of the samples was not successfully amplified despite the availability of ample genetic material. Five of the BAL2 samples analyzed showed a decrease in the relative mtDNA copy number when compared to the corresponding BAL1. Two of the samples showed no change and two showed an increase in mtDNA copy number. The efficiency of this PCR was 1.97.

\section{Discussion}

Documentation of mtDNA damage in vivo after acute insults is sparse compared with the number of in vitro studies that have demonstrated oxidative injury to mtDNA ${ }^{13}$. To the best of our knowledge, this is the first study addressing the putative mtDNA damage induced by mechanical ventilation in humans. We observed, in a population of ten preterm infants, that 2-4 days of mechanical ventilation with oxygen concentrations up to $100 \%$, and in some cases in combination with $\mathrm{NO}$, did not induce any detectable mutation or deletion in the mtDNA isolated from BAL cells. However, in five of the samples a decrease in mtDNA copy number was detected.

Our findings raise several points of discussion. First of all, whether the methods used are sensitive enough to detect mtDNA deletions and mutations. The deletion PCR we con- 
structed is considered as a sensitive method with a detection limit of $0.5-1 \%{ }^{14,15}$. Single base mutations in mtDNA can not be detected by deletion PCR. Therefore we performed heteroduplex analysis using the DHPLC method ${ }^{16,17}$ to screen the D-loop region (a mutation hot spot region in the mtDNA) ${ }^{18}$. This method has a $97-100 \%$ efficiency of mutation detection (confirmed by sequencing the abnormal PCR-products) and a threshold of 1-5\% for detection of a specific mutation ${ }^{16,17}$. Mutations can randomly occur across the DNA fragments and it can be expected that each mutation would eventually lead to a heteroduplex and an altered migration pattern producing altered peak or peaks, which would contain mixtures of different mutations. Differences in these peak patterns were not observed when BAL1 and BAL2 samples were compared, indicating that new mutations were not present. Other techniques, with very high sensitivity for mutation detection have been recently described. One mutation among 109 bases can be detected with the random mutation capture (RMC) method ${ }^{19,20}$. Whether this method could detect mutations that we did not find with the DHPLC method remains to be investigated.

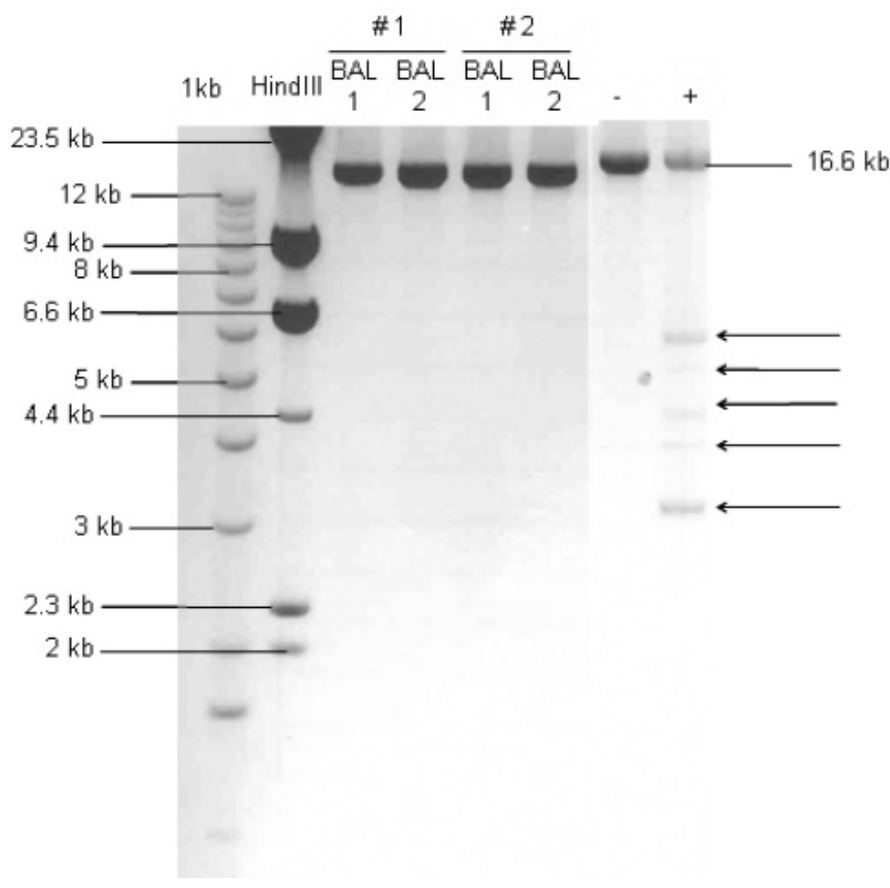

Figure 1. Representative examples of deletion PCR products from patient 1 (lane 3 and 4 ) and 2 (lane 5 and 6 ). Positive and negative controls are shown in lane 7 and 8 respectively. A 1 kb DNA ladder (lane 1 ) as well as a HindIII ladder (lane 2) were used to identify the PCR product size. A size of about $16 \mathrm{~kb}$ is a PCR product from DNA without deletions. The positive control (muscle tissue from a 45-year-old female with known deletions from aging) shows several products (arrows), apart from the $16 \mathrm{~kb}$ fragment, indicating deletions in part of the mtDNA. BAL1: first BAL; BAL2: second BAL. 

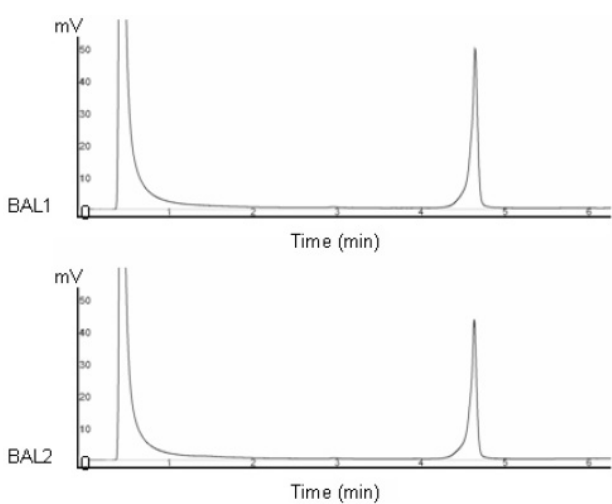
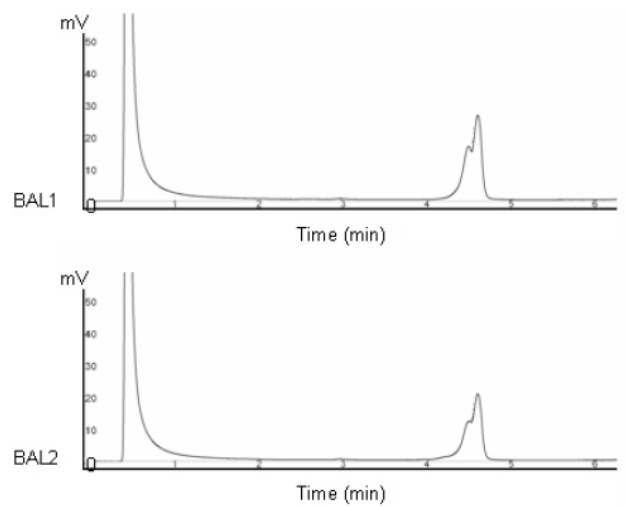

Figure 2. Representative examples of the DHPLC analysis for mutations in the mtDNA. The $x$-axis represents the retention time in minutes, which is dependent on the length of the product analyzed; the $y$-axis is a measure of absorbance (converted to $\mathrm{mV}$ ). The two panels on the left show an example of a normal homoduplex pattern in both BAL1 and BAL2 of patient 7. The two panels on the right show the presence of similar heteroduplexes in both BAL1 and BAL2 of patient 9, indicating the presence of mutations that did not change between the two BAL procedures.

Table 4. Relative mtDNA copy number. Relative copy number was calculated by the formula $2^{\text {(Ct nDNA-Ct mtDNA) }}$ where $\mathrm{Ct}$ is the threshold cycle number of the nuclear gene and the mitochondrial gene PCR (see methods for details).

\begin{tabular}{lll}
\hline$\#$ & $B A L 1$ & $B A L 2$ \\
\hline 1 & - & - \\
2 & 248.24 & 466.45 \\
3 & 133.90 & 195.76 \\
4 & 1243.33 & 130.33 \\
5 & 311.32 & 190.71 \\
6 & 455.50 & 201.39 \\
7 & 251.75 & 275.03 \\
8 & 406.42 & 426.29 \\
9 & 208.69 & 74.96 \\
10 & 312.45 & 216.77 \\
\hline
\end{tabular}

Also the intensity and duration of the insult in the studied population could be related to our negative results. It can be argued that higher levels of or longer exposures to oxidative stress would be necessary to induce mtDNA deletions or mutations. The majority of the patients in our population were exposed to high concentrations of oxygen at birth, when resuscitation was performed. A preceding hypoxic period appeared to be present in four cases (Table 1). Afterwards, between the two moments of sampling, patients were gener- 
ally exposed to gentle mechanical ventilation and the majority did not need oxygen-rich gas.

With the advent of surfactant therapy and the widespread use of antenatal steroids, the clinical picture of infant RDS changed considerably ${ }^{1}$. Nowadays, preterm newborns often require little supplemental oxygen during their initial postnatal course, and it is uncommon for such infants to receive mechanical ventilation with high inflation pressures or large tidal volumes ${ }^{1}$. Interestingly, it has been suggested that the inflammatory response is more likely than hyperoxia to lead to pulmonary oxidative damage in mechanically ventilated preterm infants ${ }^{5}$. On the other hand, our understanding of the ill effects of brief oxygen exposure at birth has been increased significantly and it has been shown that hyperoxia, even for short periods and particularly following a previous hypoxic insult, contributes to the development of several neonatal morbidities ${ }^{1,2,21-23}$. In this regard, oxygen administration in the delivery room has become a matter of discussion in the last years ${ }^{21-24}$. Moreover, an association has been suggested between the DNA damage induced by post-hypoxic neonatal exposure to high oxidative stress and childhood cancer $23,25,26$. In the present work, we analyzed mtDNA, which is more susceptible to oxidative damage than nuclear DNA ${ }^{7}$. However, our data suggest that in a normal clinical setting of mechanical ventilation DNA deletions or mutations are not produced or, alternatively, they have been repaired, although repair systems are less efficient for the mtDNA than for the nuclear DNA ${ }^{7,8}$.

There is overwhelming evidence from in vitro studies that oxidative stress damages DNA ${ }^{7,8,27}$. Also, in vivo experimental studies using exposure to hyperoxia in premature baboons ${ }^{28}$, neonatal rats ${ }^{29}$, adult rats ${ }^{30,31}$, and adult mice ${ }^{32}$ demonstrated pulmonary oxidative nuclear DNA damage. The urinary levels of 8-hydroxy-2'-deoxyguanosine, a marker of oxidative DNA damage, were significantly higher in preterm infants requiring supplemental oxygen and ventilator support than in nonmechanically ventilated preterm and healthy term neonates ${ }^{33}$. To the best of our knowledge, only one study has analyzed pulmonary mtDNA integrity after in vivo hyperoxic exposure ${ }^{13}$. In consonance with our results, Lightfoot et al. observed that hyperoxia (24-48 $\mathrm{h}$ of $95 \%$ oxygen in adult rats) failed to induce significant injury to mtDNA and only when combined with NO inhalation transient mtDNA damage was produced. They speculate that efficient removal of ROS by mitochondrial antioxidant systems or upregulation during hyperoxia of mtDNA repair systems may be the explanation for the lack of injury in the mtDNA ${ }^{13}$.

In five cases, we found a decrease in the relative mtDNA copy number between BAL1 and BAL2. With our limited sample size, we can only speculate about this finding. As different cell types contain different amounts of mtDNA, our finding may simply reflect the differences in BAL cell composition between the two moments of sampling. The majority of the studies dealing with the effects of oxidant stress on mtDNA copy number have been focused on chronic exposure to the insult and they demonstrated an increase in the copy number (see 8 for a review). This has been suggested to be a compensatory mechanism for defective mitochondria bearing impaired respiratory chain or mutated mtDNA ${ }^{8}$. Be- 
cause ROS generation by the mitochondrial respiratory chain is a continuous physiological occurrence, mitochondria have an efficient antioxidant system composed of superoxide dismutase, glutathione peroxidase, glutathione reductase, glutathione, NAD(P) transhydrogenase, NADPH, vitamins $E$ and $C$, thiol peroxidases and mitochondrial respiration itself 34,35 . However, when the capacity of antioxidant system is compromised, the exposure to higher oxidative stress may result in an increase of defective mitochondria beyond a noncompensable level and thus, a cyclic increase in ROS production leading to mitochondrial lipid peroxidation and a decrease in mtDNA copy number ${ }^{8,27,36}$. This could drive the cell into an irreversible cell death process ${ }^{8,37}$ that would lead to an increase in extracellular mtDNA with proinflammatory effects, thereby creating a vicious circle of inflammation and cell destruction ${ }^{38}$. Although it is generally accepted that extracellular and cytosolic antioxidant defenses are reduced in preterm infants ${ }^{2,4}$, this has not been demonstrated for the mitochondrial antioxidant system. Therefore, the putative maturational changes in the mitochondrial antioxidant and DNA reparation systems and their possible role in chronic lung disease require further investigation.

Although the pathogenesis of chronic lung disease of the premature infant remains unclear, much evidence suggests that reflects abnormal growth and repair of the immature lung exposed to the continuous stress of repetitive inflation with oxygen -rich gas in a setting of chronic inflammation, often aggravated by recurrent infection ${ }^{1}$. An important part of these pathogenetic insights has been obtained through the analysis of BAL fluid and cells ${ }^{3-6,10,12,39}$. Our pilot study proposes a new approach for the evaluation of lung injury and shows that the analysis of BAL cell mtDNA is feasible tool for testing the putative effects of oxidative stress during mechanical ventilation. However, and against our initial hypothesis, we could not find any detectable mtDNA mutation or deletion. The validity of our findings is limited by several factors such as the sample size, the relative inhomogeneity of the sample, the lack of parallel measurement of other oxidative stress markers, or the relative short exposure to the oxidative stimulus. The idea of our study was based on three generally accepted paradigms: I) Preterm newborns are very susceptible to oxidative stress $2,4,21,23,24,33$; II) Oxidative stress plays a significant role in the pathophysiology of ventilator-induced injury ${ }^{1,2,4}$; and III) mtDNA is highly vulnerable to oxidative stress ${ }^{7-9}$. Further studies including larger samples, which include longer periods and different strategies of mechanical ventilation, as well as different methods to evaluate mtDNA damage and function will be needed to assess whether the above paradigms also apply to the real clinical situation of mechanically ventilated preterm infants.

\section{References}

1. Bland RD. Neonatal chronic lung disease in the post-surfactant era. Biol Neonate 2005;88:181-91

2. Saugstad OD. Bronchopulmonary dysplasia-oxidative stress and antioxidants. Semin Neonatol 2003;8:3949 
3. Capoluongo E, Ameglio F, Lulli P, Minucci A, Santonocito C, Concolino P, Di Stasio E, Boccacci S, Vendettuoli V, Giuratrabocchetta G, De Cunto A, Tana M, Romagnoli C, Zuppi C, Vento G. Epithelial lining fluid free IGFI-to-PAPP-A ratio is associated with bronchopulmonary dysplasia in preterm infants. Am J Physiol Endocrinol Metab 2007;292:E308-13

4. Vento G, Mele MC, Mordente A, Romagnoli C, Matassa PG, Zecca E, Zappacosta B, Persichilli S. High total antioxidant activity and uric acid in tracheobronchial aspirate fluid of preterm infants during oxidative stress: an adaptive response to hyperoxia? Acta Paediatr 2000;89:336-42

5. Collard KJ, Godeck S, Holley JE, Quinn MW. Pulmonary antioxidant concentrations and oxidative damage in ventilated premature babies. Arch Dis Child Fetal Neonatal Ed 2004;89:F412-6

6. De Luca D, Baroni S, Vento G, Piastra M, Pietrini D, Romitelli F, Capoluongo E, Romagnoli C, Conti G, Zecca E. Secretory phospholipase A2 and neonatal respiratory distress: pilot study on broncho-alveolar lavage. Intensive Care Med 2008;34:1858-64

7. Yakes FM, Van Houten B. Mitochondrial DNA damage is more extensive and persists longer than nuclear DNA damage in human cells following oxidative stress. Proc Natl Acad Sci U S A 1997;94:514-9

8. Lee $\mathrm{HC}$, Wei $\mathrm{YH}$. Mitochondrial biogenesis and mitochondrial DNA maintenance of mammalian cells under oxidative stress. Int J Biochem Cell Biol 2005;37:822-34

9. Ballinger SW, Bouder TG, Davis GS, Judice SA, Nicklas JA, Albertini RJ. Mitochondrial genome damage associated with cigarette smoking. Cancer Res 1996;56:5692-7

10. Dik WA, Zimmermann L, Naber BA, Janssen DJ, van Kaam AH, Versnel MA. Thrombin contributes to bronchoalveolar lavage fluid mitogenicity in lung disease of the premature infant. Pediatr Pulmonol 2003;35:34-41

11. Ritov VB, Menshikova EV, He J, Ferrell RE, Goodpaster BH, Kelley DE. Deficiency of subsarcolemmal mitochondria in obesity and type 2 diabetes. Diabetes 2005;54:8-14

12. Been JV, Linssen CF, van Iwaarden JF, Zimmermann LJ. Massive bacterial cell invasion and reactive type II pneumocytes in bronchoalveolar lavage fluid from a preterm neonate. Arch Dis Child Fetal Neonatal Ed 2007;92:F319

13. Lightfoot RT, Khov S, Ischiropoulos H. Transient injury to rat lung mitochondrial DNA after exposure to hyperoxia and inhaled nitric oxide. Am J Physiol Lung Cell Mol Physiol 2004;286:L23-9

14. Tengan $\mathrm{CH}$, Moraes CT. Detection and analysis of mitochondrial DNA deletions by whole genome PCR. Biochem Mol Med 1996;58:130-4

15. De Coo IF, Gussinklo T, Arts PJ, Van Oost BA, Smeets HJ. A PCR test for progressive external ophthalmoplegia and Kearns-Sayre syndrome on DNA from blood samples. J Neurol Sci 1997;149:37-40

16. van Den Bosch BJ, de Coo RF, Scholte HR, Nijland JG, van Den Bogaard R, de Visser M, de Die-Smulders CE, Smeets HJ. Mutation analysis of the entire mitochondrial genome using denaturing high performance liquid chromatography. Nucleic Acids Res 2000;28:E89

17. Xiao W, Oefner PJ. Denaturing high-performance liquid chromatography: A review. Hum Mutat 2001;17:439-74

18. Mambo E, Gao X, Cohen Y, Guo Z, Talalay P, Sidransky D. Electrophile and oxidant damage of mitochondrial DNA leading to rapid evolution of homoplasmic mutations. Proc Natl Acad Sci USA 2003;100:1838-43

19. Bielas JH, Loeb LA. Quantification of random genomic mutations. Nat Methods 2005;2:285-90

20. Vermulst M, Bielas JH, Loeb LA. Quantification of random mutations in the mitochondrial genome. Methods 2008;46:263-8

21. Saugstad OD, Ramji S, Vento M. Oxygen for newborn resuscitation: how much is enough? Pediatrics 2006;118:789-92

22. Escrig R, Arruza L, Izquierdo I, Villar G, Saenz P, Gimeno A, Moro M, Vento M. Achievement of targeted saturation values in extremely low gestational age neonates resuscitated with low or high oxygen concentrations: a prospective, randomized trial. Pediatrics 2008;121:875-81

23. Saugstad OD. Optimal oxygenation at birth and in the neonatal period. Neonatology 2007;91:319-22

24. Vento M, Asensi M, Sastre J, Garcia-Sala F, Pallardo FV, Vina J. Resuscitation with room air instead of $100 \%$ oxygen prevents oxidative stress in moderately asphyxiated term neonates. Pediatrics 2001;107:642-7 
25. Maruyama K, Ikeda H, Koizumi T, Tsuchida Y, Tanimura M, Nishida H, Takahashi N, Fujimura M, Tokunaga Y. Case-control study of perinatal factors and hepatoblastoma in children with an extremely low birthweight. Pediatr Int 2000;42:492-8

26. Spector LG, Klebanoff MA, Feusner JH, Georgieff MK, Ross JA. Childhood cancer following neonatal oxygen supplementation. J Pediatr 2005;147:27-31

27. Suematsu N, Tsutsui H, Wen J, Kang D, Ikeuchi M, Ide T, Hayashidani S, Shiomi T, Kubota T, Hamasaki N, Takeshita A. Oxidative stress mediates tumor necrosis factor-alpha-induced mitochondrial DNA damage and dysfunction in cardiac myocytes. Circulation 2003;107:1418-23

28. Maniscalco WM, Watkins RH, Roper JM, Staversky R, O'Reilly MA. Hyperoxic ventilated premature baboons have increased p53, oxidant DNA damage and decreased VEGF expression. Pediatr Res 2005;58:549-56

29. Auten RL, Whorton MH, Nicholas Mason S. Blocking neutrophil influx reduces DNA damage in hyperoxiaexposed newborn rat lung. Am J Respir Cell Mol Biol 2002;26:391-7

30. Lee J, Reddy R, Barsky L, Weinberg K, Driscoll B. Contribution of proliferation and DNA damage repair to alveolar epithelial type 2 cell recovery from hyperoxia. Am J Physiol Lung Cell Mol Physiol 2006;290:L685L94

31. Roper JM, Mazzatti DJ, Watkins RH, Maniscalco WM, Keng PC, O'Reilly MA. In vivo exposure to hyperoxia induces DNA damage in a population of alveolar type II epithelial cells. Am J Physiol Lung Cell Mol Physiol 2004;286:L1045-54

32. Barker GF, Manzo ND, Cotich KL, Shone RK, Waxman AB. DNA damage induced by hyperoxia: quantitation and correlation with lung injury. Am J Respir Cell Mol Biol 2006;35:277-88

33. Tsukahara H, Jiang MZ, Ohta N, Sato S, Tamura S, Hiraoka M, Maeda M, Mayumi M. Oxidative stress in neonates: evaluation using specific biomarkers. Life Sci 2004;75:933-8

34. O'Donovan DJ, Fernandes CJ. Mitochondrial glutathione and oxidative stress: implications for pulmonary oxygen toxicity in premature infants. Mol Genet Metab 2000;71:352-8

35. Buonocore G, Perrone S, Bracci R. Free radicals and brain damage in the newborn. Biol Neonate 2001;79:180-6

36. Tsutsui H. Mitochondrial oxidative stress and heart failure. Intern Med 2006;45:809-13

37. Ricci C, Pastukh V, Leonard J, Turrens J, Wilson G, Schaffer D, Schaffer SW. Mitochondrial DNA damage triggers mitochondrial-superoxide generation and apoptosis. Am J Physiol Cell Physiol 2008;294:C413-22

38. Collins LV, Hajizadeh S, Holme E, Jonsson IM, Tarkowski A. Endogenously oxidized mitochondrial DNA induces in vivo and in vitro inflammatory responses. J Leukoc Biol 2004;75:995-1000

39. Schock BC, Sweet DG, Halliday HL, Young IS, Ennis M. Oxidative stress in lavage fluid of preterm infants at risk of chronic lung disease. Am J Physiol Lung Cell Mol Physiol 2001;281:L1386-91 


\section{Part 3}

Clinical observations 


\section{Chapter 9}

Histologic chorioamnionitis, fetal

involvement, and antenatal steroids: effects on neonatal outcome in preterm infants

Been JV, Rours IG, Kornelisse RF, Lima Passos V, Kramer BW, Schneider TA, de Krijger RR, Zimmermann $L$

Am J Obstet Gynecol 2009; 201: 587.e1-8 


\section{Abstract}

Objective: The objective of the study was to study the effects of histologic chorioamnionitis (HC) with or without fetal involvement and antenatal steroid (AS) exposure on neonatal outcome in a prospective cohort of preterm infants.

Study design: The clinical characteristics and placental histology were prospectively collected in 301 infants born at a gestational age 32.0 weeks or less in the Erasmus University Medical Center.

Results: In univariable analyses, HC without fetal involvement $(n=53)$ was associated with decreased severe respiratory distress syndrome (RDS) ( $11 \%$ vs $28 \%$; $P<.05$ ), whereas $\mathrm{HC}$ with fetal involvement infants $(\mathrm{n}=68)$ had more necrotizing enterocolitis ( $9 \%$ vs $2 \%$; $P$ $<.05)$, intraventricular hemorrhage (IVH) $(25 \%$ vs $12 \% ; P<.05)$, and neonatal mortality (19\% vs $9 \%$; $P$ <.05). In HC without fetal involvement infants, AS reduced the incidences of RDS (43\% vs $85 \% ; P<.05)$ and IVH (5\% vs $39 \% ; P<.01)$. In multivariable analyses, HC without fetal involvement was associated with decreased severe RDS (odds ratio, 0.22; 95\% confidence interval, $0.05-0.93 ; P<.05$ ) and increased early-onset sepsis (odds ratio, 2.22; $95 \%$ confidence interval, $1.02-4.83 ; P<.05)$.

Conclusion: In a prospective cohort of preterm infants, multivariable analyses reveal only a modest association between histologic chorioamnionitis and neonatal outcome. 


\section{Introduction}

Chorioamnionitis is an important cause of preterm birth. Consequently, the majority of very preterm infants has been exposed to chorioamnionitis, as shown by placental histology ${ }^{1}$. Several reports have linked histologic chorioamnionitis to adverse neonatal outcome.

Adverse neonatal outcome parameters most frequently associated with histologic chorioamnionitis in preterm infants include intraventricular hemorrhage (IVH), cerebral white matter abnormalities, and bronchopulmonary dysplasia (BPD) ${ }^{2-9}$. Conversely, histologic chorioamnionitis has been reported to reduce the incidence of respiratory distress syndrome (RDS) ${ }^{4,9-15}$. The additional presence of a fetal inflammatory response seems to enhance the detrimental effects of chorioamnionitis on neonatal outcome ${ }^{6,9,11,16,17}$. More recently several studies have linked chorioamnionitis to diseases beyond the neonatal period, such as cerebral palsy ${ }^{16}$, autism ${ }^{18}$, recurrent otitis media with effusion ${ }^{19}$, and asthma ${ }^{20}$.

The vast majority of studies investigating the associations between histologic chorioamnionitis and adverse outcome have been retrospective in nature. Differences in inclusion and exclusion criteria between studies, as well as methodological issues, raise questions of external validity of the obtained data ${ }^{9}$. Moreover, in many reports the data were not adjusted for important confounding variables, the most prominent being gestational age ${ }^{9}$. Very few studies evaluated the combined effects of antenatal steroids and chorioamnionitis and separated the effects of histologic chorioamnionitis with and without fetal involvement on neonatal outcome ${ }^{9}$.

Our aim was to explore the association between histologic chorioamnionitis and neonatal outcome in a prospective cohort of preterm infants, with particular focus on the distinct effects of chorioamnionitis with and without fetal involvement and the modulatory role of antenatal steroids. Multivariable models are used to adjust for potential confounders.

\section{Materials and methods}

\section{$\underline{\text { Design }}$}

This was a prospective, observational, nontherapeutic study with the aim to examine the association of histologic chorioamnionitis in early preterm delivery with neonatal outcome. Pregnant women, who delivered between May 2001-February 2003 in the Erasmus University Medical Center-Sophia Children's Hospital in Rotterdam, The Netherlands, at a gestational age of 32.0 weeks or less, were eligible for the study. Routine health care workers (residents, research-nursing staff, and neonatologists) informed the women about the study. 
Enrolment was immediately after delivery when the newborns were admitted to the neonatal intensive care unit. Antenatal, perinatal, and neonatal data were prospectively stored in a database. Neonates who were transferred to another hospital were followed up to complete the data. Women received antenatal steroids (betamethasone $12 \mathrm{mg}$ intramuscularly, repeated after 24 hours) in case of imminent premature delivery.

We used the following clinical definitions. Clinical chorioamnionitis included maternal temperature greater than $38.0^{\circ} \mathrm{C}$ in the absence of another focus for infection, with 2 or more of the following criteria: uterine tenderness, malodorous vaginal discharge, maternal leucocytosis (white blood cell count $>15,000$ cells $/ \mu \mathrm{L}$ ), raised serum C-reactive protein (CRP), maternal tachycardia ( $>100$ beats/min), and fetal tachycardia ( $>160$ beats $/ \mathrm{min}$ ). Preeclampsia was comprised of new onset hypertension (blood pressure $>140 / 90 \mathrm{~mm} \mathrm{Hg}$ or mean arterial pressure $>105 \mathrm{~mm} \mathrm{Hg}$ ) with proteinuria and/or edema. HELLP syndrome (clinical presentation of intravascular hemolysis, elevated liver enzymes, and a low platelet count). Fetal distress was considered present when indicated by the obstetrician based on cardiotocographic criteria.

Small for gestational age (SGA) was defined as birth weight less than 2 SD of the mean for gestational age. RDS was a clinical presentation (expiratory grunting, sub- or intercostal or sternal retractions, nasal flaring, tachypnea, cyanosis in room air with or without apnea) and characteristic radiographic appearance according to Giedion et al. ${ }^{21}$. BPD was a dependency on oxygen supplementation at a postmenstrual age of 36 weeks. IVH and cystic periventricular leukomalacia (PVL) were defined according to Volpe ${ }^{22}$. Clinical neonatal sepsis was a clinical presentation of sepsis with raised CRP. Culture-proven neonatal sepsis was any systemic bacterial infection documented by a positive blood or cerebrospinal fluid culture in the first 2 months of life. Early-onset neonatal sepsis was neonatal sepsis occurring during the first 72 hours of life. Necrotizing enterocolitis (NEC) was defined as stage 2 or higher according to Bell et al. ${ }^{23}$. Patent ductus arteriosus (PDA) was persistence of the open ductus arteriosus postnatally, as demonstrated by ultrasonographic examination. Ethnicity was self-classified in this study. Gestational age was estimated by ultrasonography or by using the last menstrual period when reliable.

\section{Histopathology}

Placentae and membranes were fixed in formalin for at least 16 hours immediately after delivery. Sampling was performed according to a standard protocol with 2 membrane rolls, 2 cross-sections of the cord, and 3 representative blocks of the placental disk as a minimum. The tissues were embedded in paraffin until histopathologic examination.

To prevent interexaminer variation, the same pathologist (R.R.d.K.) examined all placentas for histologic evidence of infection. The pathologist was blinded to clinical information. Placental infection was categorized according to the stages of maternal and fetal inflammatory response, as suggested by the Amniotic Fluid Infection Nosology Committee

${ }^{24}$. According to these guidelines, fetal involvement was diagnosed when any of the follow- 
ing was present: chorionic vasculitis, umbilical phlebitis or vasculitis, (subacute) necrotizing funisitis, or concentric umbilical perivasculitis.

\section{Ethical aspects}

The study was approved by the Medical Ethics Committee for Research on Human Subjects of the Erasmus University Medical Center, Rotterdam, The Netherlands.

\section{Statistics}

Data are presented as mean \pm SD for continuous data, and median and interquartile range for ordinal data. Dichotomous data are expressed as frequencies and associated percentages. Depending on the variable at stake, groups' comparisons were carried out with either parametric or nonparametric tests (Student $t$ test or 1-way analysis of variance [ANOVA] with Dunnett's post hoc analysis for the former and Mann-Whitney $U$ test or Kruskall-Wallis test for the latter). $\chi^{2}$ or Fisher exact test was used for categorical data.

Logistic multiple regression analysis was conducted to estimate the adjusted effects of the main explanatory variables of interest (gestational age and histologic chorioamnionitis with or without fetal involvement), as well as other potential predictors on the dichotomous outcomes (RDS, severe RDS, PDA [early-onset] sepsis, IVH, severe IVH, cystic PVL, NEC, BPD, and neonatal mortality). Other potential predictors were the following: birth weight, ethnicity, sex, antenatal steroids, HELLP syndrome, preeclampsia, umbilical artery $\mathrm{pH}$, mechanical ventilation (for BPD and mortality), PDA (for BPD and mortality), sepsis (for BPD and mortality), early-onset sepsis (for PDA and IVH), severe IVH, and NEC (both for mortality). The specified variables were entered in the start model together with a few prespecified 2-way interaction terms deemed as clinically relevant. A topdown procedure for variables selection was handled. Statistical analyses were performed using SPSS 15.0 software (SPSS, Inc, Chicago, IL).

\section{Results}

\section{Maternal and delivery characteristics}

Three hundred one preterm infants were included in the study. Histologic chorioamnionitis was present in 121 of these (40.2\%), 68 (56.2\%) of whom had signs of fetal involvement. Of the latter, all but 4 had inflammatory signs of both the fetal and maternal compartment. Maternal and delivery characteristics for the groups are shown in Table 1.

Both chorioamnionitis groups had lower gestational age and significantly higher rates of clinical chorioamnionitis and preterm premature rupture of membranes when compared with infants without chorioamnionitis. Conversely, mothers of infants without chorioamnionitis were more likely to have HELLP syndrome and preeclampsia and deliver by cesarean section. Their infants more often were SGA and more frequently experienced fetal distress, also reflected in lower umbilical cord $\mathrm{pH}$ and base excess. 
Table 1. Maternal and delivery characteristics.

\begin{tabular}{|c|c|c|c|c|}
\hline \multicolumn{2}{|c|}{ Maternal characteristics } & $H C-(n=180)$ & $H C+F-(n=53)$ & $H C+F+(n=68)$ \\
\hline \multicolumn{2}{|c|}{ Maternal age (yrs) } & $30.8 \pm 5.3$ & $30.8 \pm 4.9$ & $30.6 \pm 5.3$ \\
\hline \multicolumn{2}{|c|}{ Parity } & $1(1-2)$ & $1(1-2)$ & $1(1-3)$ \\
\hline \multicolumn{2}{|l|}{ Gravidity } & $2(1-2)$ & $2(1-2)$ & $2(1-3)$ \\
\hline \multicolumn{5}{|l|}{ Ethnicity } \\
\hline \multicolumn{2}{|l|}{ Western Europe } & $132(73)$ & $40(76)$ & $45(66)$ \\
\hline \multicolumn{2}{|c|}{ Eastern Europe / Asia } & $4(2)$ & $4(8)$ & $2(3)$ \\
\hline \multicolumn{2}{|l|}{ Mediterranean } & $16(9)$ & $5(9)$ & $8(12)$ \\
\hline \multicolumn{2}{|c|}{ Sub-Saharan Africa } & $11(6)$ & $3(6)$ & $9(13)$ \\
\hline \multicolumn{2}{|c|}{ South America / Caribbean } & $17(9)$ & $1(2)$ & $4(6)$ \\
\hline \multicolumn{5}{|c|}{ Pregnancy characteristics } \\
\hline \multicolumn{2}{|c|}{ PPROM } & $28(16)$ & $16(30)^{\S}$ & $42(62)^{\dagger}$ \\
\hline \multicolumn{2}{|c|}{ Clinical chorioamnionitis } & $21(12)$ & $28(53)^{\ddagger}$ & $46(68)^{\ddagger}$ \\
\hline \multicolumn{2}{|c|}{ Temperature $\geq 38.0^{\circ} \mathrm{C}$} & $10(6)$ & $18(34)^{\ddagger}$ & $29(43)^{\ddagger}$ \\
\hline \multicolumn{2}{|c|}{ CRP raised } & $10(6)$ & $20(38)^{\ddagger}$ & $39(57)^{\ddagger}$ \\
\hline \multicolumn{2}{|l|}{ Leucocytosis } & $1(1)$ & $8(15)^{\dagger}$ & $18(27)^{\ddagger}$ \\
\hline \multicolumn{2}{|c|}{ Uterine tenderness } & $0(0)$ & $5(9)^{\ddagger}$ & $3(4)$ \\
\hline \multicolumn{2}{|c|}{ Cervical discharge } & $0(0)$ & $7(13)^{+}$ & $19(28)^{\ddagger}$ \\
\hline \multicolumn{2}{|c|}{ HELLP } & $62(34)$ & $3(6)^{\ddagger}$ & $0(0)^{\ddagger}$ \\
\hline \multicolumn{2}{|l|}{ Preeclampsia } & $100(56)$ & $5(9)^{\ddagger}$ & $2(3)^{\ddagger}$ \\
\hline \multirow[t]{3}{*}{ Antenatal steroid } & None & $32(18)$ & $6(11)$ & $12(18)$ \\
\hline & 1 dose & $23(13)$ & $7(13)$ & $7(10)$ \\
\hline & $\geq 2$ doses & $123(68)$ & $40(76)$ & $49(72)$ \\
\hline \multicolumn{5}{|c|}{ Delivery characteristics } \\
\hline \multicolumn{2}{|c|}{ Gestational age (wks) } & $29.6 \pm 1.7$ & $28.7 \pm 1.9^{\S}$ & $28.0 \pm 2.1^{\ddagger}$ \\
\hline \multicolumn{2}{|c|}{ Caesarean section } & $138(77)$ & $19(36)^{\ddagger}$ & $19(28)^{\ddagger}$ \\
\hline \multicolumn{2}{|c|}{ Singleton pregnancy } & $132(73)$ & $33(62)$ & $51(75)$ \\
\hline \multicolumn{2}{|c|}{ Male sex } & $90(50)$ & $30(57)$ & $34(50)$ \\
\hline \multicolumn{2}{|c|}{ Placental weight (g) } & $296 \pm 183$ & $354 \pm 164$ & $290 \pm 91$ \\
\hline \multicolumn{2}{|c|}{ Birth weight $(g)$} & $1112 \pm 339$ & $1249 \pm 365^{\S}$ & $1142 \pm 353$ \\
\hline Small for gestatic & & $70(39)$ & $5(9)^{\ddagger}$ & $4(6)^{\ddagger}$ \\
\hline Fetal distress & & $109(61)$ & $17(32)^{\ddagger}$ & $12(18)^{\ddagger}$ \\
\hline Umbilical artery & $p H$ & $7.23 \pm 0.12$ & $7.25 \pm 0.11$ & $7.30 \pm 0.08^{\ddagger}$ \\
\hline & $B E(m m o l / l)$ & $-5.7 \pm 4.9$ & $-5.7 \pm 4.7$ & $-3.4 \pm 2.9^{\dagger}$ \\
\hline Apgar score & $1 \mathrm{~min}$ & $6(4-8)$ & $6(4-8)$ & $5(3-7)$ \\
\hline & $5 \mathrm{~min}$ & $8(7-9)$ & $8(7-9)$ & $8(7-9)$ \\
\hline & $10 \mathrm{~min}$ & $9(8-10)$ & $9(8-10)$ & $9(8-10)$ \\
\hline
\end{tabular}


Table 1 (previous page). Maternal and delivery characteristics of infants without histologic chorioamnionitis (HC negative) and those with chorioamnionitis with ( $\mathrm{HC}$ positive, $\mathrm{F}$ positive) or without fetal involvement (HC positive, $\mathrm{F}$ negative). Numbers represent number of infants or mothers (positive percentage) in which characteristic is present for dichotomous data, median, and interquartile range for ordinal data and mean \pm SD for continuous data. $B E$, base excess; $C R P, C$-reactive protein; $F$, fetal involvement; $H C$, histologic chorioamnionitis; HELLP, clinical presentation of intravascular hemolysis, elevated liver enzymes, and a low platelet count; $P P R O M$, preterm premature rupture of membranes; SGA, small for gestational age. ${ }^{\S} P<.05 ;{ }^{\dagger} P<.01 ;{ }^{\ddagger} P<.001$ vs $\mathrm{HC}$ negative (ANOVA or $\chi^{2}$ test, with Dunnett's post hoc analysis).

\section{Neonatal outcome}

Neonatal outcome parameters for infants with histologic chorioamnionitis vs those without chorioamnionitis are shown in Table 2. Infants with chorioamnionitis with fetal involvement had higher incidences of $\mathrm{NEC}, \mathrm{IVH}$, and neonatal mortality when compared with infants without chorioamnionitis. The incidence of severe RDS was significantly lower in infants without fetal involvement but not in those with fetal involvement. Clinical chorioamnionitis was associated with an increased incidence of NEC ( $8 \%$ vs $2 \% ; P=.02$ ) but no significant change in any other outcome parameter (not shown).

\section{Chorioamnionitis, antenatal steroids, and neonatal outcome}

Within the 3 groups, no differences in any of the general characteristics were present between infants who had or had not received a full course of antenatal steroids (not shown). Neonatal outcome parameters for the 3 groups subdivided by antenatal steroid exposure are shown in Table 3. A full course of antenatal steroids significantly improved neonatal outcome only for infants with chorioamnionitis without fetal involvement, reducing the need for surfactant replacement therapy and the incidence of RDS, IVH, and severe IVH within this group. In addition, administration of any antenatal steroids ( $\geq 1$ doses) reduced the need for PDA ligation in these infants ( $2 \%$ vs 33\%; $P=.006$ ).

When all infants with chorioamnionitis were considered, administration of any antenatal steroids was associated with an overall decrease in neonatal mortality ( $11 \%$ vs $28 \%$, respectively; $P=.048)$. Finally, in infants with clinical chorioamnionitis, antenatal steroids decreased the need for mechanical ventilation (76\% vs $100 \% ; P=.049$ ) and PDA ligation (4\% vs $23 \%$; $P=.009$ ) and tended to decrease mortality ( $11 \%$ vs $31 \% ; P=.06)$, IVH ( $14 \%$ vs $31 \% ; P=.055)$ and severe IVH (2\% vs $10 \% ; P=.053)$. Importantly, antenatal steroid administration was not associated with an increase in adverse outcome in any chorioamnionitis group.

\section{Chorioamnionitis and outcome: multivariable analyses}

In multivariable models, the only outcome parameters significantly affected by chorioamnionitis were severe RDS (Table 4) and early-onset sepsis (Table 5). Chorioamnionitis without fetal involvement significantly reduced the risk for severe RDS when adjusted for ethnicity, preeclampsia, and gestational age (Table 4). Interestingly, in infants with fetal involvement, a similar effect was present in the very preterm infants, whereas in contrast, in 
more mature infants, fetal involvement was associated with an increased risk for severe RDS (Table 4). When adjusted for gestational age and birth weight, chorioamnionitis without fetal involvement increased the risk for early-onset sepsis (Table 5).

Table 2. Neonatal outcome. Neonatal outcome parameters in infants without histologic chorioamnionitis (HC negative) and those with chorioamnionitis with (HC positive, F positive ) or without fetal involvement (HC positive, $\mathrm{F}$ negative). $B P D$, bronchopulmonary dysplasia; $F$, fetal involvement; $H C$, histologic chorioamnionitis; $I V H$, intraventricular hemorrhage; NEC, necrotizing enterocolitis; $P D A$, patent ductus arteriosus; $P V L$, periventricular leukomalacia; $R D S$, respiratory distress syndrome. ${ }^{\S} P<.05$ vs HC negative ( $\chi^{2}$ test with Dunnett's post hoc analysis).

\begin{tabular}{|c|c|c|c|c|}
\hline \multicolumn{2}{|c|}{$\begin{array}{l}\text { Outcome parameter } \\
(n(\%))\end{array}$} & \multirow{2}{*}{$\begin{array}{l}H C- \\
(n=180) \\
102(57)\end{array}$} & \multirow{2}{*}{$\begin{array}{l}H C+F- \\
(n=53) \\
28(53)\end{array}$} & \multirow{2}{*}{$\begin{array}{l}H C+F+ \\
(n=68)\end{array}$} \\
\hline$R D S$ & any grade & & & \\
\hline & severe & $50(28)$ & $6(11)^{\S}$ & $19(28)$ \\
\hline \multicolumn{2}{|c|}{ Mechanical ventilation } & $134(74)$ & $36(68)$ & $59(87)$ \\
\hline \multicolumn{2}{|c|}{ Surfactant administered } & $88(49)$ & $25(47)$ & $33(49)$ \\
\hline \multicolumn{2}{|l|}{$B P D$} & $25(15)$ & $9(18)$ & $11(20)$ \\
\hline \multicolumn{2}{|c|}{ Dexamethasone } & $11(6)$ & $7(13)$ & $6(9)$ \\
\hline \multicolumn{2}{|c|}{$B P D$ or death } & $38(21)$ & $11(21)$ & $23(34)$ \\
\hline \multicolumn{2}{|c|}{ Death } & $16(9)$ & $3(6)$ & $13(19)^{\S}$ \\
\hline \multirow[t]{3}{*}{$P D A$} & total & $55(31)$ & $21(40)$ & $23(34)$ \\
\hline & indomethacin treated & $51(28)$ & $20(38)$ & $21(31)$ \\
\hline & ligated & $6(3)$ & $3(6)$ & $4(6)$ \\
\hline \multicolumn{2}{|l|}{ NEC } & $3(2)$ & $4(8)$ & $6(9)^{\S}$ \\
\hline \multirow[t]{4}{*}{ Sepsis } & early onset & $35(20)$ & $18(34)$ & $15(22)$ \\
\hline & culture proven & $12(7)$ & $6(11)$ & $4(6)$ \\
\hline & any sepsis & $91(51)$ & $33(62)$ & $32(47)$ \\
\hline & culture proven & $66(42)$ & $22(42)$ & $27(40)$ \\
\hline \multirow[t]{2}{*}{ IVH } & any grade & $22(12)$ & $7(13)$ & $17(25)^{\S}$ \\
\hline & grade $3-4$ & $8(4)$ & $2(4)$ & $3(4)$ \\
\hline \multicolumn{2}{|c|}{ Cystic PVL } & $5(3)$ & $2(4)$ & $2(3)$ \\
\hline
\end{tabular}

\section{Comment}

In this prospective cohort of preterm infants, chorioamnionitis with fetal involvement was associated with increased incidences of IVH, NEC, and neonatal mortality in univariable analyses. However, none of these associations remained after multivariable adjustment. Conversely, chorioamnionitis without fetal involvement was independently associated with a lower severe RDS risk, whereas the effect of chorioamnionitis with fetal involvement on the incidence of severe RDS was gestational age dependent. In addition, 
chorioamnionitis without fetal involvement was independently associated with early onset sepsis. No other significant effect of chorioamnionitis on any adverse outcome parameter remained after multivariable adjustment. Antenatal steroids were shown to decrease neonatal mortality and morbidity predominantly in infants with chorioamnionitis without fetal involvement.

The current study is one of very few prospective studies on neonatal outcome after histologic chorioamnionitis. The observed reduction in RDS incidence after chorioamnionitis is in line with previous, mainly retrospective, reports ${ }^{4,9-15}$. Both human and animal experimental data show that antenatal exposure to inflammation results in increased fetal lung maturation, providing a pathophysiologic basis for this association ${ }^{25,26}$.

Table 3. Neonatal outcome stratified by antenatal steroid exposure. Neonatal outcome parameters in patients without histologic chorioamnionitis ( $\mathrm{HC}$ negative) and those with chorioamnionitis with (HC positive, $\mathrm{F}$ positive) or without fetal involvement ( $\mathrm{HC}$ positive, F negative), depending on whether they received a full course of antenatal steroids (AS). BPD, bronchopulmonary dysplasia; F, fetal involvement; HC, histologic chorioamnionitis; $\mathrm{IVH}$, intraventricular hemorrhage; NEC, necrotizing enterocolitis; PDA, patent ductus arteriosus; PVL, periventricular leukomalacia; RDS, respiratory distress syndrome. ${ }^{\S} \mathrm{P}<.05{ }^{\dagger}{ }^{\dagger} \mathrm{P}<.01$ vs AS negative $\left(\chi^{2}\right.$ test with Dunnett's post hoc analysis).

\begin{tabular}{|c|c|c|c|c|c|c|c|}
\hline \multirow{2}{*}{\multicolumn{2}{|c|}{$\begin{array}{l}\text { Outcome parameter } \\
\text { (no. of patients (\%)) }\end{array}$}} & \multicolumn{2}{|c|}{$H C-(n=180)$} & \multicolumn{2}{|c|}{$H C+F-(n=53)$} & \multicolumn{2}{|c|}{$H C+F+(n=68)$} \\
\hline & & \multirow{2}{*}{$\frac{S-(n=55)}{29(53)}$} & \multirow{2}{*}{$\frac{S+(n=123)}{72(59)}$} & \multirow{2}{*}{$\frac{S-(n=13)}{11(85)}$} & \multirow{2}{*}{$\frac{S+(n=40)}{17(43)^{\S}}$} & \multirow{2}{*}{$\frac{S-(n=19)}{12(63)}$} & \multirow{2}{*}{$\frac{S+(n=49)}{28(57)}$} \\
\hline$R D S$ & any grade & & & & & & \\
\hline & severe & $12(22)$ & $38(31)$ & $2(15)$ & $4(10)$ & $7(37)$ & $12(25)$ \\
\hline \multicolumn{2}{|c|}{ Mechanical ventilation } & $39(71)$ & $93(76)$ & $11(85)$ & $25(63)$ & $18(95)$ & $41(84)$ \\
\hline \multicolumn{2}{|c|}{ Surfactant administered } & $30(55)$ & $58(47)$ & $11(85)$ & $14(35)^{+}$ & $10(53)$ & $23(47)$ \\
\hline \multicolumn{2}{|l|}{$B P D$} & $6(12)$ & $19(17)$ & $4(31)$ & $5(13)$ & $3(20)$ & $8(20)$ \\
\hline \multicolumn{2}{|c|}{ Dexamethasone } & $6(11)$ & $5(4)$ & $2(15)$ & $5(13)$ & $1(5)$ & $5(10)$ \\
\hline \multicolumn{2}{|c|}{$B P D$ or death } & $9(16)$ & $29(24)$ & $4(31)$ & $7(18)$ & $7(37)$ & $16(33)$ \\
\hline \multicolumn{2}{|l|}{ Death } & $4(7)$ & $12(10)$ & $0(0)$ & $3(8)$ & $5(26)$ & $8(16)$ \\
\hline \multirow[t]{3}{*}{$P D A$} & total & $13(24)$ & $42(34)$ & $8(62)$ & $13(33)$ & $7(37)$ & $16(33)$ \\
\hline & indomethacin treated & $13(24)$ & $38(31)$ & $7(54)$ & $13(33)$ & $7(37)$ & $14(27)$ \\
\hline & ligated & $2(4)$ & $4(3)$ & $2(15)$ & $1(3)$ & $1(5)$ & $3(6)$ \\
\hline \multicolumn{2}{|l|}{$N E C$} & $1(2)$ & $2(2)$ & 1 (8) & $3(8)$ & $1(5)$ & $5(10)$ \\
\hline \multirow[t]{4}{*}{ Sepsis } & early onset & $9(16)$ & $26(21)$ & $3(23)$ & $15(38)$ & $3(16)$ & $12(25)$ \\
\hline & culture proven & $2(4)$ & $10(8)$ & $0(0)$ & $6(15)$ & $1(5)$ & $3(6)$ \\
\hline & any sepsis & $25(46)$ & $66(54)$ & $8(62)$ & $25(63)$ & $8(42)$ & $24(49)$ \\
\hline & culture proven & $23(42)$ & $53(43)$ & $5(39)$ & $17(43)$ & $8(42)$ & $19(39)$ \\
\hline \multirow[t]{2}{*}{ IVH } & any grade & $8(15)$ & $13(11)$ & $5(39)$ & $2(5)^{\dagger}$ & $4(21)$ & $13(27)$ \\
\hline & grade $3-4$ & $3(6)$ & $5(4)$ & $2(15)$ & $0(0)^{5}$ & $1(5)$ & $2(4)$ \\
\hline \multicolumn{2}{|c|}{ Cystic PVL } & $3(6)$ & $1(1)$ & $1(8)$ & $1(3)$ & $1(5)$ & $1(2)$ \\
\hline
\end{tabular}


Table 4. Multivariable model for prediction of severe respiratory distress syndrome. Estimated odds ratios based on the multiple logistic regression model for prediction of severe respiratory distress syndrome. Arbitrary cutoff values for gestational age are used to explore the interaction with chorioamnionitis with fetal involvement. $\mathrm{Cl}$, confidence interval; OR, odds ratio.

\begin{tabular}{|c|c|c|}
\hline \multicolumn{3}{|l|}{ Outcome = severe respiratory distress syndrome } \\
\hline Factor & OR $(95 \% \mathrm{Cl})$ & P value \\
\hline \multicolumn{3}{|l|}{ Ethnicity (ref = Western Europe) } \\
\hline Eastern Europe / Asia & $0.28(0.03-2.40)$ & .25 \\
\hline Mediterranean & $0.30(0.10-0.97)$ & .04 \\
\hline Sub-Saharan Africa & $0.07(0.01-0.60)$ & .02 \\
\hline South America / Caribbean & $0.51(0.17-1.53)$ & .23 \\
\hline Preeclampsia & $2.45(1.20-4.98)$ & .01 \\
\hline \multicolumn{3}{|l|}{ Chorioamnionitis (ref = no chorio) } \\
\hline Chorioamnionitis (maternal side only) & $0.22(0.05-0.93)$ & .04 \\
\hline Chorioamnionitis + fetal involvement & $1.41(0.60-3.32)$ & .43 \\
\hline Gestational age (per wk increase) & $0.55(0.43-0.69)$ & $<.001$ \\
\hline Chorioamnionitis (maternal side only) $x$ gestational age & $0.98(0.52-1.83)$ & .94 \\
\hline Chorioamnionitis + fetal involvement $x$ gestational age & $1.57(1.10-2.25)$ & .01 \\
\hline Gestational age $=26$ wks & $0.35(0.11-1.08)$ & \\
\hline Gestational age $=28 w k s$ & $0.86(0.39-1.91)$ & \\
\hline Gestational age $=30 \mathrm{wks}$ & $2.12(0.76-5.87)$ & \\
\hline
\end{tabular}

Table 5. Multivariable model for prediction of early onset sepsis. Estimated odds ratios based on the multiple logistic regression model for prediction of early onset sepsis. $\mathrm{Cl}$, confidence interval; OR, odds ratio.

\begin{tabular}{lll}
\hline $\begin{array}{l}\text { Outcome }=\text { early onset sepsis } \\
\text { Factor }\end{array}$ & OR (95\% Cl) & P value \\
\hline Chorioamnionitis (ref = no chorio) & & .04 \\
$\quad$ Chorioamnionitis (maternal side only) & $2.22(1.02-4.83)$ & .72 \\
Chorioamnionitis + fetal involvement & $0.86(0.39-1.92)$ & .07 \\
Gestational age (per wk increase) & $0.82(0.67-1.01)$ & .047 \\
Birth weight (per kg increase) & $0.29(0.09-0.98)$ & \\
\hline
\end{tabular}

In our study, the effect was predominantly present in infants without signs of fetal involvement. Paradoxically, Lahra et al ${ }^{11}$ recently showed that chorioamnionitis was associated with decreased RDS risk in infants both without and with fetal involvement and that the effect was largest in the latter group. Our data revealed an interaction between chorioamnionitis with fetal involvement and gestational age in predicting RDS risk. Infants with fetal involvement had decreased RDS risk when their gestational age was low, whereas the risk increased with advancing gestational age. Because the study by Lahra et 
al ${ }^{11}$ included younger infants than the present study, a gestational age-dependent effect of fetal inflammation on RDS incidence may explain why they found an overall reduction of RDS in these infants. This interaction underlines the complexity of the association between chorioamnionitis, gestational age, and neonatal outcome ${ }^{9}$.

Perhaps the most striking finding is the nearly complete absence of associations between chorioamnionitis and adverse outcome parameters after multivariable adjustment. This is in agreement with more recent epidemiologic studies, reporting relatively little correlation between chorioamnionitis and adverse neonatal outcome in multivariable models ${ }^{13}$. We hypothesize that changes in clinical practice in neonatal intensive care may have contributed to these seemingly diminishing associations ${ }^{9}$.

An example of such a practice change is the increased use of antenatal steroids. Previous studies have shown antenatal steroids to decrease RDS ${ }^{27}$, PDA $^{27}$, neurologic morbidity ${ }^{10,27}$, neonatal mortality ${ }^{10,27}$, and the systemic inflammatory response syndrome ${ }^{28}$ in chorioamnionitis-exposed infants. The current study is the first to investigate the distinct effects of antenatal steroids on neonatal outcome in infants with chorioamnionitis with or without additional fetal involvement. Antenatal steroids significantly improved outcome mainly for infants without fetal signs of inflammation, further supporting their beneficial role in diminishing the association of chorioamnionitis with adverse outcome. Antenatal steroids reduced adverse outcome in infants with clinical chorioamnionitis as well, and, importantly, no harmful effects were observed in any chorioamnionitis group. The observed reductions in RDS incidence, need for surfactant, IVH, and neonatal mortality after antenatal steroids are in line with earlier human reports and animal experimental data ${ }^{9,10,27,29}$. Despite the fact that all observational data currently available regarding the efficacy of antenatal steroids in infants with intrauterine inflammation have been reassuring, a hesitant attitude remains regarding the use of antenatal steroids in this group ${ }^{30,31}$. The current study adds to the available evidence, suggesting both the safety and necessity of a randomized trial of antenatal steroids in infants with suspected intrauterine inflammation $^{28,30}$.

Despite earlier evidence of significant associations between chorioamnionitis and outcome parameters, such as cystic PVL and NEC ${ }^{5,13,16}$, these were not observed in the present study. In spite of its considerable cohort size, this may relate to the low overall incidence of these outcomes. However, it is worth mentioning that the incidence of NEC was higher in infants with fetal involvement in univariable analysis and clearly tended to be higher in both chorioamnionitis groups in adjusted analyses.

Fetal signs of inflammation are considered to represent the more serious side of the chorioamnionitis continuum. In this light, the association of chorioamnionitis without fetal involvement with early-onset sepsis, as demonstrated in our cohort, is surprising. Unadjusted data from some previous studies seem to point in the same direction 3,14,32, whereas others have not separated the effects of chorioamnionitis with or without fetal involvement ${ }^{8,10,33}$. 
Experimental data in preterm sheep suggest that antenatal inflammation results in programming of the fetal immune response. Depending on time after exposure, intraamniotic endotoxin resulted in either a decreased or increased inflammatory response of cord blood monocytes to subsequent endotoxin exposure ${ }^{34}$. In addition, repeated antenatal exposure seemed to depress the inflammatory response ${ }^{34}$. Since fetal and maternal histologic signs of inflammation are believed to represent both differences in severity and timing of inflammation, differential regulation of the preterm immune response may well underlie their distinct effects on susceptibility for early-onset sepsis. Moreover, antenatal steroids have been shown to modulate the fetal immune response following exposure to inflammation in preterm sheep ${ }^{35}$. However, in the current study, an additional effect of antenatal steroids on sepsis susceptibility could not be demonstrated.

An important drawback in cohort studies investigating the effects of chorioamnionitis on outcome is the absence of a healthy control group. Most infants without chorioamnionitis have been exposed to potential adverse effects of maternal preeclampsia, HELLP syndrome, or placental insufficiency. Because most infants with chorioamnionitis have not been exposed to these entities, adverse outcome after chorioamnionitis may just as well indicate improved outcome after HELLP syndrome or preeclampsia and vice versa ${ }^{9}$. In our study, these distinct antenatal modulators have been included in multivariable models, increasing the precision of the conclusions. Moreover, this may partly explain the absence of a significant effect of chorioamnionitis on adverse neonatal outcome. Additional larger studies are needed to further disentangle the effects of various antecedents on outcome in preterm infants.

In conclusion, chorioamnionitis was shown to have relatively little impact on neonatal outcome. Changes in clinical practice may account for this gradually diminishing association over time. Complex interactions with antenatal steroid exposure and gestational agedependent effects seem to exist. Additional research is needed to study these interactions and their underlying mechanisms and further explore the long-term effects of chorioamnionitis on health and disease ${ }^{36}$.

\section{References}

1. Lahra MM, Jeffery HE. A fetal response to chorioamnionitis is associated with early survival after preterm birth. Am J Obstet Gynecol 2004;190:147-51

2. De Felice $C$, Toti $P$, Laurini RN, Stumpo M, Picciolini E, Todros T, Tanganelli P, Buonocore G, Bracci R. Early neonatal brain injury in histologic chorioamnionitis. J Pediatr 2001;138:101-4

3. Mehta R, Nanjundaswamy S, Shen-Schwarz S, Petrova A. Neonatal morbidity and placental pathology. Indian J Pediatr 2006;73:25-8

4. Watterberg KL, Demers LM, Scott SM, Murphy S. Chorioamnionitis and early lung inflammation in infants in whom bronchopulmonary dysplasia develops. Pediatrics 1996;97:210-5

5. Holcroft CJ, Askin FB, Patra A, Allen MC, Blakemore KJ, Graham EM. Are histopathologic chorioamnionitis and funisitis associated with metabolic acidosis in the preterm fetus? Am J Obstet Gynecol 2004;191:20105 
6. Dammann O, Leviton A, Bartels DB, Dammann CE. Lung and brain damage in preterm newborns. Are they related? How? Why? Biol Neonate 2004;85:305-13

7. Salafia CM, Minior VK, Rosenkrantz TS, Pezzullo JC, Popek EJ, Cusick W, Vintzileos AM. Maternal, placental, and neonatal associations with early germinal matrix/intraventricular hemorrhage in infants born before 32 weeks' gestation. Am J Perinatol 1995;12:429-36

8. De Felice C, Toti P, Parrini S, Del Vecchio A, Bagnoli F, Latini G, Kopotic RJ. Histologic chorioamnionitis and severity of illness in very low birth weight newborns. Pediatr Crit Care Med 2005;6:298-302

9. Been JV, Zimmermann LJ. Histological chorioamnionitis and respiratory outcome in preterm infants. Arch Dis Child Fetal Neonatal Ed 2009;94:F218-25

10. Dempsey E, Chen MF, Kokottis T, Vallerand D, Usher R. Outcome of neonates less than 30 weeks gestation with histologic chorioamnionitis. Am J Perinatol 2005;22:155-9

11. Lahra MM, Beeby PJ, Jeffery HE. Maternal versus fetal inflammation and respiratory distress syndrome: a 10-year hospital cohort study. Arch Dis Child Fetal Neonatal Ed 2009;94:F13-6

12. Kosuge S, Ohkuchi A, Minakami H, Matsubara S, Uchida A, Eguchi Y, Honma Y, Sato I. Influence of chorioamnionitis on survival and morbidity in singletons live-born at $<32$ weeks of gestation. Acta Obstet Gynecol Scand 2000;79:861-5

13. Andrews WW, Goldenberg RL, Faye-Petersen O, Cliver S, Goepfert AR, Hauth JC. The Alabama Preterm Birth study: polymorphonuclear and mononuclear cell placental infiltrations, other markers of inflammation, and outcomes in 23- to 32-week preterm newborn infants. Am J Obstet Gynecol 2006;195:803-8

14. Ohyama M, Itani Y, Yamanaka M, Goto A, Kato K, Ijiri R, Tanaka Y. Re-evaluation of chorioamnionitis and funisitis with a special reference to subacute chorioamnionitis. Hum Pathol 2002;33:183-90

15. Kaukola T, Tuimala J, Herva R, Kingsmore S, Hallman M. Cord immunoproteins as predictors of respiratory outcome in preterm infants. Am J Obstet Gynecol 2009;200:100 e1-8

16. Dammann O, Leviton A. Inflammatory brain damage in preterm newborns--dry numbers, wet lab, and causal inferences. Early Hum Dev 2004;79:1-15

17. Kramer BW, Kaemmerer U, Kapp M, Herbst D, Marx A, Berg D, Groneck PA, Speer CP. Decreased expression of angiogenic factors in placentas with chorioamnionitis after preterm birth. Pediatr Res 2005;58:60712

18. Limperopoulos C, Bassan H, Sullivan NR, Soul JS, Robertson RL, Jr., Moore M, Ringer SA, Volpe JJ, du Plessis AJ. Positive screening for autism in ex-preterm infants: prevalence and risk factors. Pediatrics 2008;121:758-65

19. De Felice C, De Capua B, Costantini D, Martufi C, Toti P, Tonni G, Laurini R, Giannuzzi A, Latini G. Recurrent otitis media with effusion in preterm infants with histologic chorioamnionitis - A 3 years follow-up study. Early Hum Dev 2008

20. Kumar R, Yu Y, Story RE, Pongracic JA, Gupta R, Pearson C, Ortiz K, Bauchner HC, Wang X. Prematurity, chorioamnionitis, and the development of recurrent wheezing: a prospective birth cohort study. J Allergy Clin Immunol 2008;121:878-84 e6

21. Giedion A, Haefliger H, Dangel P. Acute pulmonary X-ray changes in hyaline membrane disease treated with artificial ventilation and positive end-expiratory pressure (PEP). Pediatr Radiol 1973;1:145-52

22. Volpe JJ. Hypoxic-ischemic encephalopathy: clinical aspects. In: Volpe JJ ed, Neurology of the newborn. Philadelphia: Saunders; 2001:331-94

23. Bell MJ, Ternberg JL, Feigin RD, Keating JP, Marshall R, Barton L, Brotherton T. Neonatal necrotizing enterocolitis. Therapeutic decisions based upon clinical staging. Ann Surg 1978;187:1-7

24. Redline RW, Faye-Petersen O, Heller D, Qureshi F, Savell V, Vogler C. Amniotic infection syndrome: nosology and reproducibility of placental reaction patterns. Pediatr Dev Pathol 2003;6:435-48

25. Kramer BW, Kallapur S, Newnham J, Jobe AH. Prenatal inflammation and lung development. Semin Fetal Neonatal Med 2009;14:2-7

26. Chaiworapongsa T, Hong JS, Hull WM, Romero R, Whitsett JA. Amniotic fluid concentration of surfactant proteins in intra-amniotic infection. J Matern Fetal Neonatal Med 2008;21:663-70

27. Elimian A, Verma U, Beneck D, Cipriano R, Visintainer P, Tejani N. Histologic chorioamnionitis, antenatal steroids, and perinatal outcomes. Obstet Gynecol 2000;96:333-6 
28. Goldenberg RL, Andrews WW, Faye-Petersen OM, Cliver SP, Goepfert AR, Hauth JC. The Alabama preterm birth study: corticosteroids and neonatal outcomes in 23- to 32-week newborns with various markers of intrauterine infection. Am J Obstet Gynecol 2006;195:1020-4

29. Kallapur SG, Kramer BW, Moss TJ, Newnham JP, Jobe AH, Ikegami M, Bachurski CJ. Maternal glucocorticoids increase endotoxin-induced lung inflammation in preterm lambs. Am J Physiol Lung Cell Mol Physiol 2003;284:L633-42

30. Been JV, Kramer BW, Zimmermann L. Antenatal corticosteroids to prevent preterm birth. Lancet 2009;373:894

31. Effect of corticosteroids for fetal maturation on perinatal outcomes. NIH Consens Statement 1994;12:1-24

32. Park CW, Moon KC, Park JS, Jun JK, Romero R, Yoon BH. The involvement of human amnion in histologic chorioamnionitis is an indicator that a fetal and an intra-amniotic inflammatory response is more likely and severe: clinical implications. Placenta 2009;30:56-61

33. Ogunyemi D, Murillo M, Jackson U, Hunter N, Alperson B. The relationship between placental histopathology findings and perinatal outcome in preterm infants. J Matern Fetal Neonatal Med 2003;13:102-9

34. Kramer BW, Ikegami M, Moss TJ, Nitsos I, Newnham JP, Jobe AH. Endotoxin-induced chorioamnionitis modulates innate immunity of monocytes in preterm sheep. Am J Respir Crit Care Med 2005;171:73-7

35. Kramer BW, Ikegami M, Moss TJ, Nitsos I, Newnham JP, Jobe AH. Antenatal betamethasone changes cord blood monocyte responses to endotoxin in preterm lambs. Pediatr Res 2004;55:764-8

36. Been JV, Kramer BW, Zimmermann LJ. In utero and early-life conditions and adult health and disease. $N$ Engl J Med 2008;359:1523-4 


\section{Appendix}

\section{Antenatal corticosteroids to prevent preterm birth}

Been JV, Kramer BW, Zimmermann LJ

Lancet 2009; 373: 894

(Comment on: Murphy KE et al. Lancet 2008; 372: 2143-2151)

Note:

This letter was written in response to the publication of a randomised controlled trial of repeat courses of antenatal steroids for fetal lung maturation. The aim was to emphasize the importance of investigating the effects of antenatal steroids in patients with chorioamnionitis, a group excluded from this trial, as well as from most previous antenatal steroid trials. 


\section{To the editor,}

We welcome publication of the MACS trial report ${ }^{1}$. What concerns us is that, in line with many earlier trials of single-course and with all trials of multiple-course antenatal steroids for preterm birth, infants with chorioamnionitis were excluded. In very preterm infants the incidence of clinical chorioamnionitis is around $10-30 \%$. Thus, exclusion of these infants leads to an important reduction in external validity. Moreover, a growing body of evidence suggests that an opportunity is being missed when withholding antenatal steroids from infants with chorioamnionitis. In infants with signs of intrauterine inflammation, including clinical and histological chorioamnionitis, antenatal steroid administration is associated with reductions in respiratory distress syndrome, patent ductus arteriosus, systemic inflammatory response syndrome, severe cerebral lesions, cerebral palsy, and neonatal mortality ${ }^{2-4}$. In a prospective cohort $(n=301)$, we saw similar reductions in respiratory distress syndrome, intraventricular haemorrhage, ductus ligation, and mortality after antenatal steroids in infants with chorioamnionitis (unpublished data). Additionally, a meta-analysis of single-course studies showed particular benefit in infants with preterm, prelabour rupture of membranes, without an adverse effect on maternal outcome ${ }^{5}$.

Thus, whereas a general concern exists around antenatal steroid administration when intrauterine infection is suspected, recent studies leave no grounds for this fear and even seem to support this practice. We are in need of randomised trials of antenatal steroids that either focus on infants with chorioamnionitis or provide specific subgroup analysis for this group. Only then will we be able to validate or decline the generally restricted use of antenatal steroids in the setting of suspected intrauterine infl ammation.

\section{References}

1. Murphy KE, Hannah ME, Willan AR, Hewson SA, Ohlsson A, Kelly EN, Matthews SG, Saigal S, Asztalos E, Ross S, Delisle MF, Amankwah K, Guselle P, Gafni A, Lee SK, Armson BA. Multiple courses of antenatal corticosteroids for preterm birth (MACS): a randomised controlled trial. Lancet 2009;372:2143-51

2. Been JV, Zimmermann LJ. Histological chorioamnionitis and respiratory outcome in preterm infants. Arch Dis Child Fetal Neonatal Ed 2009;94:F218-25

3. Kent A, Lomas F, Hurrion E, Dahlstrom JE. Antenatal steroids may reduce adverse neurological outcome following chorioamnionitis: neurodevelopmental outcome and chorioamnionitis in premature infants. $J$ Paediatr Child Health 2005;41:186-90

4. Locatelli A, Ghidini A, Assi F, Andreani M, Malguzzi S, Paterlini G. Which factors affect the occurrence of severe cerebral lesions in preterm neonates who are born with intrauterine infection? Am J Obstet Gynecol 2008;199:404 e1-5

5. Roberts D, Dalziel S. Antenatal corticosteroids for accelerating fetal lung maturation for women at risk of preterm birth. Cochrane Database Syst Rev 2006;3:CD004454 


\section{Chapter 10}

Antenatal steroids in chorioamnionitis:

evidence and practice

Been JV, Degraeuwe PL, Kramer BW, Lievense S, Nijhuis JG, Zimmermann LJ

BJOG; provisionally accepted 


\section{Abstract}

Background: There is debate concerning the safety and efficacy of antenatal steroids (AS) in preterm labour with suspected intrauterine infection (chorioamnionitis; CA).

Objectives: We aimed to evaluate perinatologists' views on the efficacy, potential hazards and available evidence of AS in clinical CA. Secondly, we performed a systematic literature review and meta-analysis on the efficacy of AS in clinical and histological CA.

Methods / search strategy: We performed a nationwide survey among Dutch perinatologists $(n=116)$. Furthermore, MEDLINE and EMBASE were searched using the terms 'chorioamnionitis OR intrauterine infection' and 'steroids OR corticoids'.

Selection criteria: Studies reporting selected neonatal outcome measures in preterm infants with clinical or histological chorioamnionitis, according to AS exposure, were eligible.

Data collection and analysis: Study selection, data extraction and data analysis were done by two independent investigators. Meta-analysis techniques used included MantelHaenszel analysis, assessment of study heterogeneity using Q statistic, and Eggers regression test and Funnel plots to assess publication bias.

Main results: Great diversity was present among perinatologists regarding the use of AS in CA. Most acknowledged the lack of evidence on the subject. Seven observational studies were included in the meta-analysis. In histological CA, AS were associated with reduced mortality $(\mathrm{OR}[95 \% \mathrm{Cl}]=0.45[0.30-0.68] ; \mathrm{p}<.0001)$, RDS (OR[95\%Cl] $=0.52[0.40-$ $0.71] ; p<.0001)$, PDA (OR[95\%Cl] $=0.56[0.37-0.85] ; p=.007)$, IVH (OR[95\%Cl] $=0.35[0.19-$ $0.66] ; p=.001)$, and severe IVH (OR[95\%Cl] $=0.39[0.19-0.82] ; p=.01)$. In clinical CA, AS were associated with reduced severe IVH $(\mathrm{OR}[95 \% \mathrm{Cl}]=0.28[0.09-0.87] ; p=.03)$ and $\mathrm{PVL}$ (OR[95\%Cl] $=0.31[0.12-0.76] ; \mathrm{p}=.01)$.

Conclusions: AS may reduce adverse neonatal outcome after preterm birth associated with CA. There is a need for RCTs addressing this issue. 


\section{Introduction}

Maternal administration of corticosteroids is an effective therapy to reduce respiratory distress and improve neurological morbidity and mortality in the preterm newborn. This approach has become standard care in case of imminent or anticipated preterm delivery ${ }^{1}$. However, general concern exists regarding the administration of antenatal steroids in case of suspected intrauterine infection. Available guidelines delineate chorioamnionitis as a contraindication for antenatal steroids, although the scientific basis for this recommendation remains obscure ${ }^{2,3}$. Accordingly, pregnant women exhibiting signs suggestive of intrauterine infection (clinical chorioamnionitis) have often been excluded from randomised controlled trials (RCTs) investigating the effect of antenatal steroids on neonatal outcome

${ }^{4}$. As a consequence, there is an important lack of data regarding the effects of antenatal steroids on neonatal outcome in the setting of suspected intrauterine infection ${ }^{4}$.

Antenatal infection or inflammation can be diagnosed in various ways. The diagnosis of chorioamnionitis based on histological examination of the placenta and associated tissues is probably the most reliable and valid marker of intrauterine infection/inflammation ${ }^{5}$. Although accurate, this histological diagnosis can only be made after birth, which is why clinical criteria are often used to try to identify patients with intrauterine infection. However, numerous studies have shown the agreement between this socalled clinical chorioamnionitis and the histological diagnosis to be poor ${ }^{6}$. To the best of our knowledge, RCTs reporting the effect of antenatal steroids in the subgroup of patients with either clinical or histological chorioamnionitis are non-existent. Observational studies addressing this issue are available, which thus should represent the best evidence currently available on the efficacy of antenatal steroids in patients with chorioamnionitis. Contrary to the general reluctance, the positive findings of single studies have led investigators to suggest justification of a more liberal use of antenatal steroids in patients with suspected intrauterine infection/inflammation ${ }^{4,7,8}$.

In this current report, we describe the results of a nationwide survey in the Netherlands to assess perinatologists' views on giving antenatal steroids in the setting of suspected intrauterine infection. Furthermore, we performed a systematic review and metaanalysis on antenatal steroid administration and neonatal outcome in preterm infants with chorioamnionitis. These results are reported separately for clinical and histological chorioamnionitis because of important differences in diagnostic criteria between the two.

\section{Methods}

\section{Survey}

An email-based nationwide questionnaire survey was performed among all Dutch perinatologists $(n=116)$. The survey consisted of four multiple choice questions aimed at assessing the respondent's view on the efficacy, potential hazards and available evidence re- 
garding administration of antenatal steroids in the setting of suspected intrauterine infection (Table 1). A single reminder was sent to all non-responders one month after the first approach.

\section{Systematic review - sources}

A systematic literature search was performed independently by two investigators (JVB and PLD) using online databases for medical literature (MEDLINE and EMBASE (both from 1966 onwards)). In order to maximise the probability of identifying potentially relevant articles, broad search terms were used ((chorioamnionitis OR intrauterine infection) AND (steroids OR corticoids)) without additional restrictions. Additional searches were made by screening references lists from articles of interest as well as citations to articles of interest, using ISI Web of Knowledge.

\section{Systematic review - study selection}

Articles in any language were eligible for inclusion in the meta-analysis if they reported one or more neonatal outcome measures of interest according to antenatal steroid status in preterm infants with either histological or clinical chorioamnionitis. Neonatal outcome measures of interest were the following: neonatal mortality, RDS, bronchopulmonary dysplasia (BPD), IVH, severe IVH (grade 3-4), periventricular leukomalacia (PVL), necrotising enterocolitis (NEC), patent ductus arteriosus (PDA), culture proven early onset sepsis (within 72 hrs after birth) and any culture proven sepsis during admission. Composite outcome measures were not included in the meta-analysis. Study characteristics and patient data were extracted separately by the two investigators and subsequently crossreferenced. Any disagreement was resolved by consensus. The corresponding author of an article of interest was contacted in order to clarify any indistinctions, if present.

\section{Systematic review - analyses}

Aggregate odds ratios (OR) and $95 \%$ confidence intervals $(\mathrm{Cl})$ were calculated using Mantel-Haenszel analysis (fixed effects model). Study heterogeneity was examined using both qualitative and quantitative assessment ( $Q$ statistic). When important heterogeneity was present, a random effects model was applied. Given the absence of valid and relevant general quality scores for observational studies ${ }^{9}$, study quality was assessed in a nonquantitative manner. To further assess effects of potential heterogeneity, fixed effect and random effect models were compared for each outcome, and subgroup analyses were performed were possible. Eggers regression test and Funnel plots were used to assess publication bias. An alpha level of .05 was applied in all analyses except for testing of study heterogeneity, where $p<.10$ was considered significant. All calculations were performed using MIX 1.7 software ${ }^{10}$. Results are presented according to the MOOSE criteria for meta-analysis of observational studies ${ }^{9}$. 
Table 1. Survey. Translated from Dutch. Abbreviations: ROM=rupture of membranes; $C R P=C$-reactive protein; $\mathrm{CTG}=$ cardiotocography; RCT=randomised controlled trial.

\begin{tabular}{ll}
\hline Question & $\begin{array}{l}\text { Response } \\
(n(\%))\end{array}$ \\
\hline
\end{tabular}

1. A woman is 30 weeks pregnant and presents with ROM, preterm labour and clinical chorioamnionitis ( $\mathrm{T} 38.5^{\circ} \mathrm{C}$, leucocytosis, elevated $\mathrm{CRP}$, no other focus). CTG registration shows mild tachycardia, but is otherwise uneventful.
A. I give antibiotics \pm paracetamol, and wait and see.
B. A. plus I give antenatal steroids.
C. I give antibiotics \pm paracetamol, and start tocolysis.
D. C. plus I give antenatal steroids.
E. I give antibiotics and perform a C-section

2. Antenatal steroids improve neonatal outcome, also when intrauterine infection is clinically present

$\begin{array}{ll}\text { A. Yes } & 7(12) \\ \text { B. No } & 3(5) \\ \text { C. Insufficient evidence is available on this issue } & 48(83) \\ \text { 3. Antenatal steroids are potentially hazardous when intrauterine infection is clinically present } & 7(12) \\ \text { A. No } & 1(2) \\ \text { B. Yes, for the fetus } & 7(12) \\ \text { C. Yes, for the mother } & 14(24) \\ \text { D. Yes, for both mother and fetus } & 29(50) \\ \text { E. Insufficient evidence is available on this issue } & \end{array}$

4. Performing an RCT assessing the safety and efficacy of antenatal steroids in imminent preterm birth with suspected intrauterine infection would be:
A. Useful
B. Pointless, sufficient evidence is available
C. Unethical, antenatal steroids should be given regardless of whether intrauterine infection is present

\section{Results}

\section{Survey}

Four perinatologists (3.4\%) could not be reached by email. Of the remaining 112 perinatologists, 59 responded (53\%). The full results are displayed in Table 1. Briefly, in a pregnant woman of 30 weeks gestation with preterm labour and clinical chorioamnionitis, a minority would start tocolysis (9\%) while another $9 \%$ would perform a caesarean section. Conversely, only two percent would start tocolysis. Fifty-four percent would give antenatal steroids, even though many feel there is a lack of evidence on their efficacy (83\%) and safety (50\%) in chorioamnionitis. Giving steroids to a mother with clinical chorioamnionitis is considered potentially harmful to either the baby, the mother, or both by $38 \%$. Finally, $64 \%$ of the respondents would favour an RCT on the efficacy and safety of antenatal steroids in preterm labour with clinical chorioamnionitis, although another $26 \%$ fear the potential risks for mother and child. 


\section{Systematic review - study selection and characteristics}

Eight studies were identified that reported one or more outcome measures of interest for infants exposed to chorioamnionitis who did or did not receive antenatal steroids (Table 2) 6,7,11-16. All studies were observational cohort studies, no RCTs addressing the effect of antenatal steroids within chorioamnionitis-exposed infants were identified. Of the eight studies, one small study was excluded because it included a highly selected cohort and applied liberal exclusion criteria, complicating extrapolation of the findings ${ }^{16}$. General characteristics of the studies included in the meta-analysis are shown in Table 2.

Table 2. Study characteristics. AS+ indicates the number of antenatal steroid doses used as a cut-off to determine antenatal steroids administration as positive. - no exclusion criteria used; ? no data available; *rescue course in selected cases $\geq 1 \mathrm{wk}$ after initial full course. Abbreviations: AS=antenatal steroids; US=United States; $\mathrm{CC}=$ clinical chorioamnionitis; Retro=retrospective; $\mathrm{HC}=$ histological chorioamnionitis; Beta=betamethasone; Fra=France; DM=diabetes mellitus; Dex=dexamethasone; Aus=Australia; Pro=prospective; NL=Netherlands.

\begin{tabular}{|c|c|c|c|c|c|c|c|c|c|c|c|c|c|c|}
\hline 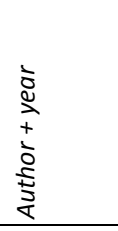 & 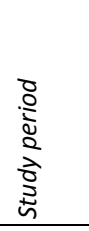 & 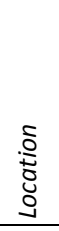 & 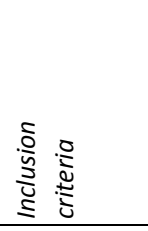 & 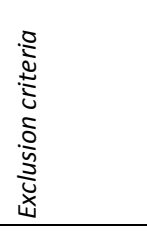 & $\begin{array}{l}\delta \\
: \\
0 \\
0 \\
0 \\
0 \\
0 \\
0 \\
0 \\
0\end{array}$ & 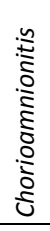 & $\frac{0}{2}$ & $\begin{array}{l}\text { के } \\
\text { है } \\
\text { ڤั } \\
0\end{array}$ & 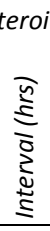 & $\stackrel{+}{\overleftarrow{c}}$ & 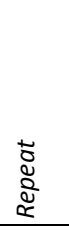 & $N(C)$ & $\stackrel{\dot{\sigma}}{\dot{t}}$ & 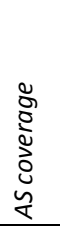 \\
\hline $\begin{array}{l}\text { Elimian } \\
2000^{10}\end{array}$ & $\begin{array}{l}1990- \\
1997\end{array}$ & US & $500-1750 \mathrm{~g}$ & $\mathrm{CC}$ & Retro & $\mathrm{HC}$ & Beta & 12 & 24 & $\geq 2 x$ & Yes & 169 & 358 & $32 \%$ \\
\hline $\begin{array}{l}\text { Baud } \\
2000^{11}\end{array}$ & $\begin{array}{l}1993- \\
1997\end{array}$ & Fra & $\begin{array}{l}<33 \text { wks } \\
\text { Singletons }\end{array}$ & $\begin{array}{l}\text { Severe DM; } \\
\text { multiple } \\
\text { malforma- } \\
\text { tions }\end{array}$ & Retro & CC & $\begin{array}{l}\text { Beta } \\
\text { /Dex }\end{array}$ & $\begin{array}{l}12 \\
6\end{array}$ & $\begin{array}{l}24 \\
12\end{array}$ & $\geq 1 \times$ & Yes & 60 & 110 & $35 \%$ \\
\hline $\begin{array}{l}\text { Dempsey } \\
2005^{12}\end{array}$ & $\begin{array}{l}1989- \\
1999\end{array}$ & US & $\begin{array}{l}<30 \text { wks } \\
\text { Singletons }\end{array}$ & - & Retro & $\mathrm{HC}$ & Beta & 12 & 24 & $\geq 2 x$ & $?$ & 88 & 42 & $68 \%$ \\
\hline $\begin{array}{l}\text { Foix- } \\
\text { L'Helias }^{\prime} \\
2005^{13}\end{array}$ & $\begin{array}{l}1993- \\
1996\end{array}$ & Fra & $\begin{array}{l}24-31 \text { wks } \\
\text { Singletons }\end{array}$ & - & Retro & CC & $\begin{array}{l}\text { Beta } \\
\text { /Dex }\end{array}$ & $\begin{array}{l}12 \\
6\end{array}$ & $\begin{array}{l}24 \\
12\end{array}$ & $\geq 1 \times$ & Yes & 45 & 52 & $46 \%$ \\
\hline $\begin{array}{l}\text { Kent } \\
2005^{14}\end{array}$ & $\begin{array}{l}1996- \\
2001\end{array}$ & Aus & $<30$ wks & - & Pro & $\mathrm{HC}$ & Dex & 12 & 12 & $\geq 2 x$ & Yes & 58 & 14 & $81 \%$ \\
\hline $\begin{array}{l}\text { Golden- } \\
\text { berg } \\
2006^{7}\end{array}$ & $\begin{array}{l}1996- \\
2001\end{array}$ & US & $\begin{array}{l}23-32 \text { wks } \\
\text { Singletons }\end{array}$ & - & Retro & $\begin{array}{l}\mathrm{HC} \\
\mathrm{CC}\end{array}$ & Beta & 12 & 24 & $\geq 1 x$ & Yes* & 182 & 36 & $80 \%$ \\
\hline $\begin{array}{l}\text { Been } \\
2009^{6}\end{array}$ & $\begin{array}{l}2001- \\
2003\end{array}$ & NL & $<32$ wks & $\begin{array}{l}\text { Congenital } \\
\text { anomalies }\end{array}$ & Pro & $\begin{array}{l}\mathrm{HC} \\
\mathrm{CC}\end{array}$ & Beta & 12 & 24 & $\geq 2 \times$ & No & 89 & 32 & $74 \%$ \\
\hline
\end{tabular}

Three studies report the effect of antenatal steroids in infants with histological chorioamnionitis only ${ }^{11,13,15}$, two in infants with clinical chorioamnionitis only ${ }^{12,14}$ and two in both groups $^{6,7}$. All studies accepted overlap between clinical and histological chorioamnionitis, except for one in which infants with clinical chorioamnionitis were excluded ${ }^{11}$. Variation 
exists in the diagnostic criteria used to define both clinical and histological chorioamnionitis and the outcome measures of interest (Table 3 ). The overall study quality was comparable between reports. In all of the studies, consecutively born preterm infants were studied and essential maternal, perinatal and neonatal characteristics were documented, although data collection was retrospective in most studies. Only one study reported comparison of chorioamnionitis-exposed infants treated or not treated with antenatal steroids with regard to baseline characteristics, showing no differences ${ }^{6}$.

Corresponding authors were contacted to obtain crude data when percentages were used $^{7,13,14}$ and obtain additional information on antenatal steroid administration (preparation, dose, dosing scheme) ${ }^{7,12,14,15}$. Several responded and supplied additional information 7,12,14,15. A 10\% cohort overlap between the studies by Foix-L'Helias et al and Baud et al was reported ${ }^{12,14}$. This was not accounted for in the meta-analysis and thus may slightly affect the pooled estimate on RDS after clinical chorioamnionitis (Figure 2).

\section{Meta-analysis - histological chorioamnionitis}

Individual study data and the results of meta-analysis of the effects of antenatal steroids in infants with histological chorioamnionitis are shown in Figure 1. For this purpose, results reported separately for chorioamnionitis with and without fetal inflammatory response were pooled ${ }^{6,15}$. Administration of antenatal steroids was associated with significant reductions in neonatal mortality, RDS, PDA, IVH and severe IVH after histological chorioamnionitis. No significantly increased risk for any adverse outcome was detected after antenatal steroids. For early onset sepsis a random effects model was applied because of study heterogeneity $(p=.04)$. No statistical indications for publication bias were present for any outcome measure.

\section{Meta-analysis - clinical chorioamnionitis}

Figure 2 shows individual study data and results of meta-analysis of the effects of antenatal steroids in infants with clinical chorioamnionitis. In these infants, antenatal steroids were associated with significant reductions in severe IVH and PVL. Again, no significant association between antenatal steroid administration and any adverse outcome measure was observed. In meta-analyses that included at least three studies, no indications for publication bias were present.

\section{Meta-analysis - sensitivity analysis}

The low number of studies and almost complete absence of subgroup specific data reports did not allow for subgroup analyses to be performed. Application of a random effects model did not importantly affect the effect size or significance level for most outcome measures (not shown). However, regarding the effect of antenatal steroids on severe IVH and PVL in infants with clinical chorioamnionitis, the random effects model resulted in loss of significance, although the point estimate remained essentially the same $(\mathrm{OR}[95 \% \mathrm{Cl}]=$ 0.32 [0.03-3.29], $\mathrm{p}=.32$; and $\mathrm{OR}[95 \% \mathrm{Cl}]=0.38$ [0.07-2.02], $\mathrm{p}=.25$, respectively). 
Table 3. Diagnostic criteria from individual studies. - outcome not reported. Abbreviations: HC=histological chorioamnionitis; $\mathrm{CC}=$ clinical chorioamnionitis; $\mathrm{PL}=$ preterm labour; mat=maternal; $\mathrm{CRP}=\mathrm{C}$-reactive protein; $\mathrm{WBC}=$ white blood cell count; +ve=positive; $\mathrm{AF}=$ amniotic fluid; $\mathrm{PMNs=polymorphonuclear} \mathrm{leucocytes;}$ PPROM=preterm premature rupture of membranes; $E O S=$ early onset sepsis; RDS=respiratory distress syndrome; $\mathrm{MV}=$ mechanical ventilation; $\mathrm{TAF}=$ tracheal aspirate fluid; $\mathrm{FiO}_{2}=$ fraction of inspired oxygen; $\mathrm{CPAP}=$ continuous positive airway pressure; $\mathrm{BPD}=$ bronchopulmonary dysplasia; $\mathrm{PMA}=$ postmenstrual age; IVH=intraventricular haemorrhage; $\mathrm{PVL}=$ periventricular leukomalacia; $\mathrm{NEC}=$ necrotising enterocolitis; $\mathrm{PDA}=$ patent ductus arteriosus; $\mathrm{CSF}=$ cerebrospinal fluid.

\begin{tabular}{|c|c|c|c|c|c|c|c|}
\hline Diagnosis & $\begin{array}{l}\text { Elimian } \\
2000\end{array}$ & $\begin{array}{l}\text { Baud } \\
2000\end{array}$ & $\begin{array}{l}\text { Dempsey } \\
2005\end{array}$ & $\begin{array}{l}\text { Foix-L'Helias } \\
2005\end{array}$ & $\begin{array}{l}\text { Kent } \\
2005\end{array}$ & $\begin{array}{l}\text { Goldenberg } \\
2006\end{array}$ & $\begin{array}{l}\text { Been } \\
2009\end{array}$ \\
\hline $\begin{array}{l}\text { Chorio- } \\
\text { amnionitis }\end{array}$ & HC: Salafia ${ }^{17}$ & $\begin{array}{l}\text { CC: } \mathrm{PL}+\geq 2 \\
\text { of: } \geq 2 \mathrm{x} \text { mat } \mathrm{T} \\
>38^{\circ} \mathrm{C} ; \text { mat } \\
\mathrm{CRP}>40 \mathrm{mg} / \mathrm{l} \\
\text { or } \mathrm{WBC} \\
>18 \mathrm{e} 3 / \mathrm{ml} ; \\
\text { +ve AF } \\
\text { culture }\end{array}$ & $\begin{array}{l}\text { HC: Abun- } \\
\text { dant PMNs } \\
\text { in chorion + } \\
\text { amnion }\end{array}$ & $\begin{array}{l}\text { CC: PL without } \\
\text { PPROM }+\geq 2 \\
\text { of the follow- } \\
\text { ing: mat T } \\
>38^{\circ} \mathrm{C} \text {; mat } \\
\text { CRP>20mg/l; } \\
\text { +ve AF cultu- } \\
\text { re; EOS }\end{array}$ & $\begin{array}{l}\text { HC: } \\
\text { Naeye } \\
\text { and } \\
\text { Lewis }^{19}\end{array}$ & $\begin{array}{l}\text { HC: Bendon }{ }^{20}, \\
\text { Faye-Petersen }{ }^{21}, \\
\text { and Redline }{ }^{22} \\
\text { CC: diagnosed by } \\
\text { obstetrician } \\
\text { (usually fever + } \\
\text { abdominal pain + } \\
\text { elevated WBC) }\end{array}$ & $\begin{array}{l}\mathrm{HC}: \text { Redline } \\
\mathrm{CC}: \text { mat } \mathrm{T}>38^{\circ} \mathrm{C}+ \\
\text { no other focus }+\geq 2 \text { of: } \\
\text { uterine tenderness; } \\
\text { malodorous vaginal } \\
\text { discharge; mat WBC } \\
>15 \mathrm{e} 3 / \mathrm{ml} \text {, raised CRP, } \\
\text { mat / fetal tachycardia }\end{array}$ \\
\hline$R D S$ & $\begin{array}{l}\mathrm{MV}+\mathrm{O}_{2} \\
\text { need for } \\
\geq 48 \mathrm{~h}+ \\
\text { typical X-ray }\end{array}$ & $\begin{array}{l}\text { at }<24 \mathrm{~h} \geq 2 \\
\text { of: clinical } \\
\text { signs; } \\
\text { typical X-ray; } \\
\text { lung imma- } \\
\text { turity in TAF }\end{array}$ & $\begin{array}{l}\geq 3 \text { of: clinical } \\
\text { signs; } \mathrm{FiO}_{2} \\
>30 \% \text { at } 12- \\
72 \mathrm{~h} \text {; CPAP/ } \\
\mathrm{MV} \text {; typical } \\
\text { X-ray }\end{array}$ & $\begin{array}{l}\text { at }<48 \mathrm{~h} \geq 2 \text { of: } \\
\mathrm{MV}+\mathrm{O}_{2} \text { need; } \\
\text { surfactant; } \\
\text { typical } \mathrm{X} \text {-ray; } \\
\text { lung immatur- } \\
\text { ity in TAF }\end{array}$ & - & $\begin{array}{l}\mathrm{O}_{2} \text { need at } 6-24 \mathrm{~h} \\
\text { or X-ray at }<24 \mathrm{~h} \\
\text { consistent with } \\
\text { RDS or need for } \\
\text { surfactant }\end{array}$ & $\begin{array}{l}\text { Clinical signs } \\
+ \text { typical X-ray } \\
\text { according to Giedion }{ }^{24}\end{array}$ \\
\hline$B P D$ & - & - & - & $\begin{array}{l}\mathrm{O}_{2} \text { at } 36 \mathrm{w} \\
\mathrm{PMA}\end{array}$ & - & $\mathrm{O}_{2}$ at $36 \mathrm{w}$ PMA & $\mathrm{O}_{2}$ at 36 w PMA \\
\hline$I V H$ & Papile ${ }^{25}$ & Papile $^{25}$ & Papile ${ }^{25}$ & - & $\begin{array}{l}\text { Papile }{ }^{25} \\
\text { and De } \\
\text { Vries }^{26}\end{array}$ & Volpe ${ }^{27}$ & Volpe ${ }^{27}$ \\
\hline$P V L$ & $\begin{array}{l}\text { echolucency } \\
\text { or persistent } \\
\text { echogenicity }\end{array}$ & $\begin{array}{l}\text { cystic echo- } \\
\text { lucency } \\
\text { before death } \\
\text { or } 6 \mathrm{w} \text { of age }\end{array}$ & - & - & - & Volpe ${ }^{27}$ & Volpe ${ }^{27}$ \\
\hline$N E C$ & $\begin{array}{l}\text { Clinical signs } \\
+ \text { X-ray, } \\
\text { surgery/ } \\
\text { autopsy } \\
\text { confirmed }\end{array}$ & - & $\begin{array}{l}\text { Intramural } \\
\text { gas on X-ray } \\
\text { or perfora- } \\
\text { tion or } \\
\text { necrosis at } \\
\text { surgery } \\
\text { /autopsy }\end{array}$ & - & - & Bell stage $\geq 2^{28}$ & Bell stage $\geq 2^{28}$ \\
\hline$P D A$ & $\begin{array}{l}\text { requiring } \\
\text { medication } \\
\text { or surgery }\end{array}$ & - & - & - & - & - & $\begin{array}{l}\text { Ultrasound criteria + } \\
\text { requiring medication } \\
\text { or surgery }\end{array}$ \\
\hline Sepsis & $\begin{array}{l}\text { +ve blood or } \\
\text { CSF culture }\end{array}$ & - & - & - & - & $\begin{array}{l}\text { +ve blood culture } \\
\text { no contamination }\end{array}$ & $\begin{array}{l}\text { +ve blood or CSF } \\
\text { culture + clinical signs }\end{array}$ \\
\hline $\begin{array}{l}\text { Early on- } \\
\text { set sepsis }\end{array}$ & - & - & $\begin{array}{l}\text { +ve blood } \\
\text { culture } \leq 72 \mathrm{~h}\end{array}$ & - & - & - & sepsis $\leq 72 \mathrm{~h}$ \\
\hline
\end{tabular}


A: Mortality

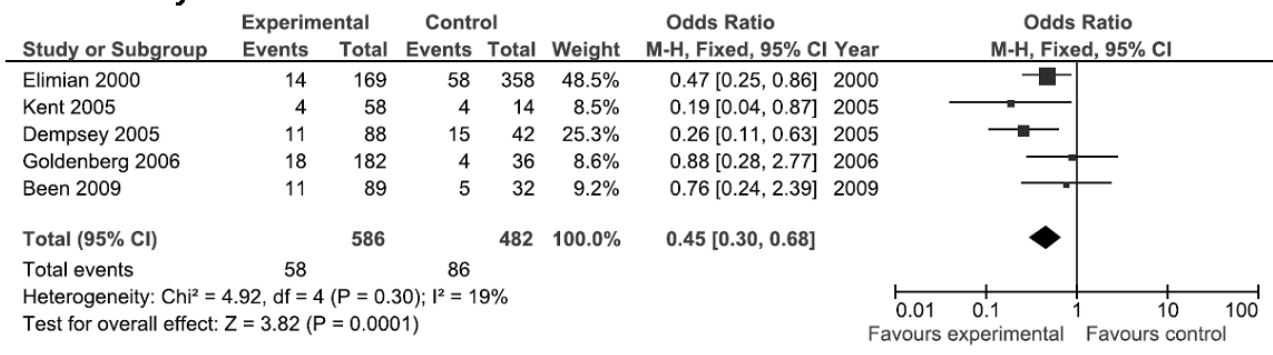

\section{B: Respiratory distress syndrome (RDS)}

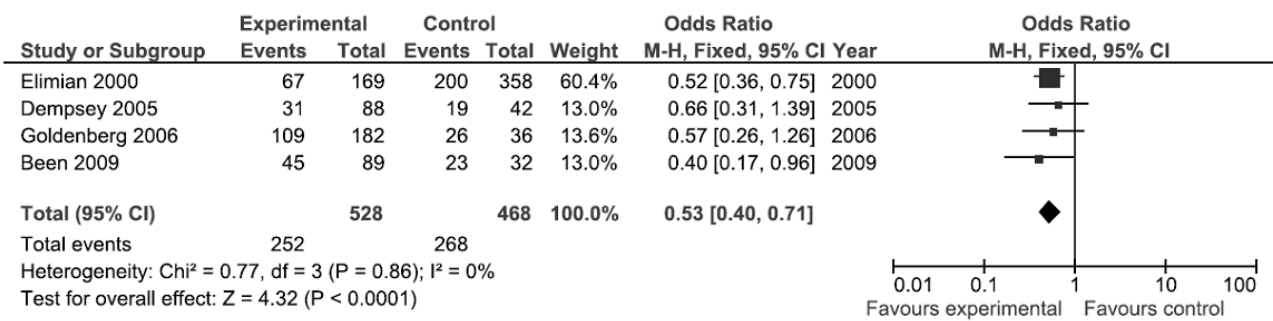

\section{C: Bronchopulmonary dysplasia (BPD)}

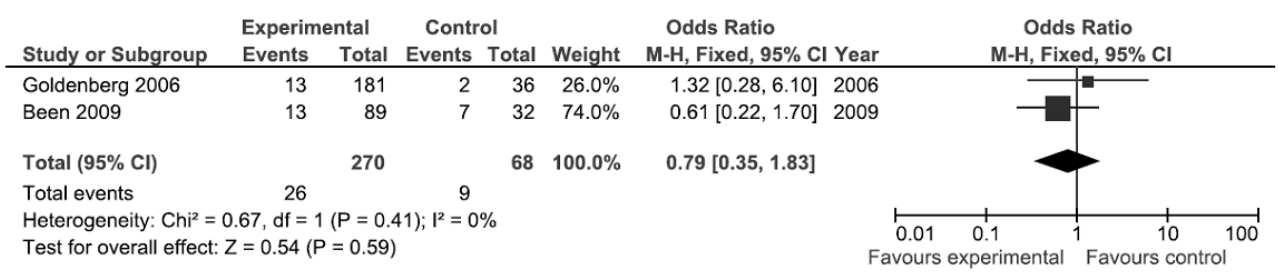

\section{D: Intraventricular haemorrhage (IVH)}

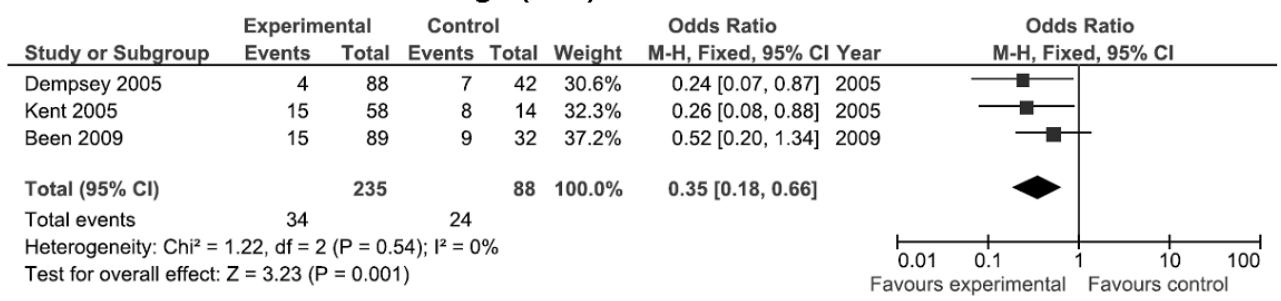

\section{E: Intraventricular haemorrhage grade 3-4 (IVH grade 3-4)}

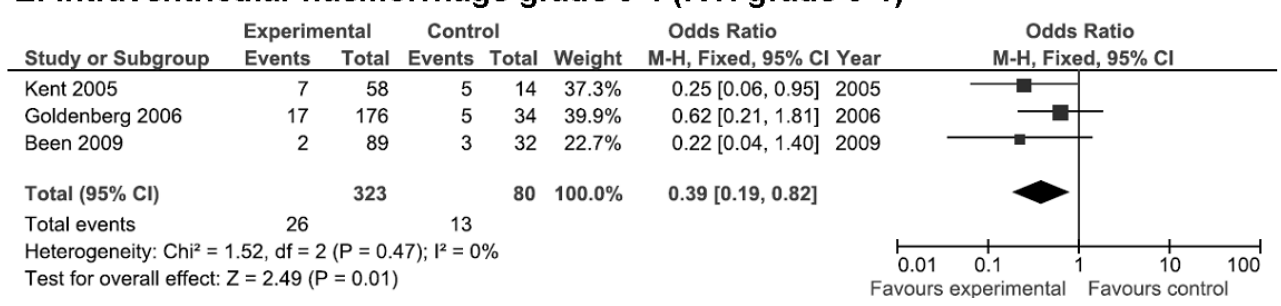

Figure 1 A-E. Histological chorioamnionitis: Meta-analysis of the effect of antenatal steroids on selected neonatal outcome measures. 


\section{F: Periventricular leucomalacia (PVL)}

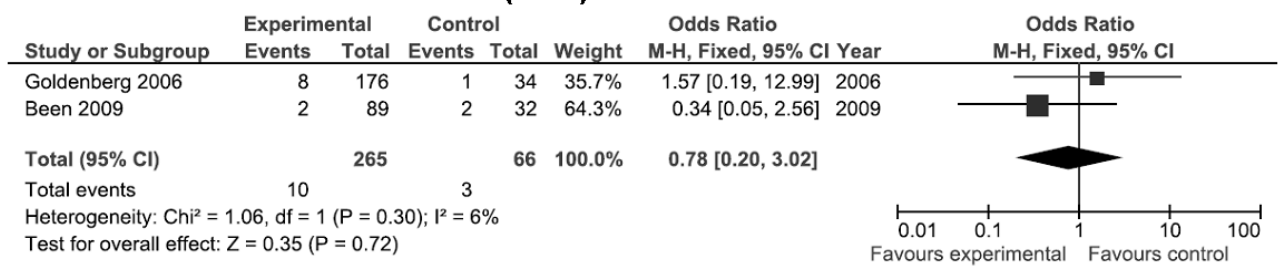

\section{G: Necrotising enterocolitis (NEC)}

Experimental Control

Odds Ratio

Odds Ratio

Study or Subgroup Events Total Events Total Weight $\mathrm{M}-\mathrm{H}, \mathrm{Fixed}, 95 \% \mathrm{Cl}$ Year

$\begin{array}{llllllll}\text { Elimian } 2000 & 10 & 169 & 22 & 358 & 55.7 \% & 0.96[0.44,2.08] & 2000\end{array}$

Dempsey 2005

Goldenberg 2006

Been 2009

$\begin{array}{rrrr}88 & 2 & 42 & 10.3 \%\end{array}$

$2.00[0.41,9.86] 2005$

$\begin{array}{rrrrr}8 & 88 & 2 & 42 & 10.3 \% \\ 34 & 182 & 4 & 36 & 22.8 \%\end{array}$

$1.84[0.61,5.54] 2006$

Total $(95 \% \mathrm{Cl})$

182
89

$2 \quad 32 \quad 11.2 \%$

$1.48[0.30,7.38] 2009$

Total events

528

$468 \quad 100.0 \%$

$1.33[0.78,2.26]$

Heterogeneity: $\mathrm{Chi}^{2}=1.28, \mathrm{df}=3(\mathrm{P}=0.73) ; \mathrm{I}^{2}=0 \%$

Test for overall effect: $Z=1.04(P=0.30)$

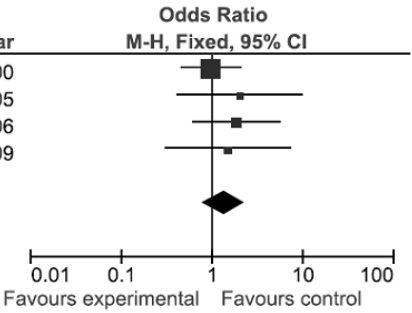

\section{H: Patent ductus arteriosus (PDA)}

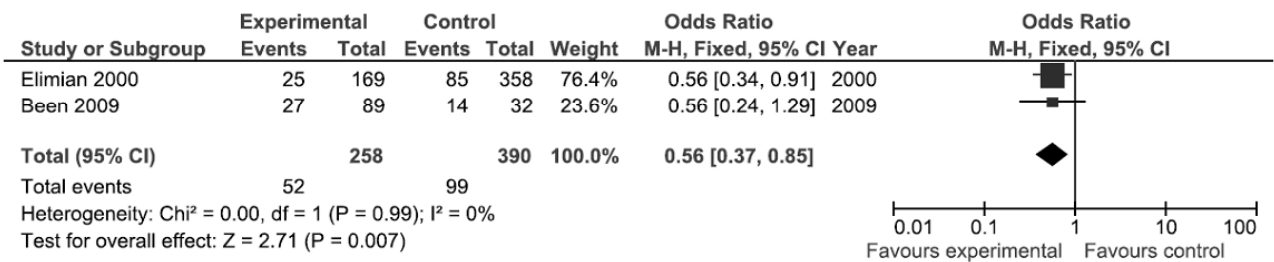

\section{I: Early onset sepsis}

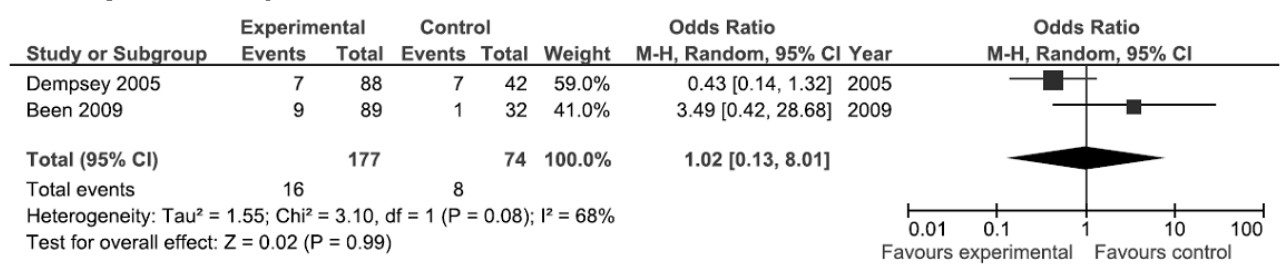

\section{$\mathrm{J}$ : Sepsis}

Experimental Control Odds Ratio

Study or Subgroup Events Total Events Total Weight $\mathrm{M}-\mathrm{H}$, Fixed, $95 \% \mathrm{Cl}$ Year

$\begin{array}{llllllll}\text { Elimian } 2000 & 31 & 169 & 50 & 358 & 68.2 \% & 1.38[0.85,2.26] & 2000\end{array}$

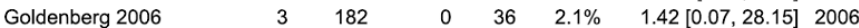

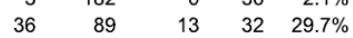

$0.99[0.44,2.26] 2009$

Total $(95 \% \mathrm{Cl})$

440

$\begin{array}{lcc}\text { Total events } & 70 & 63 \\ \text { Heterogeneity: } \mathrm{Chi}^{2}=0.47, \mathrm{df}=2(\mathrm{P}=0.79) ; \mathrm{I}^{2}=0 \%\end{array}$

Test for overall effect: $Z=1.11(P=0.27)$

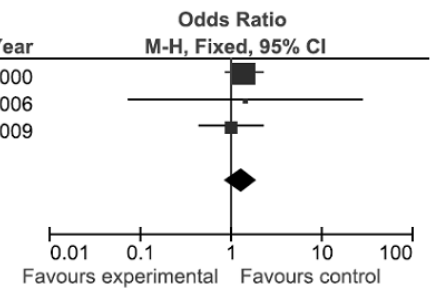

Figure 1 F-J. Histological chorioamnionitis: Meta-analysis of the effect of antenatal steroids on selected neonatal outcome measures. 


\section{A: Mortality}

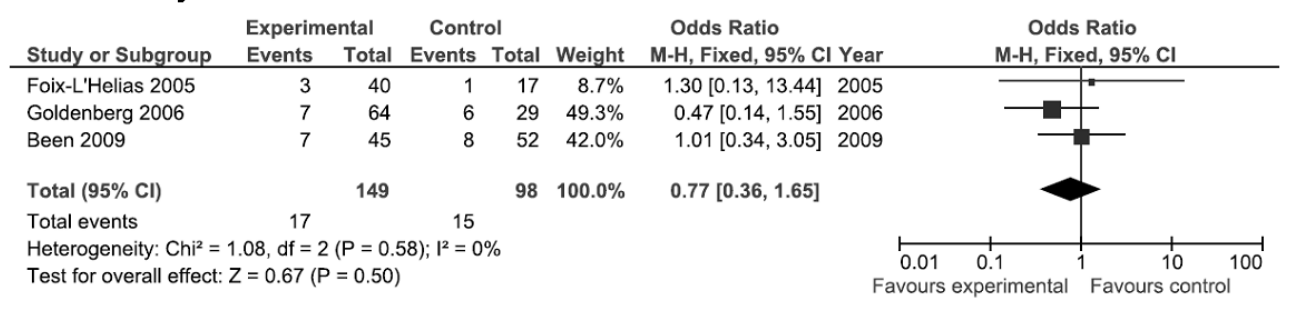

\section{B: Respiratory distress syndrome (RDS)}

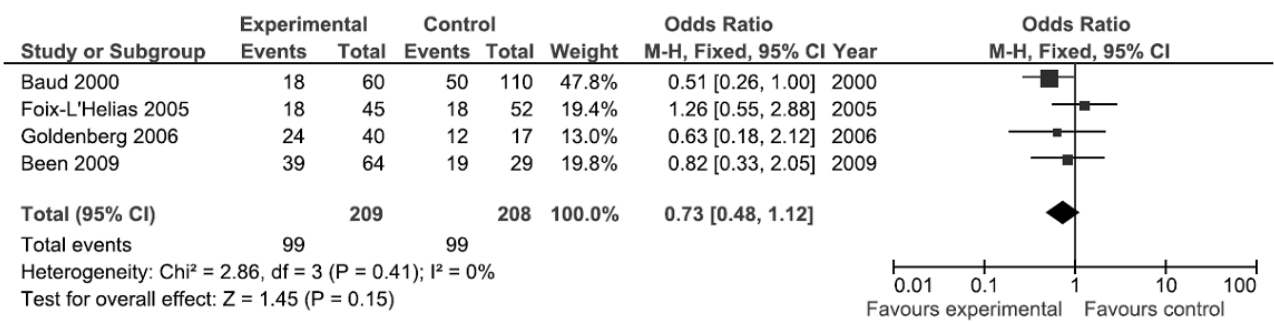

\section{C: Bronchopulmonary dysplasia (BPD)}

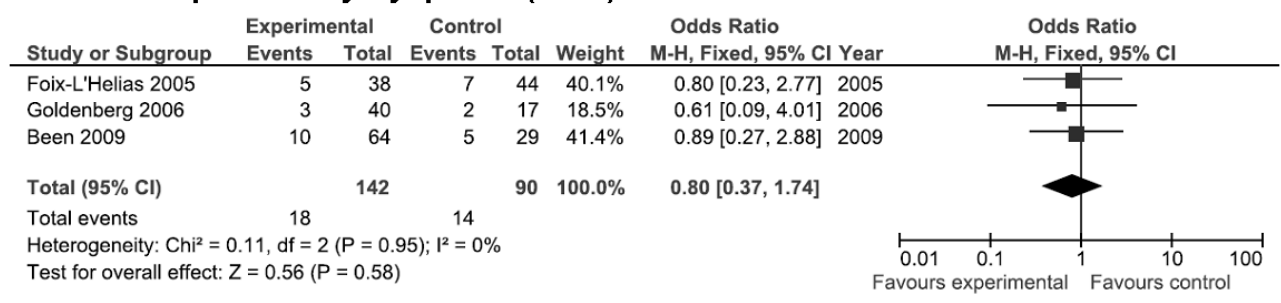

\section{D: Intraventricular haemorrhage (IVH)}

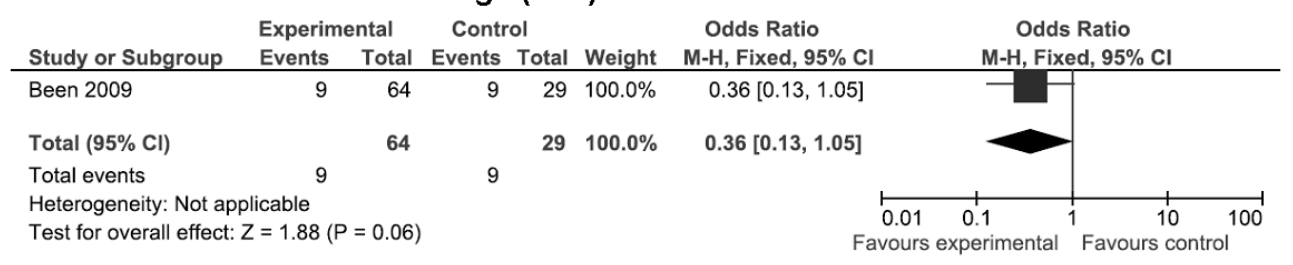

\section{E: Intraventricular haemorrhage grade 3-4 (IVH grade 3-4)}

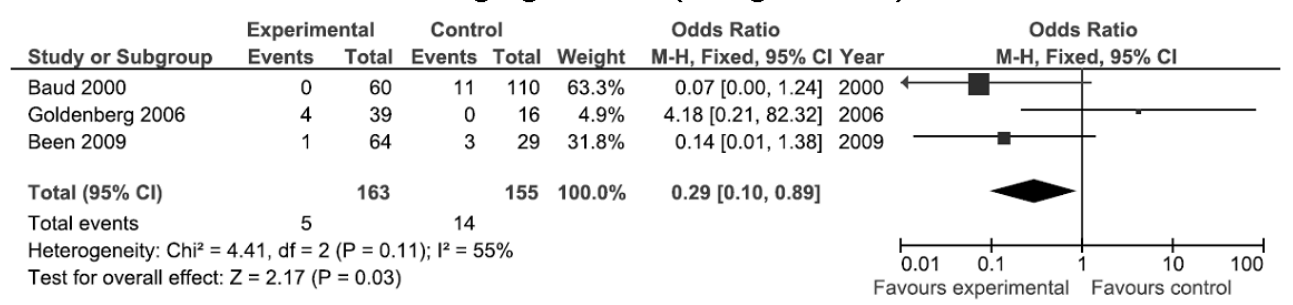

Figure 2 A-E. Clinical chorioamnionitis: Meta-analysis of the effect of antenatal steroids on selected neonatal outcome measures. Figures from Been et al are partly unpublished data. 


\section{F: Periventricular leucomalacia (PVL)}

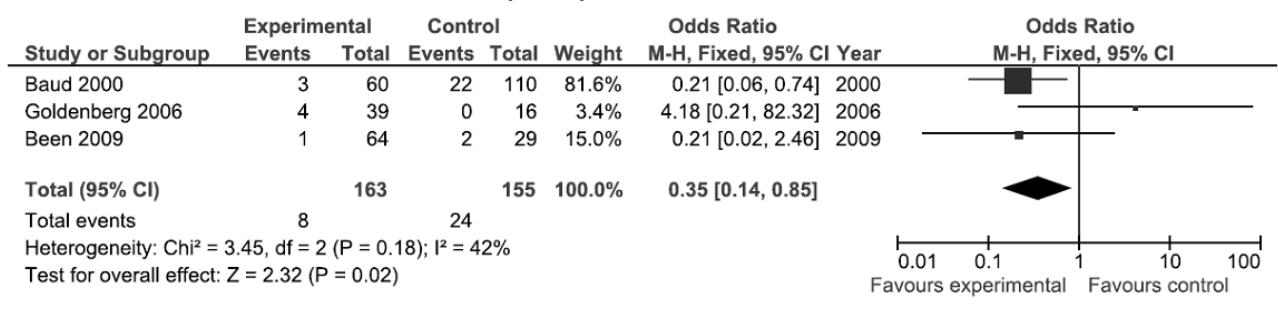

\section{G: Necrotising enterocolitis (NEC)}

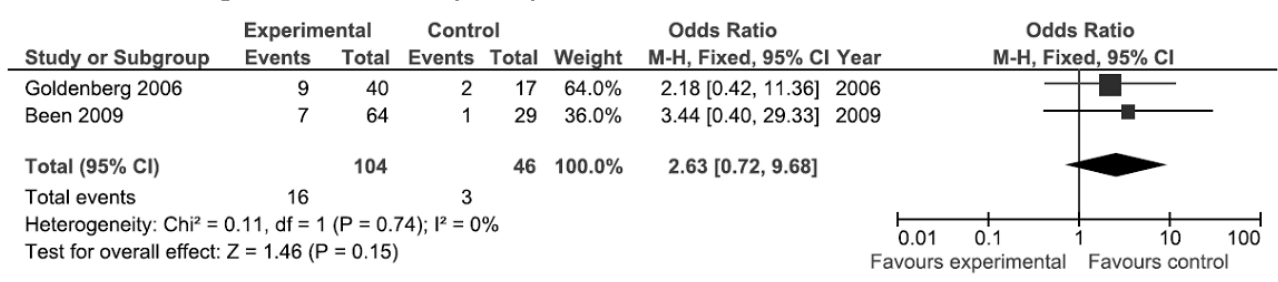

\section{H: Patent ductus arteriosus (PDA)}

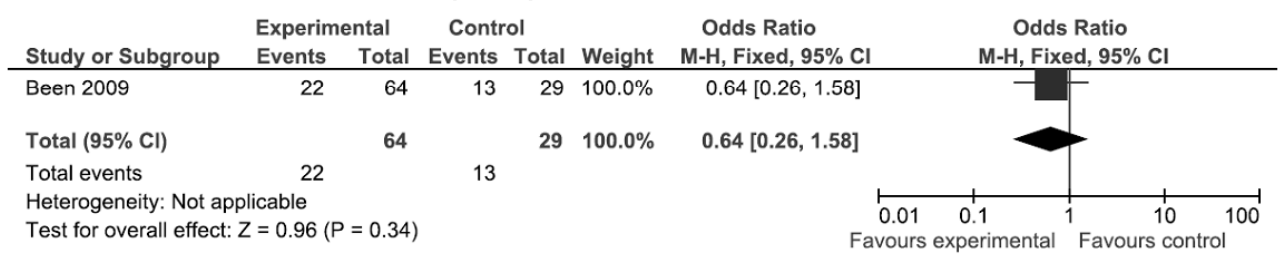

\section{I: Early onset sepsis}

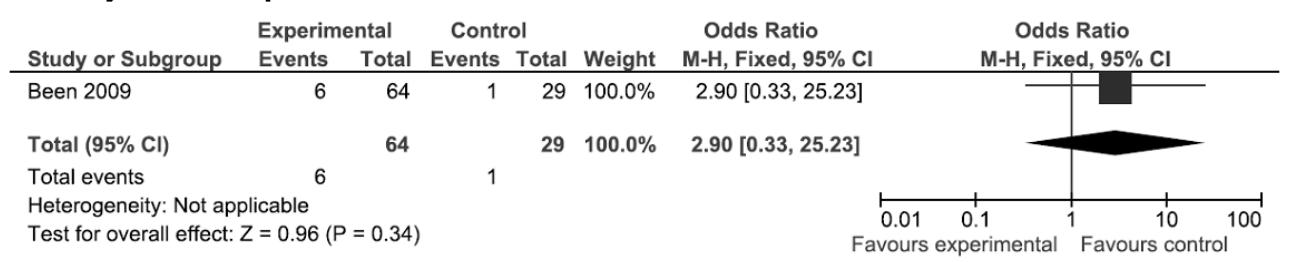

\section{$\mathrm{J}$ : Sepsis}

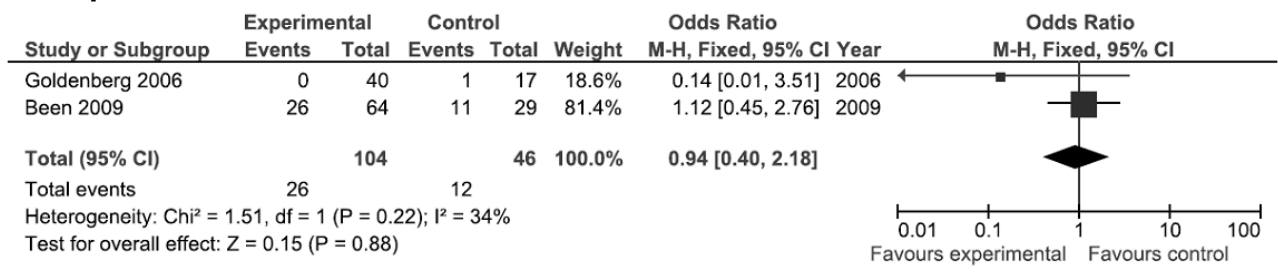

Figure 2 F-J. Clinical chorioamnionitis: Meta-analysis of the effect of antenatal steroids on selected neonatal outcome measures. Figures from Been et al are partly unpublished data. 


\section{Discussion}

There is great diversity in perinatologists' views on the efficacy and safety of antenatal steroids in suspected chorioamnionitis. Many fear adverse effects in mother or child, and acknowledge the lack of evidence available on the subject. Although the majority would support an RCT to resolve the issue, many fear potential harms for mother and child. By performing a systematic review and meta-analysis, we aimed to put together the current best evidence on the subject. Only observational studies were available, and when aggregated these suggest that antenatal steroids are beneficial in both histological and clinical chorioamnionitis, without increasing adverse outcome.

Clearly, there is debate regarding the efficacy and potential hazards of antenatal steroids in chorioamnionitis. To the best of our knowledge, as yet no aggregated data were available on how treating physicians view this issue and cope with it in daily practice. Our data show that, at least in the Netherlands, great diversity exists in whether or not antenatal steroids are given in the setting of suspected intrauterine infection, as well as in the underlying rationale. This underlines the scarcity of evidence on the subject, also acknowledged by the majority of respondents. By restricting the questionnaire to four multiple choice questions and making it email-based, we aimed to increase our response rate, which in the end was reasonable.

To our knowledge, no previous attempt was made to systematically review the available evidence on the efficacy and safety of antenatal steroids in chorioamnionitis. Given the lack of RCTs on the issue, the current aggregation of observational studies provides the current best evidence on this subject.

The MOOSE statement underlines the usefulness of meta-analyses of observational studies when assessing efficacy and effectiveness of therapies, as long as potential sources of bias are considered and discussed ${ }^{9}$. We believe the relative uniformity of inclusion criteria and outcome parameters used, and the separation of analyses for histological and clinical chorioamnionitis, justify performing a meta-analysis by statistically aggregating the data. The absence of statistical indications for publication bias and study heterogeneity (except for early onset sepsis after clinical chorioamnionitis) further supports the validity of the results. However as noted, although a meta-analysis may substantiate the conclusions drawn from the available evidence, several important limitations should be acknowledged.

Overall the number of studies suitable for inclusion was low. Although individual cohorts were of considerable size, this may introduce bias mainly through differences in inclusion and exclusion criteria between studies. An important example is the exclusion of infants with clinical chorioamnionitis by Elimian and colleagues ${ }^{11}$. Given the association between clinical chorioamnionitis and severity of histological chorioamnionitis, this may have led to exclusion of more severely affected infants with histological chorioamnionitis ${ }^{29}$. While antenatal steroids seem to improve outcome predominantly in infants with less severe chorioamnionitis ${ }^{6}$, an overestimation of their positive effect on neonatal outcome 
may result. Resultant bias could be important due to the large cohort size of this particular study. Another consequence of the small number of studies, is that results from a single study may sometimes largely explain the overall meta-analysis outcome. An example is the association between antenatal steroids and improved neurological outcome in infants with clinical chorioamnionitis, which is largely explained by results from the study by Baud et $a l^{12}$.

Aspects regarding the administration of antenatal steroids need additional consideration. Differences between studies are present in the type of drug used, in drug dosing and timing, and whether or not multiple courses were allowed. The latter may be a confounder, since repeat courses are less likely to have been given to mothers with chorioamnionitis ${ }^{4}$. In some instances, steroids may not have been given because delivery ensued very quickly after admission, leading to a potential source of bias. Moreover, antenatal steroid administration was scored as positive by some authors only when a full course was administered, while others also included infants that received incomplete courses in the steroid group. Incomplete courses of antenatal steroids have been shown to have some effect on outcome. Thus, differences between studies may arise from whether infants who received an incomplete course were assigned to the treatment group or the control group. Another source of variation between studies is introduced by differences in diagnostic criteria related to both chorioamnionitis and outcome definitions. Comparison of random effects and fixed effects models suggests that the effect of heterogeneity is limited for most outcomes. However, in infants with clinical chorioamnionitis the random effects model resulted in loss of significance of the beneficial effect of antenatal steroids, suggesting that study heterogeneity could account for part of the observed effect. In summary, while the meta-analysis clearly suggests that antenatal steroids may be beneficial in both histological and clinical chorioamnionitis, the results should be interpreted with great care given these methodological considerations.

Certain additional issues should be taken into account when interpreting the data. Most importantly, there is a lack of information on timing of steroid administration relative to the emergence of signs suggestive of intrauterine infection. As stressed by Goldenberg et al, steroids may have been administered before the occurrence of clinical chorioamnionitis in the majority of cases ${ }^{7}$. Outcome measures of these infants obviously are not very helpful in guiding the use of antenatal steroids when intrauterine infection is clinically apparent. Thus, although antenatal steroids are associated with improved shortterm neurological outcome in infants with clinical chorioamnionitis in the current metaanalysis, one should be prudent in extrapolating these findings to the clinical situation directly. Also, identification of potential maternal adverse effects of steroid administration in the setting of suspected intrauterine infection was beyond the scope of this review, although none were reported in the studies included in this meta-analysis. In this respect it is important to note that antenatal steroid administration in itself has been shown not to increase the risk of developing clinical chorioamnionitis ${ }^{1}$. 
From one standpoint, the efficacy of antenatal steroids in histological chorioamnionitis may not seem clinically relevant, since placental histology is not available to the obstetrician when deciding whether or not to give antenatal steroids. On the other hand, the beneficial effect of antenatal steroids after histological chorioamnionitis indicates that treatment may indeed be safe and effective, regardless of whether subclinical inflammation is present. Moreover, a meta-analysis of RCTs showing particular benefit of antenatal steroids in pregnant women with PPROM supports their therapeutic potential when intrauterine infection is imminent ${ }^{1}$.

Despite these potential sources of bias, the absence of any association between antenatal steroid treatment and adverse outcome in chorioamnionitis-exposed infants is reassuring. Moreover, the highly significant differences in several outcome measures between treated and non-treated infants suggest that at least part of these effects is genuine. Animal experimental data further support some of these associations. Antenatal steroids enhance lung maturation after experimental chorioamnionitis in preterm sheep, corresponding to the reduction in RDS observed in this meta-analysis ${ }^{30-32}$. Data from the same model show that antenatal steroids and chorioamnionitis modulate the fetal innate immune response, both solitary and combined ${ }^{33-35}$. Immunological effects may well mediate some of the associations between chorioamnionitis, antenatal steroids and outcome after preterm birth ${ }^{36}$.

The current meta-analysis provides information on steroid effects regarding neonatal outcome only. Data concerning the effects of antenatal steroids on outcome beyond the neonatal period in infants exposed to chorioamnionitis are virtually absent. We are aware of only one small study that was unable to show any difference in neurodevelopmental outcome at the ages of one and three years ${ }^{15}$. Moreover, although not specifically designed to address this issue, no data were found on the association between antenatal steroids and maternal outcome in chorioamnionitis. Additional research is needed to evaluate the maternal and long term offspring effects of antenatal steroids in chorioamnionitis.

\section{Conclusion}

In conclusion, there is considerable diversity in perinatologists' opinions regarding the use of antenatal steroids in suspected intrauterine infection. Most agree that insufficient evidence is currently present to resolve this issue. A meta-analysis of observational studies suggests that antenatal steroids are safe and effective in preterm infants born before 33 weeks gestation with subclinical chorioamnionitis. However, when chorioamnionitis is clinically apparent, the evidence is less obvious and more sensitive to bias. Retrospective subgroup analysis of observational studies and RCTs in which data on chorioamnionitis and antenatal steroid exposure are available, may further increase our knowledge on this important topic. We, as well as most clinicians responding to our survey, would favour an 
RCT to assess the efficacy and safety of antenatal steroids in clinical chorioamnionitis. Both maternal and neonatal outcome need to be evaluated, and should include long term follow-up. Until such a trial has been carried out, one should be cautious to make any clinical recommendation regarding this issue.

\section{References}

1. Roberts D, Dalziel S. Antenatal corticosteroids for accelerating fetal lung maturation for women at risk of preterm birth. Cochrane Database Syst Rev 2006;3:CD004454

2. Effect of corticosteroids for fetal maturation on perinatal outcomes. NIH Consens Statement 1994;12:1-24

3. Development of audit measures and guidelines for good practice in the management of neonatal respiratory distress syndrome. Report of a Joint Working Group of the British Association of Perinatal Medicine and the Research Unit of the Royal College of Physicians. Arch Dis Child 1992;67:1221-7

4. Been JV, Kramer BW, Zimmermann L. Antenatal corticosteroids to prevent preterm birth. Lancet 2009;373:894

5. Romero R, Gotsch F, Pineles B, Kusanovic JP. Inflammation in pregnancy: its roles in reproductive physiology, obstetrical complications, and fetal injury. Nutr Rev 2007;65:S194-202

6. Been JV, Rours IG, Kornelisse RF, Lima Passos V, Kramer BW, Schneider TA, de Krijger RR, Zimmermann LJ. Histologic chorioamnionitis, fetal involvement and antenatal steroids: effects on neonatal outcome in preterm infants. Am J Obstet Gynecol 2009;201:587.e1-8

7. Goldenberg RL, Andrews WW, Faye-Petersen OM, Cliver SP, Goepfert AR, Hauth JC. The Alabama preterm birth study: corticosteroids and neonatal outcomes in 23- to 32-week newborns with various markers of intrauterine infection. Am J Obstet Gynecol 2006;195:1020-4

8. Been JV, Zimmermann LJ. Histological chorioamnionitis and respiratory outcome in preterm infants. Arch Dis Child Fetal Neonatal Ed 2009;94:F218-25

9. Stroup DF, Berlin JA, Morton SC, Olkin I, Williamson GD, Rennie D, Moher D, Becker BJ, Sipe TA, Thacker $\mathrm{SB}$. Meta-analysis of observational studies in epidemiology: a proposal for reporting. Meta-analysis Of Observational Studies in Epidemiology (MOOSE) group. JAMA 2000;283:2008-12

10. Bax L, Yu LM, Ikeda N, Tsuruta H, Moons KG. Development and validation of MIX: comprehensive free software for meta-analysis of causal research data. BMC Med Res Methodol 2006;6:50

11. Elimian A, Verma U, Beneck D, Cipriano R, Visintainer P, Tejani N. Histologic chorioamnionitis, antenatal steroids, and perinatal outcomes. Obstet Gynecol 2000;96:333-6

12. Baud O, Zupan V, Lacaze-Masmonteil T, Audibert F, Shojaei T, Thebaud B, Ville Y, Frydman R, Dehan M. The relationships between antenatal management, the cause of delivery and neonatal outcome in a large cohort of very preterm singleton infants. BJOG 2000;107:877-84

13. Dempsey E, Chen MF, Kokottis T, Vallerand D, Usher R. Outcome of neonates less than 30 weeks gestation with histologic chorioamnionitis. Am J Perinatol 2005;22:155-9

14. Foix-L'helias L, Baud O, Lenclen R, Kaminski M, Lacaze-Masmonteil T. Benefit of antenatal glucocorticoids according to the cause of very premature birth. Arch Dis Child Fetal Neonatal Ed 2005;90:F46-8

15. Kent A, Lomas F, Hurrion E, Dahlstrom JE. Antenatal steroids may reduce adverse neurological outcome following chorioamnionitis: neurodevelopmental outcome and chorioamnionitis in premature infants. J Paediatr Child Health 2005;41:186-90

16. Shimoya K, Taniguchi T, Matsuzaki N, Moriyama A, Murata Y, Kitajima H, Fujimura M, Nakayama M. Chorioamnionitis decreased incidence of respiratory distress syndrome by elevating fetal interleukin- 6 serum concentration. Hum Reprod 2000;15:2234-40

17. Salafia CM, Weigl C, Silberman L. The prevalence and distribution of acute placental inflammation in uncomplicated term pregnancies. Obstet Gynecol 1989;73:383-9

18. Naeye RL. Functionally important disorders of the placenta, umbilical cord, and fetal membranes. Hum Pathol 1987; 18:680-91 
19. Lewis SH, Perrin E. In, Pathology of the placenta. 2nd ed. New York: Churchill Livingstone; 1999:318-20

20. Bendon RW, Faye-Petersen O, Pavlova Z, Qureshi F, Elder N, Das A, Hauth J, McNellis D, Mercer B, Miodovnik M. Histologic features of chorioamnion membrane rupture: development of methodology. Pediatr Pathol Lab Med 1997;17:27-42

21. Faye-Petersen O, Heller DS, Joshi VV. In, Handbook of placental pathology. Oxford: Taylor and Francis Medical Publishers; 2005:142-52

22. Redline RW. Placental inflammation. Semin Neonatol 2004;9:265-74

23. Redline RW. Inflammatory responses in the placenta and umbilical cord. Semin Fetal Neonatal Med 2006;11:296-301

24. Giedion A, Haefliger H, Dangel P. Acute pulmonary X-ray changes in hyaline membrane disease treated with artificial ventilation and positive end-expiratory pressure (PEP). Pediatr Radiol 1973;1:145-52

25. Papile LA, Burstein J, Burstein R, Koffler H. Incidence and evolution of subependymal and intraventricular hemorrhage: a study of infants with birth weights less than 1,500 gm. J Pediatr 1978;92:529-34

26. de Vries LS, Groenendaal F. Neuroimaging in the preterm infant. Ment Retard Dev Disabil Res Rev 2002;8:273-80

27. Volpe JJ. Hypoxic-ischemic encephalopathy: clinical aspects. In: Volpe JJ ed, Neurology of the newborn. Philadelphia: Saunders; 2001:331-94

28. Bell MJ, Ternberg JL, Feigin RD, Keating JP, Marshall R, Barton L, Brotherton T. Neonatal necrotizing enterocolitis. Therapeutic decisions based upon clinical staging. Ann Surg 1978;187:1-7

29. Dammann O, Allred EN, Leviton A, Shen-Schwarz S, Heller D, Genest DR, Collins MH. Fetal vasculitis in preterm newborns: interrelationships, modifiers, and antecedents. Placenta 2004;25:788-96

30. Newnham JP, Moss TJ, Padbury JF, Willet KE, Ikegami M, Ervin MG, Sly P, Jobe A. The interactive effects of endotoxin with prenatal glucocorticoids on short-term lung function in sheep. Am J Obstet Gynecol 2001;185:190-7

31. Sweet DG, Huggett MT, Warner JA, Moss TJ, Kloosterboer N, Halliday HL, Newnham JP, Kallapur SG, Jobe $\mathrm{AH}, \mathrm{Kramer} \mathrm{BW}$. Maternal betamethasone and chorioamnionitis induce different collagenases during lung maturation in fetal sheep. Neonatology 2008;94:79-86

32. Kallapur SG, Kramer BW, Moss TJ, Newnham JP, Jobe AH, Ikegami M, Bachurski CJ. Maternal glucocorticoids increase endotoxin-induced lung inflammation in preterm lambs. Am J Physiol Lung Cell Mol Physiol 2003;284:L633-42

33. Kallapur SG, Jobe AH, Ball MK, Nitsos I, Moss TJ, Hillman NH, Newnham JP, Kramer BW. Pulmonary and systemic endotoxin tolerance in preterm fetal sheep exposed to chorioamnionitis. J Immunol 2007;179:8491-9

34. Kramer BW, Ikegami M, Moss TJ, Nitsos I, Newnham JP, Jobe AH. Endotoxin-induced chorioamnionitis modulates innate immunity of monocytes in preterm sheep. Am J Respir Crit Care Med 2005;171:73-7

35. Kramer BW, Ikegami M, Moss TJ, Nitsos I, Newnham JP, Jobe AH. Antenatal betamethasone changes cord blood monocyte responses to endotoxin in preterm lambs. Pediatr Res 2004;55:764-8

36. Gantert M, Been JV, Gavilanes AW, Garnier Y, Zimmermann L, Kramer BW. Chorioamnionitis - a multiorgan disease of the fetus? J Perinatol in press 



\section{Chapter 11}

Chorioamnionitis, secondary 'hits'

and bronchopulmonary dysplasia

Been JV, Rours IG, Kornelisse RF, de Krijger RR, Zimmermann L

Submitted 


\section{Abstract}

Chorioamnionitis, sepsis and prolonged mechanical ventilation have been reported to have a joint predisposing effect on bronchopulmonary dysplasia (BPD) in preterm infants. Our aim was to re-evaluate these findings in a prospective cohort of preterm infants (gestational age $\leq 32.0$ weeks; $n=301$ ). Using multiple logistic regression analysis we were unable to reproduce a joint association or interaction between chorioamnionitis, sepsis and prolonged mechanical ventilation related to development of BPD. We hypothesise that changes in neonatal care contributed to the diminishing association between chorioamnionitis and bronchopulmonary dysplasia. 


\section{Introduction}

Considerable evidence links antenatal inflammation to adverse lung development in preterm infants ${ }^{1,2}$. However, the underlying mechanisms and associations are both complex and poorly understood. In an elegant case-control study published in 2002, Van Marter and colleagues showed evidence for an interrelationship between chorioamnionitis, sepsis and prolonged mechanical ventilation in the development of bronchopulmonary dysplasia (BPD) in very-low-birth-weight infants ${ }^{3}$. Whereas chorioamnionitis in itself was associated with lower BPD risk, BPD susceptibility was significantly increased after subsequent exposure to sepsis or prolonged mechanical ventilation ${ }^{3}$. Their results were suggestive of increased susceptibility to 'second hits' in the neonatal period in infants with chorioamnionitis. Although highly cited for these presumed associations, the results have never been reproduced.

Our aim was to re-evaluate the hypothesis derived from this study that chorioamnionitis, sepsis and prolonged mechanical ventilation have a combined effect on the development of BPD, in a prospective cohort of preterm infants reported previously ${ }^{4}$. To maximise comparability, the inclusion criteria and analyses used are equivalent to those applied by Van Marter and colleagues to maximum extent ${ }^{3}$.

\section{Methods}

All infants born at gestational age $\leq 32$ weeks who were admitted to the neonatal intensive care unit of the Erasmus MC between May 2001 and February 2003, were prospectively included in this study. Those with major congenital abnormalities were excluded. Histological examination of each infant's placenta was performed according to the Amniotic Fluid Infection Nosology Committee guidelines to detect signs of chorioamnionitis

with or without fetal involvement ${ }^{5}$. Relevant clinical parameters were stored in a database. Definitions of mechanical ventilation, sepsis and BPD were equivalent to those used by Van Marter and colleagues ${ }^{3,4}$.

Logistic regression analysis was performed to test associations between BPD and the presence of chorioamnionitis, sepsis and prolonged mechanical ventilation ( $>7$ days), either solitary or combined. All analyses were adjusted for gestational age and birth weight. In accordance with the Van Marter study, further analyses were additionally adjusted for ethnicity ${ }^{3}$. The study was approved by the local Medical Ethics Committee for Research on Human Subjects.

\section{Results}

The cohort consisted of 301 preterm infants ${ }^{4}, 249$ of whom had a birth weight $\leq 1500 \mathrm{~g}$ corresponding to the inclusion criterion of the Van Marter study ${ }^{3}$. Chorioamnionitis was 
present in 96 (38.6\%) infants in the latter group. Infants with chorioamnionitis had a lower gestational age $(27.8 \pm 1.8$ vs. $29.3 \pm 1.7, p<.001)$ and less often were small for gestational age ( 9 vs $46 \%, p<.001$ ). Their mothers had lower rates of preeclampsia ( 7 vs $58 \%, p<.001$ ), HELLP (haemolysis, elevated liver enzymes and low platelets; 2 vs $37 \%, p<.001$ ), and caesarean section (34 vs $80 \%, p<.001$ ). Conversely, clinical chorioamnionitis (65 vs $9 \%$, $\mathrm{p}<.001$ ) and PPROM (preterm premature rupture of membranes; 48 vs. $12 \%, p<.001$ ) occurred more frequently in patients with histological chorioamnionitis. No significant differences in other perinatal variables were present. Moreover, rates of respiratory distress syndrome (RDS), BPD and neonatal mortality were not different between the groups in univariable analyses. Detailed mechanical ventilation data for $\geq 7$ days were unavailable from 20 infants. Twenty-seven died before reaching 36 weeks postmenstrual age.

As shown in Table 1, most infants who developed BPD were exposed to sepsis, prolonged mechanical ventilation, or both. Chorioamnionitis tended to have an additional effect predominantly in those with either sepsis or mechanical ventilation, although these differences were not statistically significant.

Table 1. Number of infants that developed bronchopulmonary dysplasia related to exposure to chorioamnionitis, prolonged mechanical ventilation and postnatal sepsis. Odds ratios are given versus patients exposed to

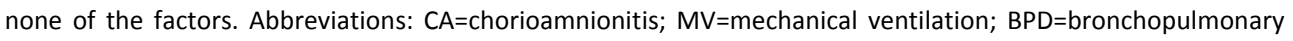
dysplasia; $\mathrm{OR}=$ odds ratio; $\mathrm{Cl}=$ confidence interval.

\begin{tabular}{|c|c|c|c|c|c|c|c|}
\hline & & Sepsis & & & No Sepsis & & \\
\hline$C A$ & $M V>7 d$ & BPD/total (\%) & OR $(95 \% \mathrm{Cl})$ & $P$ value & BPD/total (\%) & OR $(95 \% \mathrm{Cl})$ & Pvalue \\
\hline \multirow{2}{*}{ Yes } & Yes & $11 / 25(44)$ & $19.8(1.86-211)$ & .01 & $4 / 6(67)$ & $55.8(3.75-830)$ & .004 \\
\hline & No & $3 / 23(13)$ & $5.05(0.46-56.1)$ & .19 & $0 / 22(0)$ & - & - \\
\hline \multirow{2}{*}{ No } & Yes & $16 / 29(55)$ & $26.8(3.06-235)$ & .003 & $2 / 6(33)$ & $11.7(0.81-168)$ & .07 \\
\hline & No & $3 / 39(8)$ & $1.54(0.13-17.9)$ & .73 & $1 / 46(2)$ & Reference group & - \\
\hline
\end{tabular}

In additional multivariable models, the main characteristic associated with the development of BPD was prolonged mechanical ventilation, while a trend was observed for sepsis (Table 2). No significant effect of chorioamnionitis or interaction between chorioamnionitis and either sepsis or prolonged mechanical ventilation was present. Moreover, further analysis revealed no additional effect of chorioamnionitis with fetal involvement (not shown) ${ }^{5}$. The results were similar when infants $>1500 \mathrm{~g}$ were also included (not shown).

\section{Discussion}

In a prospective cohort of preterm infants, we were unable to reproduce the joint association of chorioamnionitis, sepsis and prolonged mechanical ventilation with development of BPD previously reported by Van Marter and colleagues ${ }^{3}$. While prolonged mechanical 
ventilation, and to a lesser extent sepsis, did increase the risk for BPD, an additional effect of chorioamnionitis could not be demonstrated.

Table 2. Odds ratios for development of bronchopulmonary dysplasia in multivariable models, adjusted for BW, GA and ethnicity. Abbreviations: CA=chorioamnionitis; $M V=$ mechanical ventilation. Model 1=including one predictor; Model 2=including all three predictors; Model 3=model 2 including interaction terms.

\begin{tabular}{lllllll}
\hline & Model 1 & Pvalue & Model 2 & P value & Model 3 & P value \\
\hline CA & $1.22(0.52-2.87)$ & .65 & $1.28(0.46-3.59)$ & .64 & $2.64(0.27-25.6)$ & .40 \\
Sepsis & $2.25(0.92-5.55)$ & .08 & $2.14(0.71-6.48)$ & .18 & $2.94(0.64-13.6)$ & .17 \\
$M V>7 d$ & $17.8(5.74-55.5)$ & $<.001$ & $16.6(5.28-52.0)$ & $<.001$ & $17.8(4.59-68.8)$ & $<.001$ \\
$C A \times M V>7 d$ & - & - & - & - & - & .82 \\
$C A \times$ Sepsis & - & - & - & - & - & .53 \\
\hline
\end{tabular}

Although effort was made to maximise comparability with the Van Marter study, some dissimilarities were inevitable. Our study was a prospective cohort study, while the previous one had a case-control design, with matching for gestational age and birth weight. Although we adjusted our analyses for these parameters, some confounding may remain. Whereas in our study $20 \%$ of patients developed BPD, by design this portion was $50 \%$ in the Van Marter study. Furthermore, their data were adjusted for hypothyroxinemia, while this information was lacking in our study. However, these differences are unlikely to fully explain the total absence of an effect of chorioamnionitis in our cohort.

Several other factors may contribute to the dissimilar findings. Importantly, there is a ten year difference in inclusion period between both studies. Over this decade, considerable changes in neonatal intensive care have taken place. A general tendency towards more gentle and less prolonged mechanical ventilation of preterm newborns is facilitated by increased use of surfactant, non-invasive modes of ventilatory support, and antenatal steroid administration. These modalities may diminish inflammation and thus be of particular benefit for chorioamnionitis-exposed infants ${ }^{1}$. Indeed, mechanical ventilation has been shown to reduce alveolar surfactant content, and to exaggerate pulmonary injury and decrease ventilatory efficiency after prior exposure to inflammation ${ }^{6}$. Moreover, whereas early studies often identified chorioamnionitis as a risk factor for BPD development, more recent studies have repeatedly failed to identify this association ${ }^{1}$.

However, the absence of an association between chorioamnionitis and BPD needs to be considered in the light of a reduction in RDS after chorioamnionitis ${ }^{1}$. That is, given the decreased incidence of acute respiratory distress and the conjoining reduced need for invasive respiratory support, one would expect an accompanying reduction in chronic lung disease ${ }^{1}$. The fact that this is not observed suggests that there is still a trade-off for the accelerated lung maturation, also reflected by an arrest in lung development observed 
after experimental chorioamnionitis in animals ${ }^{2}$. Additional research is needed to evaluate which factors contribute to and, more importantly, may reverse this process.

In conclusion, our data are in line with recent reports suggesting a diminishing association between chorioamnionitis and BPD, even in the presence of secondary proinflammatory hits. Advances in neonatal care are likely to explain most of the effect. Despite these changes, mechanical ventilation remains a critical predisposing factor for BPD.

\section{References}

1. Been JV, Zimmermann LJ. Histological chorioamnionitis and respiratory outcome in preterm infants. Arch Dis Child Fetal Neonatal Ed 2009;94:F218-25

2. Kramer BW. Antenatal inflammation and lung injury: prenatal origin of neonatal disease. J Perinatol 2008;28 Suppl 1:S21-7

3. Van Marter L, Dammann O, Allred EN, Leviton A, Pagano M, Moore M, Martin C. Chorioamnionitis, mechanical ventilation, and postnatal sepsis as modulators of chronic lung disease in preterm infants. $J$ Pediatr 2002;140:171-6

4. Been JV, Rours IG, Kornelisse RF, Lima Passos V, Kramer BW, Schneider TA, de Krijger RR, Zimmermann LJ. Histologic chorioamnionitis, fetal involvement, and antenatal steroids: effects on neonatal outcome in preterm infants. Am J Obstet Gynecol 2009;201:587 e1-8

5. Redline RW, Faye-Petersen O, Heller D, Qureshi F, Savell V, Vogler C. Amniotic infection syndrome: nosology and reproducibility of placental reaction patterns. Pediatr Dev Pathol 2003;6:435-48

6. Ikegami M, Kallapur SG, Jobe AH. Initial responses to ventilation of premature lambs exposed to intraamniotic endotoxin 4 days before delivery. Am J Physiol Lung Cell Mol Physiol 2004;286:L573-9 


\section{Chapter 12}

Chorioamnionitis alters the response to surfactant in preterm infants

Been JV, Rours IG, Kornelisse RF, Jonkers F, de Krijger RR, Zimmermann LJ

J Pediatr 2010; 156: 10-5 


\section{Abstract}

Objective. To study the association between antenatal exposure to chorioamnionitis and the neonatal response to surfactant.

Study design. Prospective observational cohort of 301 preterm infants of gestational age $\leq 32.0$ weeks, 146 of whom received surfactant according to standardized criteria. Fraction of inspired oxygen $\left(\mathrm{FiO}_{2}\right)$ requirement (using analysis of variance) and time to extubation (using Kaplan-Meier and Cox regression analyses) were compared between groups based on the presence of histological chorioamnionitis ( $\mathrm{HC}$ ) with or without fetal involvement ( $\mathrm{HC}-, \mathrm{n}=88 ; \mathrm{HC}+\mathrm{F}-, \mathrm{n}=25 ; \mathrm{HC}+\mathrm{F}+, \mathrm{n}=33$ ) and between infants who developed bronchopulmonary dysplasia (BPD) or died $(n=57)$ and BPD-free survivors $(n=89)$. Multiple logistic regression was performed to investigate the association between $\mathrm{HC}$ and BPD.

Results. Compared with $\mathrm{HC}$ - infants, $\mathrm{HC}+\mathrm{F}+$ infants had significantly greater $\mathrm{FiO}_{2}$ requirement and prolonged time to extubation postsurfactant, not accounted for by differences in gestational age and birth weight. Infants with BPD/death had a strikingly similar pattern of increased $\mathrm{FiO}_{2}$ requirement postsurfactant. Moreover, in infants who received surfactant, $\mathrm{HC}+\mathrm{F}+$ status was associated with increased risk for BPD (odds ratio [OR] = 3.40; 95\% confidence interval $[\mathrm{Cl}]=1.02-11.3 ; \mathrm{P}=.047)$ and for $\mathrm{BPD} /$ death $(\mathrm{OR}=2.72$; $95 \% \mathrm{Cl}=1.00-7.42 ; \mathrm{P}=.049$ ).

Conclusions. An impaired surfactant response was observed in preterm infants with severe chorioamnionitis and may be involved in the association between chorioamnionitis, mechanical ventilation, and the development of BPD. 


\section{Introduction}

Surfactant deficiency is the hallmark of the respiratory distress syndrome (RDS) in preterm infants, and the introduction of surfactant replacement therapy has greatly improved survival in this population ${ }^{1}$. An important cause of preterm birth is chorioamnionitis, which affects up to $60 \%$ of extremely preterm infants ${ }^{2}$. Chorioamnionitis is an antenatal inflammatory state associated with bacterial invasion of the uterine environment and subsequent neutrophil invasion of the placenta ${ }^{3}$. More severe cases may exhibit signs of a fetal inflammatory response ${ }^{4}$.

Antenatal inflammation enhances lung maturation and increases surfactant production in preterm animal models ${ }^{5,6}$. Correspondingly, chorioamnionitis is associated with decreased incidence of RDS in many human studies ${ }^{7-15}$. Despite accelerating lung maturation, antenatal inflammation is associated with adverse lung development ${ }^{14,16}$. Human evidence suggests that secondary proinflammatory hits, such as sepsis and mechanical ventilation, highly augment this association ${ }^{17}$. Likewise, mechanical ventilation exaggerates pulmonary inflammation after experimental chorioamnionitis in preterm sheep ${ }^{18}$, and higher pressures are needed to adequately ventilate these animals ${ }^{19}$, despite previous administration of surfactant. This suggests that the efficacy of exogenous surfactant may be reduced after antenatal inflammation. Indeed, considerable evidence links inflammation to decreased surfactant function ${ }^{20,21}$. Human studies investigating the association between antenatal inflammation and the subsequent response to surfactant are lacking, however.

The aim of the present study was to explore the relationship between histological chorioamnionitis ( $\mathrm{HC}$ ) with or without fetal involvement and the response to exogenous surfactant in a prospective cohort of preterm infants reported previously ${ }^{13,22}$. We hypothesised that chorioamnionitis would be associated with decreased surfactant efficacy.

\section{Methods}

Inborn preterm infants (gestational age $\leq 32.0$ weeks) admitted to the neonatal intensive care unit of the Erasmus Medical Center-Sophia Children's Hospital, Rotterdam, the Netherlands, between May 2001 and February 2003 were eligible for the study. Antenatal, perinatal, and neonatal data were prospectively stored in a database. Women received antenatal steroids (betamethasone $12 \mathrm{mg}$ i.m., repeated after 24 hours) in case of imminent preterm delivery. Gestational age was estimated by early ultrasonography or based on the last menstrual period when information was reliable. Bronchopulmonary dysplasia (BPD) was defined as dependency on oxygen supplementation at postmenstrual age 36 weeks. Other clinical definitions used in the study were as described previously ${ }^{13}$. The study was approved by Erasmus University Medical Center's Medical Ethics Committee for Research on Human Subjects. 


\section{Histopathology}

Placentas and membranes were fixed in formalin and embedded in paraffin according to a standard protocol, and then examined by a single pathologist blinded for clinical information ${ }^{13}$. Chorioamnionitis was diagnosed as proposed by the Amniotic Fluid Infection Nosology Committee ${ }^{4}$. Accordingly, fetal involvement was diagnosed when any of the following was present: chorionic vasculitis, umbilical phlebitis or vasculitis, (subacute) necrotising funisitis, or concentric umbilical perivasculitis.

\section{Criteria for surfactant administration}

Exogenous surfactant (beractant, $100 \mathrm{mg} / \mathrm{kg}$ ) was administered endotracheally to mechanically ventilated infants if the following criteria were met: mean airway pressure $(\mathrm{MAP}) \times$ fraction of inspired oxygen $\left(\mathrm{FiO}_{2}\right) \geq 2$ for infants $\leq 1000 \mathrm{~g}$ or $\mathrm{MAP} \times \mathrm{FiO}_{2} \geq 2.5$ for infants $>1000 \mathrm{~g}$. A second dose was given when the criteria were still met 6-8 hours after the first dose. Data after the first dose were kept in time-dependent analyses, irrespective of whether a second dose was given. Subsequent ventilatory management was at the discretion of the attending physician, who was unaware of the diagnosis of chorioamnionitis.

\section{Statistics}

Differences between groups were tested by analysis of variance or the $\chi^{2}$ test for dichotomous data. Survival curves were compared between groups using the Mantel-Cox logrank test for simple comparisons and Cox regression analysis for multivariate analyses. Dunnett post hoc analysis was applied for multiple group comparisons. Logistic regression analysis was performed to identify risk factors for adverse outcome. Significance was accepted at $\mathrm{P}<.05$ (2-sided). All analyses were performed using SPSS version 15.0 (SPSS Inc, Chicago, Illinois).

\section{Results}

A total of 323 infants were eligible for inclusion in the study. Nineteen infants were excluded because of insufficient data, and 3 were excluded due to severe congenital anomalies. Of the remaining 301 infants, 146 (48.5\%) received surfactant, 98 of whom received 2 doses. Infants treated with surfactant had lower gestational age and birth weight, more often were male, and less often received antenatal steroids (Table). There were no significant differences between the infants without $\mathrm{HC}(\mathrm{HC}-)$ and those with $\mathrm{HC}$ with $(\mathrm{HC}+\mathrm{F}+)$ or without fetal involvement $(\mathrm{H}+\mathrm{F}-)$ in terms of the proportion receiving surfactant or receiving a second dose. Infants with HC had lower rates of cesarean section, HELLP (hemolysis, elevated liver enzymes, low platelets), and preeclampsia, and higher rates of preterm premature rupture of membranes (PPROM) and clinical chorioamnionitis. Moreover, the $\mathrm{HC}+\mathrm{F}$ - infants had less severe RDS. 
Table. Infant characteristics according to surfactant treatment and presence of HC with or without fetal involvement. Data are presented as mean \pm standard deviation for continuous data and $\mathrm{n}(\%)$ for dichotomous data. ${ }^{5} \mathrm{P}<.05,{ }^{\dagger} \mathrm{P}<.01,{ }^{\ddagger} \mathrm{P}<.001$ versus $\mathrm{HC}$ (analysis of variance or $\chi^{2}$ test, with Dunnett post hoc analysis).

\begin{tabular}{|c|c|c|c|c|c|c|c|c|c|}
\hline \multirow[b]{2}{*}{ Characteristic } & \multicolumn{3}{|c|}{ No surfactant } & \multicolumn{3}{|c|}{ Surfactant dose 1} & \multicolumn{3}{|c|}{ Surfactant dose 2} \\
\hline & $\begin{array}{l}H C- \\
(n=92)\end{array}$ & $\begin{array}{l}H C+F- \\
(n=28)\end{array}$ & $\begin{array}{l}H C+F+ \\
(n=35)\end{array}$ & $\begin{array}{l}H C- \\
(n=88)\end{array}$ & $\begin{array}{l}H C+F- \\
(n=25)\end{array}$ & $\begin{array}{l}H C+F+ \\
(n=33)\end{array}$ & $\begin{array}{l}H C- \\
(n=61)\end{array}$ & $\begin{array}{l}H C+F- \\
(n=13)\end{array}$ & $\begin{array}{l}H C+F+ \\
(n=24)\end{array}$ \\
\hline Age at surfactant (hrs) & - & - & - & $\begin{array}{l}4.2 \\
\pm 5.9\end{array}$ & $\begin{array}{l}2.6 \\
\pm 1.8\end{array}$ & $\begin{array}{l}5.2 \\
\pm 10.5\end{array}$ & $\begin{array}{l}11.5 \\
\pm 5.3\end{array}$ & $\begin{array}{l}11.6 \\
\pm 4.9\end{array}$ & $\begin{array}{l}12.3 \\
\pm 12.0\end{array}$ \\
\hline Time after $1^{\text {st }}$ dose (hrs) & - & - & - & - & - & - & $\begin{array}{l}8.1 \\
\pm 3.5\end{array}$ & $\begin{array}{l}9.0 \\
\pm 4.3\end{array}$ & $\begin{array}{l}7.1 \\
\pm 2.3\end{array}$ \\
\hline \multicolumn{10}{|l|}{ Antenatal characteristics } \\
\hline Maternal age & $\begin{array}{l}30.7 \\
\pm 5.4\end{array}$ & $\begin{array}{l}30.7 \\
\pm 5.1\end{array}$ & $\begin{array}{l}30.4 \\
\pm 5.3\end{array}$ & $\begin{array}{l}30.8 \\
\pm 5.2\end{array}$ & $\begin{array}{l}30.8 \\
\pm 4.7\end{array}$ & $\begin{array}{l}30.8 \\
\pm 5.4\end{array}$ & $\begin{array}{l}30.8 \\
\pm 5.1\end{array}$ & $\begin{array}{l}30.3 \\
\pm 5.6\end{array}$ & $\begin{array}{l}30.6 \\
\pm 6.2\end{array}$ \\
\hline Preeclampsia & $51(55)$ & $4(14)^{\ddagger}$ & $1(3)^{\ddagger}$ & $49(56)$ & $1(4)^{\ddagger}$ & $1(3)^{\ddagger}$ & $36(59)$ & $0(0)^{\ddagger}$ & $1(4)^{\ddagger}$ \\
\hline HELLP & $28(30)$ & $1(4)^{\dagger}$ & $0(0)^{\ddagger}$ & 34 (39) & $2(8)^{\dagger}$ & $0(0)^{\ddagger}$ & $28(46)$ & $1(8)^{+}$ & $0(0)^{\ddagger}$ \\
\hline PPROM & $18(20)$ & $9(32)$ & $24(69)^{\ddagger}$ & $10(11)$ & $7(28)$ & $18(55)^{\ddagger}$ & $6(10)$ & $3(23)$ & $14(58)^{\ddagger}$ \\
\hline Clinical chorioamnionitis & $8(9)$ & $13(46)$ & $21(60)$ & $13(15)$ & $15(60)^{\ddagger}$ & $25(76)^{\ddagger}$ & $8(13)$ & $7(54)^{\dagger}$ & $18(75)^{\ddagger}$ \\
\hline Antenatal steroids & $65(72)$ & $26(93)^{\S}$ & $26(74)$ & $67(77)$ & $19(76)$ & $27(82)$ & $52(85)$ & $10(77)$ & $19(79)$ \\
\hline \multicolumn{10}{|l|}{ Delivery characteristics } \\
\hline Caesarean section & 73 (79) & $9(32)^{\ddagger}$ & $11(31)^{\ddagger}$ & $65(74)$ & $10(40)^{\dagger}$ & $8(24)^{\ddagger}$ & $45(74)$ & $5(39)^{\S}$ & $6(25)^{\ddagger}$ \\
\hline Gestational age & $\begin{array}{l}30.3 \\
\pm 1.3\end{array}$ & $\begin{array}{l}29.6 \\
\pm 1.5\end{array}$ & $\begin{array}{l}28.9 \\
\pm 2.1^{\ddagger}\end{array}$ & $\begin{array}{l}28.7 \\
\pm 1.7\end{array}$ & $\begin{array}{l}27.8 \\
\pm 1.8^{\S}\end{array}$ & $\begin{array}{l}27.2 \\
\pm 1.7^{\ddagger}\end{array}$ & $\begin{array}{l}28.6 \\
\pm 1.7\end{array}$ & $\begin{array}{l}27.8 \\
\pm 1.9\end{array}$ & $\begin{array}{l}27.2 \\
\pm 1.9^{+}\end{array}$ \\
\hline Birth weight & $\begin{array}{l}1165 \\
\pm 356\end{array}$ & $\begin{array}{l}1363 \\
\pm 365^{\S}\end{array}$ & $\begin{array}{l}1275 \\
\pm 374\end{array}$ & $\begin{array}{l}1056 \\
\pm 313\end{array}$ & $\begin{array}{l}1121 \\
\pm 325\end{array}$ & $\begin{array}{l}1001 \\
\pm 269\end{array}$ & $\begin{array}{l}1053 \\
\pm 337\end{array}$ & $\begin{array}{l}1157 \\
\pm 380\end{array}$ & $\begin{array}{l}1009 \\
\pm 293\end{array}$ \\
\hline Small for gestational age & $41(45)$ & $2(7)^{\ddagger}$ & $1(3)^{\ddagger}$ & $29(33)$ & $3(12)$ & $3(9)^{\S}$ & $19(31)$ & $1(8)$ & $2(8)^{\S}$ \\
\hline Male sex & $40(45)$ & $16(57)$ & $14(40)$ & $50(57)$ & $14(56)$ & $20(61)$ & $32(53)$ & $7(54)$ & $15(63)$ \\
\hline \multicolumn{10}{|l|}{ Neonatal outcome } \\
\hline$R D S$ & $20(22)$ & $6(21)$ & $9(26)$ & $82(93)$ & $22(88)$ & $31(94)$ & $59(97)$ & $12(92)$ & $23(96)$ \\
\hline grade $3-4$ & $5(5)$ & $1(4)$ & $2(6)$ & $45(51)$ & $5(20)^{\S}$ & $17(52)$ & $37(61)$ & $2(15)^{\dagger}$ & $15(63)$ \\
\hline Early onset sepsis & $16(18)$ & $7(25)$ & $5(14)$ & $19(22)$ & $11(44)$ & $10(30)$ & $15(25)$ & $6(46)$ & $7(29)$ \\
\hline culture proven & $6(7)$ & $3(11)$ & $0(0)$ & $6(7)$ & $3(12)$ & $4(12)$ & $6(10)$ & $2(15)$ & $3(13)$ \\
\hline$B P D$ & $6(7)$ & $2(7)$ & $2(6)$ & $19(24)$ & $7(30)$ & 9 (39) & $14(27)$ & $5(46)$ & $6(38)$ \\
\hline In-hospital mortality & $3(3)$ & $0(0)$ & $4(11)$ & $13(15)$ & $3(12)$ & $9(27)$ & $11(18)$ & $2(15)$ & $7(29)$ \\
\hline
\end{tabular}

After the first surfactant dose, a similar decrease in $\mathrm{FiO}_{2}$ was initially observed in all groups (Figure 1, A). However, a subsequent rise in $\mathrm{FiO}_{2}$ requirement was apparent in the $\mathrm{HC}+\mathrm{F}+$ infants, with significantly higher levels up to 12 hours postsurfactant. Conversely, $\mathrm{FiO}_{2}$ requirement continued to decrease after surfactant in the other 2 groups. Results were similar after a second surfactant dose (Figure 1, B). Moreover, time to extubation was prolonged with increasing severity of chorioamnionitis after both surfactant doses $(P=$ .047 and .009, respectively) (Figures 2, A and 3). 

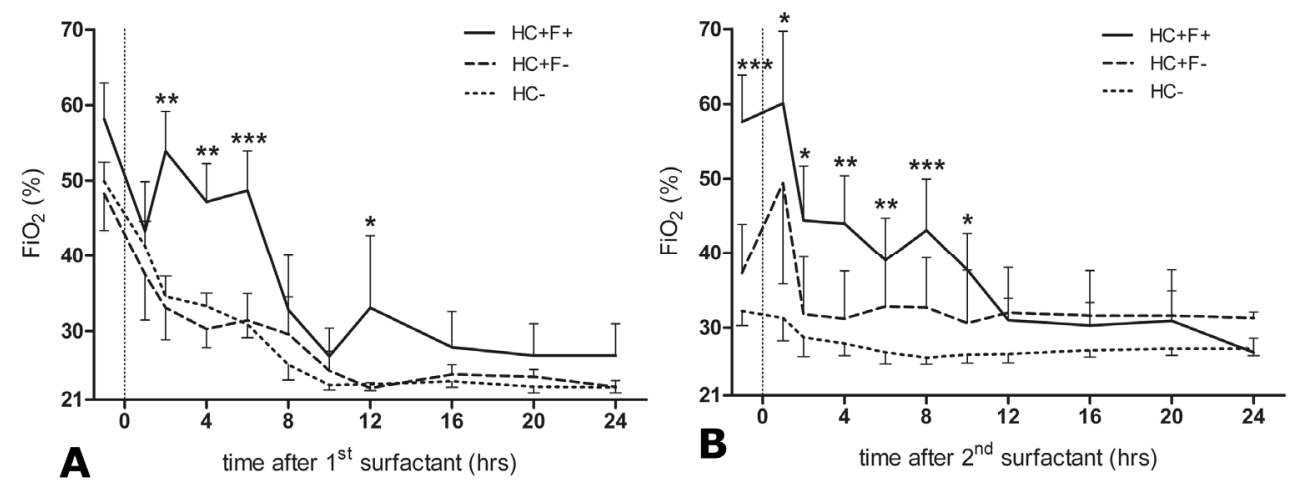

Figure 1. Change in $\mathrm{FiO}_{2}$ requirement in response to exogenous surfactant for groups based on placental histology. A, First dose. B, Second dose. Points represent means for each group \pm standard error of the mean. ${ }^{*} \mathrm{P}<$ $.05 ; * * \mathrm{P}<.01 ; * * \mathrm{P}<.001$ versus $\mathrm{HC}$.
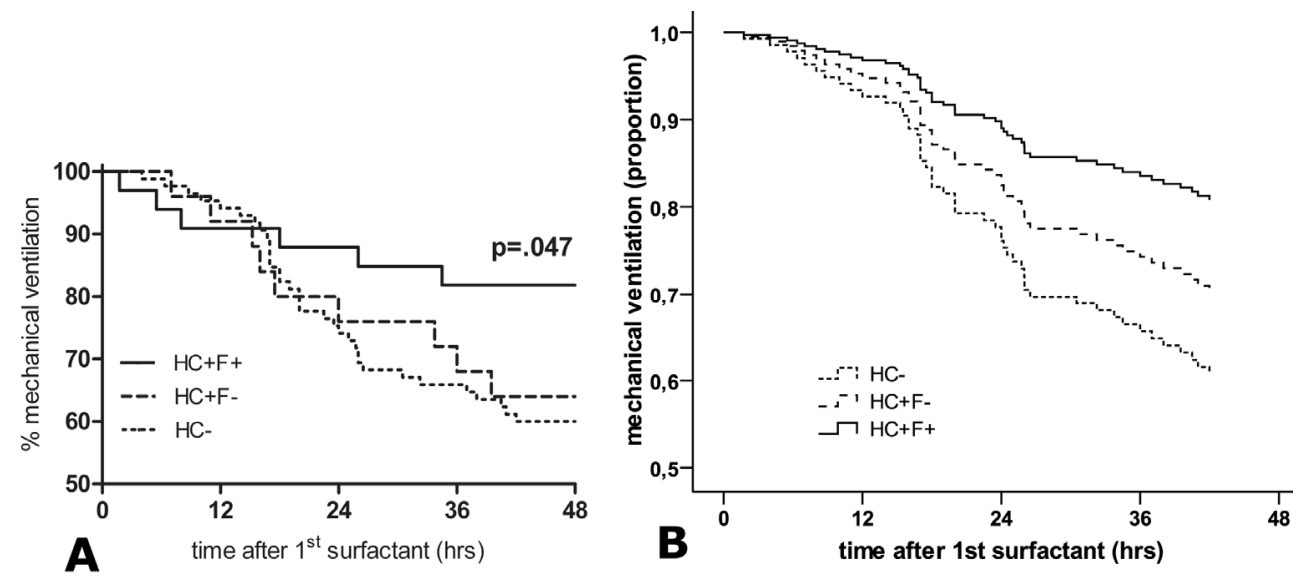

Figure 2. A, Kaplan-Meier analysis and B, Cox regression analysis adjusted for gestational age and birth weight of time until extubation after the first dose of exogenous surfactant for groups based on placental histology.

To disentangle the relative contributions of gestational age and chorioamnionitis, we compared the effects of surfactant between different gestational age strata in the HCinfants ( $<28.0$ weeks, $28.0-30.0$ weeks, and $\geq 30.0$ weeks). There were no significant differences among these strata in $\mathrm{FiO}_{2}$ requirement at any time after surfactant administration, although the likelihood of extubation within 48 hours postsurfactant increased with advancing gestational age (data not shown). To evaluate whether this might explain the decreased chance of extubation after chorioamnionitis, we performed Cox regression analysis with adjustment for gestational age and birth weight. HC+F- infants were less likely to be extubated in the first 48 hours after the second surfactant dose (hazard rate 
$[\mathrm{HR}]=0.12 ; 95 \%$ confidence interval $[\mathrm{Cl}]=0.01-0.96 ; \mathrm{P}=.046)$, while similar trends remained after both surfactant doses for $\mathrm{HC}+\mathrm{F}+$ infants $(\mathrm{HR}=0.42 ; 95 \% \mathrm{Cl}=0.17-1.05 ; \mathrm{P}=$ .06 and $\mathrm{HR}=0.26 ; 95 \% \mathrm{Cl}=0.06-1.15 ; \mathrm{P}=.08$ ) (Figures 2, $\mathrm{B}$ and 4 ).

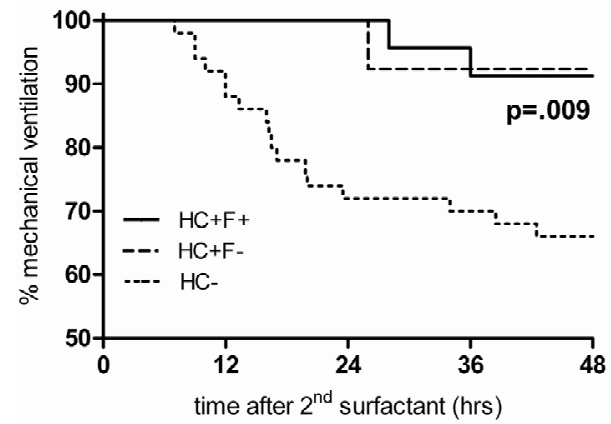

Figure 3. Kaplan-Meier analysis of time until extubation after the second dose of exogenous surfactant for groups based on placental histology.

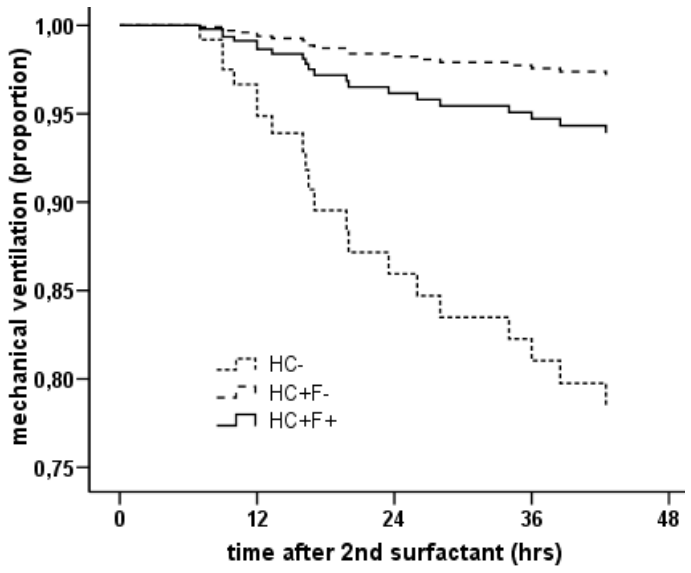

Figure 4. Cox regression analysis of estimated time to extubation after the second dose of exogenous surfactant, adjusted for gestational age and birth weight in groups according to placental histology. $P<.05 \mathrm{HC}+\mathrm{F}-\mathrm{vs}$ HC-.

To evaluate the association between the response to surfactant and the composite adverse outcome BPD/death, data were grouped according to this outcome. Infants who died or developed BPD demonstrated a less effective response to surfactant (Figures 5 and $6)$, very similar to that in the $\mathrm{H}+\mathrm{F}+$ infants. The time-dependent likelihood of extubation was decreased in infants who either died or developed BPD after both the first and the 
second surfactant dose, as analyzed by Cox regression analysis, with adjustment for gestational age and birth weight $(P=.03$ and .02 , respectively).

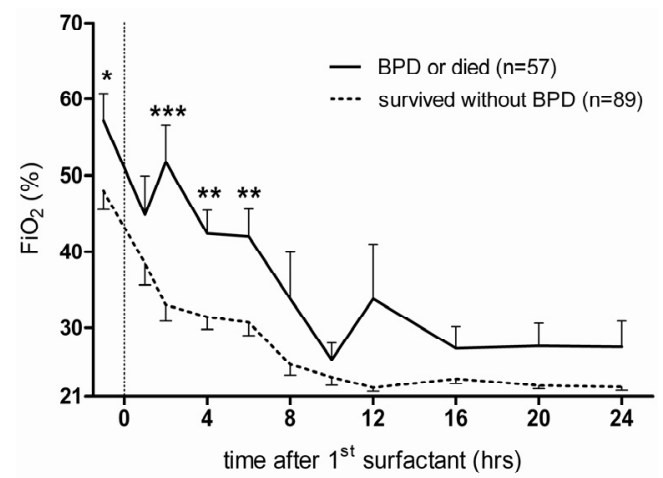

Figure 5. Change in $\mathrm{FiO}_{2}$ requirement in response to the first dose of exogenous surfactant for infants who developed BPD or died versus BPD-free survivors. Points represent means for each group \pm standard error of the mean. ${ }^{*} \mathrm{P}<.05 ;{ }^{* * P}<.01 ;{ }^{* * * P}<.001$.

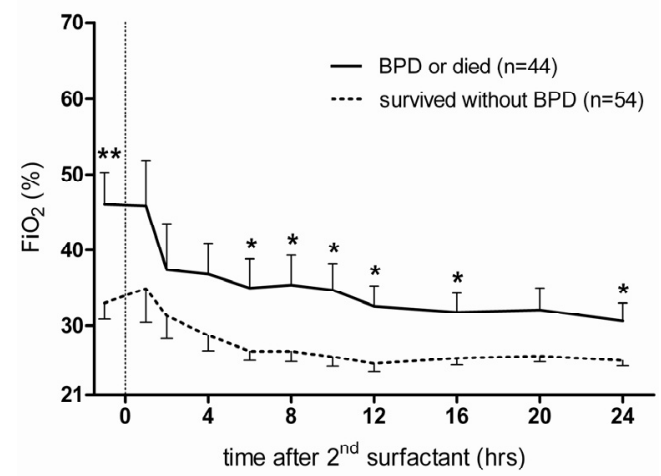

Figure 6. Change in $\mathrm{FiO}_{2}$ requirement in response to the second dose of exogenous surfactant for infants who developed BPD or died versus BPD-free survivors. Points represent means for each group \pm standard error of the mean. ${ }^{*} \mathrm{P}<.05 ;{ }^{* *} \mathrm{P}<.01$.

We performed logistic regression analysis to investigate the association of chorioamnionitis with BPD and mortality in infants requiring surfactant. In a model adjusting for sex, gestational age, birth weight, patent ductus arteriosus, and sepsis, $\mathrm{HC}+\mathrm{F}+$ infants had an increased risk for $\mathrm{BPD}$ (odds ratio $[\mathrm{OR}]=3.40 ; 95 \% \mathrm{Cl}=1.02-11.3 ; \mathrm{P}=.047$ ) and for $\mathrm{BPD} /$ death $(\mathrm{OR}=2.73 ; 95 \% \mathrm{Cl}=1.00-7.42 ; \mathrm{P}=.049)$. 


\section{Discussion}

In this prospective cohort of preterm infants, antenatal exposure to inflammation altered the response to postnatal surfactant administration. $\mathrm{HC}+\mathrm{F}+$ status was associated with increased $\mathrm{FiO}_{2}$ requirement postsurfactant. A strikingly similar pattern was observed in infants who died or developed BPD. Moreover, the likelihood of extubation over the first 48 hours postsurfactant decreased with increasing severity of chorioamnionitis. The lower gestational age in these infants only partially explains these differences, although the possibility of additional effects of differences in other baseline characteristics cannot be excluded. Finally, in infants requiring surfactant, $\mathrm{HC}+\mathrm{F}+$ status was associated with development of BPD in multivariate analysis.

Pulmonary inflammation is a recognized modulator of the subsequent response to treatment. Previous exposure to inflammation aggravates the pulmonary inflammatory response to mechanical ventilation in several animal models ${ }^{23-25}$. A similar effect has been demonstrated after antenatal inflammation ${ }^{18}$, despite enhanced pulmonary maturation and surfactant production ${ }^{16}$. Likewise, chorioamnionitis in preterm infants is associated with decreased BPD risk in those ventilated for less than 7 days, while prolonged mechanical ventilation significantly increases the risk of BPD ${ }^{17}$. Our data suggest that an altered response to exogenous surfactant may be an important modulator of this association. Surfactant was less effective in decreasing the $\mathrm{FiO}_{2}$ requirement in $\mathrm{HC}+$ infants, associated with a prolonged need for mechanical ventilation. These effects were most prominent in the $\mathrm{HC}+\mathrm{F}+$ infants, generally considered the most severely affected. The consequent increased need for respiratory support may explain, at least in part, the predisposition to $B P D$ in $\mathrm{HC}+$ infants ${ }^{14,17,26}$. Our observations of a similar reduced response to surfactant in infants with BPD, and an association between $\mathrm{HC}+\mathrm{F}+$ status and BPD in infants treated with surfactant, further support this.

The concept of decreased surfactant efficacy in an inflammatory environment is supported by earlier reports ${ }^{20}$. In preterm infants with sepsis, tracheal aspirate fluid surface tension is increased, indicating poorer surfactant function ${ }^{27}$. Likewise, in patients with acute respiratory distress syndrome, surfactant phospholipid composition is disturbed, and both surfactant protein levels and the active surfactant fraction are reduced ${ }^{28-30}$. In accordance with our findings, surfactant dysfunction was correlated with adverse outcome in these patients ${ }^{28}$. Both inactivation and increased clearance of surfactant may reduce its efficacy ${ }^{20,21}$. Inactivation may result from leakage of serum proteins into the alveolar space, inhibition by C-reactive protein, and altered expression or structural alteration of surfactant proteins and phospholipids ${ }^{20,21,31,32}$. Recruited inflammatory cells may cause increased surfactant clearance, as demonstrated after lipopolysaccharide instillation in rats ${ }^{33}$. Accordingly, infants with BPD have a smaller alveolar surfactant pool size, but a larger total pulmonary surfactant pool ${ }^{34}$.

Several alternative approaches may increase surfactant efficacy in infants with chorioamnionitis. These include higher surfactant dosing ${ }^{35,36}$ and methods of surfactant 
administration in nonintubated infants ${ }^{1}$. The latter may preclude the need for mechanical ventilation, an important modulator of adverse pulmonary outcome after chorioamnionitis ${ }^{17,37}$. Moreover, surfactant enrichment with additives capable of reducing inactivation, such as nuclear factor-kB inhibitors, show great potential to improve surfactant function in lungs exposed to chorioamnionitis $1,21,38-40$.

Decreased efficacy of exogenous surfactant is present in preterm infants with chorioamnionitis. Previous reports of increased surfactant clearance and inactivation in an inflammatory setting support this concept. Additional analyses further suggest links among decreased surfactant efficacy, chorioamnionitis, and development of BPD. Interventions aimed at increasing surfactant efficacy may be of particular benefit for infants exposed to chorioamnionitis.

\section{References}

1. Been JV, Zimmermann LJ. What's new in surfactant? A clinical view on recent developments in neonatology and paediatrics. Eur J Pediatr 2007;166:889-99

2. Lahra MM, Jeffery HE. A fetal response to chorioamnionitis is associated with early survival after preterm birth. Am J Obstet Gynecol 2004;190:147-51

3. Goldenberg RL, Hauth JC, Andrews WW. Intrauterine infection and preterm delivery. N Engl J Med 2000;342:1500-7

4. Redline RW, Faye-Petersen O, Heller D, Qureshi F, Savell V, Vogler C. Amniotic infection syndrome: nosology and reproducibility of placental reaction patterns. Pediatr Dev Pathol 2003;6:435-48

5. Kramer BW, Kallapur S, Newnham J, Jobe AH. Prenatal inflammation and lung development. Semin Fetal Neonatal Med 2009;14:2-7

6. Kramer BW, Ladenburger A, Kunzmann S, Speer CP, Been JV, van Iwaarden JF, Zimmermann LJ, Gantert M, Garnier Y. Intravenous lipopolysaccharide-induced pulmonary maturation and structural changes in fetal sheep. Am J Obstet Gynecol 2009;200:195 e1-10

7. Lahra MM, Beeby PJ, Jeffery HE. Maternal versus fetal inflammation and respiratory distress syndrome: a 10-year hospital cohort study. Arch Dis Child Fetal Neonatal Ed 2009;94:F13-6

8. Kosuge S, Ohkuchi A, Minakami H, Matsubara S, Uchida A, Eguchi Y, Honma Y, Sato I. Influence of chorioamnionitis on survival and morbidity in singletons live-born at $<32$ weeks of gestation. Acta Obstet Gynecol Scand 2000;79:861-5

9. Watterberg KL, Demers LM, Scott SM, Murphy S. Chorioamnionitis and early lung inflammation in infants in whom bronchopulmonary dysplasia develops. Pediatrics 1996;97:210-5

10. Dempsey E, Chen MF, Kokottis T, Vallerand D, Usher R. Outcome of neonates less than 30 weeks gestation with histologic chorioamnionitis. Am J Perinatol 2005;22:155-9

11. Andrews WW, Goldenberg RL, Faye-Petersen O, Cliver S, Goepfert AR, Hauth JC. The Alabama Preterm Birth study: polymorphonuclear and mononuclear cell placental infiltrations, other markers of inflammation, and outcomes in 23- to 32-week preterm newborn infants. Am J Obstet Gynecol 2006;195:803-8

12. Lee J, Seong HS, Kim BJ, Jun JK, Romero R, Yoon BH. Evidence to support that spontaneous preterm labor is adaptive in nature: neonatal RDS is more common in "indicated" than in "spontaneous" preterm birth. $J$ Perinat Med 2009;37:53-8

13. Been JV, Rours IG, Kornelisse RF, Lima Passos V, Kramer BW, Schneider TA, de Krijger RR, Zimmermann LJ. Histologic chorioamnionitis, fetal involvement, and antenatal steroids: effects on neonatal outcome in preterm infants. Am J Obstet Gynecol 2009;201:587 e1-8

14. Been JV, Zimmermann LJ. Histological chorioamnionitis and respiratory outcome in preterm infants. Arch Dis Child Fetal Neonatal Ed 2009;94:F218-25 
15. Watterberg KL, Scott SM, Naeye RL. Chorioamnionitis, cortisol, and acute lung disease in very low birth weight infants. Pediatrics 1997;99:E6

16. Kramer BW. Antenatal inflammation and lung injury: prenatal origin of neonatal disease. $J$ Perinatol 2008;28 Suppl 1:S21-7

17. Van Marter LJ, Dammann O, Allred EN, Leviton A, Pagano M, Moore M, Martin C. Chorioamnionitis, mechanical ventilation, and postnatal sepsis as modulators of chronic lung disease in preterm infants. J Pediatr 2002;140:171-6

18. Ikegami $\mathrm{M}$, Jobe $\mathrm{AH}$. Postnatal lung inflammation increased by ventilation of preterm lambs exposed antenatally to Escherichia coli endotoxin. Pediatr Res 2002;52:356-62

19. Ikegami M, Kallapur SG, Jobe AH. Initial responses to ventilation of premature lambs exposed to intraamniotic endotoxin 4 days before delivery. Am J Physiol Lung Cell Mol Physiol 2004;286:L573-9

20. Meyer KC, Zimmerman JJ. Inflammation and surfactant. Paediatr Respir Rev 2002;3:308-14

21. Zuo YY, Veldhuizen RA, Neumann AW, Petersen NO, Possmayer F. Current perspectives in pulmonary surfactant - Inhibition, enhancement and evaluation. Biochim Biophys Acta 2008;1778:1947-77

22. Been JV, Kornelisse RF, Rours IG, Passos VL, De Krijger RR, Zimmermann LJ. Early postnatal blood pressure in preterm infants: effects of chorioamnionitis and timing of antenatal steroids. Pediatr Res 2009;66:571-6

23. Altemeier WA, Matute-Bello G, Frevert CW, Kawata Y, Kajikawa O, Martin TR, Glenny RW. Mechanical ventilation with moderate tidal volumes synergistically increases lung cytokine response to systemic endotoxin. Am J Physiol Lung Cell Mol Physiol 2004;287:L533-42

24. Tremblay L, Valenza F, Ribeiro SP, Li J, Slutsky AS. Injurious ventilatory strategies increase cytokines and cfos m-RNA expression in an isolated rat lung model. J Clin Invest 1997;99:944-52

25. Chiumello D, Pristine G, Slutsky AS. Mechanical ventilation affects local and systemic cytokines in an animal model of acute respiratory distress syndrome. Am J Respir Crit Care Med 1999;160:109-16

26. Laughon M, Allred EN, Bose C, O'Shea TM, Van Marter L, Ehrenkranz RA, Leviton A. Patterns of respiratory disease during the first 2 postnatal weeks in extremely premature infants. Pediatrics 2009;123:1124-31

27. Merrill JD, Ballard RA, Cnaan A, Hibbs AM, Godinez RI, Godinez MH, Truog WE, Ballard PL. Dysfunction of pulmonary surfactant in chronically ventilated premature infants. Pediatr Res 2004;56:918-26

28. Schmidt R, Markart P, Ruppert C, Wygrecka M, Kuchenbuch T, Walmrath D, Seeger W, Guenther A. Timedependent changes in pulmonary surfactant function and composition in acute respiratory distress syndrome due to pneumonia or aspiration. Respir Res 2007;8:55

29. Raymondos K, Leuwer M, Haslam PL, Vangerow B, Ensink M, Tschorn H, Schurmann W, Husstedt H, Rueckoldt $\mathrm{H}$, Piepenbrock S. Compositional, structural, and functional alterations in pulmonary surfactant in surgical patients after the early onset of systemic inflammatory response syndrome or sepsis. Crit Care Med 1999;27:82-9

30. Nakos G, Kitsiouli El, Tsangaris I, Lekka ME. Bronchoalveolar lavage fluid characteristics of early intermediate and late phases of ARDS. Alterations in leukocytes, proteins, PAF and surfactant components. Intensive Care Med 1998;24:296-303

31. Markart P, Ruppert C, Wygrecka M, Colaris T, Dahal B, Walmrath D, Harbach H, Wilhelm J, Seeger W, Schmidt R, Guenther A. Patients with ARDS show improvement but not normalisation of alveolar surface activity with surfactant treatment: putative role of neutral lipids. Thorax 2007;62:588-94

32. Baker CS, Evans TW, Randle BJ, Haslam PL. Damage to surfactant-specific protein in acute respiratory distress syndrome. Lancet 1999;353:1232-7

33. Malloy JL, Wright JR. In vivo clearance of surfactant lipids during acute pulmonary inflammation. Respir Res 2004;5:8

34. Cogo PE, Zimmermann L, Pesavento R, Sacchetto E, Burighel A, Rosso F, Badon T, Verlato G, Carnielli VP. Surfactant kinetics in preterm infants on mechanical ventilation who did and did not develop bronchopulmonary dysplasia. Crit Care Med 2003;31:1532-8

35. Halliday HL, Tarnow-Mordi WO, Corcoran JD, Patterson CC. Multicentre randomised trial comparing high and low dose surfactant regimens for the treatment of respiratory distress syndrome (the Curosurf 4 trial). Arch Dis Child 1993;69:276-80

36. Halliday HL. History of surfactant from 1980. Biol Neonate 2005;87:317-22 
37. Bohlin K, Jonsson B, Gustafsson AS, Blennow M. Continuous positive airway pressure and surfactant. Neonatology 2008;93:309-15

38. Lu KW, Taeusch HW, Robertson B, Goerke J, Clements JA. Polyethylene glycol/surfactant mixtures improve lung function after $\mathrm{HCl}$ and endotoxin lung injuries. Am J Respir Crit Care Med 2001;164:1531-6

39. Cheah FC, Winterbourn CC, Darlow BA, Mocatta TJ, Vissers MC. Nuclear factor kappaB activation in pulmonary leukocytes from infants with hyaline membrane disease: associations with chorioamnionitis and Ureaplasma urealyticum colonization. Pediatr Res 2005;57:616-23

40. von Bismarck P, Klemm K, Wistadt CF, Winoto-Morbach S, Uhlig U, Schutze S, Uhlig S, Lachmann B, Krause MF. Surfactant "fortification" by topical inhibition of nuclear factor-kappaB activity in a newborn piglet lavage model. Crit Care Med 2007;35:2309-18 
Part 4

General discussion 


\section{Overview}

In the current thesis, particular associations are described between perinatal events and pulmonary outcome in preterm infants. The main focus was on chorioamnionitis, the antenatal event most frequently associated with preterm birth. The key findings will be highlighted and put into perspective. Finally, potential therapeutic consequences of the reported work and follow-on directions for future research will be discussed.

\section{Perinatal events and the lung: molecular and cellular effects}

Lung development is a complex and tightly regulated process. Physiologically, the uterine environment provides the ideal circumstances for lung growth. Preterm birth interferes with this physiological situation and thus affects normal lung development. Moreover, the various causes of preterm birth have different implications for both maternal and fetal health, and as such further modulate this relationship. Additional effects of adverse postnatal events and of therapeutic interventions associated with preterm birth and its complications, are present. In a cohort of preterm infants we investigated the effects of several of these perinatal modulators on markers of lung development, injury and repair.

Growth factors are important regulators of normal lung development ${ }^{1,2}$. Numerous animal studies have shown that disruption of normal growth factor expression patterns may have devastating effects on development of the lung and its response to subsequent injury ${ }^{3-6}$. In line with these observations, we found important associations between temporal growth factor expression in BALF from ventilated preterm infants, and subsequent BPD development (Chapter 6). Preeclampsia emerged as an important modulator of pulmonary growth factor expression from multivariable modeling. Fetal hypoxia is considered an important effect of preeclampsia, resulting in intrauterine growth retardation. In a chicken model for hypoxia-induced fetal growth restriction, we found a differential effect of hypoxia on VEGF expression, depending on hypoxia timing and duration (Chapter 7). This is in line with a key role for preeclampsia and less prevalent causes of prenatal hypoxia in the regulation of pulmonary growth factor expression ${ }^{7,8}$. Earlier studies as well as ours suggest that alterations in VEGF expression affect surfactant production as well as several other key aspects of lung development, with important implications for postnatal respiratory health ${ }^{8,9}$.

Chorioamnionitis has been associated with adverse lung development and BPD in both human (Chapter 3 ) and animal studies ${ }^{10,11}$. Chorioamnionitis adversely affected the expression of the growth factors KGF and VEGF, important regulators of lung development and repair (Chapter 5). Moreover, chorioamnionitis decreased alveolar epithelial repair potential in BALF from preterm infants. These processes may play a role in the association between chorioamnionitis and adverse lung development. 
Furthermore, chorioamnionitis appeared the most important modulator of early postnatal lung inflammation, as measured by BALF cytokine and chemokine expression (Chapter 4). Intriguingly, increased pulmonary inflammation during the first postnatal week did not correlate with subsequent BPD development. This underlines the complexity of the association between inflammation, chorioamnionitis and BPD, in which postnatal events are increasingly recognised to play an important role ${ }^{12-14}$, as discussed later. We hypothesised that one way in which postnatal events may affect lung development would be through induction of DNA damage. However, we were unable to detect mutations in mitochondrial DNA from lung-derived cells over time in infants exposed to mechanical ventilation and hyperoxia (Chapter 8 ). This may be due to the relatively short follow-up. Alternatively, it may reflect the potential of the current strategy of 'gentle' ventilation and restriction of hyperoxia to limit secondary injury as measured by mitochondrial DNA mutation analysis.

\section{Changing pathophysiology of BPD}

Altogether, the data presented above are in line with the current concept of a changing pathophysiology of BPD ${ }^{15,16}$. The picture of 'old BPD', characterised by lung injury, inflammation and fibrosis due to secondary lung injury ${ }^{17}$, is proposed to have shifted towards that of 'new BPD', reflecting a developmental arrest of the lung ${ }^{16}$. Although this concept is now widely acknowledged, there is a paucity of supportive pathophysiological evidence from human studies ${ }^{18}$. In this regard, investigation of pathophysiological aspects attributed to both 'old' and 'new' BPD in the same cohort as presented in this thesis, is unique and provides evidence indeed supporting this pathophysiological change.

Early postnatal inflammation did not predict BPD development in our cohort (Chapter 4). Furthermore, over the early course of mechanical ventilation no alterations were detected in mitochondrial DNA, which is considered highly susceptible to injury ${ }^{19}$ (Chapter 8). On the other hand, BPD was preceded by alterations in the expression of growth factors known to play an important role in lung development (Chapter 6). In addition, decreased surfactant availability, as measured by phospholipid content, likely reflects lung immaturity and was associated with BPD (Chapter 6). Thus, early developmental changes rather than lung inflammation seem to precede progression to BPD, in line with the current concept of 'new BPD' ${ }^{16}$. The application of multivariable modeling to account for important confounders further strengthens our findings. We did not apply these models to the chemokine and cytokine data due to methodological issues related to the large number of markers quantified in a relatively small cohort.

In our cohort, changes in molecular markers and cellular processes were evaluated over time. This is an important strength, since lung development, injury and repair are dynamic processes. We aimed to identify early processes that play a role in the pathophysiology of BPD in order to potentiate development of early interventional and preven- 
tive strategies. Therefore we chose to focus on the first postnatal week. Our data support a major contribution of a lung developmental arrest in the pathophysiology of BPD, and indeed provide room for potential therapeutic intervention, as discussed later.

Still, recent studies show that prolonged mechanical ventilation and pro-inflammatory hits such as sepsis remain important modulators of BPD development ${ }^{12,13,20,21}$. These processes likely exert their effects mainly beyond the first week of life and thus our data do not allow for conclusions to be made regarding their contributions.

\section{Chorioamnionitis and pulmonary outcome}

Over the last decade, chorioamnionitis is increasingly recognised to be an important modulator of pulmonary outcome after preterm birth (Chapter 3). Evidence suggests that chorioamnionitis enhances lung maturation, but at the expense of pulmonary inflammation and subsequent developmental arrest of the lung ${ }^{10,11}$. In a prospective cohort of preterm infants, we found an association between chorioamnionitis and decreased severe RDS (Chapter 9). Enhanced structural maturation of the lung as well as increased surfactant production seem to account for this effect (Chapter 3 ).

Through this accelerated lung maturation and through increased pulmonary inflammation, subsequent lung development is believed to be adversely affected ${ }^{10,11}$. Animal studies support this concept and are currently employed to study the underlying mechanisms ${ }^{10,11}$. Although in several early human cohorts a direct association between chorioamnionitis and BPD was described, subsequent studies have generally failed to reproduce this finding (Chapter 3 ). Likewise, in our cohort we were unable to find an association between chorioamnionitis and BPD in simple comparisons, despite a decreased risk of severe RDS (Chapter 9).

Important recent work has shown that the association between chorioamnionitis and adverse pulmonary outcome after preterm birth is highly dependent upon exposure to postnatal hits such as (prolonged) mechanical ventilation and sepsis ${ }^{12,13}$. However, in an attempt to reproduce the findings of the study by Van Marter et $a l^{12}$ we found no interaction between chorioamnionitis, postnatal sepsis, and prolonged mechanical ventilation in the prediction of BPD (Chapter 11). Methodological issues complicate comparison of the two studies. The Van Marter study was a case-control study with a relatively large BPD group ${ }^{12}$, while ours was a cohort with a smaller proportion of BPD-affected infants. Thus, insufficient power may explain part of the discrepancy. Treatment changes over time, including more 'gentle' ventilation strategies and increased use of antenatal steroids and postnatal surfactant may have contributed additionally.

We studied the aspect of surfactant therapy in this regard, using the same cohort (Chapter 12). It was found that prior exposure to chorioamnionitis was associated with a less favourable response to surfactant administration. This resulted in increased exposure to hyperoxia and prolonged need for mechanical ventilation. Consequently, chorioamnio- 
nitis was associated with development of BPD in those with severe chorioamnionitis (with fetal involvement) that needed surfactant treatment. This again underlines the complexity of the association between chorioamnionitis and adverse lung development (Chapter 3 ). Furthermore, it supports the concept of secondary postnatal hits modulating this association $^{12,13,22}$.

Earlier we showed how chorioamnionitis is associated with increased pulmonary inflammation shortly after birth (Chapter 4). Given the propensity of surfactant to inactivation by inflammatory mechanisms ${ }^{23-25}$, this may well explain its observed decreased efficacy in chorioamnionitis-exposed infants. Moreover, in these babies reduced potential for alveolar epithelial repair may be an important mechanisms underlying their increased susceptibility to secondary lung injury (Chapter 5 ).

\section{Chorioamnionitis and antenatal steroids}

Over the last two decades, maternal administration of steroids in case of imminent preterm delivery has become standard care in obstetrical practice ${ }^{26}$. However, fears of potential adverse effects have limited their use in preterm delivery with suspected intrauterine infection ${ }^{27,28}$. A nationwide survey among perinatologists underlines how the issue remains unsolved until today (Chapter 10). Hence, data on the efficacy of antenatal steroids as well as their potential undesirable effects in infant with chorioamnionitis, are scarce (Appendix I).

In our cohort of preterm infants, we found that administration of antenatal steroids was associated with improved outcome in infants with chorioamnionitis (Chapter 9). The effect was present regardless of whether chorioamnionitis was defined histologically or clinically, and of whether a full course of steroids or a single dose was administered (Chapter $9+10)$. In a subsequent meta-analysis of observational studies, it was confirmed that antenatal steroids were associated with improved neonatal outcome in preterm infants with either histological or clinical chorioamnionitis (Chapter 10).

This suggests that, contrary to what seems to be the ruling opinion, a more liberal use of antenatal steroids may improve survival and reduce morbidity in preterm infants with chorioamnionitis. However, several issues remain to be resolved. Most importantly, the systematic review identified only observational evidence. Clearly, there is a need for substantiation by a randomised controlled trial. Additional issues that need to be addressed in such a trial include potential adverse effects in both mother and child, and effects on long term outcome. 


\section{Therapeutic implications}

Clinicians will always be interested in clinical applicability of translational research; from bench-to-bedside. The discussion of a thesis provides the ideal platform for elaboration on this issue. As discussed above, one important therapeutic implication of the work reported in this thesis could be a shift towards a more liberal use of antenatal steroids in the setting of (suspected) intrauterine infection (Chapter 9+10). Again, a randomised controlled trial should ideally precede such a practice change.

We have shown that surfactant efficacy is reduced in infants exposed to chorioamnionitis, which predisposes them to development of chronic lung disease (Chapter 12). One way to potentially increase surfactant efficacy is to overcome its inactivation by proinflammatory mechanisms. Promising reports are available showing the potential of various additives to increase the resistance of surfactant to inactivation (Chapter 2). Moreover, anti-inflammatory agents added to surfactant preparations may prove to be useful in overcoming inactivation and decreasing local inflammation ${ }^{29,30}$. While awaiting further development of such preparations, a potential way of increasing surfactant efficacy may simply be reached by increasing the dose. Increased surfactant dosing has previously been shown to improve outcome ${ }^{31}$, and our research suggests that chorioamnionitis-exposed infants may particularly benefit.

In order to develop such tailor-made treatment strategies for chorioamnionitisexposed infants, the early identification of chorioamnionitis needs to be improved. The current gold standard for diagnosing chorioamnionitis is through histological examination of the placenta ${ }^{32}$. However, in general practice the final result of this 'test' may take several weeks, limiting its usefulness as a diagnostic marker to guide early treatment strategies. Additional research is needed to develop reproducible ways in which to early identify infants exposed to chorioamnionitis.

Likewise, early identification is invaluable to guide early preventive and interventional strategies for infants developing BPD. Although currently the efficacy of these strategies is limited ${ }^{33,34}$, several lines of research carry great potential for early intervention for BPD in the future. With regard to our data, BALF growth factor levels may be used to identify infants at risk for BPD as early as the first day after birth (Chapter 6). Inclusion of additional markers in a 'risk profile' may further improve the diagnostic properties for BPD risk identification. Clearly, the diagnostic ability of VEGF and possible other markers needs to be studied in other and larger cohorts to confirm their potential. As soon as a marker with good diagnostic properties is identified, its potential to guide early interventions may be investigated in the setting of a clinical trial.

The fact that VEGF and other growth factors predict future development of BPD, suggests a modulating role for these molecules in the pathophysiology of BPD. This is supported by several lines of animal research showing how disruption of growth factor expression affects lung development ${ }^{3-6}$. Consequently, modulation of growth factor expression carries great potential to treat or prevent adverse lung development in the future. 
Consider VEGF, the lack of which has been associated with BPD, in our study (Chapter 6) as well as in others ${ }^{35,36}$. Increasing the pulmonary availability of VEGF is effective in stimulating surfactant production, enhancing lung maturation, and overcoming lung injury ${ }^{4,8,37}$. Similar positive effects have been described of modulation of the expression of several other growth factors in animal models ${ }^{38}$. Our results indicate that timing of growth factor expression is highly important with regard to pulmonary outcome (Chapter 6). Timing issues, as well as optimal dosing, identification of the right vehicle, and assessment of adverse (long term) effects are among the key questions that need to be resolved before such treatments can be adapted in clinical practice. Our findings furthermore indicate that potential treatment with VEGF ${ }^{4,8,37}$ as well as with $\mathrm{KGF}^{38}$ may be of particular benefit to chorioamnionitis-exposed infants (Chapter 5), another topic requiring further study.

As for clinical factors related to adverse lung development, our results are in line with accumulating evidence indicating that postnatal sepsis and mechanical ventilation remain among the most important risk factors for BPD ${ }^{12,13,20,21}$. Once again these results stress the importance of continuing effort to develop ways in which exposure to sepsis and (prolonged) mechanical ventilation may be avoided. In this regard, increased use of noninvasive modes of ventilation such as $\mathrm{nCPAP}{ }^{39}$, and ways to safely and effectively administer surfactant in non-intubated infants (Chapter 2), deserve special attention.

\section{(Further) future directions}

The main goal of this thesis was to identify in preterm infants perinatal factors that contribute to adverse pulmonary outcome. As much as certain answers have been obtained, new questions did arise. Some prospects for future research concerning potential therapeutic options have been highlighted in the last paragraph. In addition, increased knowledge of the underlying mechanisms of both normal and abnormal lung development is necessary to continue to develop new interventions. A drawback of our mechanistic studies using BALF is that as a consequence of the technique only ventilated infants were included. Given the general trend towards less invasive ventilatory strategies, it is essential to develop new ways of sampling the newborn airspace. Initial reports have been made of collection of exhaled air sampling in newborn infants ${ }^{40,41}$. This technique as well as others such as new lung imaging modalities require further development to ensure future analysis of new aspects of (adverse) lung development in a reproducible manner.

Research effort should be guided not only towards pathophysiological mechanisms and development of new interventions. We are in need of early diagnostic tools to adequately identify infants at risk for adverse outcome. Several potential markers, including VEGF as in our study (Chapter 6), have been proposed and need evaluation in multiple larger cohorts to evaluate their usefulness. Newer diagnostic techniques are becoming available that are capable of simultaneously quantifying an increasing amount of markers 
in a biological sample of decreasing size. These should be adapted to identify populations at risk and further individualise treatment strategies in neonatology.

Finally, there is a huge need for adequate follow-up studies of preterm infants. Previous cohorts have provided us with major insight into the long-term consequences of preterm birth. However, many new questions have arisen, requiring new cohorts and alternative approaches to become answered. Furthermore, due to treatment changes and increasing survival with time, outcome will change, necessitating continuous collection of new data. Simultaneous collection of biological specimens is indispensable to facilitate identification of (epi)genetic associations and underlying mechanisms. Given the indications from our studies and recent work by others, long-term outcome after preterm birth may well be modulated to a significant degree by perinatal factors ${ }^{42}$. These include aspects associated with the distinct causes of prematurity, including preeclampsia and chorioamnionitis. Future follow-up studies should evaluate the effects of these and other perinatal factors to facilitate the development of tailor-made preventive and interventional strategies. Given the increased recognition of early-life origins of adult health and disease, such strategies may prove to extend their effects well beyond the neonatal period (Appendix II).

\section{References}

1. Jankov RP, Tanswell KA. Growth factors, postnatal lung growth and bronchopulmonary dysplasia. Paediatr Respir Rev 2004;5 Suppl A:S265-75

2. Thebaud B, Abman SH. Bronchopulmonary dysplasia: where have all the vessels gone? Roles of angiogenic growth factors in chronic lung disease. Am J Respir Crit Care Med 2007;175:978-85

3. Hoyle GW, Li J, Finkelstein JB, Eisenberg T, Liu JY, Lasky JA, Athas G, Morris GF, Brody AR. Emphysematous lesions, inflammation, and fibrosis in the lungs of transgenic mice overexpressing platelet-derived growth factor. Am J Pathol 1999;154:1763-75

4. Thebaud B, Ladha F, Michelakis ED, Sawicka M, Thurston G, Eaton F, Hashimoto K, Harry G, Haromy A, Korbutt G, Archer SL. Vascular endothelial growth factor gene therapy increases survival, promotes lung angiogenesis, and prevents alveolar damage in hyperoxia-induced lung injury: evidence that angiogenesis participates in alveolarization. Circulation 2005;112:2477-86

5. Kramer EL, Deutsch GH, Sartor MA, Hardie WD, Ikegami M, Korfhagen TR, Le Cras TD. Perinatal increases in TGF-\{alpha\} disrupt the saccular phase of lung morphogenesis and cause remodeling: microarray analysis. Am J Physiol Lung Cell Mol Physiol 2007;293:L314-27

6. Gauldie J, Galt T, Bonniaud P, Robbins C, Kelly M, Warburton D. Transfer of the active form of transforming growth factor-beta 1 gene to newborn rat lung induces changes consistent with bronchopulmonary dysplasia. Am J Pathol 2003;163:2575-84

7. Breen EC. VEGF in biological control. J Cell Biochem 2007;102:1358-67

8. Compernolle V, Brusselmans K, Acker T, Hoet P, Tjwa M, Beck H, Plaisance S, Dor Y, Keshet E, Lupu F, Nemery B, Dewerchin M, Van Veldhoven P, Plate K, Moons L, Collen D, Carmeliet P. Loss of HIF-2alpha and inhibition of VEGF impair fetal lung maturation, whereas treatment with VEGF prevents fatal respiratory distress in premature mice. Nat Med 2002;8:702-10

9. Blacker HA, Orgeig S, Daniels CB. Hypoxic control of the development of the surfactant system in the chicken: evidence for physiological heterokairy. Am J Physiol Regul Integr Comp Physiol 2004;287:R403-10

10. Gantert M, Been JV, Gavilanes AW, Garnier Y, Zimmermann L, Kramer BW. Chorioamnionitis - a multiorgan disease of the fetus? J Perinatol in press 
11. Kramer BW. Antenatal inflammation and lung injury: prenatal origin of neonatal disease. J Perinatol 2008;28 Suppl 1:S21-7

12. Van Marter LJ, Dammann O, Allred EN, Leviton A, Pagano M, Moore M, Martin C. Chorioamnionitis, mechanical ventilation, and postnatal sepsis as modulators of chronic lung disease in preterm infants. $J$ Pediatr 2002;140:171-6

13. Lahra MM, Beeby PJ, Jeffery HE. Intrauterine inflammation, neonatal sepsis, and chronic lung disease: a 13-year hospital cohort study. Pediatrics 2009;123:1314-19

14. Laughon M, Allred EN, Bose C, O'Shea TM, Van Marter L, Ehrenkranz RA, Leviton A. Patterns of respiratory disease during the first 2 postnatal weeks in extremely premature infants. Pediatrics 2009;123:1124-31

15. Jobe AH, Bancalari E. Bronchopulmonary dysplasia. Am J Respir Crit Care Med 2001;163:1723-9

16. Jobe AJ. The new BPD: an arrest of lung development. Pediatr Res 1999;46:641-3

17. Northway WH, Jr., Rosan RC, Porter DY. Pulmonary disease following respirator therapy of hyalinemembrane disease. Bronchopulmonary dysplasia. N Engl J Med 1967;276:357-68

18. Husain AN, Siddiqui NH, Stocker JT. Pathology of arrested acinar development in postsurfactant bronchopulmonary dysplasia. Hum Pathol 1998;29:710-7

19. Yakes FM, Van Houten B. Mitochondrial DNA damage is more extensive and persists longer than nuclear DNA damage in human cells following oxidative stress. Proc Natl Acad Sci USA 1997;94:514-9

20. Akram Khan M, Kuzma-O'Reilly B, Brodsky NL, Bhandari V. Site-specific characteristics of infants developing bronchopulmonary dysplasia. J Perinatol 2006;26:428-35

21. Van Marter L, Allred EN, Pagano M, Sanocka U, Parad R, Moore M, Susser M, Paneth N, Leviton A. Do clinical markers of barotrauma and oxygen toxicity explain interhospital variation in rates of chronic lung disease? The Neonatology Committee for the Developmental Network. Pediatrics 2000;105:1194-201

22. Been JV, Zimmermann LJ. Chorioamnionitis and chronic lung disease in preterm infants. Pediatrics 2009; http://pediatrics.aappublications.org/cgi/eletters/123/5/1314

23. Zuo YY, Veldhuizen RA, Neumann AW, Petersen NO, Possmayer F. Current perspectives in pulmonary surfactant - Inhibition, enhancement and evaluation. Biochim Biophys Acta 2008;1778:1947-77

24. Meyer KC, Zimmerman JJ. Inflammation and surfactant. Paediatr Respir Rev 2002;3:308-14

25. Malloy JL, Wright JR. In vivo clearance of surfactant lipids during acute pulmonary inflammation. Respir Res 2004;5:8

26. Roberts D, Dalziel S. Antenatal corticosteroids for accelerating fetal lung maturation for women at risk of preterm birth. Cochrane Database Syst Rev 2006;3:CD004454

27. Effect of corticosteroids for fetal maturation on perinatal outcomes. NIH Consens Statement 1994;12:1-24

28. Development of audit measures and guidelines for good practice in the management of neonatal respiratory distress syndrome. Report of a Joint Working Group of the British Association of Perinatal Medicine and the Research Unit of the Royal College of Physicians. Arch Dis Child 1992;67:1221-7

29. von Bismarck P, Klemm K, Wistadt CF, Winoto-Morbach S, Uhlig U, Schutze S, Uhlig S, Lachmann B, Krause MF. Surfactant "fortification" by topical inhibition of nuclear factor-kappaB activity in a newborn piglet lavage model. Crit Care Med 2007;35:2309-18

30. von Bismarck P, Klemm K, Garcia Wistadt CF, Winoto-Morbach S, Schutze S, Krause MF. Selective NFkappaB inhibition, but not dexamethasone, decreases acute lung injury in a newborn piglet airway inflammation model. Pulm Pharmacol Ther 2009;22:297-304

31. Halliday HL. History of surfactant from 1980. Biol Neonate 2005;87:317-22

32. Redline RW. Inflammatory responses in the placenta and umbilical cord. Semin Fetal Neonatal Med 2006;11:296-301

33. Kramer BW, Lievense S, Been JV, Zimmermann LJ. [Bronchopulmonary dysplasia]. Ned Tijdschr Geneeskd 2010;154:A1024

34. Schmidt B, Roberts R, Millar D, Kirpalani H. Evidence-based neonatal drug therapy for prevention of bronchopulmonary dysplasia in very-low-birth-weight infants. Neonatology 2008;93:284-7

35. Hasan J, Beharry KD, Valencia AM, Strauss A, Modanlou HD. Soluble vascular endothelial growth factor receptor 1 in tracheal aspirate fluid of preterm neonates at birth may be predictive of bronchopulmonary dysplasia/chronic lung disease. Pediatrics 2009;123:1541-7 
36. Lassus P, Turanlahti M, Heikkila P, Andersson LC, Nupponen I, Sarnesto A, Andersson S. Pulmonary vascular endothelial growth factor and Flt-1 in fetuses, in acute and chronic lung disease, and in persistent pulmonary hypertension of the newborn. Am J Respir Crit Care Med 2001;164:1981-7

37. Kunig AM, Balasubramaniam V, Markham NE, Morgan D, Montgomery G, Grover TR, Abman SH. Recombinant human VEGF treatment enhances alveolarization after hyperoxic lung injury in neonatal rats. Am J Physiol Lung Cell Mol Physiol 2005;289:L529-35

38. Panos RJ, Bak PM, Simonet WS, Rubin JS, Smith LJ. Intratracheal instillation of keratinocyte growth factor decreases hyperoxia-induced mortality in rats. J Clin Invest 1995;96:2026-33

39. Bohlin K, Jonsson B, Gustafsson AS, Blennow M. Continuous positive airway pressure and surfactant. Neonatology 2008;93:309-15

40. Hitka P, Cerny M, Vizek M, Wilhelm J, Zoban P. Assessment of exhaled gases in ventilated preterm infants. Physiol Res 2004;53:561-4

41. Nycyk JA, Drury JA, Cooke RW. Breath pentane as a marker for lipid peroxidation and adverse outcome in preterm infants. Arch Dis Child Fetal Neonatal Ed 1998;79:F67-9

42. Kumar R, Yu Y, Story RE, Pongracic JA, Gupta R, Pearson C, Ortiz K, Bauchner HC, Wang X. Prematurity, chorioamnionitis, and the development of recurrent wheezing: a prospective birth cohort study. J Allergy Clin Immunol 2008;121:878-84 e6 


\section{Appendix II}

\section{In utero and early-life conditions and adult health and disease}

Been JV, Kramer BW, Zimmermann LJ

N Engl J Med 2008; 359: 1523-4

(Comment on: Gluckman PD et al. N Engl J Med 2008; 359: 61-73)

Note:

This letter was written in response to a review article in which the effects of prenatal and early postnatal events on adult health and disease were discussed. The aim was to emphasise the potential impact of antenatal exposure to inflammation on health and disease later in life, a subject not discussed in the review. 


\section{To the editor,}

Gluckman et al. review evidence on the effects of fetal conditions on adult disease. However, an important potential player is being left out of their discussion. Prenatal inflammation, reflected by chorioamnionitis and the fetal inflammatory response syndrome, has been recognized as a fetal condition that contributes to disease in the perinatal period and beyond, mainly affecting the developing lung and brain ${ }^{1,2}$. The evidence is increasing that prenatal exposure to inflammation in utero is related to disease, later in childhood, involving the affected organs and is associated with physician-diagnosed asthma ${ }^{3}$, recurrent wheezing ${ }^{3}$, autistic behavior ${ }^{4}$, and adverse neurodevelopmental outcome ${ }^{5}$. Experimental chorioamnionitis results in pathogenic programming of the fetal immune response, endotoxin tolerance, and crucial developmental changes, suggesting an important programming effect ${ }^{1}$.

Thus, accumulating evidence implies an important role of antenatal inflammation in fetal programming and subsequent disease development, the mechanism of which need further investigation. Considering the immature stage of the exploration of these effects, we may well currently be looking at the tip of the iceberg, anticipating potential links with adult pulmonary and neurologic diseases like chronic obstructive pulmonary disease and dementia.

\section{References}

1. Kramer BW. Antenatal inflammation and lung injury: prenatal origin of neonatal disease. J Perinatol 2008;28 Suppl 1:S21-7

2. Romero R, Gotsch F, Pineles B, Kusanovic JP. Inflammation in pregnancy: its roles in reproductive physiology, obstetrical complications, and fetal injury. Nutr Rev 2007;65:S194-202

3. Kumar R, Yu Y, Story RE, Pongracic JA, Gupta R, Pearson C, Ortiz K, Bauchner HC, Wang X. Prematurity, chorioamnionitis, and the development of recurrent wheezing: a prospective birth cohort study. J Allergy Clin Immunol 2008;121:878-84 e6

4. Limperopoulos C, Bassan H, Sullivan NR, Soul JS, Robertson RL, Jr., Moore M, Ringer SA, Volpe JJ, du Plessis AJ. Positive screening for autism in ex-preterm infants: prevalence and risk factors. Pediatrics 2008;121:758-65

5. Redline RW, Minich N, Taylor HG, Hack M. Placental lesions as predictors of cerebral palsy and abnormal neurocognitive function at school age in extremely low birth weight infants ( $<1 \mathrm{~kg})$. Pediatr Dev Pathol 2007;10:282-92 
Summary 


\section{Introduction}

Approximately ten percent of all babies is born preterm, at less than 37 weeks gestation. Preterm birth is associated with increased morbidity and lifelong complications. The most important complication early after birth is respiratory distress, due to the lungs being immature. There is a deficiency of surfactant, a complex mixture of lipids and proteins required to keep the lungs open. In these infants, breathing may be supported by mechanical ventilation and oxygen supplementation. In addition, exogenous surfactant may be administered to treat respiratory distress.

Although such treatments are often necessary to ensure survival of preterm infants, they may cause harm to the immature lungs of these babies. Consequently, an important subset may develop chronic lung disease (bronchopulmonary dysplasia; BPD). BPD is associated with long-term complications including impaired lung function, increased susceptibility for infections, and neurodevelopmental delay.

Chapter 1 provides an introduction on normal lung development. Its disruption by preterm birth is discussed and how this may lead to chronic lung disease. Chapter $\mathbf{2}$ describes the role of surfactant in both the aetiology and treatment of neonatal respiratory distress. In chapter 3 the role of antenatal exposure to inflammation in the development of neonatal lung disease is discussed. Preterm birth is highly associated with occurrence of chorioamnionitis, an inflammatory process within the uterus. The fetal lungs are exposed to this inflammation through direct contact with the amniotic fluid. Previous studies have shown that chorioamnionitis enhances lung maturation, thus preparing the fetus for potential preterm delivery. On the other hand evidence suggests an adverse effect of chorioamnionitis on subsequent lung development (as opposed to lung maturation). Thus, while the fetal lungs seem to benefit from exposure to inflammation on the short term, the eventual outlook may well be less favourable.

\section{Overview}

The current thesis describes several processes that take place within the lung during the first postnatal week in preterm infants. We aimed to gain additional insight in the underlying causes of chronic lung disease in this group. Special attention is given to the role of chorioamnionitis. In addition, the effect of maternal administration of steroids before delivery is studied. Steroids are adrenal gland hormones that are known to enhance fetal lung maturation. Antenatal administration of steroids thus prepares the fetus for imminent preterm delivery. 


\section{Summary of the thesis}

Part of the thesis describes analyses done in bronchoalveolar lavage fluid (BALF). When infants are mechanically ventilated, the ventilator is attached to a small tube entering the trachea. Through this tube a catheter is advanced into a certain lung section. A small amount of saline is flushed into the lung, after which suction is applied while the catheter is withdrawn. In this way a sample of lung-derived fluid is obtained. BALF contains cells and molecules which reflect the state the lung is in at that time.

In chapter 4, quantification of a large group of inflammatory mediators in BALF is reported. Inflammatory mediators are molecules that regulate inflammation in the lung, for example by attracting or activating white blood cells. Using a new technique (luminex immunoassay) we show that it is feasible to quantify these mediators in a very small amount of BALF. Levels of these factors were linked to several clinical aspects of lung disease in preterm infants. Using this approach, we found that antenatal exposure to chorioamnionitis increases the presence of inflammatory mediators directly after birth. Previous reports have shown pulmonary inflammation to be linked to the development of chronic lung disease. However, in our study we were unable to reproduce these findings. We hypothesise that the increasing awareness of minimising lung injury through reduction of mechanical ventilation and oxygen supplementation may have contributed to this.

As mentioned earlier, both chorioamnionitis and administration of antenatal steroids affect lung development already before birth. Chapter $\mathbf{5}$ describes the specific effects of these factors on lung injury repair. Alveolar type 2 cells were cultured in the laboratory. These cells are very important for the lung, since they produce surfactant and are necessary for the formation of type 1 cells. When cultured, these cells form a thin layer. The cell layer was wounded by scratching the surface, resulting in a linear defect. This is a well recognised model for epithelial injury in general, and for alveolar epithelial injury in this case. BALF was added to the wounded cell layer, and the effects on epithelial repair were evaluated. BALF from infants exposed to chorioamnionitis was much less effective in inducing wound repair. This may partly explain the increased risk for lung injury in ventilated infants exposed to chorioamnionitis. Conversely, epithelial repair was stimulated by BALF from infants in whom antenatal steroids had been given. We investigated whether these effects could be explained by altered expression of two growth factors known to be important for lung development (vascular endothelial growth factor; VEGF, and keratinocyte growth factor; KGF). However, we were unable to establish a significant effect of these factors.

Several other growth factors with important roles in lung development besides VEGF and KGF were quantified in BALF. In chapter 6 we show that important differences are present in the levels of these factors between infants who do and do not develop chronic lung disease. Decreased BALF levels of VEGF directly after birth predict subsequent development of chronic lung disease several weeks later. Together with the results reported in chapter 4 , these data support the current concept in which disruption of lung develop- 
ment seems more important than other processes including inflammation in the aetiology of chronic lung disease. Quantification of growth factors may facilitate early identification of a risk profile for chronic lung disease which may be used to tailor postnatal respiratory management.

Several causes of preterm birth other than chorioamnionitis are associated with fetal hypoxia due to impaired placental function. Previous reports on effects of prenatal hypoxia on lung development have yielded contradictory results. The chick embryo develops outside of the mother, thus allowing for the effects of hypoxia to be studied without interference maternal influences. In chapter 7 we show that short-term hypoxia stimulates surfactant production, while long-term hypoxia has no significant effect. Thus, the effects of hypoxia on lung development seem highly dependent on timing and duration of the stimulus. Additional experiments again suggest an important role for VEGF in this process.

Exposure to hyperoxia and mechanical ventilation are known to injure lung. In chapter 8 we investigated whether this would result in injury to the genetic material (DNA) within the lung. We focused on DNA from mitochondria, the energy producing organelles within the cell, while this DNA is known to be most susceptible to injury. Surprisingly, no DNA injury was found during mechanical ventilation for a mean duration of three days, albeit in a small group of infants. Increased awareness of the potentially injurious effects of mechanical ventilation and hyperoxia may have contributed to our findings.

In chapter 9 we explored the association between chorioamnionitis and the occurrence of known complications of preterm birth in a cohort of preterm infants. We found that chorioamnionitis leads to a decrease in acute respiratory problems in this group, indicative of enhanced lung maturation. On the other hand, the incidence of severe infections after birth is increased after chorioamnionitis. In addition we investigated how antenatal administration of steroids affected the incidence of postnatal complications in infants with chorioamnionitis. Administration of antenatal steroids was associated with a decrease in acute respiratory problems and intraventricular haemorrhage in this group. This is important, because to date antenatal steroids are believed to be harmful when chorioamnionitis is present (appendix I).

To further evaluate this effect, our data were combined with those of similar studies previously published as described in chapter 10. The overall effect of antenatal steroids in all studies together can be evaluated by means of a statistical technique called metaanalysis. The results indicated that besides a reduction in acute respiratory problems and intraventricular haemorrhage, antenatal steroids were associated with increased survival. However, several aspects complicate interpretation of these findings, and we cannot draw definite conclusions regarding the safety and efficacy of antenatal steroids in infants with chorioamnionitis. Additional research on this topic is needed to further improve the outcome of preterm infants.

While previous studies showed a direct association between chorioamnionitis and chronic lung disease, we were unable to reproduce this (chapter 9). The results of one particular study suggest that chorioamnionitis is associated with an increased risk for 
chronic lung disease only when combined with prolonged mechanical ventilation or postnatal sepsis. In chapter $\mathbf{1 1}$ we investigated whether these findings could be reproduced in our cohort described in chapter 9 . While we could confirm an association between prolonged mechanical ventilation and chronic lung disease, we were unable to detect significant associations between chorioamnionitis, sepsis, and chronic lung disease. Again, part of these inconsistencies may be explained by improvements in treatment of preterm infants over time.

The complex association between chorioamnionitis and chronic lung disease is further explored in chapter 12. We show that ventilated infants with chorioamnionitis have a less effective response to surfactant treatment. This necessitates prolonged use of mechanical ventilation and increased use of supplemental oxygen. These factors then contribute to an increased risk for chronic lung disease in these infants, particularly those with severe chorioamnionitis. Altogether the relationship between chorioamnionitis and chronic lung disease is a complex one, in which decreased surfactant efficacy seems to play a role. Additional research is needed to investigate whether chorioamnionitis-exposed infants could benefit from increased surfactant dosing or addition of anti-inflammatory agents to surfactant.

\section{Conclusion}

The results reported in this thesis provide new insights into the background of lung development and lung damage in preterm infants. Our findings are in agreement with the concept of the changing pathophysiology of chronic lung disease in this group. In addition, our data underline the intriguing and complex effects that chorioamnionitis may have with regard to the lung and other organs. Additional research is needed to evaluate the longterm effects of preterm birth and chorioamnionitis in particular, in order to improve the prospects for future preterm babies (appendix II). Several results reported in this thesis provide new directions for future research to develop strategies to improve the treatment, and more importantly, the early recognition and prevention of chronic lung disease after preterm birth. 



\section{Nederlandse samenvatting}




\section{Introductie}

Rond de tien procent van alle kinderen wordt te vroeg geboren (voor de $37^{\mathrm{e}}$ zwangerschapsweek). Vroeggeboorte gaat gepaard met een verhoogd risico op allerhande complicaties, die gevolgen kunnen hebben voor de rest van het leven. Ademhalingsproblemen vormen de belangrijkste complicatie direct na de geboorte. De longen zijn nog onderontwikkeld en er is een tekort aan surfactant, een mengsel van stoffen dat de longblaasjes openhoudt. De ademhaling kan worden ondersteund door middel van beademing en het geven van zuurstof. Ook kan surfactant als medicijn worden toegediend.

Deze behandelingen zijn vaak noodzakelijk voor de overleving van de vroeggeboren baby, maar gaan ook gepaard met schade aan de onderontwikkelde longen. Hierdoor ontstaat bij een belangrijk deel van deze kinderen chronische longschade (bronchopulmonale dysplasie; BPD). Deze ziekte gaat niet alleen gepaard met langdurige beperking van de longfunctie, maar ook met een verhoogde gevoeligheid voor infecties en slechtere neurologische ontwikkeling.

In hoofdstuk 1 wordt de normale longontwikkeling beschreven. Tevens wordt uitgelegd hoe deze bij vroeggeboorte wordt verstoord, waardoor chronische longschade kan ontstaan. In hoofdstuk 2 wordt de rol van surfactant in het ontstaan van ademhalingsproblemen na de geboorte besproken. Daarnaast wordt besproken hoe het geven van surfactant als medicijn de acute ademhalingsproblemen na vroeggeboorte kan verminderen. Hoofdstuk 3 gaat in op de rol van blootstelling van de long aan ontsteking vóór de geboorte. Vroeggeboorte gaat vaak gepaard met chorioamnionitis, een ontsteking binnen de baarmoeder. De longen van de foetus staan via het vruchtwater in contact met deze ontsteking. Eerder onderzoek heeft laten zien dat hierdoor de longrijping wordt versneld; de foetus wordt als het ware voorbereid op een mogelijke vroeggeboorte. Aan de andere kant zijn er aanwijzingen dat chorioamnionitis slecht is voor de latere ontwikkeling van de long. Waar de foetus dus op korte termijn voordeel lijkt te hebben van deze ontsteking, kan dit op lange termijn wel eens nadelig zijn.

\section{Overzicht}

In dit proefschrift worden verschillende processen bestudeerd die zich in de long afspelen in de eerste week na de geboorte bij beademde vroeggeboren baby's. Het doel hiervan is meer inzicht te krijgen in de onderliggende oorzaken van chronische longschade in deze groep. Specifieke aandacht is er voor het effect hierop van blootstelling aan chorioamnionitis. Daarnaast wordt de invloed van het toedienen van steroïden aan de moeder voor de geboorte bestudeerd. Steroïden zijn bijnierschorshormonen en hebben een stimulerend effect op de longrijping van de foetus. Wanneer deze worden gegeven bij dreigende vroeggeboorte, is de foetus daarmee beter voorbereid op het leven buiten de baarmoeder. 


\section{Samenvatting proefschrift}

In verschillende onderdelen van het proefschrift worden metingen gedaan in vloeistof verkregen via longspoeling (bronchoalveolaire lavage vloeistof; BALV). Kinderen die beademd worden, zijn via een buisje in de luchtpijp aangesloten op een beademingsmachine. Via dit buisje wordt een dun slangetje ingebracht in een deel van de long en wordt een kleine hoeveelheid zoutwater ingespoten. Dit wordt bijna direct weer opgezogen, waardoor materiaal uit de long wordt verzameld. BALV bevat onder andere cellen en moleculen en de samenstelling ervan zegt iets over de toestand van de long op dat moment.

In hoofdstuk 4 wordt de meting van een grote groep ontstekingsfactoren in BALV beschreven. Ontstekingsfactoren zijn moleculen die een rol spelen in het reguleren van ontsteking, bijvoorbeeld door witte bloedcellen aan te trekken of te activeren. Met een nieuwe techniek (luminex immunoassay) laten we zien dat het goed mogelijk is deze stoffen te meten in een zeer kleine hoeveelheid BALV. Daarnaast hebben we een relatie gelegd tussen deze ontstekingsfactoren en aspecten van longproblemen bij deze vroeggeborenen. Zo blijkt dat blootstelling aan chorioamnionitis voor de geboorte leidt tot een toename van ontstekingsfactoren in de long direct na de geboorte. Eerdere onderzoeken lieten ook een belangrijke samenhang zien tussen ontsteking en de ontwikkeling van chronische longschade. Deze samenhang wordt in ons onderzoek niet meer gevonden. Wij denken dat een toenemende aandacht voor het beperken van de schadelijke gevolgen van beademing en zuurstoftoediening hieraan bijdraagt.

Zoals genoemd beïnvloeden chorioamnionitis en toediening van steroïden de longontwikkeling al voor de geboorte. In hoofdstuk 5 wordt het specifieke effect van deze factoren onderzocht op herstel van longschade na de geboorte. In het laboratorium kweekten we een bepaald type longcellen, alveolaire type 2 cellen. Dit zijn cellen die van groot belang zijn voor de long, onder meer doordat ze surfactant aanmaken en als voorloper dienen voor type 1 cellen. Wanneer deze cellen worden gekweekt vormen ze een dunne laag. Hierin werd schade aangebracht door cellen over een bepaald traject weg te schrapen, waardoor een defect ontstaat. Dit is een veelgebruikt model voor slijmvliesschade en in dit geval voor longschade. Aan de beschadigde cellaag werd BALV toegevoegd, waarna werd gemeten in hoeverre dit het herstel bevorderde. Dit herstel bleek veel minder effectief wanneer kinderen voor de geboorte waren blootgesteld aan chorioamnionitis. Mogelijk verklaart dit ten dele waarom chorioamnionitis een verhoogd risico geeft op longschade bij beademde vroeggeborenen. Anderzijds werd het herstel juist extra gestimuleerd wanneer steroïden waren gegeven voor de geboorte. We onderzochten of twee groeifactoren die belangrijk zijn voor longontwikkeling (vascular endothelial growth factor; VEGF, en keratinocyte growth factor; KGF) van invloed waren op deze processen, maar konden geen duidelijk effect aantonen.

Naast VEGF en KGF hebben we verschillende andere groeifactoren die van belang zijn voor longontwikkeling, gemeten in BALV. In hoofdstuk 6 laten we zien dat er belangrijke verschillen zijn in de aanwezigheid van groeifactoren tussen kinderen die wel of geen 
chronische longschade ontwikkelen. Zo is een tekort aan VEGF in BALV op de eerste dag na de geboorte al voorspellend voor het ontstaan van chronische longschade meerdere weken later. Samen met de bevindingen in hoofdstuk 4 ondersteunt dit de theorie dat chronische longschade tegenwoordig meer een gevolg is van verstoorde longontwikkeling dan van processen als ontsteking. Mogelijk kan het meten van groeifactoren in de toekomst helpen om vroeg een risico-inschatting voor chronische longschade te maken en daarop de behandeling aan te passen.

Naast chorioamnionitis gaan de meeste andere oorzaken van vroeggeboorte samen met een zuurstoftekort bij de foetus (hypoxie) door bijvoorbeeld verstoorde functie van de moederkoek (placenta). Eerdere onderzoeken laten tegenstrijdige effecten zien van hypoxie op de longontwikkeling. Kippenkuikens ontwikkelen zich buiten de moeder, waardoor het effect van hypoxie kan worden bestudeerd zonder effecten van de moeder. In hoofdstuk 7 laten we zien dat kortdurende hypoxie de productie van surfactant in kippenembryo's stimuleert, terwijl langdurige hypoxie geen effect heeft. Het effect van hypoxie lijkt dus in belangrijke mate af te hangen van de duur van de blootstelling. Verdere experimenten suggereren dat VEGF ook hierbij een belangrijke rol speelt.

Blootstelling aan beademing en een teveel aan zuurstof zijn schadelijk voor de long. In hoofdstuk 8 onderzochten we of er tijdens behandeling met beademing en zuurstof schade optreedt in het erfelijk materiaal (DNA). We bekeken hierbij in BALV het DNA van mitochondriën, de energieproducerende onderdelen van cellen, omdat dit DNA het meest gevoelig is voor schade. Opvallend genoeg werd geen schade aangetoond na een gemiddelde beademingsduur van drie dagen in een weliswaar kleine groep kinderen. Mogelijk speelt ook hier de toegenomen aandacht voor minder schadelijke beademing en verminderde blootstelling aan zuurstof een rol.

In hoofdstuk 9 wordt de samenhang beschreven tussen chorioamnionitis en algemene complicaties van vroeggeboorte in een grote groep vroeggeborenen. We vonden dat chorioamnionitis minder ernstige acute ademhalingsproblemen geeft, passend bij een stimulatie van de longrijping in deze groep. Verder is het risico op ernstige infecties kort na de geboorte verhoogd na chorioamnionitis. Daarnaast bekeken we hoe toediening van steroïden voor de geboorte het optreden van complicaties beïnvloedt bij kinderen met chorioamnionitis. Kinderen met chorioamnionitis bleken minder acute ademhalingsproblemen en minder hersenbloedingen (intraventriculaire bloedingen; IVH) te hebben wanneer ze steroïden hadden gekregen. Dit is belangrijk, omdat in het algemeen wordt aangenomen dat steroïden gevaarlijk zijn bij chorioamnionitis (appendix I).

Om dit effect verder te onderzoeken werden de resultaten van ons onderzoek in hoofdstuk 10 samengevoegd met die van vergelijkbare eerdere onderzoeken. Door een statistische techniek (meta-analyse) kan zo het totale effect van sterö̈den over alle onderzoeken samen worden onderzocht. Toediening van steroïden bleek niet alleen gerelateerd met minder acute ademhalingsproblemen en minder hersenbloedingen, maar ook met een betere overleving. Verschillende factoren bemoeilijken echter de uitleg van deze resultaten, waardoor de veiligheid en werkzaamheid van steroïden bij chorioamnionitis nog 
niet vaststaan. Wij maken ons hard voor aanvullend onderzoek in deze richting, om zo de uitkomst van vroeggeborenen verder te verbeteren.

In tegenstelling tot eerdere onderzoeken, vonden wij geen directe relatie tussen chorioamnionitis en chronische longschade (hoofdstuk 9). In een van die eerdere studies wordt gesuggereerd dat het risico op chronische longschade na chorioamnionitis alleen is toegenomen wanneer deze kinderen na de geboorte langdurig worden beademd of een ernstige infectie (sepsis) krijgen. In hoofdstuk 11 onderzochten wij of deze samenhang ook aanwezig was in de eerder beschreven groep vroeggeborenen van hoofdstuk 9 . Hoewel we duidelijk zagen dat langdurige beademing het risico op chronische longschade verhoogde, kon geen samenhang worden aangetoond met chorioamnionitis of sepsis. Ook hierbij is het goed mogelijk dat verbeteringen in de behandeling van vroeggeborenen bijdragen aan deze verandering over de tijd.

In hoofdstuk 12 gaan we dieper in op de complexe samenhang tussen chorioamnionitis en chronische longschade. We zien dat beademde vroeggeborenen die blootgesteld zijn aan chorioamnionitis minder goed reageren op behandeling met surfactant. Hierdoor zijn langere beademing en meer zuurstof nodig bij deze kinderen. Dit blijkt met name bij kinderen met ernstige chorioamnionitis te leiden tot een verhoogd risico op chronische longschade. Al met al is de relatie tussen chorioamnionitis en chronische longschade dus complex, en lijkt behandeling met surfactant minder effectief te zijn bij deze kinderen. Mogelijk kan deze behandeling verbeterd worden door meer surfactant te geven of ontstekingsremmende medicijnen toe te voegen aan de behandeling.

\section{Conclusie}

De onderzoeken beschreven in dit proefschrift geven nieuwe informatie over de achtergrond van longontwikkeling en longschade bij vroeggeborenen. De resultaten ondersteunen de recent geïntroduceerde theorie van een verandering in de ontstaanswijze van chronische longproblemen in deze groep kinderen. Daarnaast wordt onderstreept hoe chorioamnionitis een proces blijft met intrigerende effecten op ontwikkeling van de long en andere organen. Nader onderzoek is nodig naar de lange termijn effecten van vroeggeboorte en chorioamnionitis in het bijzonder, om de vooruitzichten voor deze kwetsbare groep kinderen in de toekomst te verbeteren (appendix II). Verschillende bevindingen uit dit proefschrift kunnen richting geven aan toekomstig onderzoek naar strategieën om chronische longschade in de toekomst beter te behandelen, of nog liever: te voorspellen en te voorkómen. 

Curriculum

Vitae 
Jasper Valentijn Been werd op 16 maart 1978 geboren te Utrecht. In 1996 voltooide hij het Gymnasium aan het Christelijk Lycaeum Veenendaal. Datzelfde jaar begon hij de opleiding Geneeskunde aan de Universiteit Maastricht (UM), welke hij eind 2002 'met genoegen' afrondde. Na een periode als arts-assistent kindergeneeskunde niet in opleiding in het Máxima Medisch Centrum Veldhoven en het Maastricht Universitair Medisch Centrum (MUMC), startte hij eind 2004 met een combinatietraject van promotieonderzoek binnen de School for Oncology and Developmental Biology (GROW) en specialisatie tot kinderarts in het MUMC (opleider Prof. dr. L.J.I. Zimmermann) en het Atrium MC Heerlen (opleider dr. J. Dankert).

Het promotieonderzoek onder begeleiding van dr. J.F. van Iwaarden en Prof. dr. L.J.I. Zimmermann richtte zich op aspecten van longontwikkeling en ontstaan van chronische longschade bij vroeggeborenen, zoals beschreven in dit proefschrift. De inhoud ervan werd onder andere onderscheiden met de Pelerinprijs 2009 voor beste onderzoek door een arts-assistent in het MUMC en de Bengt Robertson Award 2010 voor neonataal longonderzoek van de European Academy of Paediatric Sciences. Recent ontving Jasper van het MUMC een Kootstra Talent Fellowship voor voortzetting van onderzoek. Verder volgt hij momenteel de Masteropleiding Epidemiology aan de UM, welke hij eind 2010 hoopt af te ronden. Jasper is getrouwd met Dorcas en samen hebben ze twee lieve dochters.

Jasper Valentijn Been was born March 16th 1978 in Utrecht. He graduated from high school at the Christelijk Lycaeum Veenendaal in 1996 and subsequently started Medical school at Maastricht University (UM). He graduated with distinction in 2002, and worked as a paediatric resident-not-in-training for some time at the Máxima Medical Centre in Veldhoven and the Maastricht University Medical Centre (MUMC). He alternated working as a PhD-student at the School for Oncology and Developmental Biology (GROW) and a resident in training at the departments of paediatrics of the MUMC (supervisor Prof. L.J.I. Zimmermann) and the Atrium Medical Centre in Heerlen (supervisor Dr. J. Dankert).

In his PhD project supervised by dr. J.F. van Iwaarden and Prof. dr. L.J.I. Zimmermann, Jasper focused on aspects of lung development and chronic lung disease in preterm infants, resulting in the current thesis. Part of its content was awarded the Pelerin prize 2009 for best research by a MUMC resident and the Bengt Robertson Award 2010 for neonatal lung research from the European Academy of Paediatric Sciences. Recently Jasper received a Kootstra Talent Fellowship grant which will allow him to continue his research. In addition, he aims to complete his Masters course in Epidemiology at Maastricht University before the end of 2010. Jasper is married to Dorcas, together they have two lovely daughters. 
List of publications 


\section{Internationaal}

1. Been JV, Degraeuwe PL, Kramer BW, Zimmermann L. Antenatal steroids and neonatal outcome after chorioamnionitis: a meta-analysis. BJOG; provisionally accepted.

2. Gantert M, Been JV, Gavilanes DA, Garnier Y, Zimmermann LJ, Kramer BW. Chorioamnionitis - a multiorgan disease of the fetus? J Perinatol; in press.

3. Been JV, Zimmermann L, Jonkers F, Rours IG, Kornelisse RF, de Krijger RR. Reply to letter 'Chorioamnionitis bites the lung'. J Pediatr 2010 [Epub ahead of print].

4. Been JV, Rours IG, Kornelisse RF, Jonkers F, de Krijger RR, Zimmermann LJ. Chorioamnionitis alters the response to surfactant in preterm infants. J Pediatr 2010; 156: 10-5.

5. Been JV, Debeer A, van Iwaarden JF, Kloosterboer N, Lima Passos V, Naulaers G, Zimmermann LJ. Early alterations in growth factor patterns in bronchoalveolar lavage fluid from preterm infants developing bronchopulmonary dysplasia. Pediatr Res 2010; 67: 83-9.

6. Been JV, Zimmermann LJ. Exploring the association between chorioamnionitis and respiratory outcome. BJOG 2010; 117: 497.

7. Been JV, Zoer B, Kloosterboer N, Kessels CG, Zimmermann LJ, van Iwaarden JF, Villamor E. Pulmonary vascular endothelial growth factor expression and disaturated phospholipid content in a chicken model of hypoxia-induced fetal growth restriction. Neonatology 2010; 97: 183-9.

8. Schuurman MJ, Robben SG, Been JV. A congenital anomaly in a preterm newborn. BMJ 2010; 340: b5241.

9. Zoer B, Been JV, Jongen E, Debeer A, Hendrickx A, Smeets H, Zimmermann LJ, Villamor E. Mitochondrial DNA damage analysis in bronchoalveolar lavage cells of preterm infants. Front Biosci 2010; E2: 361-8.

10. Bok LA, Been JV, Struys EA, Jakobs C, Rijper EA, Willemsen MA. Antenatal treatment in two Dutch families with pyridoxine-dependent seizures. Eur J Pediatr 2010; 169: 297-303.

11. Kunzmann S, Glogger K, Been JV, Kallapur SG, Nitsos I, Moss TJ, Speer CP, Newnham JP, Jobe AH, Kramer BW. Thymic changes after chorioamnionitis induced by intraamniotic lipopolysaccharide in fetal sheep. Am J Obstet Gynecol 2010; 202: 476.e1-8.

12. Been JV, Zimmermann L, Debeer A, Kloosterboer N, van Iwaarden JF. Bronchoalveolar lavage fluid from preterm infants with chorioamnionitis inhibits alveolar epithelial repair. Respir Res 2009; 10: 116.

13. Been JV, Kramer BW, Zimmermann LJ. Antenatal corticosteroids to prevent preterm birth. Lancet 2009; 373: 894.

14. Been JV, Rours IG, Kornelisse RF, Lima Passos V, Kramer BW, Schneider TA, de Krijger RR, Zimmermann LJ. Histologic chorioamnionitis, fetal involvement, and 
antenatal steroids: effects on neonatal outcome in preterm infants. Am J Obstet Gynecol 2009; 201: 587.e1-8.

15. Been JV, Kornelisse RF, Rours IG, Lima Passos V, de Krijger RR, Zimmermann LJ. Early postnatal blood pressure in preterm infants: effects of chorioamnionitis and timing of antenatal steroids. Pediatr Res 2009; 66: 571-6.

16. Been JV, Zimmermann L. Histological chorioamnionitis and respiratory outcome in preterm infants. Arch Dis Child Fetal Neonatal Ed 2009; 94: F218-25.

17. Been JV, Zimmermann L. Chorioamnionitis and chronic lung disease in preterm infants. Pediatrics 2009; http://pediatrics.aappublications.org/cgi/eletters/123/5/ 1314.

18. Been JV, Robben SG, Delhaas T, Theunissen P, Dompeling E, Jöbsis Q. A 3-year old female with cough, dyspnoea and low-grade fever. Eur Respir J 2009; 33: 690-3.

19. Degraeuwe PL, Been JV. Letter by Degraeuwe and Been regarding article, "Evidence of arteriolar narrowing in low-birth-weight children". Circulation 2009; 119: e537.

20. Kramer BW, Ladenburger A, Kunzmann S, Speer CP, Been JV, van Iwaarden JF, Zimmermann LJ, Gantert M, Garnier Y. Intravenous lipopolysaccharide-induced pulmonary maturation and structural changes in preterm sheep. Am J Obstet Gynecol 2009; 200: 195.e1-10.

21. Been JV, Kramer BW, Zimmermann LJ. In utero and early-life conditions and adult health and disease. N Engl J Med 2008; 359: 1523-4.

22. Been JV, Degraeuwe PL. Pleural effusion due to intra-abdominal extravasation of parenteral nutrition. Pediatr Pulmonol 2008; 43: 1033-5.

23. Been JV, Bok LA, Willemsen MA, Struys EA, Jakobs C. Mutations in the ALDH7A1 gene cause pyridoxine-dependent seizures. Arq Neuropsiquiatr 2008; 66: 288-9.

24. Been JV, Zimmermann L. What's new in surfactant? - A clinical view on recent developments in neonatology and paediatrics. Eur J Pediatr 2007; 166: 889-9.

25. Been JV, Linssen CF, van Iwaarden JF, Zimmermann LJ. Massive bacterial cell invasion and reactive type II pneumocytes in bronchoalveolar lavage fluid from a preterm neonate. Arch Dis Child Fetal Neonatal Ed 2007; 92: F319.

26. Been JV, Kramer BW, Mulder TL, Zimmermann LJ. Conservative treatment of symptomatic patent ductus arteriosus beyond the first week of life. Arch Dis Child Fetal Neonatal Ed 2007; http://fn.bmj.com/cgi/eletters/92/6/F498\#1967.

27. Bok LA, Struys E, Willemsen MA, Been JV, Jakobs C. Pyridoxine dependent seizures in Dutch patients: diagnosis by elevated urinary alpha-aminoadipic semialdehyde levels. Arch Dis Child 2007; 92: 687-9.

28. Been JV, Bok LA, Andriessen P, Renier WO. Epidemiology of pyridoxine dependent seizures in the Netherlands. Arch Dis Child 2005; 90: 1293-6.

29. Been JV, Smits MG, Bok LA. Improvement of sleep disturbances and behaviour in Smith-Magenis syndrome with morning melatonin. J Med Genet 2003; http://jmg.bmj.com/cgi/eletters/40/1/74\#30. 


\section{Nationaal}

30. Kramer BW, Lievense S, Been JV, Zimmermann LJ. Van klassieke naar nieuwe bronchopulmonale dysplasie. Ned Tijdschr Geneeskd 2010; 154: A1024.

31. van Eldik N, Been JV, van Well GT. Een ongewone verwekker van mastoïditis. Tijdsch Infect 2009; 4: 148-52.

32. Bok LA, Struys E, Jakobs C, Been JV, Willemsen MA. Pyridoxine afhankelijke epilepsie. Tijdschr Neurol Neurochir 2007; 108: 51-6.

33. Been JV, Bok LA, Buijs J, Andriessen P, Roos FG, Bambang Oetomo S. Pyridoxine afhankelijke epilepsie: casusbeschrijving en landelijke inventarisatie. Medisch Journaal MMC 2006; 35: 95-7.

\section{Submitted}

34. Been JV, van Iwaarden JF, de Jager W, Debeer A, Zimmermann L. Bronchoalveolar lavage fluid cytokine and chemokine profiles in ventilated preterm infants.

35. Been JV, Rours IG, Kornelisse RF, de Krijger RR, Zimmermann LJ. Chorioamnionitis, secondary 'hits' and bronchopulmonary dysplasia.

36. Lievense S, Kramer BW, Zimmermann L, Nijhuis JG, Been JV. Wel of geen antenatale steroïden bij dreigende vroeggeboorte met chorioamnionitis? De mening van Nederlandse perinatologen.

37. van der Putten ME, Been JV, Robben SG, Zimmermann L. An unusual cause of hydronephrosis in a preterm infant.

38. Debeer A, Mayer S, Been JV, Roubliova X, Lewi P, Naulaers G, Carmeliet P, Deprest J. A placebo controlled study of intra-amniotic injection of VEGF on lung maturation in preterm rabbits. 


\section{Co-author affiliations}

Debeer A, Naulaers G. Dept of Neonatology, University Hospital Gasthuisberg, Leuven, Belgium

Degraeuwe PL, van Iwaarden JF, Kessels CG, Kloosterboer N, Kramer BW, Lievense S, Villamor E, Zimmermann LJ, Zoer B. Dept of Paediatrics, Maastricht University Medical Centre, Maastricht

Hendrickx A, Jongen E, Smeets H. Dept of Clinical Genetics, Maastricht University, Maastricht

de Jager W. Dept of Paediatric Immunology, University Medical Centre Utrecht, Utrecht

Jonkers F. Dept of Internal Medicine, Maastricht University Medical Centre, Maastricht

Kornelisse RF. Dept of Paediatrics, Erasmus University MC - Sophia Children's Hospital, Rotterdam

de Krijger RR. Dept of Pathology, Erasmus University MC, Rotterdam

Lima Passos V. Dept of Methodology and Statistics, Maastricht University, Maastricht

Nijhuis JG. Dept of Obstetrics and Gynaecology, Maastricht University Medical Centre, Maastricht

Rours IG. Dept of Paediatrics, Maasstad Hospital, Rotterdam; Dept of Paediatric Infectious Diseases / Medical Microbiology, Erasmus University MC, Rotterdam

Schneider TA. Dept of Obstetrics, Erasmus University MC, Rotterdam 
Dankwoord 
Zeer veel dank gaat uit naar mijn promotor, Prof. Zimmermann en co-promotor, Dr. van Iwaarden. Luc, dank voor je inspirerende en positief kritische begeleiding, waarin je vaak snel tijd kon maken ondanks de drukte. Dank voor de leuke tijd tijdens en het mogelijk maken van congresbezoeken, en dank ook voor je steun in het opzetten van vervolgonderzoek. Freek, dank voor de inwijding in de basistechnieken van het lab en je begeleiding van het onderzoek in het lab. Veel heb ik ook gehad aan je kritische houding tijdens de wordingsfase van verschillende artikelen.

Ouders van kinderen die deel uitmaakten van de studies, bedankt voor het in ons/mij gestelde vertrouwen door toestemming voor deelname te geven. Verpleegkundigen van de NICU, dank voor de praktische ondersteuning van het onderzoek en de leuke sfeer.

Nico, bedankt voor je onmisbare bijdrage in de opzet en uitvoer van al het labwerk. Boris voor je enthousiasme en dat je me betrok bij verschillende andere projecten. Laten we vooral samen dingen blijven doen! Bea, Lilian en Eduardo, dank voor jullie aandeel en initiatief ten aanzien van de kippen en het mitochondrieel DNA. Coen, je wordt bedankt voor je ondersteuning in de aanvullende celkweekproeven, succes met je eigen afronding! Pieter, het blijft leuk met je van gedachten te wisselen over methodologische aspecten van onderzoek, zeker wanneer hier zo nu en dan weer iets over op te schrijven valt. Tamara, ontzettend bedankt voor alle secretariële ondersteuning die onmisbaar was tijdens het promotietraject.

Dr. Anne Debeer, dank voor de succesvolle samenwerking in het onderzoek met de broncho-alveolaire lavages, je bijdrage was onmisbaar. Dank ook aan Prof. Gunnar Naulaers voor de betrokkenheid hierin. Voor de samenwerking in het chorioamnionitis onderzoek van het Erasmus MC veel dank aan Ingrid Rours, René Kornelisse, Femke Jonkers, en Ronald de Krijger.

Verschillende mensen wil ik bedanken voor de praktische ondersteuning toen ons lab nog in wording was: Mo, Joep, Jacco en Tim (nu 'one of us') van de algemene heelkunde, Harry en Ramon van de pulmonologie, de mensen van de anatomie voor het gebruik van de stereomicroscoop, Eduard en Menno en vooral ook Cees en Leon van de biochemie, enthousiaste begeleiders van mijn eerste onderzoekservaringen. Dank ook aan Kitty Linssen en anderen van de microbiologie voor de gastvrijheid en begeleiding bij de cytospins en natuurlijk voor alle differentiaties. Valéria voor de kritische en zeer zinvolle statistische begeleiding, Wilco voor de cytokine en chemokine metingen.

Mijn kamergenoten tijdens het onderzoek: Charlotte, Bianca en later ook Rob en Cécile. Lief, leed, sportiviteit en een enkele frustratie hebben we gedeeld, waarvoor dank. Rob, you're next! 
De mensen in Veldhoven, dank voor belangrijke begeleiding in de vroege fase van mijn kindergeneeskundige loopbaan. Martin de Kleine voor de stimulering van betrokkenheid in onderzoek. Peter Andriessen, veel heb ik geleerd van je intensieve begeiding van het schrijven van mijn eerste artikel, al werd het nooit gepubliceerd. Vinus Bok, leuk dat we zoveel samen hebben gedaan in het uiteindelijk boven verwachting succesvolle onderzoek naar de pyridoxine-afhankelijke epilepsie. Succes met de afronding van je eigen promotie hierin!

Graag wil ik ook de leden van de beoordelingscommissie, Professoren Nijhuis, van Schayck, Buurman, Bambang Oetomo en Walther bedanken voor hun tijd en moeite. Onno, dank ook voor je belangrijke begeleiding in het opstarten van een vervolgtraject.

Mijn paranimfen, Bjorn en Jeroen: dank dat jullie me terzijde willen/durven staan. Watch out for that statistical question!

Dr. Tim, kort na jouw dankwoord mag ik ook het mijne aan jou richten. Onze wederzijdse, deels onderzoeksgerelateerde weerspiegelingen zijn onmisbaar voor de relativering van wat we aan het doen zijn, waarvoor veel dank.

Papa en mama: ik weet dat mijn dank en waardering voor wie jullie zijn niet alleen hoeft te blijken uit wat ik hier schrijf. Toch wil ik jullie hierbij enorm bedanken voor jullie liefde en betrokkenheid en jullie stimulering en onvoorwaardelijke steun tijdens mijn school, studie en huidige leven. Zonder jullie had dit nooit gekund! Ook mijn zusjes bedankt voor jullie betrokkenheid, en Maaike speciaal voor alle posters en de omslag voor het boekje. Oma Cis en ook opa, die dit jammergenoeg net niet meer mee mocht maken, voor het altijd meeleven en op de voet volgen van alle vorderingen.

Dorcas, mijn lieve, mooie vrouw: dank voor de tijd en mogelijkheden die je me hebt gegeven om dit mogelijk te maken, je bent fantastisch! Lieve Éowyn en Lore, jullie geven het leven zoveel meer zin en vrolijkheid en helpen het belang van andere zaken te relativeren. Love you lots!

God, ik prijs u voor uw onnavolgbare en ondoorgrondelijke schepping. 

Faith is being sure

of what we hope for

and being certain

of what we do not see

Hebrews 11:1 